\title{
Chain-transfer kinetics for free-radical homo- and copolymerizations of styrene and methyl methacrylate in supercritical carbon dioxide
}

\author{
Dissertation \\ zur Erlangung des Doktorgrades \\ der Mathematisch-Naturwissenschaftlichen Fakultäten \\ der Georg-August-Universität zu Göttingen
}

vorgelegt von

Véronique El Rezzi

aus Beirut, Libanon

Göttingen 2001 
D 7

Referent: $\quad$ Prof. Dr. M. Buback

Korreferent: Prof. Dr. K. Hoyermann

Tag der mündlichen Prüfung: 27.06.2001 


\section{Table of contents}

$\begin{array}{lll}\text { 1. Abstract } & 1\end{array}$

2. Introduction 3

3. Experimental 7

$\begin{array}{lll}3.1 & \text { Apparatus } & 7\end{array}$

3.1.1 Optical high-pressure cell 7

3.1.2 Optical internal cell 9

3.1.3 Pressure generation and control 9

3.1.4 Heating and temperature control 10

3.1.5 Experimental set-up for polymerizations in $\mathrm{scCO}_{2}$

3.1.6 FT-IR/NIR spectrometer 12

3.1.7 Excimer laser $\quad 12$

3.1.8 Size-Exclusion Chromatography (SEC) 12

3.1.9 Preparation of the mixtures containing the cobalt-complex 13

$\begin{array}{lll}3.2 & \text { PLP-SEC technique } & \mathbf{1 3}\end{array}$

$\begin{array}{lll}3.3 & \text { Determination of } C_{\mathrm{T}} \text { and } \mathrm{CO}_{2} \text {-content } & 14\end{array}$

$\begin{array}{lll}3.4 & \text { Substances used } & \mathbf{1 4}\end{array}$

3.4.1 Monomers 14

$\begin{array}{lll}3.4 .2 & \text { Carbon dioxide } & 15\end{array}$

$\begin{array}{lll}3.4 .3 & \text { Initiators and inhibitor } & 15\end{array}$

$\begin{array}{lll}3.4 .4 & \text { Chain-transfer agents } & 16\end{array}$

$\begin{array}{lll}3.5 & \text { FT-IR/NIR spectroscopy } & \mathbf{1 8}\end{array}$

$\begin{array}{lll}3.6 & \text { Consideration of errors } & 19\end{array}$

$\begin{array}{lll}3.7 & \text { References } & \mathbf{2 0}\end{array}$ 
4.1 Selection of temperature and pressure $\quad \mathbf{2 3}$

4.2 SEC calibration $\quad \mathbf{2 3}$

4.3 Determination of $C_{\mathrm{T}} \quad \mathbf{2 5}$

4.3.1 Background 25

4.3.1.1 Mayo method 28

4.3.1.2 Chain-Length Distribution method 29

4.3.2 Comparison of both procedures 31

4.3.2.1 Theoretical comparison 31

4.3.2.2 Experimental comparison $\quad 32$

4.3.3 CLD method 33

4.4 Conditions for the determination of $C_{\mathrm{T}}$ by PLP 34

4.5 Consideration of errors 39

$\begin{array}{lll}4.6 & \text { References } & \mathbf{4 0}\end{array}$

5. Results and discussions 43

5.1 DDM as chain-transfer agent $\mathbf{4 3}$

5.1.1 Homopolymerization of styrene 44

5.1.1.1 Mayo method 44

5.1.1.2 CLD method 46

5.1.1.3 Results 46

5.1.2 Homopolymerization of MMA 50

5.1.3 Copolymerization of styrene and MMA 53

$\begin{array}{lll}5.1 .4 & \text { Summary } & 57\end{array}$

5.2 COPhBF as catalytic chain-transfer agent 59

5.2.1 Preliminary investigations $\quad 60$

5.2.2 Homopolymerization of MMA 62

5.2.3 Homopolymerization of styrene 66

$\begin{array}{lll}\text { 5.2.4 Copolymerization of styrene and MMA } & 70\end{array}$

$\begin{array}{lll}\text { 5.2.5 Closing remarks } & 77\end{array}$

5.3 MMA trimer as chain-transfer agent $\quad 79$

$\begin{array}{lll}\text { 5.3.1 Homopolymerization of styrene } & 81\end{array}$ 
5.3.2 Homopolymerization of MMA

$\begin{array}{lll}5.3 .3 & \text { Summary } & 89\end{array}$

5.4 Discussions $\quad 91$

5.4.1 Mechanism of the chain-transfer reaction 91

$\begin{array}{ll}\text { 5.4.1.1 DDM } & 92\end{array}$

5.4.1.2 MMA trimer 93

$\begin{array}{ll}\text { 5.4.1.3 COPhBF } & 95\end{array}$

5.4.2 Activation volume $\Delta V^{\#}$ and $\mathrm{scCO}_{2}$ influence on $k_{\mathrm{tr}} \quad 98$

$\begin{array}{ll}\text { 5.4.2.1 DDM } & 98\end{array}$

5.4.2.2 MMA trimer 100

$\begin{array}{ll}\text { 5.4.2.3 } \mathrm{COPhBF} & 101\end{array}$

$\begin{array}{lll}5.5 & \text { References } & 104\end{array}$

6. Kinetic modeling $\quad 109$

$\begin{array}{lll}6.1 & \text { Theoretical background } & 109\end{array}$

6.1.1 Simulations of $k_{\text {tr }}$ applying terminal and PUE models 109

$\begin{array}{ll}\text { 6.1.2 Endgroups estimate } & 115\end{array}$

6.1.3 Simulation tool PREDICI ${ }^{\circledR} \quad 116$

6.2 Simulation of $k_{\mathrm{tr}}$ applying terminal and PUE models 116

$\begin{array}{lll}\text { 6.2.1 Free-radical copolymerization } & 117\end{array}$

6.2.2 Copolymerizations in the presence of DDM 119

6.2.3 Copolymerizations in the presence of COPhBF 120

6.3 Modeling of full molecular weight distributions of styrene-MMA copolymers via PREDICI ${ }^{\circledR}$

6.3.1 Experimental considerations 122

6.3.2 DDM as chain-transfer agent 126

6.3.3 COPhBF as catalytic chain-transfer agent $\quad 130$

$\begin{array}{ll}\text { 6.3.4 Closing remarks } & 131\end{array}$

6.4 Endgroups estimate 132

$\begin{array}{lll}6.5 & \text { References } & \mathbf{1 3 3}\end{array}$ 
7. Closing remarks

7.1 References

8. Abbreviations

9. Appendix 


\section{Abstract}

Chain-transfer kinetics have been studied for styrene and MMA homo- and copolymerizations in bulk and in solution of supercritical $\mathrm{CO}_{2}\left(40 \mathrm{wt} \% \mathrm{scCO}_{2}\right)$. Three chain-transfer agents (CTAs) were used in this work: $n$-dodecyl mercaptan (DDM), the bis(methanol) complex of bis(difluoroboryl) diphenylglyoximato cobalt (II) $(\mathrm{COPhBF})$, and the methyl methacrylate trimer (MMAt). Chain-transfer constants, $C_{\mathrm{T}}$, which are defined as $k_{\mathrm{tr}} / k_{\mathrm{p}}$, the ratio of the transfer and propagation rate coefficients have been measured by the pulsed-laser polymerization (PLP)-size exclusion chromatography (SEC) technique. $C_{\mathrm{T}}$ values are derived by the chain-length distribution (CLD) procedure. $k_{\mathrm{tr}}$ is calculated from $C_{\mathrm{T}}$ by way of the known propagation rate coefficient, $k_{\mathrm{p}}$. The pressure dependence of $k_{\mathrm{tr}}$ has been investigated between 300 and 1500 bar in both media, bulk and $\mathrm{scCO}_{2}$, at $80^{\circ} \mathrm{C}$.

$k_{\text {tr }}$ obtained for the CTAs differ by orders of magnitude: In MMA homopolymerization $k_{\text {tr }}$ is close to $10^{2}, 10^{3}$ and $10^{7} \mathrm{~L} \cdot \mathrm{mol}^{-1} \cdot \mathrm{s}^{-1}$ for the MMA trimer, for DDM and for COPhBF, respectively. In styrene homopolymerization $k_{\mathrm{tr}}$ is close to $10^{2}, 10^{4}$ and $10^{5} \mathrm{~L} \cdot \mathrm{mol}^{-1} \cdot \mathrm{s}^{-1}$ for the MMA trimer, for DDM and for COPhBF, respectively. The difference in $k_{\mathrm{tr}}$ for these CTAs is due to different transfer mechanisms.

The presence of $\mathrm{scCO}_{2}$ has no influence on $k_{\text {tr }}$ with the exception of MMA homopolymerizations with COPhBF being the catalytic CTA. In this case, $k_{\text {tr }}$ is significantly higher in the presence of $40 \mathrm{wt} \% \mathrm{scCO}_{2}$. Even for the transfer reaction of MMA with $\mathrm{COPhBF}$, the activation volume in bulk and in $\mathrm{scCO}_{2}$ is the same.

The high $k_{\mathrm{tr}}$ value, the $\mathrm{scCO}_{2}$ influence on $k_{\mathrm{tr}}$, and the significant pressure dependence associated with an activation volume around $+35 \mathrm{~cm}^{3} \cdot \mathrm{mol}^{-1}$ observed in MMA homopolymerization with $\mathrm{COPhBF}$ are consistent with a diffusion-controlled transfer reaction.

The transfer reaction with DDM and MMA trimer as CTAs are chemically controlled. The activation volumes are around $\pm 3 \mathrm{~cm}^{3} \cdot \mathrm{mol}^{-1}$.

Kinetic modeling of $k_{\text {tr }}$ indicates that the terminal model does not allow for an accurate description of the experimental results in the transfer process in styrene-MMA copolymerizations in the presence of DDM as CTA. Models, which consider penultimate units, describe the copolymerization $k_{\mathrm{tr}}$ behavior as a function of the monomer feed well. Estimates of the type of polymer endgroups for polymerizations with DDM as CTA clearly 
indicate that even at very low $f_{\mathrm{S}}$, styrene is the dominant endgroup. In case of COPhBF as CTA, kinetic modeling has shown that the simple terminal model is sufficient to describe the copolymerization $k_{\mathrm{tr}}$ observed.

MWDs obtained by simulations via PREDICI ${ }^{\circledR}$ considering a PUE model for the transfer process in styrene-MMA copolymerization with DDM as CTA are in excellent agreement with the experimental MWDs.

$C_{\mathrm{T}}$ values, thus $k_{\text {tr }}$ values, obtained with DDM may be used for simulations of homo-, copoor terpolymerizations of styrene and methacrylates since it is known that $C_{\mathrm{T}}$ of DDM for methacrylates is independent of the ester size. In addition, knowing the activation energy of $k_{\mathrm{tr}}$, simulations at different temperatures may be investigated. 


\section{Introduction}

Environmental concern over the emission of volatile organic solvents used in polymer synthesis has prompted researchers to look for less harmful alternatives. A very promising technology area should be the polymerization in supercritical fluids ${ }^{1}$. These fluids show gaslike diffusivities while having liquidlike densities that allow for solvation of many compounds. They exhibit a change in solvent density upon small variations in temperature or pressure without altering solvent composition ${ }^{2}$. In addition, the low viscosity of supercritical fluids and their ability to plasticize glassy polymers have implications on polymer processing and kinetics. When carbon dioxide is used as a supercritical solvent, additional advantages can be realized. $\mathrm{CO}_{2}$ is naturally occurring and abundant, it exists in natural reservoirs of high purity located throughout the world. $\mathrm{CO}_{2}$ has a critical temperature of $31^{\circ} \mathrm{C}$, a modest critical pressure of 74 bar and a critical density of $0.468 \mathrm{~g} \cdot \mathrm{cm}^{-3}$. These characteristics ${ }^{3}$ allow for liquidlike densities at temperatures slightly above room temperature and by implication, liquidlike solvent characteristics. DeSimone and co-workers have shown that $\mathrm{scCO}_{2}$ is an ideal medium for both homogeneous and heterogeneous radical polymerizations ${ }^{4}$. Most of the investigations into polymerizations in $\mathrm{scCO}_{2}$ focused on reaction in heterogeneous phase as polymer solubility in $\mathrm{scCO}_{2}$ is generally rather low. Recently, several studies showed a significant influence of $\mathrm{scCO}_{2}$ on homogeneous phase polymerizations. For example, in butyl acrylate homopolymerization $\mathrm{scCO}_{2}$ was shown to have a significant influence on the propagation and termination rate coefficients ${ }^{5,6,7}$.

The controlled synthesis of low molecular weight (MW) polymers is gaining greater importance as applications in coatings, detergents and water treatment industries continue to develop. The interest in the free-radical polymerization with respect to the preparation of these materials is originating from the fact that in contrast to ionic polymerization a greater number of monomers may be utilized. Although most common styrenic and meth(acrylic) polymers show only limited solubility, the synthesis of low molecular weight material in the presence of $\mathrm{scCO}_{2}$ is a promising alternative process. Due to the significantly increased polymer solubility at low MW, high degrees of monomer conversion are accessible in homogeneous phase of $\mathrm{scCO}_{2}$. For example styrene-methacrylate terpolymers which are used in coatings may be synthesized at complete monomer conversion $\left(M_{\mathrm{n}} \approx 3000 \mathrm{~g} \cdot \mathrm{mol}^{-1}\right)$ in $\mathrm{scCO}_{2}{ }^{8}$. Because polymer properties are strongly dependent on $\mathrm{MW}$, it is of great interest to effectively control 
MW. One approach to molecular weight reduction involves the use of chain-transfer agents (CTAs). The knowledge of the transfer activity of a CTA, which is measured via the chaintransfer rate coefficient, $k_{\text {tr }}$, is necessary to predict the molecular weight of the polymer obtained. Thus, the aim of this work is to investigate the influence of $\mathrm{scCO}_{2}$ as a solvent on the transfer process in free-radical polymerization. Three types of CTAs in styrene and MMA homo- and copolymerizations are studied: A mercaptan ( $n$-dodecyl mercaptan, DDM), a cobalt-complex (bis(difluoroboryl)diphenylglyoximato cobalt (II), COPhBF), and a methyl methacrylate macromonomer (MMAt). The use of these CTAs has two major advantages. Firstly, by using these CTAs it is possible to obtain polymers in very different MW ranges. Secondly, the polymer endgroups obtained are dissimilar: A saturated carbon bond is produced with DDM, whereas an unsaturated carbon bond is produced with COPhBF. In case of the MMA trimer, the polymer chain length is increased by three monomer units due to the incorporation of the MMA trimer into the polymer backbone and an unsaturated endgroup is obtained. This aspect is interesting as the type of terminal group in the polymer determines potential subsequent reactions and the properties of the polymer generated.

A great advantage of using mercaptans as CTA is that they have a good transfer activity towards usual vinyl monomers. However, mercaptans are incorporated into the propagating chains which may affect the polymer properties. A new technology has emerged in recent years $^{9,10}$ : The use of catalytic chain transfer (CCT) agents, which is well known as a highly efficient method for producing oligomers. CCT has many favorable characteristics: The catalysts, which are generally cobalt complexes, are used in low concentration (ppm range), are generally non toxic and are regenerated during the polymerization. The mechanism is such that each polymer molecule has a terminal vinyl group, which can be used subsequently for copolymerization with other monomers, usually macromonomers such as MMA trimer, resulting in graft, comb, and star architectures ${ }^{11,12,13}$. The mode of reaction is an additionfragmentation reaction ${ }^{14}$. The type structure of the CCT substituents determines the functionality introduced at the polymer chain ends.

Literature shows only few reports on the chain-transfer activity, thus on the chain-transfer constant $\left(C_{\mathrm{T}}=k_{\mathrm{tr}} / k_{\mathrm{p}}\right)$ of cobalt complexes ${ }^{10,15,16}$ and macromonomers ${ }^{17}$. Even for the frequently used mercaptans only few informations on $k_{\text {tr }}$ are available ${ }^{18}$.

Investigations into $C_{\mathrm{T}}$ in styrene and methacrylates homopolymerizations at ambient pressure have shown that the transfer activity of DDM is more effective with styrene than with methyl 
methacrylate (MMA) $)^{18} . C_{\mathrm{T}}$ of 15.6 and 0.706 were reported for $60^{\circ} \mathrm{C}$ and 1 bar in styrene and MMA homopolymerization, respectively.

The chain-transfer activity of COPhBF has been tested in styrene and MMA polymerizations at ambient pressure and different temperatures ${ }^{15}$. The reported $C_{\mathrm{T}}$ values indicate that CCT is by one order of magnitude more effective in MMA homopolymerization than in styrene. However, even in case of styrene, $C_{\mathrm{T}}$ values are high, which implies a strong transfer activity of COPhBF compared to common CTAs ${ }^{19} . C_{\mathrm{T}}$ values reported at $60^{\circ} \mathrm{C}$ and 1 bar are in the range of $10^{4}$ and $10^{2}$ in MMA and in styrene homopolymerization, respectively.

Investigations into $C_{\mathrm{T}}$ for MMA homopolymerizations in the presence of MMA trimer ${ }^{17}$ result in $C_{\mathrm{T}}$ of 0.188 at $80^{\circ} \mathrm{C}$ and 1 bar. No literature data have been reported on $C_{\mathrm{T}}$ in styrene homopolymerization with MMA trimer as CTA so far.

In order to effectively control $\mathrm{MW}$ in polymerizations in $\mathrm{scCO}_{2}$, knowledge of $k_{\mathrm{tr}}$ in the presence of $\mathrm{CO}_{2}$ is required. However, so far only for MMA homopolymerization with $\mathrm{COPhBF}$ at 150 bar and $50^{\circ} \mathrm{C}$ the influence of $\mathrm{CO}_{2}$ on the transfer process was studied ${ }^{16}$. Due to the lack of $k_{\text {tr }}$ data in the presence of $\mathrm{CO}_{2}$, this work is focused on the influence of $\mathrm{scCO}_{2}$ as a solvent on $k_{\text {tr }}$ of DDM, COPhBF, and MMA trimer in MMA and styrene homopolymerizations. The variation of $k_{\text {tr }}$ with pressure has been studied between 300 and 1500 bar since the physical properties of the system, such as viscosity, are altered. In addition, investigations into the pressure dependence of $k_{\text {tr }}$ are useful for the understanding of the mechanism of the transfer process. $k_{\text {tr }}$ data are derived from the pulsed-laser polymerization (PLP) technique combined with the molecular weight distribution analysis of the resulting polymer by size exclusion chromatography (SEC).

The studies of the chain-transfer activity of CTAs are extended to styrene-MMA copolymerizations in case of DDM and COPhBF. These copolymers have many important applications in the polymer industry, e.g. are used in adhesive and coatings compositions, as dispersants and in the biomedical industry. In order to model and optimize the copolymerizations, the knowledge of copolymerization $k_{\text {tr }}$ is required. In addition, copolymerization $k_{\text {tr }}$ should improve the understanding of the transfer mechanisms.

In order to understand the results obtained for styrene-MMA copolymerizations in the presence of $\mathrm{DDM}$ and $\mathrm{COPhBF}$, kinetic modeling is carried out. Chain-transfer rate coefficients are determined via different kinetic models, applying a penultimate unit effect model and a terminal unit model in the transfer reaction. With the knowledge of $k_{\mathrm{tr}}$ values 
determined experimentally, simulations of molecular weight distribution are performed via the program PREDICI $^{\circledR, 20}$.

\subsection{References}

1. Jessop, P. G.; Leitner, W. Chemical Synthesis using Supercritical Fluids, Wiley-VCH, Weinheim 1999.

2. McHugh, M. A.; Krukonis, V. J. J. Supercritical Fluid Extraction: Principles and Practice, 2nd Ed. Butterworth-Heineman: Stone-ham, 1993.

3. Baser, S. J.; Stern, K. M.; In Catalytic Activation of Carbon Dioxide: Ayers, W. M.; Ed. American Chemical Society: Washington, DC, 1998.

4. $\quad$ DeSimone, J. M.; Guan, Z.; Elsbernd, C. S. Science 1992, 257, 945.

5. Beuermann, S.; Buback, M.; Schmaltz, C.; Kuchta, F.-D. Macromol. Chem. Phys. 1998, 199, 1209.

6. Beuermann, S.; Buback, M.; Schmaltz, C. Macromolecules 1998, 31, 8069.

7. Beuermann, S.; Buback, M.; Schmaltz, C. Ind. Eng. Chem. Res. 1999, 38, 3338.

8. Jürgens, M. Ph.-D 2001, Göttingen.

9. Gridnev, A.; J. Polym. Sci., Polym. Chem. Ed. 2000, 38, 1753.

10. Heuts, J. P. A.; Kukulj, D.; Foster, D. J.; Davis, T. P. Macromolecules 1998, 31, 2894.

11 Antonelli, J. A.; Scopazzi, C.; Doherty, M. M.; E. I. Dupont de Nemours and Company, invs.: US 1991, 5010140.

12. Antonelli, J. A.; Scopazzi, C. E. I. Dupont de Nemours and Company, invs.: US 1994, 5362813.

13. Chu, I. C.; Fryd, M.; Lynch, L. E. E. I. Dupont de Nemours and Company, invs.: US 1993, 5231131.

14. Berge, C. T.; Darmon, M. J.; Antonelli, J. A. US Patent US 5, 1994, 362, 826.

15. Heuts, J. P. A.; Foster, D. J.; Davis, T. P.; Yamada, B.; Yamazoe, H.; Azukizawa, M. Macromolecules 1999, 32, 2511.

16. Foster, D. J.; Heuts, P. A.; Lucien, F. P.; Davis, T. P. Macromolecules 1999, 32, 5514.

17. Moad, L. C.; Moad, G.; Rizzardo, E.; Thang, S. H. Macromolecules 1996, 29, 7717.

18. Hutchinson, R. A.; Paquet, D. A.; Mc Minn, J. H. Macromolecules 1995, 28, 5655.

19. Odian, G. Principles of Polymerization, 2nd Ed., Wiley: New york, 1981.

20. Wulkow, M. Macromol. Theory Simul. 1996, 5, 393. 


\section{Experimental}

\subsection{Apparatus}

\subsubsection{Optical high-pressure cell}

The optical high-pressure cell used for spectroscopic investigations of pulsed laser induced homo- and copolymerizations under high pressure is illustrated in Fig. 3.1. The cell is designed for pressures up to 3500 bar and temperatures up to $350{ }^{\circ} \mathrm{C}$. The cylindrical cell body and sealing flanges are made of a nickel-based alloy of high ultimate tensile strength (RGT 601, Material No. 2.4668, Arbed Saarstahl). The body length is $100 \mathrm{~mm}$, and the outer and inner diameters are 80 and $22 \mathrm{~mm}$, respectively. Four holes bored perpendicular to the cylindrical axis allow for fitting of high-pressure capillaries and insertion of a sheathed thermocouple (6) directly into the sample volume. Unused borings are sealed with plugs.

The cell is sealed at each end by a conical ram (5) (Material No. 2.4668, Arbed Saarstahl) which sits into the cell cone. The ram is pressed against the cell cone by the flange (2) (Material No. 2.4668, Saarstahl) which is secured by six high-pressure bolts (1) (Material No. 2.4969). 


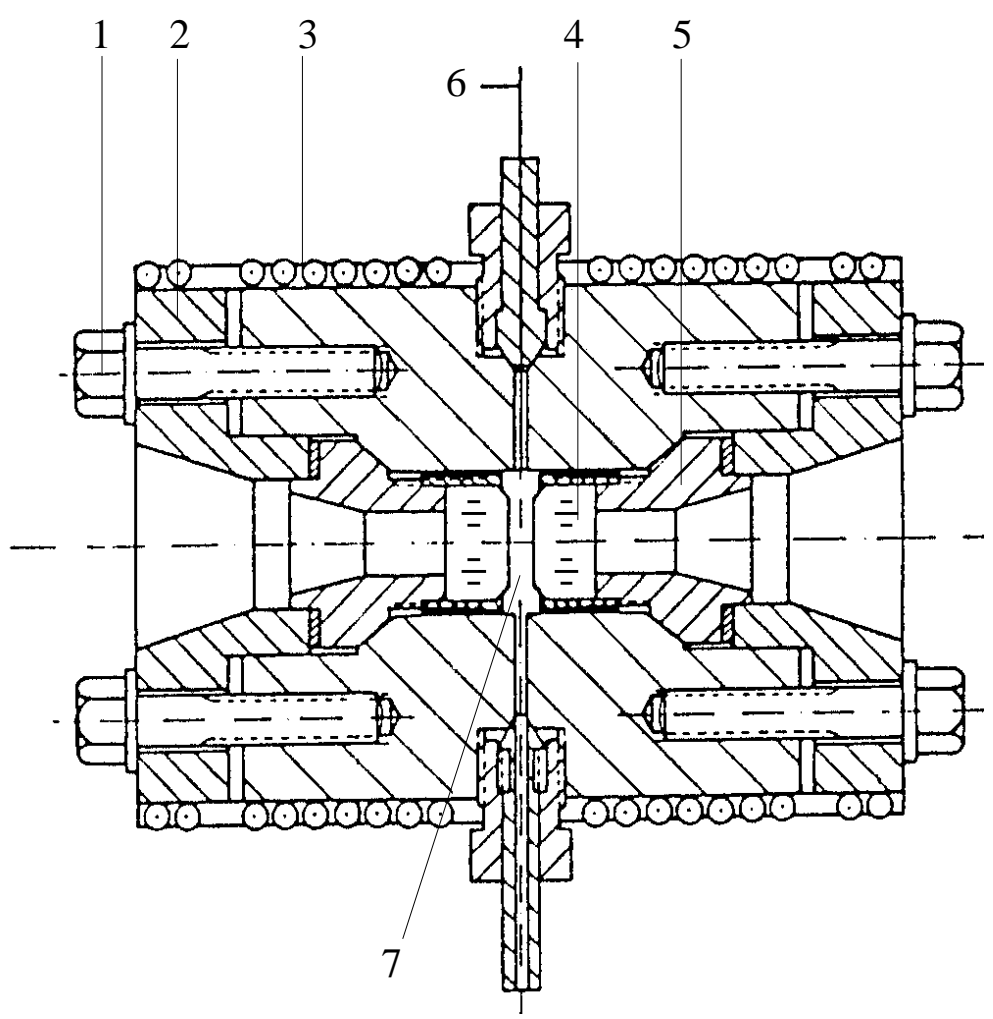

Figure 3.1: Optical high-pressure cell.

(1) bolt, (2) flange, (3) heating jacket, (4) high-pressure window,

(5) ram, (6) sheathed thermocouple, (7) adjustable optical path length

Each high-pressure window (4) is fitted against the polished surface of the ram and held in place by a stainless steel cealing cap. To compensate for surface area irregularities, a $\sim 12 \mu \mathrm{m}$ thick teflon foil is placed between the polished surfaces of the window. This set-up is selfsealing under pressure in accordance with the Poulter principle ${ }^{1}$. The high-pressure optical windows used in this work were synthetic sapphire crystals (diameter $18 \mathrm{~mm}$, height $10 \mathrm{~mm}$, UV grade, Roditi, Union Carbide) made by the Czochralski procedure. This material is transparent in the wavenumber range from 2000 to $50000 \mathrm{~cm}^{-1}$. The optical transparency at the pulsed laser wavelength is not affected by laser irradiation or by changing the temperature.

The optical high-pressure cell is mounted on a metal holder with wooden grip for easy handling and fitting into the sample chamber of the FT-IR spectrometer. 


\subsubsection{Optical internal cell}

The optical internal cell used for the kinetic investigations in bulk polymerizations is depicted in Fig. 3.2. The cell consists of a teflon tube (1) (outer diameter $10 \mathrm{~mm}$, inner diameter $9 \mathrm{~mm}$, length $\sim 11 \mathrm{~mm}$ ) which is closed at each end by a calcium fluoride window (2) (diameter 10 $\mathrm{mm}$, thickness $\sim 5 \mathrm{~mm}$, Korth). To facilitate optimal sealing of the cylindrical cell, the sides of the $\mathrm{CaF}_{2}$ windows are polished using a diamond micrometer suspension (4-8 micron, Mikrodiamant $\mathrm{GmbH}$ ). $\mathrm{CaF}_{2}$ was chosen as the window material as it is transparent in the wavenumber range above $1100 \mathrm{~cm}^{-1}$, thus allowing detection in the desired IR region. The sample volume (3) is contained between the two windows. The distance between the $\mathrm{CaF}_{2}$ windows determines the sample volume and optical path length, which was about $1.2 \mathrm{~mm}$. The internal cell is fitted between the high-pressure windows of the high-pressure cell ((7) in Fig. 3.1) and held in place by a solid teflon spacer.

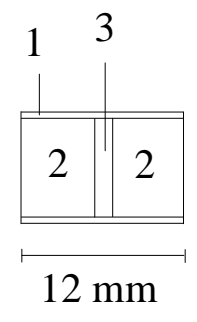

Figure 3.2: $\quad$ Optical internal cell used for bulk investigations.

(1) teflon tube, (2) $\mathrm{CaF}_{2}$ window, (3) sample volume

An excellent survey on the high-pressure techniques described within this section can be found in ref. 2.

\subsubsection{Pressure generation and control}

For the kinetic investigations in bulk polymerizations, $n$-heptane served as the pressure transmitting medium. The system is pressurized using a manually driven ("syringe" type) pressure generator (volume $12 \mathrm{~cm}^{3}$ ). The pressure is measured using a high-pressure precision manometer (Class 0.1, 0 - 4 kbar, Wiegand). The pressure generating system is depicted in Fig. 3.3. 


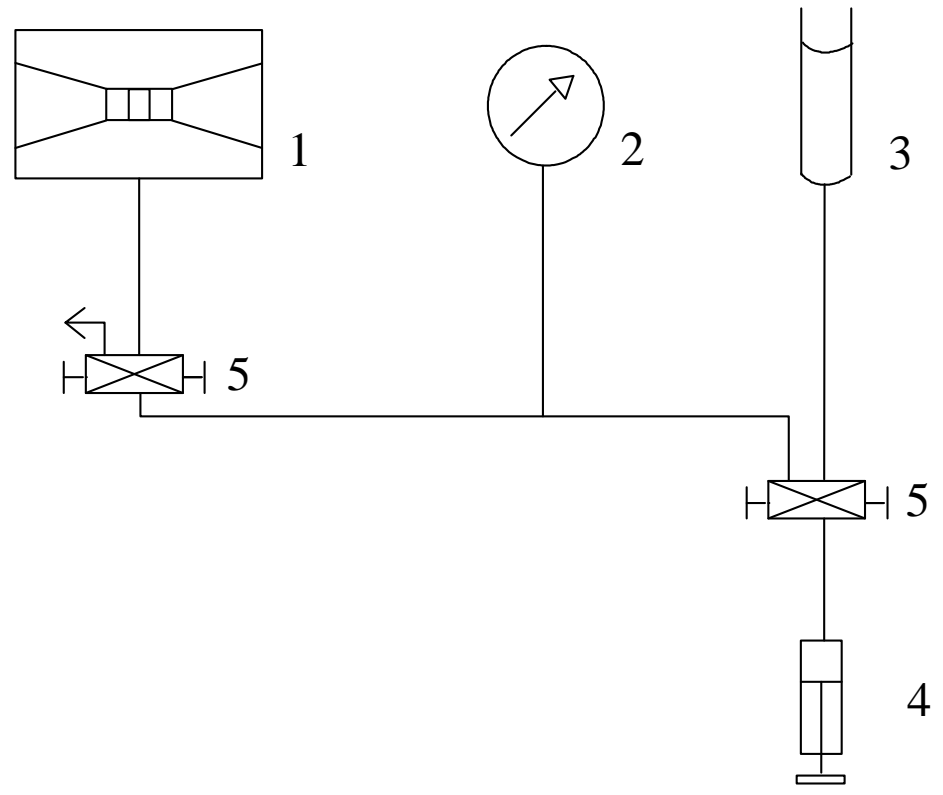

Figure 3.3: $\quad$ Pressure generating system for bulk polymerizations.

(1) optical high-pressure cell, (2) manometer, (3) pressure medium $n$-heptane,

(4) "syringe" type pressure generator, (5) valve

\subsubsection{Heating and temperature control}

The optical high-pressure cell is heated by two heating jackets. They consist of a brass matrix, into which is embedded a sheathed resistance heating wire (CGE-Asthom). The closely fitting jackets slide over each end of the cell body (see Fig. 3.1 (3)). The temperature is measured via a sheathed thermocouple (Nickel-chromium against nickel, CIA S250, CGE-Alsthom) and regulated by a PID-controller (Eurotherm 815 ).

\subsubsection{Experimental set-up for polymerizations in $\mathrm{scCO}_{2}$}

The experimental set-up used for polymerization in supercritical $\mathrm{CO}_{2}\left(\mathrm{scCO}_{2}\right)$ is described in Fig. 3.4. The major components are a high-pressure liquid chromatography pump (HPLC), a pressure intensifier, an optical high-pressure cell and a mixing autoclave. The autoclave is equipped with a magnetic stir bar and a cooling device that keeps the mixture at $0^{\circ} \mathrm{C}$ to prevent polymerization. The pressure intensifier is used to compress $\mathrm{CO}_{2}$ up to a supercritical pressure. The HPLC pump generates a pressure of 200 bar inside the mixing autoclave and keeps the pressure at a constant level of 250 bar while filling the optical high-pressure cell. 
The reaction mixture consisting of monomer, photoinitiator and chain-transfer agent is filled into the autoclave and $\mathrm{CO}_{2}$ is added by means of a syringe pump. The pressure intensifier is used to provide $\mathrm{CO}_{2}$ at a pressure up to 400 bar. To achieve a homogeneous reaction system in the autoclave, the mixture is vigorously stirred for one hour at $0^{\circ} \mathrm{C}$. Before filling, the optical high-pressure cell is purged with $\mathrm{CO}_{2}$ to remove $\mathrm{O}_{2}$.

While part of the reaction mixture is transferred from the autoclave into the optical highpressure cell via the HPLC pump, the pressure is kept at a sufficiently high level to ensure homogeneity of the monomer/photoinitiator/chain-transfer agent/ $\mathrm{CO}_{2}$ mixture. Further compression of the system is achieved by means of the syringe pump. Once the reaction pressure and temperature are reached, the high-pressure cell is disconnected from the pressure branch, inserted into the sample compartment of a Fourier-Transform infrared spectrometer, and subsequently into the laser irradiation assembly.

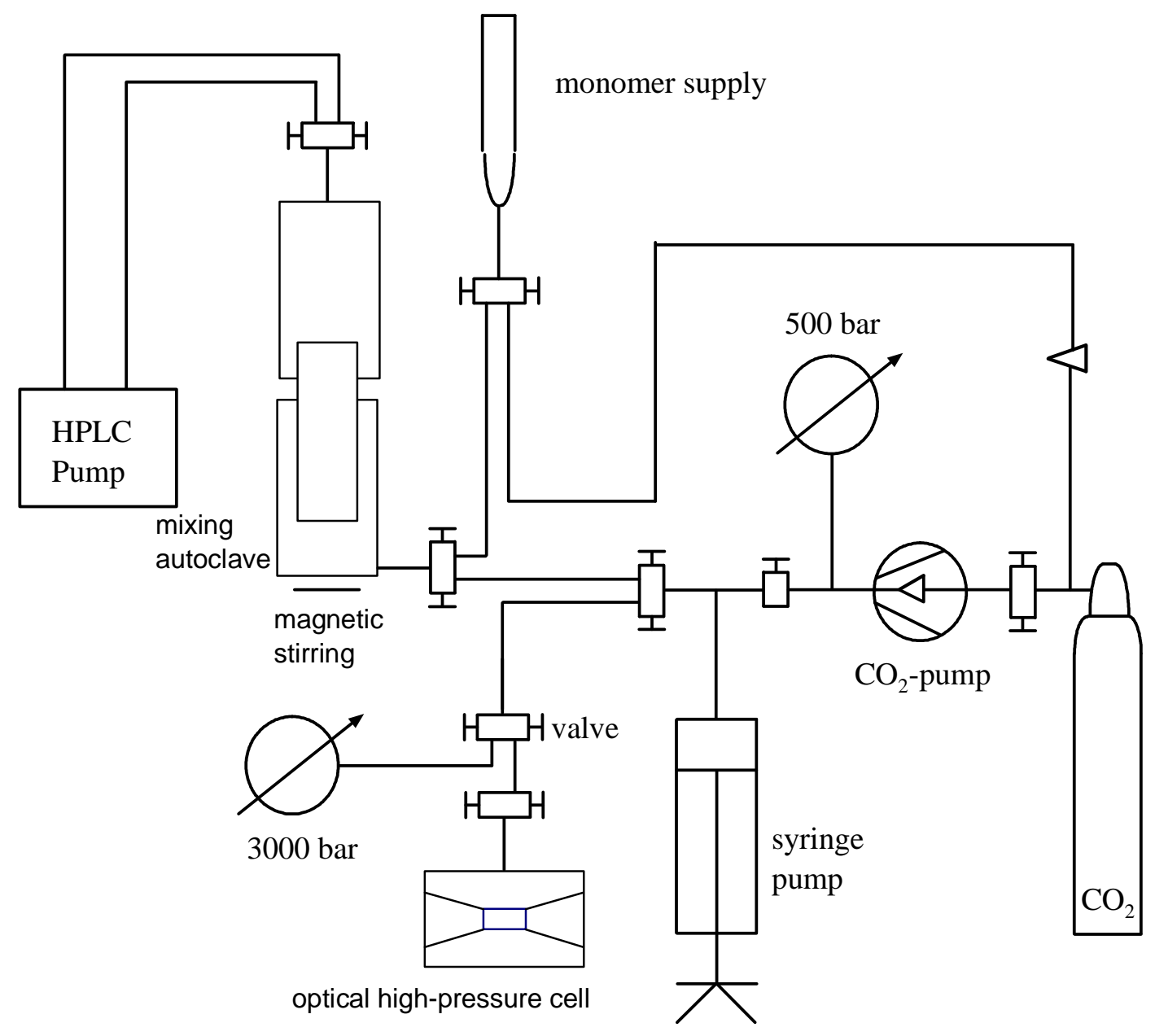

Figure 3.4: $\quad$ Set-up for the preparation of the polymerization mixtures containing $\mathrm{scCO}_{2}$ 


\subsubsection{FT-IR/NIR spectrometer}

Infrared and near infrared spectra were recorded on a Bruker IFS-88 Fourier-Transform spectrometer. To accommodate the heated optical high-pressure cell, the sample chamber of the spectrometer is enlarged (heightened) and fitted with a water-cooled cell holder (to prevent heat transfer). The chamber is purged with compressed air that has been freed from water and carbon dioxide.

The optical configuration of the present work consisted of a halogen source, a silicon-coated calcium fluoride beam splitter, and an InSb detector. This configuration allows for optimal recording in the spectral range of 4000 to $10000 \mathrm{~cm}^{-1}$.

Data acquisition and data processing were performed using the Opus software.

\subsubsection{Excimer laser}

The polymerizations were carried out with the pulsed-laser polymerization (PLP) technique. The XeF line (351 nm) of an LPX 200 excimer laser (Lambda Physik, EMG 103 MSC) was used to induce initiator decomposition and thus polymerization. The laser repetition rate is of $1 \mathrm{~Hz}$, see section 4.4. The incident laser energy was chosen to be close to $4 \mathrm{~mJ}$ per single pulse.

\subsubsection{Size-Exclusion Chromatography (SEC)}

The molecular weight distributions (MWDs) were determined by size-exclusion chromatography $(\mathrm{SEC})^{3}$ using a Waters 515 pump, Waters 410 refractive index detector, PSS-SDV-columns with nominal pore sizes of $10^{5}, 10^{3}$ and $10^{2} \AA$ with tetrahydrofuran (THF) at $30^{\circ} \mathrm{C}$ as the eluent and toluene as the internal standard. The calibration of the SEC was carried out with PS standards $\left(M_{\mathrm{w}}\right.$ between 410 and $\left.2 \cdot 10^{6} \mathrm{~g} \cdot \mathrm{mol}^{-1}\right)$ and PMMA standards $\left(M_{\mathrm{w}}\right.$ between 670 and $\left.2.4 \cdot 10^{6} \mathrm{~g} \cdot \mathrm{mol}^{-1}\right)$ supplied from PSS, Mainz.

A part of the molecular weight distributions analysis was determined at the Polymer Institute in Bratislava, Slovakia by Dr. I. Lacík. 


\subsubsection{Preparation of the mixtures containing the cobalt-complex}

The Co-complex was kept in a glove box because of its air sensitivity. Very careful precautions were taken to prevent any air contact of the complex. All mixtures were prepared in a glove box and deoxygenated by four freeze-pump-thaw cycles. It should also be mentioned that the cobalt-complex was dissolved in the monomer mixture using an ultra-son bad. In case of the bulk polymerizations, the solution was filled into an internal cell (described in section 3.1.2) under argon atmosphere. For the $\mathrm{CO}_{2}$ polymerizations, the solution was filled in the glove box into a Schlenk flask which was closed with a valve. The $\mathrm{CO}_{2}$ set-up described in section 3.1.5 was evacuated with a vacuum pump and purged several times with $\mathrm{CO}_{2}$. A bulb was connected between the $\mathrm{CO}_{2}$ set-up and the Schlenk flask containing the solution. The equipment was evacuated for ten minutes. Then, the solution contained in the Schlenk flask was filled into the bulb by opening the valve and transferred into the autoclave.

\subsection{PLP-SEC Technique}

The pulsed laser polymerizations were performed using an optical high-pressure cell as described in section 3.1.1.

In this work, the homo- and copolymerizations of styrene and methyl methacrylate (MMA) were performed in bulk and in supercritical $\mathrm{CO}_{2}\left(\sim 40 \mathrm{wt} \% \mathrm{scCO}_{2}\right)$ at $80^{\circ} \mathrm{C}$ under pressure with $n$-dodecyl mercaptan, methyl methacrylate trimer, and a cobalt complex as chain-transfer agents. The influence of $\mathrm{scCO}_{2}$ acting as solvent and the pressure dependence of $k_{\mathrm{tr}}$ were studied for these three chain-transfer agents.

For the bulk experiments, monomer, photoinitiator, and chain-transfer agent were mixed and the solution was filled into an internal cell. The internal cell, consisting of a teflon tube and two $\mathrm{CaF}_{2}$ windows is then inserted into the optical high-pressure cell and the assembly is brought to reaction conditions. The polymerization in $\mathrm{scCO}_{2}$ is described in the section 3.1.5. The excimer laser was used to induce initiator decomposition and thus polymerization, as described in section 3.1.7. Samples were initiated by successive laser pulses with a repetition rate of $1 \mathrm{~Hz}$, an incident single pulse energy of about $4 \mathrm{~mJ}$ and a photoinitiator concentration of about $0.2 \mathrm{mmol} \cdot \mathrm{L}^{-1}$. After irradiation of the sample, near infrared (NIR) spectra were recorded in order to determine monomer conversion, which is typically below $4 \%$. The 
resulting polymer was then precipitated with an excess of a mixture of methanol with hydroquinone and isolated.

Molecular weight distributions were determined by means of size-exclusion chromatography.

\subsection{Determination of $C_{\mathrm{T}}$ and $\mathrm{CO}_{2}$-content}

As explained in section 4.3 , the chain-length distribution method is used to determine the chain-transfer constant, $C_{\mathrm{T}}$. Eq. 4.17 indicates that $C_{\mathrm{T}}$ is derived from $[\mathrm{CTA}] /[\mathrm{M}]$, thus the monomer concentration under conditions is not required for data evaluation. The ratio $[\mathrm{CTA}] /[\mathrm{M}]$ was calculated from the weighted masses of monomer and chain-transfer agent, and their respective molecular weights:

$$
\frac{[\mathrm{CTA}]}{[\mathrm{M}]}=\frac{m_{\mathrm{CTA}} / \mathrm{M}_{\mathrm{CTA}}}{m_{\mathrm{M}} / \mathrm{M}_{\mathrm{M}}}
$$

The $\mathrm{CO}_{2}$ content was calculated from the weighted masses of styrene and MMA and the known amount of $\mathrm{CO}_{2}$ used for the preparation of the reaction mixture ${ }^{4,5}$.

\subsection{Substances used}

\subsubsection{Monomers}

Methyl methacrylate (MMA)

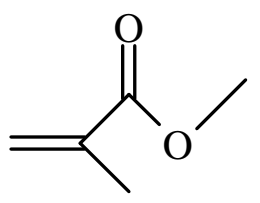

Methyl methacrylate (MMA, $99.5 \%$, stabilized by 0.02 wt \% hydroquinone, Fluka Chemie AG, Buchs, Switzerland) was distilled (using a Vigreux column) under reduced pressure ( $\approx 47^{\circ} \mathrm{C}, 240$ Torr) in the presence of $\mathrm{K}_{2} \mathrm{CO}_{3}$ to remove the stabilizer. Great care has to be 
taken to avoid contamination of the monomer by vacuum grease. Therefore the distillation apparatus is kept sealed by teflon washers.

Styrene

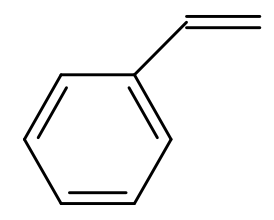

Styrene (99.5\%, stabilized with $0.005 \%$ 4-tert-butylbrenzkatechlin, Fluka Chemie AG, Buchs, Switzerland) was washed several times with aqueous $\mathrm{NaOH}$ and water to remove the inhibitor, then dried with $\mathrm{Na}_{2} \mathrm{SO}_{4}$ and distilled under reduced pressure $\left(\approx 45{ }^{\circ} \mathrm{C}, 20\right.$ Torr $)$.

\subsubsection{Carbon dioxide}

$\mathrm{CO}_{2}$ (grade 4.5, Messer Griesheim, Krefeld, F.R.G) was used without further purification.

\subsubsection{Initiators and inhibitor}

\section{2,2-Dimethoxy-2-phenylacetophenone (DMPA)}<smiles>COC(OC)(C(=O)c1ccccc1)c1ccccc1</smiles>

The photoinitiator DMPA (Aldrich, $99 \%$ ) was used as received.

Azo-bis-isobutyronitril (AIBN) 


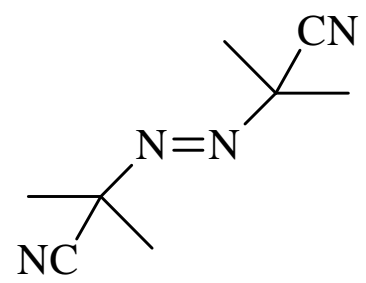

AIBN (Aldrich, $99.5 \%$ ) was recrystallized twice from diisopropylether prior to use.

AIBN was used for the polymerization in section 5.2.1.

\section{Hydroquinone}

Hydroquinone (Aldrich, >99\%) was used as received.

\subsubsection{Chain-transfer agents}

n-dodecyl mercaptan (DDM)<smiles>CCCCCCCCCCCCS</smiles>

DDM (97\%, Fluka chemie, AG, Buchs, Switzerland) was used as received.

Methyl methacrylate trimer (MMAt)<smiles>[CH]CC(C)(CC(=C)COC)C(=O)OC</smiles>

A mixture of low molecular weight MMA oligomers was provided by DuPont Performance Coatings. The fraction of MMA trimer was isolated by fractional distillation under reduced 
pressure $\left(90^{\circ} \mathrm{C}, 0\right.$ Torr). The separation was confirmed by size-exclusion chromatography analysis. The SEC analysis of MMA trimer fractions showed the presence of a small amount of MMA dimer.

bis(methanol) complex of bis(difluoroboryl)diphenylglyoximato cobalt (II) (COPhBF)

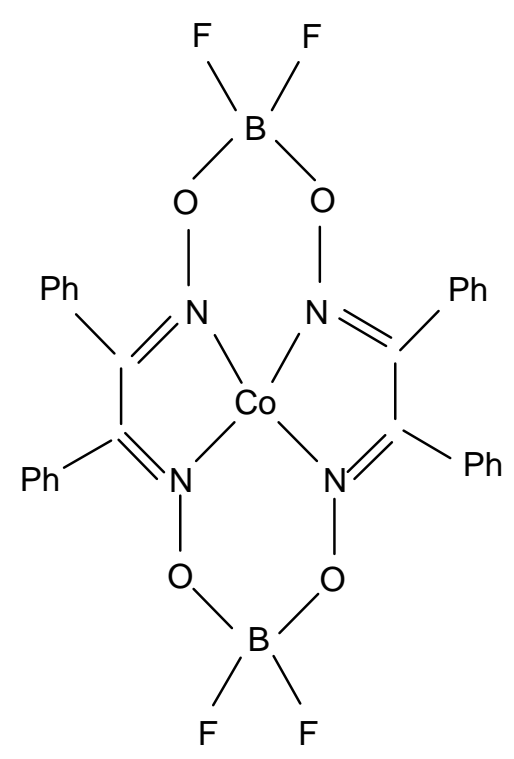

The bis(methanol) complex of COPhBF was prepared according to the method described by Bakac et al. ${ }^{6}$, replacing the dimethylglyoxime in the given procedure by diphenylglyoxime:

A suspension of $2 \mathrm{~g}$ of cobalt (II) acetate tetrahydrate $\left(\mathrm{Co}(\mathrm{OAc})_{2}, 4 \mathrm{H}_{2} \mathrm{O}, 99 \%\right.$, Lancaster) and $1.9 \mathrm{~g}$ of diphenylglyoxime $\left(\mathrm{dpgH}_{2}, 99 \%\right.$, Lancaster) in $150 \mathrm{ml}$ of oxygen free diethyl ether was treated with an excess $(100 \mathrm{ml})$ of freshly distilled boron trifluoride diethyl ether complex $\left(\mathrm{BF}_{3}, \mathrm{Et}_{2} \mathrm{O}, 99 \%\right.$, Lancaster). The mixture was stirred at room temperature for 6 hours, while the desired product precipitated. The brown solid obtained by filtration was washed several times with ice-cold water and air-dried. The powder obtained was recrystallized from methanol and isolated as the bismethanol adduct.

X-ray Structure of the complex was carried out but was not a success. The crystals obtained were not enough structured for this analysis. Therefore, the purity of the complex was checked by elemental analysis. The composition of the complex $\left(\left(\mathrm{CH}_{3} \mathrm{OH}\right)_{2}, \mathrm{COPhBF}\right)$ was calculated from the relative carbon $(\mathrm{C})$, hydrogen $(\mathrm{H})$ and nitrogen $(\mathrm{N})$ masses. The values found are in a good agreement with the calculated values: 


\begin{tabular}{cccc}
\hline & $\mathrm{C} \%$ & $\mathrm{H} \%$ & $\mathrm{~N} \%$ \\
\hline experimental & 51.59 & 4.12 & 7.92 \\
\hline calculated & 51.64 & 4.01 & 8 \\
\hline
\end{tabular}

\subsection{FT-IR/NIR spectroscopy}

The monomer conversion was controlled by FT-NIR spectroscopy. It has become standard practice $^{5,7,8}$ to use the first overtone of the $\mathrm{CH}$-vibration where the hydrogen atom is linked to a $\mathrm{C}=\mathrm{C}$ double bond for quantitative analysis of olefinic monomers. This absorbance is located at around $6140 \mathrm{~cm}^{-1}$ for styrene and at $6170 \mathrm{~cm}^{-1}$ for methyl methacrylate. The peak is integrated over the high wavenumber half-band from the band maximum toward higher wavenumbers against a horizontal baseline determined by the absorbance at $6300 \mathrm{~cm}^{-1}$. The monomer conversion $X$ is obtained from the ratio of peak integrals after pulsing $I_{n} t_{\mathrm{p}}$ and the integral prior irradiation by the UV laser $\operatorname{Int} t_{\mathrm{o}}: X=\left[1-\left(\operatorname{Int} t_{\mathrm{p}} / \operatorname{Int} t_{\mathrm{o}}\right)\right] \cdot 100$.

For a reaction mixture with $\mathrm{CO}_{2}$ a shift of the peak maximum to higher wavenumbers is observed. For example, a styrene homopolymerization at 800 bar and $80^{\circ} \mathrm{C}$ with $40 \mathrm{wt} \% \mathrm{CO}_{2}$ shows an absorbance peak at $6144 \mathrm{~cm}^{-1}$, whereas the peak for the homopolymerization in bulk is located at $6137 \mathrm{~cm}^{-1}$. Schmaltz showed the same trend for the homopolymerization of butyl acrylate (a shift by $11 \mathrm{~cm}^{-1}$ to higher wavenumbers for a polymerization in $40 \mathrm{wt} \% \mathrm{CO}_{2}$ at $11^{\circ} \mathrm{C}$ and 200 bar).

Fig. 3.5 shows typical NIR spectra of styrene (solid line) and of $\mathrm{CO}_{2}$ (dotted line) at $80^{\circ} \mathrm{C}$ and 300 bar. The insert shows the absorbance spectra between $6000 \mathrm{~cm}^{-1}$ and $6500 \mathrm{~cm}^{-1}$. The spectrum of $\mathrm{CO}_{2}$ exhibits two weak absorptions at around $6325 \mathrm{~cm}^{-1}$ and $6200 \mathrm{~cm}^{-1}$. 


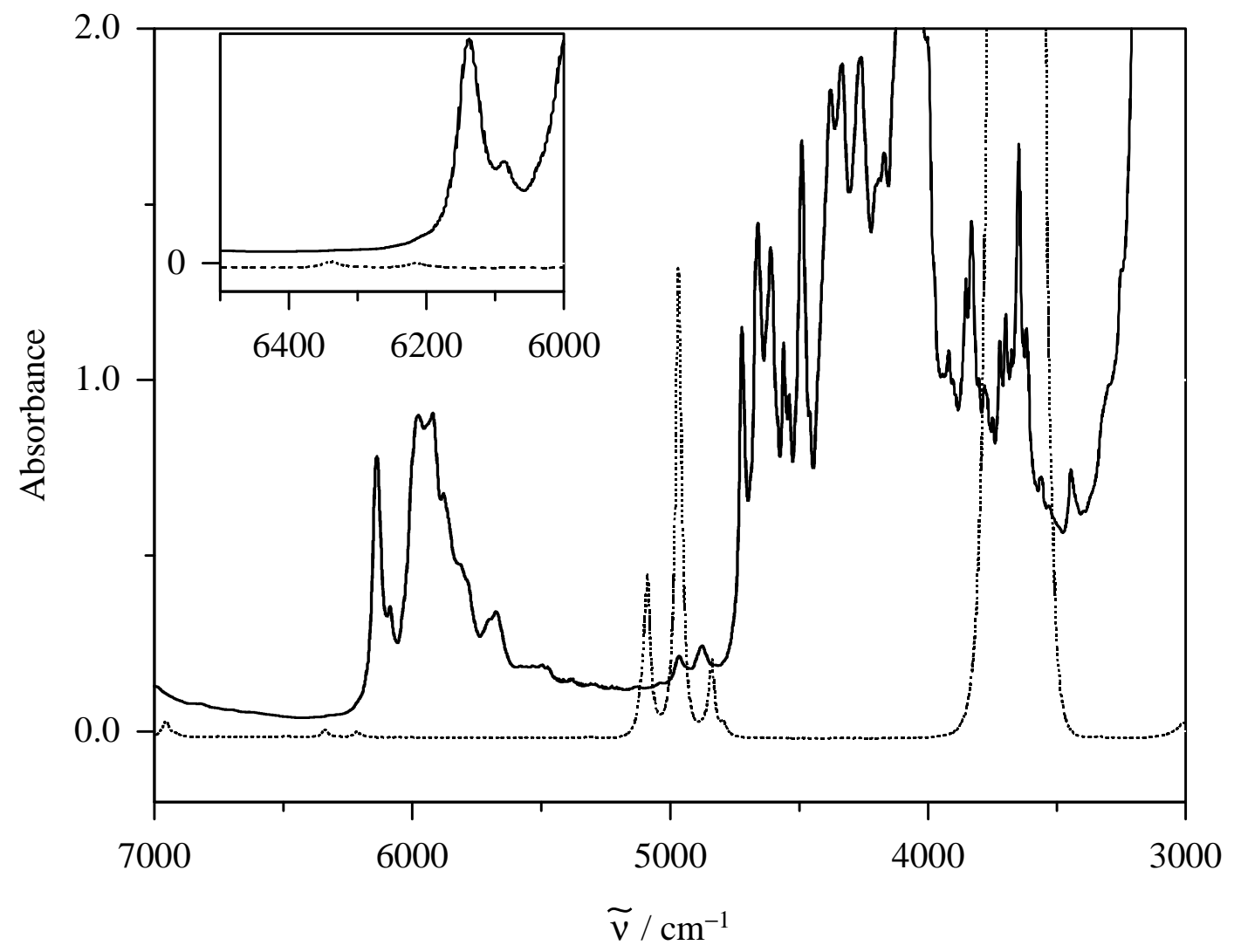

Figure 3.5: $\quad$ NIR spectra of styrene (solid line) and $\mathrm{CO}_{2}$ (dotted line) at $80^{\circ} \mathrm{C}$ and $300 \mathrm{bar}$ (optical path length of $0.25 \mathrm{~cm}$ ).

\subsection{Consideration of errors}

Measurement of the reaction temperature in the direct vicinity of the optical path of the highpressure cell is achieved with the sheathed thermocouple to better than $\pm 0.3 \mathrm{~K}$. The PID controller regulates the temperature within an error of $\pm 0.2 \mathrm{~K}$. Temperature is assumed to be accurate within $\pm 0.5 \mathrm{~K}$.

The high-pressure precision manometer of class 0.1 offers an accuracy of $\pm 0.1 \%$ of the scale limit, resulting in an error of \pm 6 bar. Due to the volume contraction associated with the polymerization activity, the pressure in the reacting system is reduced. For example, the pressure decreases at 1000 bar by approximately 50 bar between zero and $100 \%$ of monomer conversion. Therefore, the pressure variation during the experiments can be neglected in this 
work, because monomer conversions are around $3 \%$. The precise description of the technique used to determine this uncertainty can be found in ref. 5 .

For the preparation of the solutions, an analysis balance (Sartorius) was used which allows measurement up to 4 decimal places. The absolute error should therefore be $\pm 0.5 \mathrm{mg}$. However, the actual error in concentration measurement is greater than this, as the balance is very sensitive to small disturbances. It is estimated that the actual error in the concentration of the comonomer solutions does not exceed $2 \%$ for CTA masses of $50 \mathrm{mg}$ or higher. The polymerizations with the cobalt-complex as catalytic chain-transfer agent require a very small amount of the complex (few mg). To reduce the error several dilutions were carried. The error in the Co-complex concentration is assumed to be less than $5 \%$ for CTA masses of $10 \mathrm{mg}$ or higher.

The error in the $\mathrm{CO}_{2}$ content is composed of the uncertainties in monomer and $\mathrm{CO}_{2}$ densities. The error in the styrene ${ }^{9}$ and $\mathrm{MMA}^{10}$ density at $20^{\circ} \mathrm{C}$ and 1 bar is about $4 \%$. The $\mathrm{CO}_{2}$ content was calculated using the density ${ }^{11}$ of $\mathrm{CO}_{2}$ at $10^{\circ} \mathrm{C}$ and 1 bar considering an error of $3 \%$.

The error induced by the SEC calibration procedure is given by the uncertainties of the MarkHouwink coefficients of the copolymers under investigation and by SEC broadening.

\subsection{References}

1. Poulter, T. C. Phys. Rev. 1932, 40, 860.

2. Buback, M., Hinton, C. in High-pressure Techniques in Chemistry and Physics - A practical approach, Holzapfel, B . W and Isaacs, N.S, eds., Oxford University Press: Oxford, 1997.

3. Olaj, O. F.; Bitai, I.; Hinkelmann, F. Makromol. Chem. 1987, 188, 1689.

4. Beuermann, S.; Buback, M.; Schmaltz, C.; Kuchta, F.-D.; Macromol. Chem. Phys. 1998, 199, 1209.

5. C. Schmaltz, Ph.-D. Thesis 1997, Göttingen.

6. Bakac, A.; Brynildson, M. E.; Espenson, J. H. Inorg. Chem. 1986, 25, 4108.

7. Buback, M.; Kuchta, F.-D. Macromol. Chem. Phys. 1995, 198, 1455.

8. Wahl, A.; Ph.-D. Thesis 2000, Göttingen.

9. Kuchta, F.-D. Ph.-D. Thesis 1996, Göttingen. 
10. Beuermann, S. Ph.-D. Thesis 1993, Göttingen.

11. Angus, S.; Armstrong, B.; de Renck, K. M. "International Thermodynamic Tables of the Fluid State Carbon Dioxide", Pergamon Press, Oxford 1976. 


\section{Experimental considerations and choice of reaction conditions}

\subsection{Selection of temperature and pressure}

Polymerizations were performed at $80^{\circ} \mathrm{C}$ and at pressures between 300 and 1500 bar. The temperature of $80^{\circ} \mathrm{C}$ was chosen because it is a good compromise of achieving reasonable polymerization rate and avoiding significant contributions of thermally induced decomposition of the initiator. The temperature dependence was not studied, because literature already reported the influence of temperature on $C_{\mathrm{T}}$. E.g. Hutchinson and coworkers ${ }^{1}$ studied the temperature dependence of $C_{\mathrm{T}}$ in homopolymerizations of methacrylates with DDM as chain-transfer agent. Measurement of $C_{\mathrm{T}}$ at ambient pressure and temperature between 20 and $80^{\circ} \mathrm{C}$ did not show a variation of $C_{\mathrm{T}}$ with temperature. In case of the cobaltcomplex as chain-transfer agent, the temperature dependence of styrene and MMA homolymerization was investigated ${ }^{2}$. The temperature does not significantly influence the chain-transfer constant for MMA, whereas a decrease of $C_{\mathrm{T}}$ was observed for higher temperatures for styrene. A study of $C_{\mathrm{T}}$ in MMA homopolymerization with MMA trimer as CTA has shown only a slight temperature dependence ${ }^{3}$.

Informations on the pressure dependence of $C_{\mathrm{T}}$, thus of $k_{\mathrm{tr}}$, are not yet available. Therefore, pressures ranging from 300 to 1500 bar were applied.

\subsection{SEC calibration}

The molecular weight distributions, which are required for the derivation of $C_{\mathrm{T}}$, were determined by means of size-exclusion chromatography ${ }^{4}$ (SEC). Thus, the accuracy of $C_{\mathrm{T}}$ is largely governed by the calibration of the SEC system. This is especially important for copolymer analysis. In this section, the methods used for the calibration of the SEC for the homo- and copolymers are presented.

The polystyrene (PS) and poly(methyl methacrylate) (PMMA) samples were directly calibrated against PS standards and PMMA standards, respectively. 
For the copolymer samples, two methods may be used to determine the molecular weight by SEC. The first method is based on the knowledge of the Mark-Houwink (MH) constants, $a$ and $K$, for the copolymers, applying the principle of universal calibration ${ }^{5}$. To apply this technique, the SEC is calibrated against polystyrene. The Mark-Houwink (MH) constants for the copolymers are obtained from a linear interpolation between the MH constants of PMMA and PS considering the fraction of styrene in the copolymer $\left(F_{\mathrm{S}}\right)$, as suggested by Coote et $\mathrm{al}^{6}$. The MH constants for the different copolymers are listed in Table 4.1.

In this case, the absolute weight average molecular weight, $M_{\mathrm{w}}$, of the copolymer is directly determined from a single molecular weight distribution analysis.

\begin{tabular}{ccc}
\hline$F_{\mathrm{s}}$ & $a_{\text {copo }}$ & $K_{\text {copo }} 10^{5} / \mathrm{dL} \cdot \mathrm{g}^{-1}$ \\
\hline 0 & 0.7190 & 9.44 ref. 7 \\
0.30 & 0.7181 & 10.04 \\
0.55 & 0.7173 & 10.52 \\
0.78 & 0.7166 & 10.97 \\
1 & 0.7160 & 11.40 ref. 8 \\
\hline
\end{tabular}

Table 4.1: $\quad$ Mark-Houwink parameters $a$ and K for copolymers of styrene and MMA.

The second method used to obtain the molecular weight distribution of the copolymer is based on the knowledge of the MH constants of styrene and MMA homopolymers. Since the solution behavior of styrene and MMA homopolymers in tetrahydrofuran is very similar (as evidenced by their MH constants), the following approximations for their copolymers can be made ${ }^{9}$ :

$M_{\mathrm{n}, \mathrm{copo}} \approx F_{\mathrm{S}} M_{\mathrm{n}, \mathrm{S}}+\left(1-F_{\mathrm{S}}\right) M_{\mathrm{n}, \mathrm{MMA}}$

where $M_{\mathrm{n}, \text { copo }}$ is the number average molecular weight of the copolymer, $M_{\mathrm{n}, \mathrm{S}}$ and $M_{\mathrm{n}, \mathrm{MMA}}$ are the number average molecular weights considering the polymer to be PS and PMMA, respectively.

For the determination of the chain-transfer constant via the chain-length distribution method (see section 4.3), the following expression is used: 
$\Lambda_{\text {copo }}{ }^{-1} \approx F_{\mathrm{S}} \cdot \Lambda_{\mathrm{S}}{ }^{-1}+\left(1-F_{\mathrm{S}}\right) \cdot \Lambda_{\mathrm{MMA}}{ }^{-1}$

$\Lambda_{\text {copo }}$ is the slope of the $\ln f(M)$ vs $M$ plot for the copolymer, and $\Lambda_{\mathrm{S}}$ and $\Lambda_{\mathrm{MMA}}$ are the slopes considering the polymer to be PS and PMMA, respectively.

In order to check the validity of the $C_{\mathrm{T}}$ values obtained by using these two methods, some investigations on styrene-MMA copolymerizations were carried out with DDM as chaintransfer agent in bulk at $80^{\circ} \mathrm{C}$ and 300 bar. Table 4.2 lists the chain-transfer constants obtained with both procedures. Close agreement of the results was obtained, indicating that both methods are equivalent.

\begin{tabular}{ccc}
\hline$F_{\mathrm{S}}$ & $a$ and $K$ copolymers & $a$ and $K$ homopolymers \\
\hline 0.55 & $C_{\mathrm{T}}=3.34$ & $C_{\mathrm{T}}=3.38$ \\
0.78 & $C_{\mathrm{T}}=8.14$ & $C_{\mathrm{T}}=8.68$ \\
\hline
\end{tabular}

Table 4.2: $\quad$ Chain-transfer constants obtained with both methods of calibration of the SEC.

Both procedures are actually based on the knowledge of homopolymer $\mathrm{MH}$ constants and require the same amount of experimental work, the difference lies in the analysis of the sizeexclusion chromatograms. A single analysis of the molecular weight distribution is required for the first method, whereas the second method affords two molecular weight analyses. Therefore, in this work the chain-transfer constants for the copolymerization were determined by applying the first method.

\subsection{Determination of $C_{\mathrm{T}}$}

\subsubsection{Background}

According to the classical mechanism for free-radical polymerization, as shown in the following reaction scheme, a propagating radical $\mathrm{R}^{\bullet}$, once generated, has three options to 
react. It may propagate, terminate in a radical-radical reaction, or undergo a chain-transfer reaction.

Chain transfer involves the reaction of a propagating chain $R_{n}{ }^{\cdot}$ with a transfer agent to terminate one polymer chain and produce a new radical $\mathrm{X}^{\bullet}$, which initiates another chain $\mathrm{XR}_{1}{ }^{\bullet}$. The substrate for the chain transfer may be a chain-transfer agent $(\mathrm{X})$, or the initiator $\left(\mathrm{I}_{2}\right)$, the monomer $(\mathrm{M})$, or some other component of the polymerization medium.

Initiation

$$
\mathrm{I}_{2} \stackrel{k_{\mathrm{d}}}{\longrightarrow} 2 \mathrm{R}^{\bullet}
$$

Propagation

$$
\mathrm{R}_{\mathrm{n}}+\mathrm{M} \stackrel{k_{\mathrm{p}}}{\longrightarrow} \mathrm{R}_{\mathrm{n}+1}
$$

Termination

$$
\begin{gathered}
\mathrm{R}_{\mathrm{n}}+\mathrm{R}_{\mathrm{m}} \stackrel{k_{\mathrm{td}}}{\longrightarrow} \mathrm{P}_{\mathrm{n}}+\mathrm{P}_{\mathrm{m}} \\
\mathrm{R}_{\mathrm{n}} \cdot+\mathrm{R}_{\mathrm{m}} \cdot \stackrel{k_{\mathrm{tc}}}{\longrightarrow} \mathrm{P}_{\mathrm{n}+\mathrm{m}}
\end{gathered}
$$

Transfer

$$
\begin{gathered}
\mathrm{R}_{\mathrm{n}}+\mathrm{X} \stackrel{k_{\mathrm{tr}, \mathrm{X}}}{\longrightarrow} \mathrm{P}_{\mathrm{n}}+\mathrm{X}^{\bullet} \\
\mathrm{X}^{\bullet}+\mathrm{M} \stackrel{k_{\mathrm{p}, \mathrm{X}}}{\longrightarrow} \mathrm{XR}_{1} \\
\mathrm{R}_{\mathrm{n}}{ }^{+}+\mathrm{I}_{2} \stackrel{k_{\mathrm{tr}, \mathrm{I}}}{\longrightarrow} \mathrm{P}_{\mathrm{n}}+\mathrm{I}^{\bullet} \\
\mathrm{R}_{\mathrm{n}}{ }^{+}+\mathrm{M} \stackrel{k_{\mathrm{tr}, \mathrm{M}}}{\longrightarrow} \mathrm{P}_{\mathrm{n}}+\mathrm{R}_{1} \\
\mathrm{R}_{\mathrm{n}}+\mathrm{P}_{\mathrm{m}} \stackrel{k_{\mathrm{tr}, \mathrm{p}}}{\longrightarrow} \mathrm{P}_{\mathrm{n}}+\mathrm{R}_{\mathrm{m}}
\end{gathered}
$$

$k_{\mathrm{d}}$ and $k_{\mathrm{p}}$ are the decomposition and propagation rate coefficients, respectively. $k_{\mathrm{td}}$ and $k_{\mathrm{tc}}$ are the termination rate coefficients for termination by disproportionation and by combination, respectively. $k_{\mathrm{tr}, \mathrm{X}}, k_{\mathrm{tr}, \mathrm{M}}, k_{\mathrm{tr}, \mathrm{I}}$ and $k_{\mathrm{tr}, \mathrm{P}}$ are the transfer rate coefficients to CTA, initiator, monomer and polymer, respectively. 
At any given instant of the polymerization process, the probability of propagation $S$, is simply the rate of propagation divided by the sum of reaction rates of the entire set of potential reactions of the propagating radical, as follow:

$S=R_{\mathrm{p}} /\left(R_{\mathrm{p}}+R_{\mathrm{tr}}+R_{\mathrm{t}}\right)$

where,

$R_{\mathrm{p}}=k_{\mathrm{p}}[\mathrm{M}]\left[\mathrm{R}_{\mathrm{n}}{ }^{\cdot}\right]$

$R_{\mathrm{tr}}=k_{\mathrm{tr}, \mathrm{X}}[\mathrm{CTA}]\left[\mathrm{R}_{\mathrm{n}}{ }^{\cdot}\right]+k_{\mathrm{tr}, \mathrm{I}}[\mathrm{I}]\left[\mathrm{R}_{\mathrm{n}}{ }^{\circ}\right]+k_{\mathrm{tr}, \mathrm{M}}[\mathrm{M}]\left[\mathrm{R}_{\mathrm{n}}{ }^{\circ}\right]+k_{\mathrm{tr}, \mathrm{P}}\left[\mathrm{P}_{\mathrm{m}}\right]\left[\mathrm{R}_{\mathrm{n}}{ }^{\circ}\right]$

$R_{\mathrm{t}}=2 \cdot k_{\mathrm{t}}\left[\mathrm{R}_{\mathrm{n}}\right]^{2}$

Replacing the rate expressions into Eq 4.3 yields:

$$
S=\frac{k_{\mathrm{p}}[\mathrm{M}]\left[\mathrm{R}_{\mathrm{n}} \cdot\right]}{k_{\mathrm{p}}[\mathrm{M}]\left[\mathrm{R}_{\mathrm{n}} \cdot\right]+k_{\mathrm{tr}, \mathrm{X}}[\mathrm{CTA}]\left[\mathrm{R}_{\mathrm{n}} \cdot\right]+k_{\mathrm{tr}, \mathrm{I}}[\mathrm{I}]\left[\mathrm{R}_{\mathrm{n}} \cdot\right]+k_{\mathrm{tr}, \mathrm{M}}[\mathrm{M}]\left[\mathrm{R}_{\mathrm{n}} \cdot\right]+k_{\mathrm{tr}, \mathrm{P}}\left[\mathrm{P}_{\mathrm{m}}\right]\left[\mathrm{R}_{\mathrm{n}} \cdot\right]+2 \cdot k_{\mathrm{t}}\left[\mathrm{R}_{\mathrm{n}} \cdot\right]^{2}}
$$

which may be written as:

$$
S=\frac{1}{1+C_{\mathrm{T}} \frac{[\mathrm{CTA}]}{[\mathrm{M}]}+C_{\mathrm{I}} \frac{[\mathrm{I}]}{[\mathrm{M}]}+C_{\mathrm{M}}+C_{\mathrm{P}} \frac{\left[\mathrm{P}_{\mathrm{m}}\right]}{[\mathrm{M}]}+\frac{2 \cdot k_{\mathrm{t}}\left[\mathrm{R}_{\mathrm{n}} \cdot\right]}{k_{\mathrm{p}}[\mathrm{M}]}}
$$

where $C_{\mathrm{T}}, C_{\mathrm{M}}, C_{\mathrm{I}}, \mathrm{C}_{\mathrm{P}}$ are the transfer constants for transfer to the chain-transfer agent, to monomer, to initiator, and to polymer, respectively.

$$
\frac{1}{S}=1+C_{\mathrm{T}} \frac{[\mathrm{CTA}]}{[\mathrm{M}]}+C_{\mathrm{I}} \frac{[\mathrm{I}]}{[\mathrm{M}]}+C_{\mathrm{M}}+C_{\mathrm{P}} \frac{\left[\mathrm{P}_{\mathrm{m}}\right]}{[\mathrm{M}]}+\frac{2 \cdot k_{\mathrm{t}}\left[\mathrm{R}_{\mathrm{n}} \cdot\right]}{k_{\mathrm{p}}[\mathrm{M}]}
$$

The probability that a chain will propagate and terminate to yield a polymer molecule of length $i$ is given by the product of the probability of individual propagation steps and the probability of termination of the chain of length $i$. If termination is independent of chain length, this can be expressed as the probability of propagation raised to a power of $(i-1)$ multiplied by the probability of termination $(1-S)$. Thus, the chain-length distribution is:

$\mathrm{P}_{i}=(1-S) S^{i-1}$

This is the well known Schulz-Flory ${ }^{10}$ most probable distribution, for which the following equations hold: 


$$
\begin{aligned}
& D P_{\mathrm{n}}=\frac{S}{1-S} \\
& S=\frac{D P_{\mathrm{n}}}{1+D P_{\mathrm{n}}}
\end{aligned}
$$

Substitution of $S$ in Eq. 4.9 gives the Mayo equation ${ }^{11}$ (Eq. 4.13):

$\frac{1}{D P_{\mathrm{n}}}=C_{\mathrm{T}} \frac{[\mathrm{CTA}]}{[\mathrm{M}]}+C_{\mathrm{I}} \frac{[\mathrm{I}]}{[\mathrm{M}]}+C_{\mathrm{M}}+C_{\mathrm{P}} \frac{\left[\mathrm{P}_{\mathrm{m}}\right]}{[\mathrm{M}]}+\frac{2 \cdot k_{\mathrm{t}}\left[\mathrm{R}^{*} \cdot\right]}{k_{\mathrm{p}}[\mathrm{M}]}$

In the absence of an added chain-transfer agent the number average degree of polymerization is given by Eq. 4.14 .

$$
\frac{1}{D P_{\mathrm{n}_{\mathrm{o}}}}=C_{\mathrm{I}} \frac{[\mathrm{I}]}{[\mathrm{M}]}+C_{\mathrm{M}}+C_{\mathrm{P}} \frac{\left[\mathrm{P}_{\mathrm{m}}\right]}{[\mathrm{M}]}+\frac{2 \cdot k_{\mathrm{t}}\left[\mathrm{R}_{\mathrm{n}} \cdot\right]}{k_{\mathrm{p}}[\mathrm{M}]}
$$

Comparison of Eqs 4.13 and 4.14 shows that:

$$
\frac{1}{D P_{\mathrm{n}}}=\frac{1}{D P_{\mathrm{n}_{\mathrm{o}}}}+C_{\mathrm{T}} \frac{[\mathrm{CTA}]}{[\mathrm{M}]}
$$

The chain-transfer constant, $C_{\mathrm{T}}$, is defined as the ratio of $k_{\mathrm{tr}, \mathrm{X}}$ and $k_{\mathrm{p}}$.

The higher $C_{\mathrm{T}}$ is, the lower is the concentration of chain-transfer agent that is required for a particular molecular weight reduction ${ }^{12}$. This effect on polymer molecular weight is quantitatively given by the Mayo-equation ${ }^{11}$ which expresses the reciprocal of the number average degree of polymerization, $D P_{\mathrm{n}}$, as a function of the rates of chain growth and chain stopping $^{11,12}$ (Eq. 4.13).

There are two possible procedures for determining $C_{\mathrm{T}}$ data, the Mayo method and the chainlength distribution (CLD) method.

\subsubsection{Mayo method}

The usually applied procedure for measuring chain-transfer constants proceeds via the determination of the average degree of polymerization for a range of $[\mathrm{CTA}] /[\mathrm{M}]$ values and plotting the data as $D P_{\mathrm{n}}{ }^{-1}$ vs [CTA]/[M], i.e., the so called Mayo plot. The value of $C_{\mathrm{T}}$ is then determined as the slope of the straight line in the results. This procedure assumes that the product $k_{\mathrm{t}}\left[\mathrm{R}_{\mathrm{n}}{ }^{\circ}\right]$ is independent of the variation of [CTA]/[M]. However, if termination is chain 
length dependent, then $k_{\mathrm{t}}\left[\mathrm{R}_{\mathrm{n}}{ }^{\circ}\right]$ will vary with $[\mathrm{CTA}] /[\mathrm{M}]$ as the average degree of polymerization varies and hence the frequency of termination varies, even if the initiator concentration remains constant. This implies that the last term on the right hand side of Eq. 4.13 is generally not a constant and so the Mayo plot needs not to be linear. In principle, this is a weakness of the Mayo method for determining $C_{\mathrm{T}}$. However, in practice, this effect does not seem to be significant, which suggests that, in system with added chain-transfer agent, the last term of the right hand side of Eq 4.13 generally makes a negligible contribution to $D P_{\mathrm{n}}^{-1}$.

There is two ways to use the Mayo equation for determining $C_{\mathrm{T}}$. The number average degree of polymerization can be obtained directly from the number average molecular weight, $M_{\mathrm{n}}$, by dividing $M_{\mathrm{n}}$ by monomer molecular weight, $M_{0}$. Although, this procedure is in principle the only correct way to determine $D P_{\mathrm{n}}$ from a molecular weight distribution, in practice this procedure has an important shortcoming. The number average molecular weight is very sensitive to errors in the analysis of the size-exclusion chromatogram (e.g., peak and baseline selection), and it often leads to scattered results ${ }^{13}$. This is especially true for low molecular weight polymers. An alternative procedure for obtaining $D P_{\mathrm{n}}$ from the molecular weight distribution is from the weight average molecular weight ${ }^{14}, M_{\mathrm{w}}$. In a chain transfer dominated system, $M_{\mathrm{w}}$ is equal to $2 M_{\mathrm{n}}$ (except for very low molecular weights), and hence $D P_{\mathrm{n}}=M_{\mathrm{w}} /\left(2 M_{0}\right)$ for such system. The use of $M_{\mathrm{w}}$ is often more reliable because $M_{\mathrm{w}}$ is much less sensitive to errors in the analysis of the size-exclusion chromatogram.

\subsubsection{Chain-Length Distribution method}

A more recent procedure for determining $C_{\mathrm{T}}$ has been developed by Gilbert and coworkers $^{15,16,17}$. It is called the Chain Length Distribution (CLD) method. This procedure is based upon taking the high molecular weight slope of the number molecular weight distribution, $f(M)$, plotted as $\ln f(M)$ vs. $M$. The high molecular weight slope of a line on this plot, denoted as $\Lambda$, is related to the kinetic parameters as follows:

$$
\Lambda=\lim _{M \rightarrow \infty} \frac{\mathrm{d} \ln f(M)}{\mathrm{d} M}=-\left(\frac{2 \cdot k_{\mathrm{t}}\left[\mathrm{R}^{\bullet}\right]}{k_{\mathrm{p}}[\mathrm{M}]}+C_{\mathrm{M}}+C_{\mathrm{I}}+C_{\mathrm{P}}+C_{\mathrm{T}} \frac{[\mathrm{CTA}]}{[\mathrm{M}]}\right) \frac{1}{M_{0}}
$$

and,

$$
\Lambda M_{0}=\frac{\mathrm{d} \ln f(n)}{\mathrm{d} n}=a-C_{\mathrm{T}} \frac{[\mathrm{CTA}]}{[\mathrm{M}]}
$$


where, $a$ includes the contributions of all other chain stopping events.

According to Eq. 4.17, $-C_{\mathrm{T}}$ is equal to the slope of a straight line of the CLD plot, which refers to the plot of $\Lambda \cdot M_{0}$ vs $[\mathrm{CTA}] /[\mathrm{M}]$.

Recently, a discussion has started about the adequate molecular weight region from which $\Lambda$ should be determined ${ }^{13}$, i.e., whether the slope should be determined in the high molecular weight region $\left(\Lambda_{\text {high }}\right.$ : between $\mathrm{A}$ and $\left.\mathrm{B}\right)$, which is the correct theoretical limit ${ }^{15}$, or in the region of the peak molecular weight ( $\Lambda_{\text {peak }}$ : starting near $M_{\mathrm{w}}$ and ending at around $M_{\mathrm{z}}$ ), which suffers less from experimental uncertainties ${ }^{13}$. These molecular weight regions are illustrated in Fig. 4.1. In a previous study Davis and co-workers ${ }^{9}$ found that $\Lambda_{\text {peak }}$ results compare most favorably with the $M_{\mathrm{w}} / 2$ results of the Mayo method, and therefore concluded that this should be the preferred option, which has been also confirmed by several others authors ${ }^{21,2}$. The choice of the peak molecular weight region is also justified by results obtained by Moad and Moad $^{13}$, who argue that this high molecular weight region may be less affected by deviations in the baseline. In principle, $C_{\mathrm{T}}$ can be evaluated from any part of the $\ln$ CLD plot.
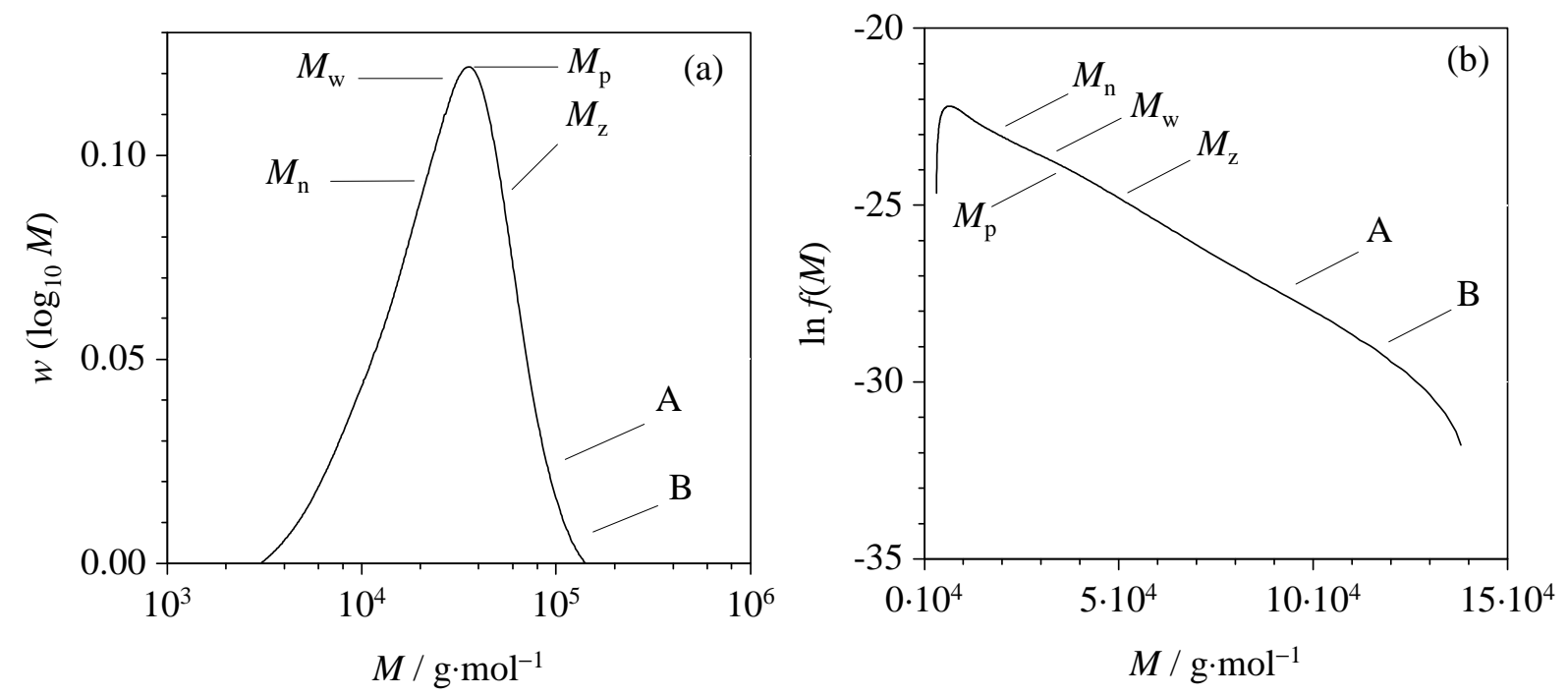

Figure 4.1: $\quad$ Typical molecular weight distribution plotted as $(a) w(\log M)$ vs $M$ and $(b) \ln$ $f(M)$ vs $M$. The positions of the most important molecular weight averages used for the determination of $C_{T}$ are indicated. 


\subsubsection{Comparison of both procedures}

\subsubsection{Theoretical comparison}

The formats of Eqs 4.15 and 4.17 for determination of $C_{\mathrm{T}}$ according to the Mayo method and to the CLD method, respectively, are very similar. However, calculation of $C_{\mathrm{T}}$ via the slope of the MWD (CLD method) provides a more robust estimate, since it is less dependent on the tails of the distribution. Since in each type of plot the ordinates are different, $D P_{\mathrm{n}}^{-1}$ for the Mayo plot and $\Lambda M_{0}$ for the CLD plot, one might get the impression that the two procedures for determining $C_{\mathrm{T}}$ are different. With respect to the required experimental material, both procedures are identical, only the analysis of the size-exclusion chromatograms is different.

It is now generally accepted that the rate coefficient of termination in radical polymerization is chain-length dependent. Bamford ${ }^{18}$ and Olaj et al. ${ }^{19}$ have considered the effect of a chainlength dependence of the termination rate coefficient on the applicability of the Mayo method. They concluded that transfer constants should be slightly overestimated by the Mayo method. Gilbert and co-workers ${ }^{15,16}$ have indicated that by examining the high molecular weight tail of the distribution, the effects of some termination by combination and the chain-length dependence of propagation and termination rate constants on the slope of a CLD plot should be negligible.

As explained before, both the Mayo and the CLD methods can be used in two different ways to determine the chain-transfer constant: Using $M_{\mathrm{n}}$ or $M_{\mathrm{w}}$ for the Mayo method and $\Lambda_{\text {peak }}$ or $\Lambda_{\text {high }}$ for the CLD. In general, $M_{\mathrm{w}}$ and $\Lambda_{\text {peak }}$ are used ${ }^{17,9}$. Indeed, it has been previously shown ${ }^{9,20}$ that in cases in which significant curvature occurs, the results based upon the Mayo procedure using $M_{\mathrm{w}}$ agree very well with the results obtained from the CLD procedure using $\Lambda_{\text {peak. }}$. As already mentioned, the CLD method is less sensitive to the presence of artefacts in the GPC traces caused by experimental noise or poor baseline selection. One major benefit of the CLD method is that the requisite information can be obtained by analyzing a small segment of the chain-length distribution. Thus problems, that may arise from an incomplete separation of low molecular weight material, e.g. residual monomer, which affects $M_{\mathrm{n}}$ and $M_{\mathrm{w}}$ are excluded or are minimized. In addition, problems resulting from difficulties in the accurate analysis of the high molecular weight side of the MWD, or due to spontaneous polymerization, or due to a lack of reliable calibration standards, or due to branching of polymer as a result of transfer to polymer reactions, may be reduced or even eliminated. In these cases, the Mayo method may not be applicable since $M_{\mathrm{n}}$ and $M_{\mathrm{w}}$ values are affected: 
This was the case in this work for styrene homopolymerizations with DDM as CTA (for comparison see section 5.1). Moreover, the $C_{\mathrm{T}}$ values determined with the CLD method, via $\Lambda_{\text {peak }}$ and $\Lambda_{\text {high }}$, are seen to be very close to each other in most experiments performed in this work (more details in section 4.3.3).

\subsubsection{Experimental comparison}

As explained in section 4.3.2.1, theoretically both methods may be used, however it seems that the CLD method is more robust. In the following section, both procedures are compared via the calculated $C_{\mathrm{T}}$ values. The weight average molecular weight, $M_{\mathrm{w}}$, was used for the Mayo method and the peak region, $\Lambda_{\text {peak }}$, for the CLD method for the reasons already explained.

The chain-transfer constants determined are listed in Table 4.3, as example for the copolymerizations of styrene and MMA $\left(f_{\mathrm{S}}=0.2\right.$ and 0.8$)$ with $\mathrm{DDM}$ and $\mathrm{COPhBF}$ at 300 bar and $80^{\circ} \mathrm{C}$.

\begin{tabular}{|c|c|c|c|c|c|}
\hline & \multirow[b]{2}{*}{ CTA } & \multicolumn{2}{|c|}{$C_{\mathrm{T}} \operatorname{CLD}\left(\Lambda_{\text {peak }}\right)$} & \multicolumn{2}{|c|}{$C_{\mathrm{T}} \operatorname{Mayo}\left(M_{\mathrm{w}}\right)$} \\
\hline & & bulk & $\mathrm{scCO}_{2}$ & bulk & $\mathrm{scCO}_{2}$ \\
\hline \multirow[b]{2}{*}{$f_{\mathrm{S}}=0.2$} & DDM & 2.03 & 2.10 & 2.10 & 1.90 \\
\hline & $\mathrm{COPhBF}$ & $42.2 \cdot 10^{2}$ & $125 \cdot 10^{2}$ & $39.4 \cdot 10^{2}$ & $111 \cdot 10^{2}$ \\
\hline \multirow{2}{*}{$f_{\mathrm{S}}=0.8$} & DDM & 8.14 & 8.98 & 7.82 & 7.75 \\
\hline & $\mathrm{COPhBF}$ & $9.34 \cdot 10^{2}$ & $10.1 \cdot 10^{2}$ & $9.73 \cdot 10^{2}$ & $9.85 \cdot 10^{2}$ \\
\hline
\end{tabular}

Table 4.3: $\quad$ Chain-transfer constants, $C_{T}$, determined via the Mayo and the CLD methods for the copolymerization of styrene and MMA at $80^{\circ} \mathrm{C}$ and 300 bar with DDM and COPhBF as chain-transfer agents.

The $C_{\mathrm{T}}$ values obtained via the CLD method are mostly slightly higher than the $C_{\mathrm{T}}$ values obtained using the Mayo method. The difference is not significant, less than $15 \%$, and close to uncertainties observed in the literature ${ }^{9,21,22}$. Madruga et al. ${ }^{21}$ determined $C_{\mathrm{T}}$ values for the homopolymerization of styrene at $50^{\circ} \mathrm{C}$ in bulk using the Mayo and CLD methods. The reported values are 12.6 and 15.1, respectively. This difference is larger than the one reported 
here. Some literature data show a larger difference of the $C_{\mathrm{T}}$ values $\left(C_{\mathrm{T}, \mathrm{Mayo}}=550\right.$ and $C_{\mathrm{T}, \mathrm{CLD}}$ $=1.5 \cdot 10^{3}$ for the same system ${ }^{23}$ ). The $C_{\mathrm{T}}$ values which are listed in Appendices 2, 3, and 4 show also a good agreement between both methods.

This section has shown that both procedures are almost equivalent. In this thesis, the analysis technique suggested by Gilbert and co-workers, the so-called CLD method, was preferentially used for the determination of $C_{\mathrm{T}}$ in section 5 .

\subsubsection{CLD method}

For all experiments performed in this work, the CLD procedure was used to determine $C_{\mathrm{T}}$ via $\Lambda_{\text {peak }}$ and via $\Lambda_{\text {high. }}$. The results obtained for styrene and MMA homopolymerizations at 300 bar and $80^{\circ} \mathrm{C}$ with DDM as CTA are shown in Fig. 4.2.
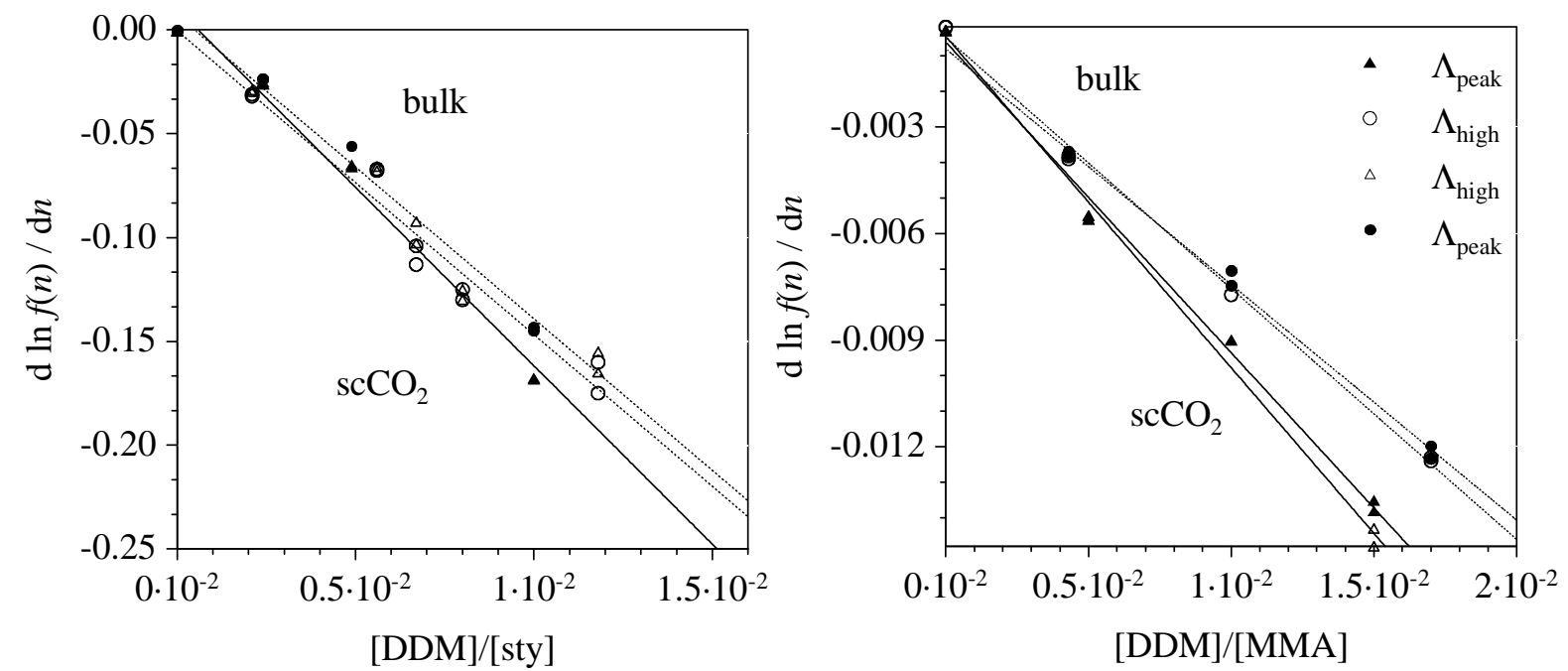

Figure 4.2: $\quad$ CLD plots for DDM as CTA. The left hand side pictures the CLD plots of styrene homopolymerizations, on the right hand side are shown the CLD plots of MMA homopolymerizations.

It is clearly seen that the slopes, corresponding to $-C_{\mathrm{T}}$, are the same in both cases, using the peak and the high molecular weight regions for analysis. The values of $C_{\mathrm{T}}$, which are summarized in Table 4.4 are independent of the considered region. Since there seems to be no convincing argument for an a priori choice of a particular region, the peak region was used to determine $C_{\mathrm{T}}$ in section 5 . However, for all systems it was verified that both $C_{\mathrm{T}}\left(\Lambda_{\text {high }}\right.$ and $\Lambda_{\text {peak }}$ ) are in good agreement. 


\begin{tabular}{ccccc}
\hline \multicolumn{4}{c}{$C_{\mathrm{T}}$ from CLD } \\
\hline \multicolumn{4}{c}{$\Lambda_{\text {high }}$} & \multicolumn{2}{c}{$\Lambda_{\text {peak }}$} \\
\hline bulk & $\mathrm{scCO}_{2}$ & bulk & scCO $_{2}$ \\
\hline MMA & 0.681 & 0.801 & 0.702 & 0.811 \\
\hline styrene & 14.9 & 15.8 & 14.6 & 16.3 \\
\hline
\end{tabular}

Table 4.4: $\quad C_{T}$ values obtained in styrene and MMA homopolymerizations at 300 bar and $80^{\circ} \mathrm{C}$ using the CLD method.

The good agreement of $C_{\mathrm{T}}$ obtained by the two approaches is not surprising. Upon examination of Fig. $4.1 \mathrm{~b}$ it can be seen that there is no curvature over the complete range of molecular weights. The same observation is made for most of the samples investigated in this thesis.

\subsection{Conditions for the determination of $C_{\mathrm{T}}$ by PLP}

Initiation by PLP has been shown to be a reliable technique for the determination of $k_{\mathrm{p}}$ if certain criteria are met. The advantages of PLP, e.g, the easy variability of the radical concentration in the polymerizing system and short reaction time, should also apply to the measurement of $k_{\mathrm{tr}}^{24,25,26,27}$.

The limitations for the estimation of $C_{\mathrm{T}}$ are examined and criteria are defined for the use of PLP in chain-transfer studies.

As explained in the preceding section, the method used for the determination of chain-transfer constants in this work is the CLD ${ }^{15}$ method. It is based on the following equation:

$\frac{\mathrm{d} \ln f(n)}{\mathrm{d} n}=a-\left(\frac{k_{\mathrm{tr}, \mathrm{X}}}{k_{\mathrm{p}}}\right) \frac{[\mathrm{CTA}]}{[\mathrm{M}]}$

The best estimate for $k_{\mathrm{tr}, \mathrm{X}} / k_{\mathrm{p}}\left(C_{\mathrm{T}}\right)$ is obtained when the contributions from other chainstopping mechanisms are small compared to that from the chain-transfer mechanism under consideration. In other words, the intercept value $a$ should be close to zero. In this work, 
experimental conditions are chosen such that chain transfer to chain-transfer agent dominates the MWD.

It is necessary to determine under which conditions it is feasible to combine PLP, inherently a non-steady-state process, with a procedure developed assuming steady state conditions.

The PLP technique involves the exposure of a monomer/photoinitiator system to laser flashes, which generate a burst of initiator radicals in a controlled and periodic fashion. Between two flashes, which occur every $t_{0}$ seconds, the radical concentration in the system decreases due to radical-radical termination:

$\mathrm{d}\left[\mathrm{R}^{\bullet}\right] / \mathrm{d} t=-2 \cdot k_{\mathrm{t}}\left[\mathrm{R}^{\cdot}\right]^{2} \quad \mathrm{x} \cdot t_{0}<t<(\mathrm{x}+1) \cdot t_{0}$

where $\mathrm{x}$ is the number of pulses.

Integration of this equation leads to an explicit expression for the variation of the total radical concentration with time:

$$
[\mathrm{R} \cdot](t)=\frac{[\mathrm{R} \cdot]^{\max }}{1+k_{\mathrm{t}}[\mathrm{R} \cdot]^{\max }\left(t-\mathrm{x} \cdot t_{0}\right)}
$$

where, $\left[\mathrm{R}^{\bullet}\right]^{\max }$ is the radical concentration immediately following the xth laser pulse.

In PLP, a fraction of the growing polymer radicals survives without undergoing a termination or transfer event until the next pulse of radicals is generated $t_{0}$ seconds later. A typical radical concentration-time profile is shown in Fig. 4.3.

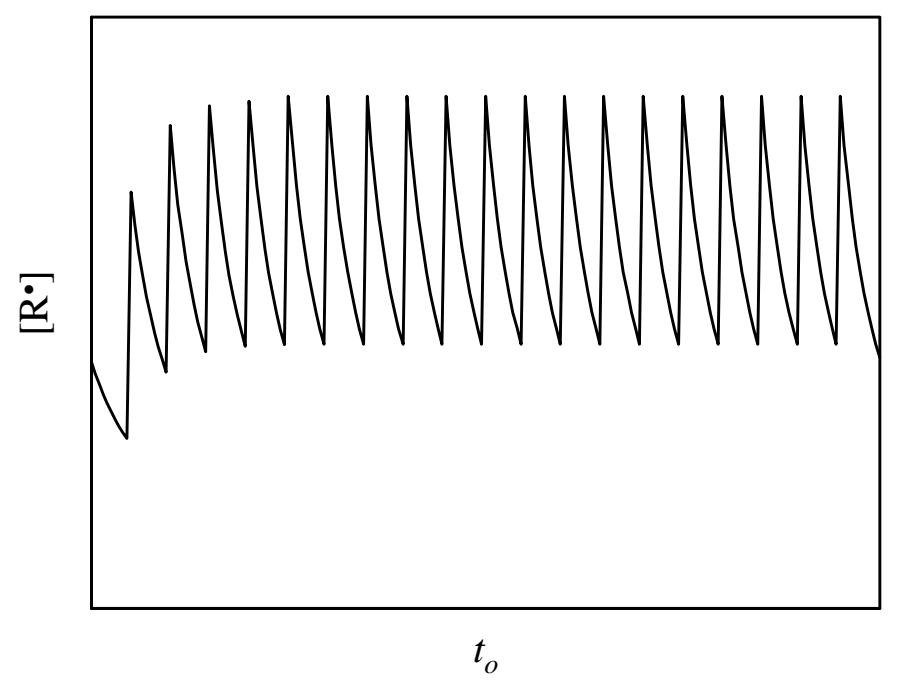

Figure 4.3: $\quad$ Typical radical concentration-time profile for the determination of $k_{p}$. 
The conditions required for the study of chain transfer are very different. It is necessary to design the experiments such that the majority of radicals undergoes a chain-transfer event before the next pulse arrives. Moreover, the calculation of $k_{\mathrm{tr}} / k_{\mathrm{p}}$ from pulsed laser generated polymer is valid only as long as chain transfer is the molecular weight controlling mechanism. Fig. 4.4 shows a typical radical concentration time profile for the case of a transfer dominated system:

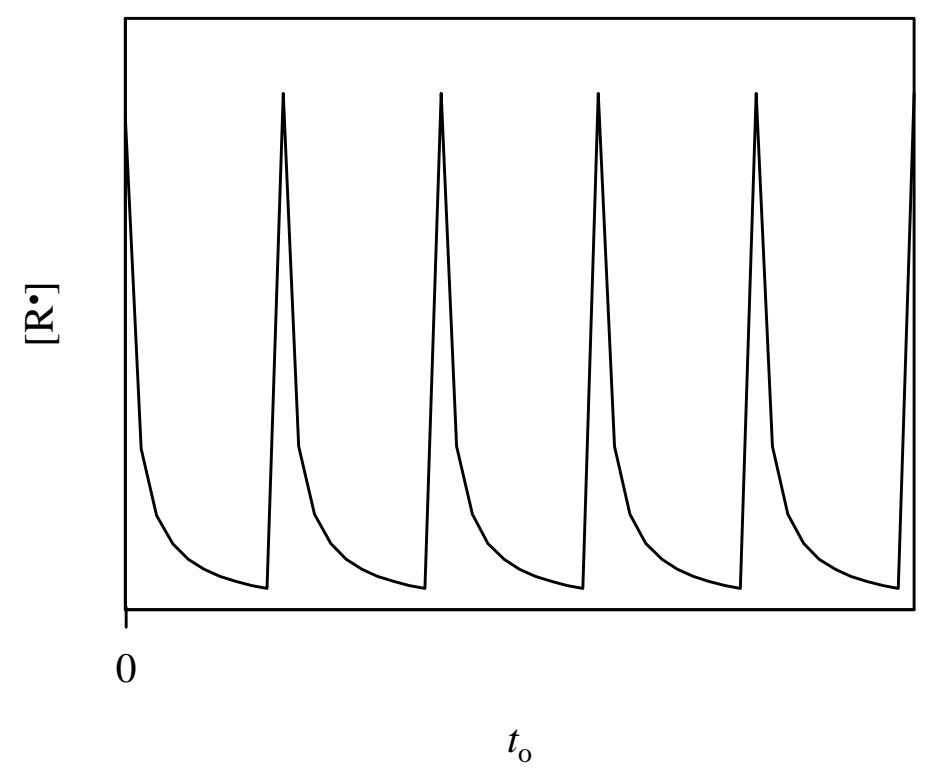

Figure 4.4: $\quad$ Typical radical concentration-time profile for transfer dominated system.

Two conditions must be met in order to get a transfer dominated MWD and to measure transfer rates by PLP.

1) Chain-transfer events must dominate termination events:

$2 \cdot k_{\mathrm{t}}\left[\mathrm{R}^{\bullet}\right]<<k_{\mathrm{tr}, \mathrm{X}} \cdot[\mathrm{CTA}]$

where $\left[\mathrm{R}^{\cdot}\right]$ varies with time according to Eq. 4.20.

Transfer is favored if:

(a) the time between pulses is increased, allowing the radical concentration to decline to lower values,

(b) the radical concentration generated per pulse is lowered,

(c) the rate of chain-transfer events is increased. 


\section{2) Transfer should have taken place before the arrival of the next pulse:}

After each pulse, the total radical concentration in the system increases up to a value of $\left[\mathrm{R}^{\bullet}\right]^{\mathrm{max}}$. At that time most radicals from the previous pulse will have undergone at least one chain-transfer event in $t_{0}$ seconds. Mathematically, this second condition is expressed by:

$$
1 / t_{0}<<k_{\mathrm{tr}, \mathrm{X}} \cdot[\mathrm{CTA}]
$$

Again this condition is favored by increasing $k_{\mathrm{tr}, \mathrm{X}} \cdot[\mathrm{CTA}]$ or increasing $t_{0}$.

Eq. 4.22 provides a more easily observable criterion than Eq. 4.21; The above given condition is met if the MWD for the monomer/chain-transfer agent system is shifted to lower molecular weights compared to a MWD from a termination dominated system without chain-transfer agent. Note that establishing Eq. 4.22 as a criterion for analyzing PLP results for chain transfer implies that $k_{\mathrm{p}}$ and $k_{\mathrm{tr}}$ cannot be estimated ${ }^{1}$ from a single experiment ${ }^{*}$. To ensure that the criterion of Eq. 4.21 is satisfied, it is necessary to perform experiments to ensure that the results are not affected by the level of termination in the system.

This highlights the limitations of PLP as a tool for measuring $k_{\mathrm{tr}}$. PLP offers advantages for studying chain transfer in systems for which the transfer can easily made to be the dominant event.

Hutchinson and co-workers ${ }^{1}$ proved experimentally that reproducible results are obtained without excessive monomer purification. Although, the radical concentration is high immediately after a pulse, it is lower toward the end of the interval between pulses. Thus the effect of termination reactions between radicals and impurities (e.g. $\mathrm{O}_{2}$ ) on the chain transfer dominated part of the MWD is minimized by the CLD technique. It is of importance to verify that experimental conditions are chosen to create transfer dominated system.

In this work the conditions required were as follow:
(a) a very low repetition rate of laser pulses, $1 \mathrm{~Hz}$
(b) low initiator concentration for controlling the level of termination
(c) variation of CTA concentration should be reflected in a systematic change in MW

\footnotetext{
* Although, by a special choice of the laser pulse pattern, $k_{\mathrm{p}}$ and $k_{\mathrm{tr}}$ may be determined from a single experiment $^{28}$.
} 
Different means of controlling the level of termination in PLP experiments were tested. The condition (c) for each polymerization was checked and described in section 5. The condition (b) is developed for a styrene homopolymerization system below.

The MWDs, obtained for styrene homopolymerization in bulk at $80^{\circ} \mathrm{C}$ and $300 \mathrm{bar}$, for three different concentrations of the photoinitiator $\left([\mathrm{DMPA}]=0.2,1\right.$ and $\left.2 \mathrm{mmol} \cdot \mathrm{L}^{-1}\right)$ and with $n$ dodecyl mercaptan as chain-transfer agent, are plotted in Fig. 4.5.
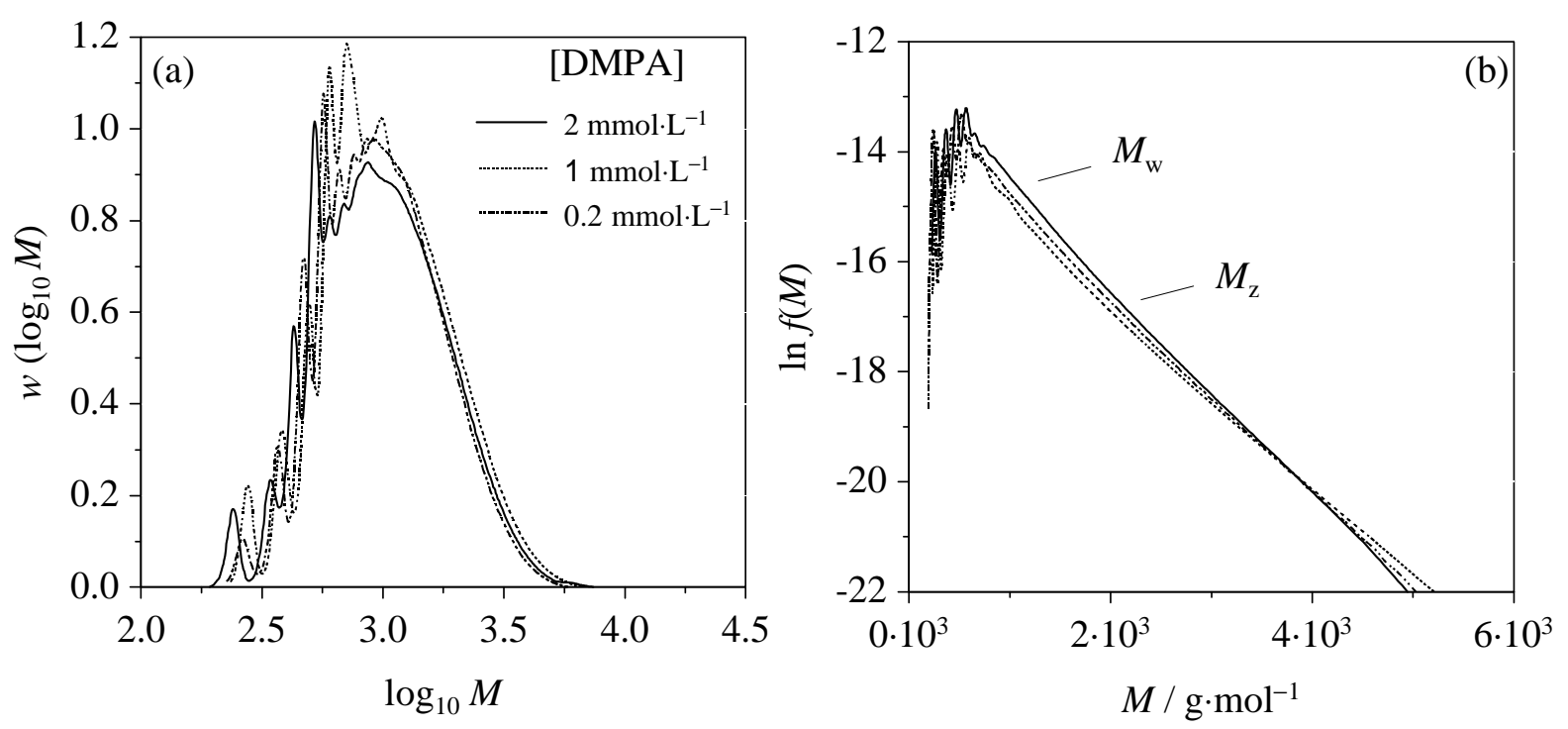

Figure 4.5: $\quad$ Polystyrene produced at $80^{\circ} \mathrm{C}$ and 300 bar, with 3 vol \% of DDM and varying amount of the photoinitiator DMPA: (a) molecular weight distributions obtained from SEC; (b) number MWD on a semilog scale.

It can be immediately seen from the GPC traces (Fig. 4.5a) that the concentration of DMPA has the most significant effect on the styrene samples on the low molecular weight side. On the high MW side, the distributions are more similar. This can be understood by considering the periodic radical concentration generated per pulse. Immediately following a laser pulse, radical-radical termination of the very short chains makes a large contribution to the total number of polymer chains being formed. Thus, the low molecular weight side of the distribution is the most affected by the concentration of DMPA. As the remaining living chains grow, the radical concentration in the system is much reduced. These chains have a high probability of being terminated through transfer with DDM; The high MWD side of the 
distribution is less affected by [DMPA]. This fact is very important since it is from the slope of this high MWD side that $k_{\text {tr }} / k_{\mathrm{p}}$ is estimated.

Fig. $4.5 \mathrm{~b}$ shows a plot of the distribution transformed to a semilog number scale. A slight initiator effect can be seen from the slopes but the high molecular weight side and particularly the slope between $M_{\mathrm{w}}$ and $M_{\mathrm{z}}$ used for the determination of $C_{\mathrm{T}}$ (see section 4.3) are not really affected. Indeed, the slopes obtained for the concentration of DMPA of 0.2 , 1, and $2 \mathrm{mmol} \cdot \mathrm{L}^{-1}$ are $1.7 \cdot 10^{-2}, 1.8 \cdot 10^{-2}, 1.75 \cdot 10^{-2}$, respectively. It is obvious from theory ${ }^{1}$ that better estimates for $C_{\mathrm{T}}$ will be obtained if radical concentration (and thus concentration of DMPA) is kept low. Therefore, all the experiments in this work were carried out at a photoinitiator concentration of $0.2 \mathrm{mmol} \cdot \mathrm{L}^{-1}$.

\subsection{Consideration of errors}

The errors in the chain-transfer rate coefficient, $k_{\mathrm{tr}}$, and in the chain-transfer constant, $C_{\mathrm{T}}$, which are determined by the PLP-SEC technique described within this section, are difficult to estimate and depend on the chain-transfer agent used. The error in $C_{\mathrm{T}}$ was estimated using the chain-length distribution (CLD) technique, as described in section 4.3. In order to determine the uncertainty of the slope of the number of distribution plot, $\ln f(M)$ vs $M$, the slope was determined from several molecular weight ranges, with $M_{\mathrm{w}}$ always being the lower limit. The error in $C_{\mathrm{T}}$ is estimated to be about 10, 20 and $10 \%$ with $n$-dodecyl mercaptan, the cobaltcomplex and MMA trimer as chain-transfer agents, respectively.

In summary, the error of the $k_{\mathrm{tr}} / k_{\mathrm{p}}$ data is composed of several contributions: The error in the masses of the monomer mixture and chain-transfer agent, the error resulting from the ambiguity in selection of the molecular weight region for the semilog $\ln f(M)$ vs $M$ plot and the error of the SEC calibration procedure. These errors sum up to a total of $\pm 30 \%$ for the chain-transfer rate constant of this work. For the hompolymerization systems, the error is reduced to $\pm 25 \%$, as direct calibration using PMMA or PS standards may be carried out. 


\subsection{References}

1. Hutchinson, R. A.; Paquet, D. A.; Mc Minn, J. H. Macromolecules 1995, 28, 5655.

2. Kukuj1, D.; Davis, T. P. Macromol. Chem. Phys. 1998, 199, 1697.

3. Moad. C. L.; Moad, G.; Rizzardo, E.; Thang, S. H. Macromolecules 1996, 29, 7717.

4. Olaj, O. F.; Bitai, I.; Hinkelmann, F. Makromol. Chem. 1987, 188, 1689.

5. Grubisic, Z.; Rempp, P.; Benoit, H. A. J. Polym. Sci., Polym. Lett. 1967, 5, 753.

6. Coote, J. M.; Zammit, M. D.; Willett, G. D.; Davis, T. P. Macromolecules 1997, 30, 8182 .

7. Beuermann, S.; Paquet, D. A.; McMinn, Jr. J. H.; Hutchinson, R. A. Macromolecules 1996, 29, 4206.

8. Beuermann, S.; Paquet, D. A.; McMinn, Jr. J. H.; Hutchinson, R. A.; Jackson, C. Ind. Eng. Chem. Res. 1997, 36, 1103.

9. Heuts, J. p. A.; Kukulj, D.; Foster, D. J.; Davis, T. P. Macromolecules 1998, 31, 2894.

10. Flory, P. J. Principles of Polymer Chemistry, Cornell University Press, Ithaca, NY, 1953, p 317.

11. Mayo, F. R. J. Am. Chem. Soc 1943, 65, 2324.

12. Moad, G.; Solomon, D. H. The chemistry of Free Radical Polymerization; Pergamon: Oxford, 1995.

13. Moad, G.; Moad, C. Macromolecules 1996, 29, 7727.

14. Sticker, M.; Meyerhoff, G. Makromol. Chem. 1978, 179, 2729.

15. Clay, P. A.; Gilbert, R. G. Macromolecules 1995, 28, 552.

16. Whang, B. C. Y.; Ballard, M. J.; Napper, D. H.; Gilbert, R. G. Aust. J. Chem. 1991, $44,1133$.

17. Heuts, J. P. A.; Clay, P. A.; Christie, D. I.; Piton, M,. C.; Hutovic, J., Kable, S. H.; Gilbert, R. G. Prog. Pac. Polym. Sci. Proc. 1994, 3, 203.

18. Bamford, C. H. Eur. Polym. J. 1990, 26, 1245.

19. Olaj, O. F.; Zifferer, G.; Gleixner, G. Macromolecules 1987, 20, 839.

20. Heuts. J. P. A.; Foster, D. J.; Davis, T. P.; Yamada, B.; Yamazoe, H.; Azukizawa, M. Macromolecules 1999, 32, 2511.

21. de la Fuente, J. L.; Madruga, E. L. J. Polym. Sci., Polym. Chem. 1998, 36, 2913.

22. de la Fuente, J. L.; Madruga, E. L. J. Polym. Sci., Polym. Chem. 2000, 38, 170.

23. Mang, A. S.; Dokolas, P.; Holmes, A. B. Am. Chem. Soc. Org. lett. 1999, 1, 125. 
24. Olaj, O. F.; Bitai, I. Angew. Makromol. Chem. 1987, 155, 177.

25. Buback, M.; Gilbert, R. G.; Russell, G. T.; Hill, D. J. T.; Moad, G.; O'Driscoll, K. F.; Shen, J.; Winnik, M. A. J. Polym. Sci., Polym. Chem. Edn. 1992, 30, 851.

26. Beuermann, S.; Buback, M.; Schmaltz, C.; Kuchta, F.-D. Macromol. Chem. Phys. 1998, 199, 1209.

27. Buback, M.; Hippler, H.; Schweer, J.; Vögele, H.-P. Makromol. Chem. Rapid. Commun. 1986, 7, 261.

28. Buback, M.; Laemmel, R. A. Macromol. Theory Simul. 1997, 6, 145. 


\section{Results and discussions}

\subsection{DDM as chain-transfer agent}

The use of mercaptans as chain-transfer agents has proven to be an effective method to reduce the molecular weight. In this section, the interest was focused on the $n$-dodecyl mercaptan (DDM). The mechanism of the chain-transfer reaction is illustrated in scheme 5.1 for styrene (a) and MMA (b) homopolymerizations. The mercaptan HST acts through a hydrogen transfer reaction with the radical chain, creating a dead polymer chain and a thiyl radical $\mathrm{ST}^{\bullet}$ which initiates a new chain.

The terminal group of the polymer obtained consists of a saturated carbon-carbon bond, as described by scheme 5.1. The thiyl group is the initiator and hence a possible functionality to be introduced as an endgroup needs to be present in the chain-transfer agent.

(a)<smiles>CCCCC[C]([NH3+])c1ccccc1</smiles>

(b)<smiles>C=Cc1ccccc1</smiles><smiles>C=C(C)C(=O)OC</smiles>

Scheme 5.1: Reaction scheme for the chain-transfer of DDM in homopolymerization of styrene (a) and MMA (b). HST represents DDM. 
In the literature, only few reports ${ }^{1,2,3}$ deal with DDM as chain-transfer agent for the polymerization of styrene and MMA. The pressure dependence of $C_{\mathrm{T}}$ and $k_{\mathrm{tr}}$ as well as the influence of $\mathrm{scCO}_{2}$ as a solvent on the chain-transfer reaction of DDM have not been studied so far. Previously, Hutchinson et al. ${ }^{1}$ investigated the temperature dependence of $C_{\mathrm{T}}$ for DDM in methacrylate homopolymerizations at ambient pressure. The values reported showed that $C_{\mathrm{T}}$ is temperature independent.

In this work, the pressure dependence of the chain-transfer rate coefficient of DDM as CTA in the homo- and copolymerization of styrene and MMA is determined in bulk and in $\mathrm{scCO}_{2}$. The PLP technique is applied using a laser pulse repetition rate of $1 \mathrm{~Hz}$ and a photoinitiator concentration, [DMPA], of $0.2 \mathrm{mmol} \cdot \mathrm{L}^{-1}$, as explained in section 4 . The same amounts of DDM are used for the different systems.

The detailed discussion about DDM as CTA in homo- and copolymerizations of styrene and MMA is given in section 5.4.

\subsubsection{Homopolymerization of styrene}

\subsubsection{Mayo method}

The molecular weight distributions of polymer obtained in the presence of DDM as CTA contain oligomer peaks in the low molecular weight region. As explained in section 4, the presence of oligomers in the MWD may influence the values of the number and weight average molecular weights, $M_{\mathrm{n}}$ and $M_{\mathrm{w}}$, respectively. The program PREDICI $^{\circledR}$ (for comparison see section 6) was used to estimate $M_{\mathrm{n}}$ and $M_{\mathrm{w}}$ for the corresponding MWDs in the absence of oligomer peaks. Fig. 5.1 shows as example the MWD obtained without (dotted line) and after applying simulation via $\operatorname{PREDICI}^{\circledR}$ (full line) for homopolymerization in $\mathrm{scCO}_{2}$ with $[\mathrm{DDM}] /[\mathrm{sty}]=0.01$.

$M_{\mathrm{n}}$ and $M_{\mathrm{w}}$ values obtained for both MWDs, without and after simulation, are listed in Table 5.1 for styrene homopolymerizations in $40 \mathrm{wt} \% \mathrm{scCO}_{2}$. As expected, $M_{\mathrm{n}}$ and $M_{\mathrm{w}}$ are very different when the peaks are eliminated to the molecular weight distribution. As explained in section $4, M_{\mathrm{n}}$ and $M_{\mathrm{w}}$ are the parameters used in the Mayo method. Thus, it is obvious that the $C_{\mathrm{T}}$ values determined using the Mayo method depend on the presence or not of these peaks. In other words, the Mayo method is not adequate for this system. 


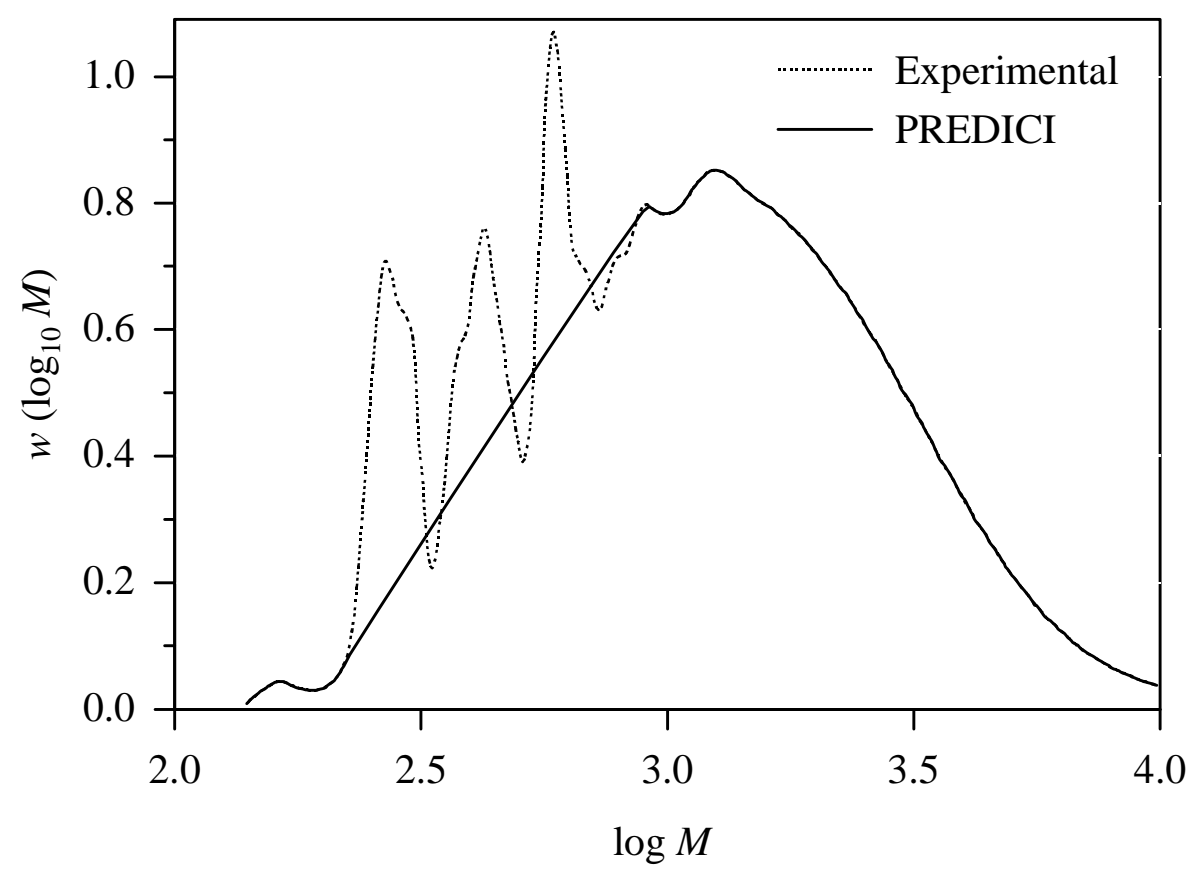

Figure 5.1: $\quad$ Molecular weight distribution obtained without (dotted line) and after applying the program PREDICI ${ }^{\circledR}$ (full line) for polystyrene from homopolymerization with DDM as CTA in $\mathrm{scCO}_{2}$ at $80^{\circ} \mathrm{C}, 300$ bar and $[\mathrm{DDM}] /[$ sty $]=0.01$.

\begin{tabular}{ccccc}
\hline & \multicolumn{2}{c}{ Experimental MWD } & \multicolumn{2}{c}{ Simulated MWD } \\
\hline$[\mathrm{DDM}] /[\mathrm{sty}]$ & $M_{\mathrm{n}}$ & $M_{\mathrm{w}}$ & $M_{\mathrm{n}}$ & $M_{\mathrm{w}}$ \\
\hline 0.0025 & $1.51 \cdot 10^{3}$ & $5.88 \cdot 10^{3}$ & $1.62 \cdot 10^{3}$ & $6.1 \cdot 10^{3}$ \\
0.005 & $8.95 \cdot 10^{2}$ & $2.67 \cdot 10^{3}$ & $1.40 \cdot 10^{3}$ & $3.37 \cdot 10^{3}$ \\
0.01 & $6.92 \cdot 10^{2}$ & $1.33 \cdot 10^{3}$ & $9.17 \cdot 10^{2}$ & $1.57 \cdot 10^{3}$ \\
0.015 & $6.53 \cdot 10^{2}$ & $9.51 \cdot 10^{2}$ & $6.88 \cdot 10^{2}$ & $1.01 \cdot 10^{3}$ \\
\hline
\end{tabular}

Table 5.1: Summary of the average numbers $M_{n}$ and $M_{w}$ determined experimentally and simulated with the program PREDICI ${ }^{\circledR}$ for styrene homopolymerizations with DDM as CTA at $80^{\circ} \mathrm{C}$ and 300 bar in $\mathrm{scCO}_{2}$. 


\subsubsection{CLD method}

As shown in Fig. 5.1, the oligomer peaks are only present in the low molecular weight region at $M<10^{3} \mathrm{~g} \cdot \mathrm{mol}^{-1}$. This was also observed in the MWD of polystyrene obtained with tetrabromo methane $\left(\mathrm{CBr}_{4}\right)$ as CTA in the same conditions of temperature and pressure ${ }^{4}$. In both cases, here and ref. 4, the MWDs of oligomer differ by one monomer unit. However, the presence of oligomers in the low molecular weight region should not affect the high molecular weight region that is used for the CLD method. As explained in section 4, MWD is shifted to lower values when the concentration of CTA is increased. Thus, the influence of oligomers on the high molecular weight region will be enhanced when [DDM] increases. Therefore small amounts of DDM were used in order to prevent the obtention of too low molecular weight. In summary, the CLD method is adequate for determining $C_{\mathrm{T}}$ in this condition when using restricted amounts of CTA in styrene homopolymerization.

\subsubsection{Results}

Homopolymerizations of styrene were carried out with DDM as chain-transfer agent in $40 \mathrm{wt} \% \mathrm{scCO}_{2}$ and in bulk at $80^{\circ} \mathrm{C}$ varying the pressure between 300 and 1500 bar.

The MWDs of PS obtained for polymerizations in $\mathrm{scCO}_{2}$ at $80^{\circ} \mathrm{C}, 300$ bar, and various amounts of DDM are shown in Fig. 5.2.

The MWDs are strongly shifted to lower molecular weights when the concentration of DDM increases. In the absence of DDM, the reaction yields polymer with a weight average molecular weight of $3.77 \cdot 10^{5} \mathrm{~g} \cdot \mathrm{mol}^{-1}$, and upon the addition of DDM (0.5 wt \%, [DDM]/[sty] $=0.0025) M_{\mathrm{w}}$ decreases to $5.91 \cdot 10^{3} \mathrm{~g} \cdot \mathrm{mol}^{-1}$. Therefore, the addition of only a small amount of CTA leads to a strong shift of the MWD to lower values. 


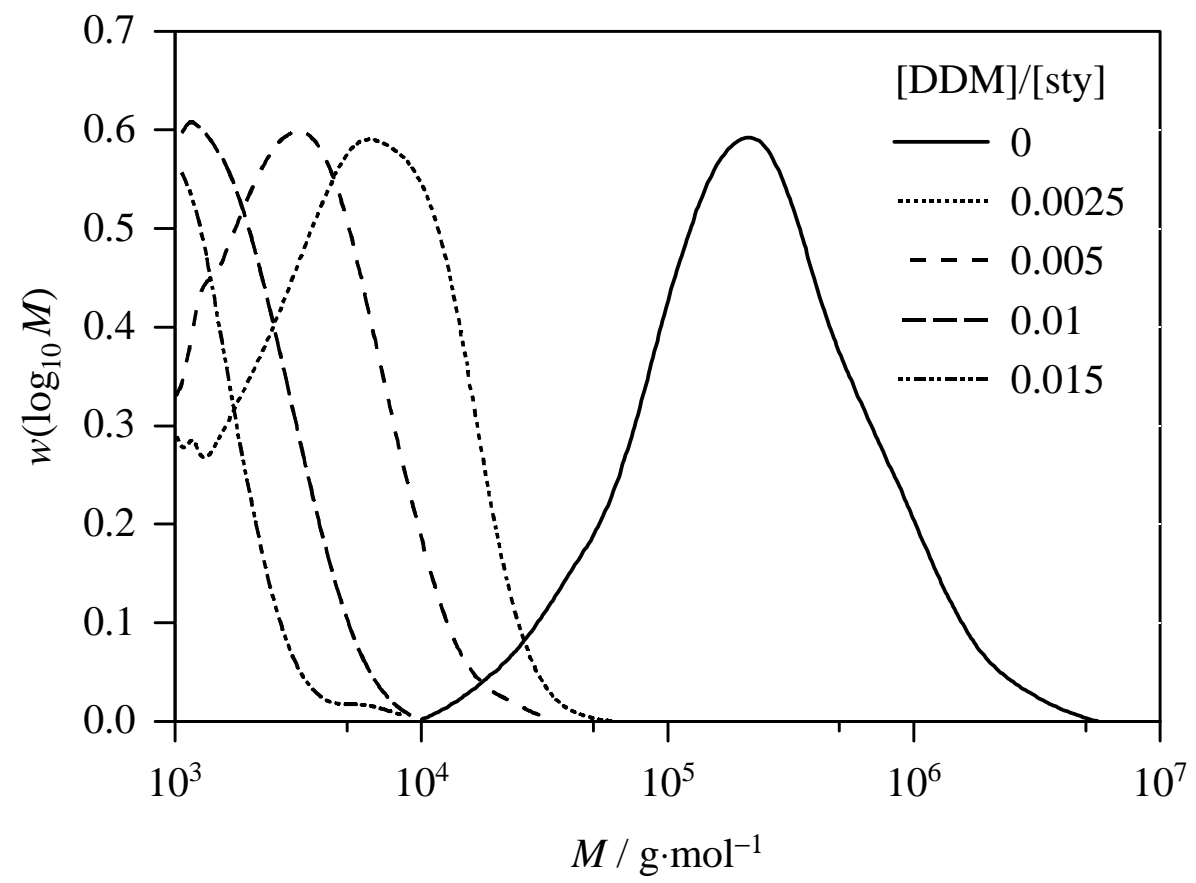

Figure 5.2: $\quad$ Molecular weight distributions of polystyrene from polymerizations in $40 \mathrm{wt} \%$ $\mathrm{scCO}_{2}$ at $80^{\circ} \mathrm{C}, 300$ bar, and DDM concentration as indicated.

The corresponding $\ln f(M)$ plots shown in Fig. 5.3 exhibit a linear part in the high molecular weight region between $M_{\mathrm{w}}$ and $M_{\mathrm{z}}$ (as indicated for the lowest value of [DDM]/[sty]), which slope is used to determine $C_{\mathrm{T}}$, as explained in section 4.

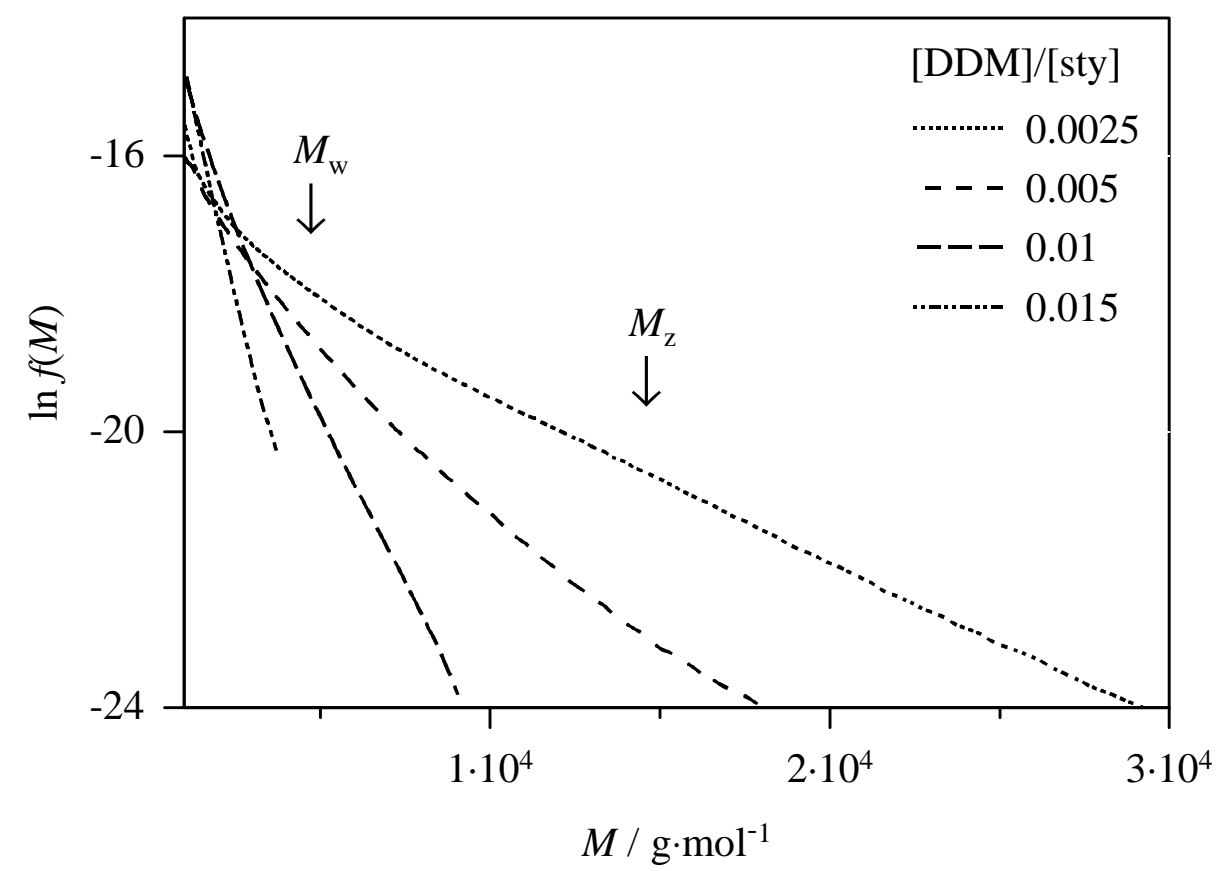

Figure 5.3: $\quad$ ln $f(M)$ distributions for polystyrene from polymerizations in 40 wt $\% s c \mathrm{CO}_{2}$ at $80^{\circ} \mathrm{C}, 300$ bar, and DDM concentration as indicated. 
The slope of the linear part increases with DDM concentration, which indicates a change in the chain-transfer activity. Fig. 5.4 exhibits the so called CLD plots for the styrene homopolymerizations at $80^{\circ} \mathrm{C}$ and 300 bar in $\mathrm{scCO}_{2}$ and in bulk. The magnitude of the slopes is not significantly different in bulk and in $\mathrm{scCO}_{2}$, which traducts very close $C_{\mathrm{T}}$ values. The values of $C_{\mathrm{T}}$ determined are $14.6 \pm 1.8$ and $16.3 \pm 1.5$ in bulk and in 40 wt $\% \mathrm{scCO}_{2}$, respectively. Thus, $\mathrm{scCO}_{2}$ has no significant influence on $C_{\mathrm{T}}$.

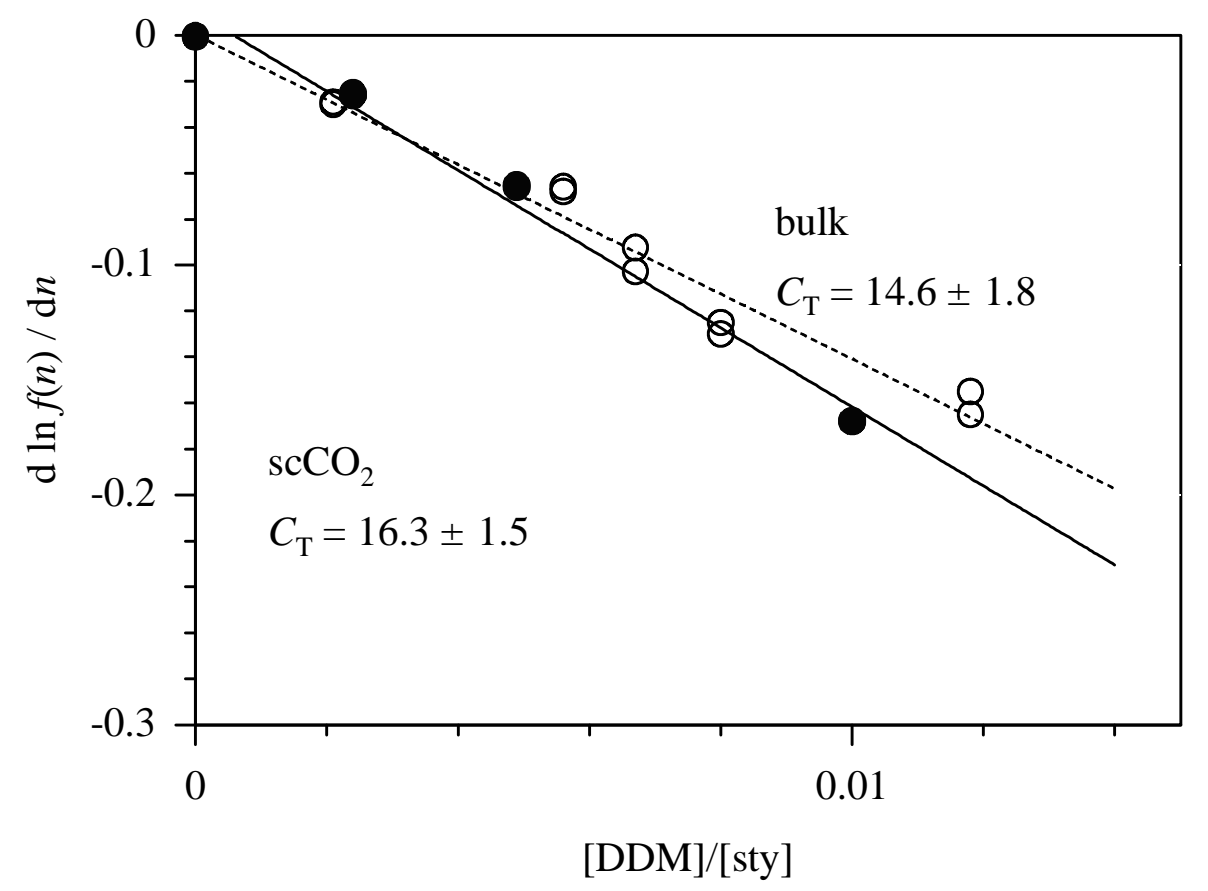

Figure 5.4: Determination of the chain-transfer constant, $C_{T}$, from a plot of $d \ln f(n) / d n v s$. [DDM]/sty] for styrene homopolymerizations at $80^{\circ} \mathrm{C}, 300$ bar in $40 \mathrm{wt} \%$ $\mathrm{scCO}_{2}$ (solid line) and in bulk (dotted line).

\section{Pressure dependence of $C_{\mathrm{T}}$ and $\boldsymbol{k}_{\mathrm{tr}}$}

The pressure dependence of $C_{\mathrm{T}}$ and $k_{\mathrm{tr}}$ for the homopolymerization of styrene was studied at $80^{\circ} \mathrm{C}$ and at pressures between 300 and 1500 bar.

The corresponding chain-transfer rate coefficients, $k_{\mathrm{tr}}$, were determined using the $C_{\mathrm{T}}$ values calculated in this study and the propagation rate coefficients, $k_{\mathrm{p}}$, reported in the literature ${ }^{5,6}$ under the same conditions of pressure and temperature. The $k_{\mathrm{p}}$ values used are listed in Appendix 1 and those are nearly equivalent in bulk and in $\mathrm{scCO}_{2}$.

Fig. 5.5 shows the pressure dependence of $C_{\mathrm{T}}$ (a) and $k_{\mathrm{tr}}$ (b) for polymerizations in $\mathrm{scCO}_{2}$ and in bulk at $80^{\circ} \mathrm{C}$. In addition, the literature value ${ }^{1}$ obtained by PLP at $60^{\circ} \mathrm{C}$ and ambient 
pressure is compared to the data of this work. $C_{\mathrm{T}}$ of 15.5 determined in bulk polymerization at $80^{\circ} \mathrm{C}$ and ambient pressure is in very good agreement with the literature data ${ }^{1}$ of 15.6 . This finding indicates that $C_{\mathrm{T}}$ may be temperature independent in styrene homopolymerization. $C_{\mathrm{T}}$ measured in both media decreases significantly with the pressure: For example, $C_{\mathrm{T}}$ values at 300 and 1500 bar in $\mathrm{scCO}_{2}$ are 16.3 and 11 , respectively. The values determined in $\mathrm{scCO}_{2}$ are very close to the bulk values in the entire pressure range. In contrast to $C_{\mathrm{T}}, k_{\mathrm{tr}}$ for polymerizations in bulk and in $\mathrm{scCO}_{2}$ slightly increases with pressure. In addition, the difference on $k_{\text {tr }}$ in both media is not significant.
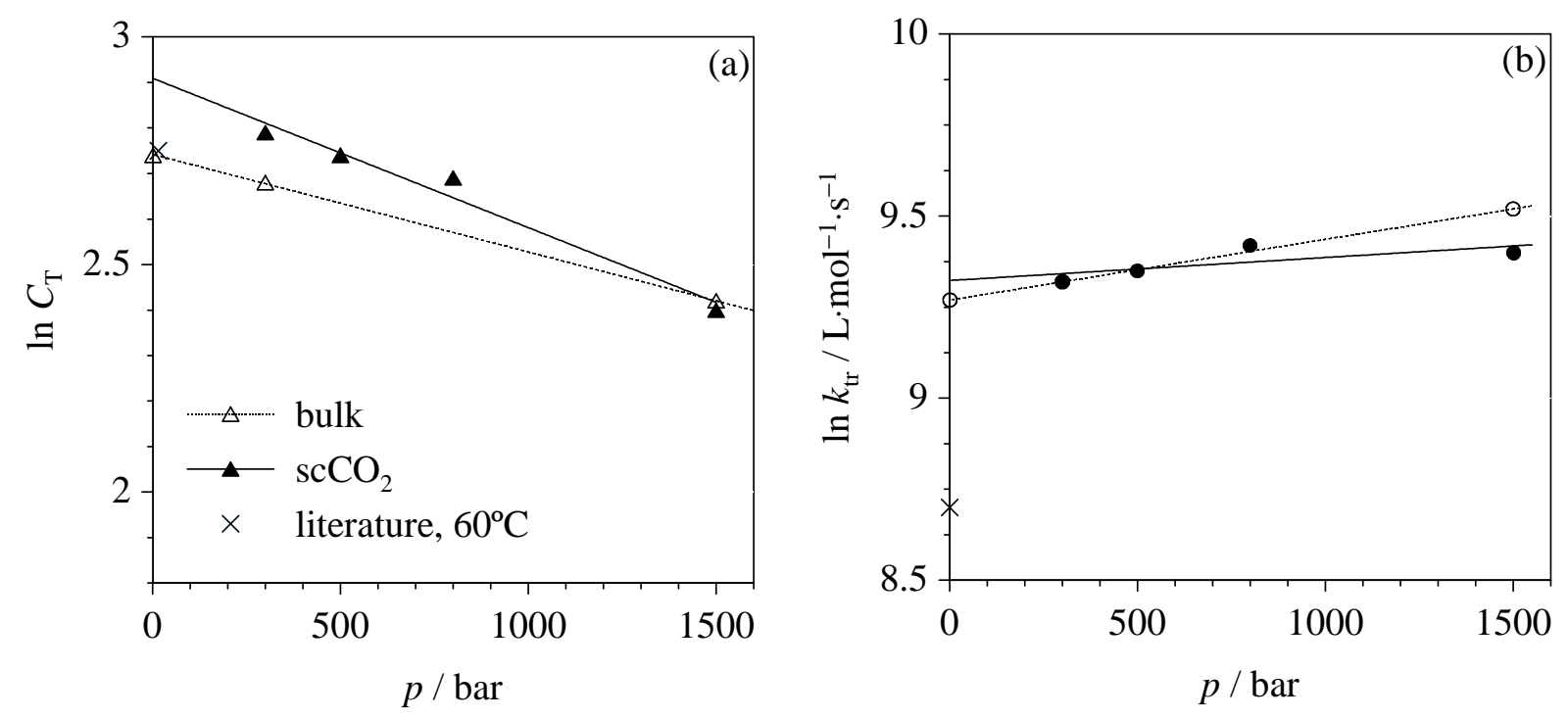

Figure 5.5: $\quad$ Pressure dependence of the chain-transfer constant, $C_{T},(a)$ and of the chaintransfer rate coefficient, $k_{t r}$, (b) for styrene homopolymerizations at $80^{\circ} \mathrm{C}$ in $40 \mathrm{wt} \% \mathrm{scCO}_{2}$ and in bulk. Experimental data are reported in Appendix 2. The literature data is taken from ref. 1.

Eqs. 5.1 to 5.4 correspond to the linear fits of the experimental data for $C_{\mathrm{T}}$ and $k_{\mathrm{tr}}$ given in Fig. 5.5.

$$
\begin{aligned}
& \ln C_{\mathrm{T}}=(2.74 \pm 0.01)-(2.16 \pm 0.31) \cdot 10^{-4}(p / \text { bar }) \\
& \ln \left[k_{\mathrm{tr}} /\left(\mathrm{L} \cdot \mathrm{mol}^{-1} \cdot \mathrm{s}^{-1}\right)\right]=(9.26 \pm 0.02)+(1.54 \pm 0.34) \cdot 10^{-4}(p / \text { bar }) \\
& \left(\text { bulk, } 80^{\circ} \mathrm{C}, 300 \leq p \leq 1500 \mathrm{bar}\right) \\
& \ln C_{\mathrm{T}}=(2.91 \pm 0.11)-(3.31 \pm 1.29) \cdot 10^{-4}(p / \text { bar }) \\
& \ln \left[k_{\mathrm{tr}} /\left(\mathrm{L} \cdot \mathrm{mol}^{-1} \cdot \mathrm{s}^{-1}\right)\right]=(9.33 \pm 0.1)+(0.62 \pm 1.18) \cdot 10^{-4}(p / \text { bar }) \\
& \left(40 \mathrm{wt} \% \mathrm{scCO}_{2}, 80^{\circ} \mathrm{C}, 300 \leq p \leq 1500 \text { bar }\right)
\end{aligned}
$$


According to $\delta\left(\ln k_{\mathrm{tr}}\right) / \delta p=-\Delta V^{\#} /(\mathrm{R} \cdot T)$ and $\delta\left(\ln C_{\mathrm{T}}\right) / \delta p=-\Delta V^{\#} /(\mathrm{R} \cdot T)$, the activation volumes for $C_{\mathrm{T}}$ and $k_{\mathrm{tr}}$ are determined as:

bulk: $\quad \Delta V^{\#}\left(C_{\mathrm{T}}\right)=+(6.3 \pm 0.7) \mathrm{cm}^{3} \cdot \mathrm{mol}^{-1}$

$\Delta V^{\#}\left(k_{\mathrm{tr}}\right)=-(4.5 \pm 1.0) \mathrm{cm}^{3} \cdot \mathrm{mol}^{-1}$

$\operatorname{scCO}_{2}: \quad \Delta V^{\#}\left(C_{\mathrm{T}}\right)=+(9.7 \pm 3.8) \mathrm{cm}^{3} \cdot \mathrm{mol}^{-1}$

$\Delta V^{\#}\left(k_{\mathrm{tr}}\right)=-(1.8 \pm 3.5) \mathrm{cm}^{3} \cdot \mathrm{mol}^{-1}$

Within experimental uncertainty, the activation volumes for $C_{\mathrm{T}}$, which are close in both media, indicate that $C_{\mathrm{T}}$ is pressure dependent. In contrast, the low values of $\Delta V^{\#}\left(k_{\mathrm{tr}}\right)$ suggest that the transfer reaction is not pressure dependent in both media. This finding will be discussed in section 5.4 .

\subsubsection{Homopolymerization of MMA}

MMA homopolymerizations were carried out in $40 \mathrm{wt} \% \mathrm{scCO}_{2}$ and in bulk at $80^{\circ} \mathrm{C}$ and at pressures between 300 and 1000 bar.

Figs. 5.6a and 5.6b show typical molecular weight distributions and their corresponding $\ln f(M)$ plots obtained for MMA homopolymerizations in $\mathrm{scCO}_{2}$ at $80^{\circ} \mathrm{C}$ and 300 bar with the indicated amount of DDM.

The MWDs are shifted to lower molecular weights with increasing CTA concentration, as seen in Fig. 5.6a. In the absence of DDM, the reaction yields polymer with a weight average molecular weight of $5 \cdot 10^{5} \mathrm{~g} \cdot \mathrm{mol}^{-1}$, and upon addition of $1 \mathrm{wt} \%$ DDM ([DDM]/[MMA] = 0.005) $M_{\mathrm{w}}$ decreases to $3.3 \cdot 10^{4} \mathrm{~g} \cdot \mathrm{mol}^{-1}$. In Fig. $5.6 \mathrm{~b}$ the part of the distribution used to calculate $C_{\mathrm{T}}$ is indicated by the bold line. The slope of this MW region is enhanced with increasing the concentration of DDM. 

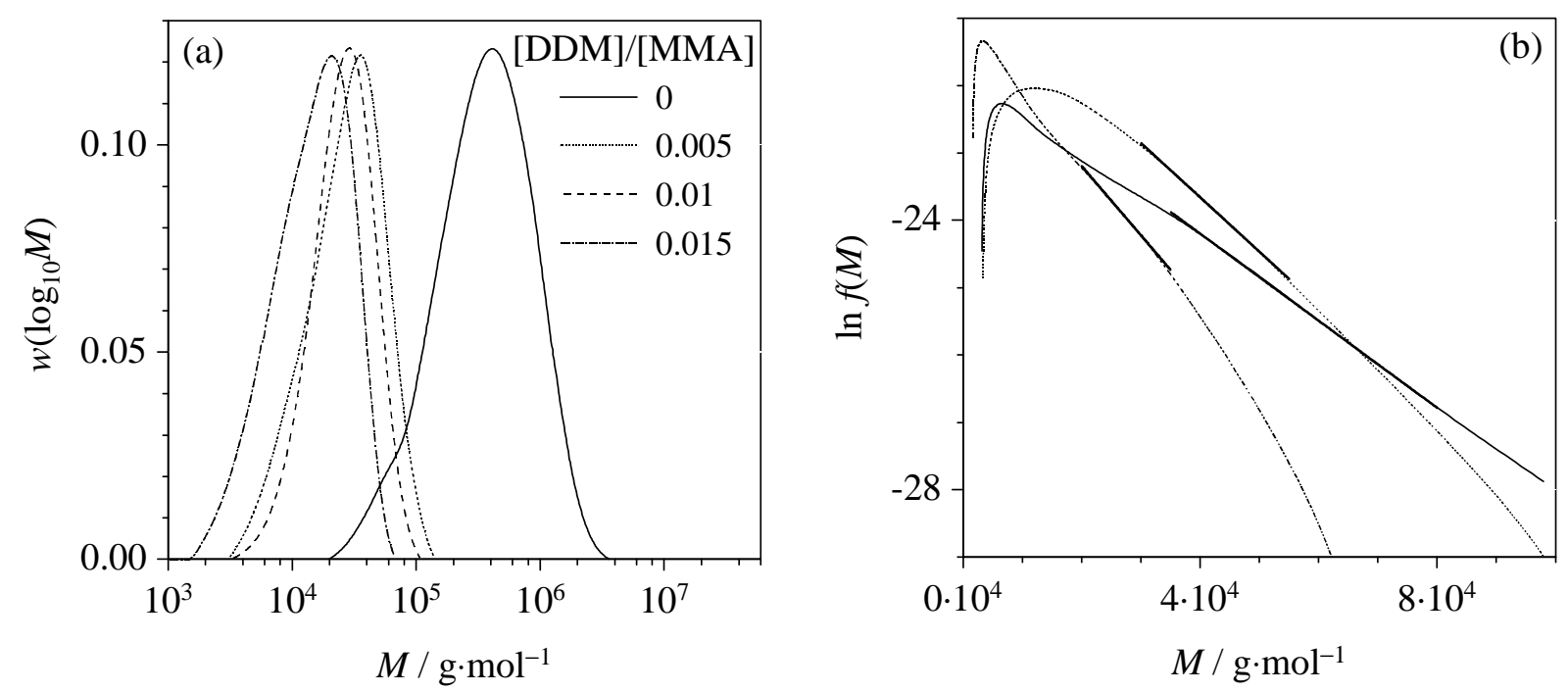

Figure 5.6: $\quad$ Molecular weight distributions (a) and corresponding $\ln f(M)$ distributions (b) for MMA homopolymerizations in $40 \mathrm{wt} \% \mathrm{scCO}_{2}$ at $80^{\circ} \mathrm{C}, 300 \mathrm{bar}$, and DDM concentration as indicated. The bold line indicates the region where the slope is measured.

Fig. 5.7 exhibits the CLD plots of MMA homopolymerizations at 300 bar and $80^{\circ} \mathrm{C}$ in bulk and in $\mathrm{scCO}_{2}$.

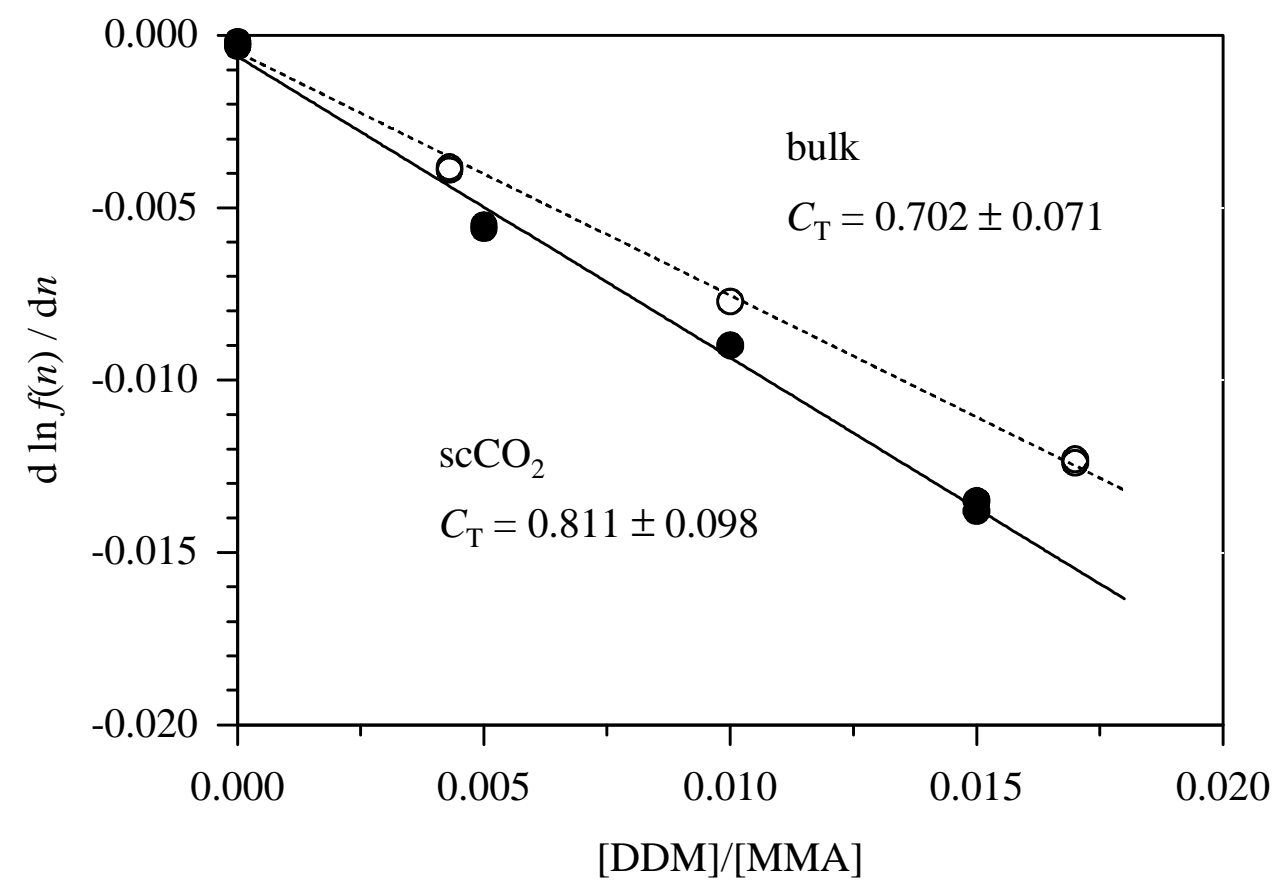

Figure 5.7: Determination of the chain-transfer constant from a plot of $d \ln f(n) / d n$ vs. [DDM]/MMA] for MMA homopolymerizations at $80^{\circ} \mathrm{C}, 300$ bar in 40 wt \% $\mathrm{scCO}_{2}$ (solid line) and in bulk (dotted line). 
The $C_{\mathrm{T}}$ values obtained in $\mathrm{scCO}_{2}$ and in bulk are $0.811 \pm 0.098$ and $0.702 \pm 0.071$, respectively. Within experimental uncertainty, the chain-transfer constants obtained for MMA are close in both media. Thus, $\mathrm{scCO}_{2}$ as a solvent has no significant effect on the chaintransfer activity.

\section{Pressure dependence of $C_{\mathrm{T}}$ and $\boldsymbol{k}_{\mathrm{tr}}$}

The pressure dependence of $C_{\mathrm{T}}$ and $k_{\text {tr }}$ for MMA homopolymerization was studied in a pressure range from 300 to 1000 bar. The values of $k_{\text {tr }}$ were calculated from the $C_{\mathrm{T}}$ values and $k_{\mathrm{p}}$ data. For bulk polymerization the propagation rate coefficient is determined using the equation given by Beuermann et al. ${ }^{7} k_{\mathrm{p}}$ values in $\mathrm{scCO}_{2}$ were determined in this work using the PLP-SEC method, as described in the literature ${ }^{6} . k_{\mathrm{p}}$ at 1000 bar in $\mathrm{scCO}_{2}$ was estimated using a ratio of $k_{\mathrm{p}, \text { bulk }} / k_{\mathrm{p}, \mathrm{scCO} 2}$ of 0.9 , which is calculated for the different pressures measured. The $k_{\mathrm{p}}$ values used in bulk and in $\mathrm{scCO}_{2}$ are listed in Appendix 1.

Fig. 5.8 shows the pressure dependence of $k_{\mathrm{tr}}$ and $C_{\mathrm{T}}$ for polymerizations in $\mathrm{scCO}_{2}$ and in bulk at $80^{\circ} \mathrm{C}$.
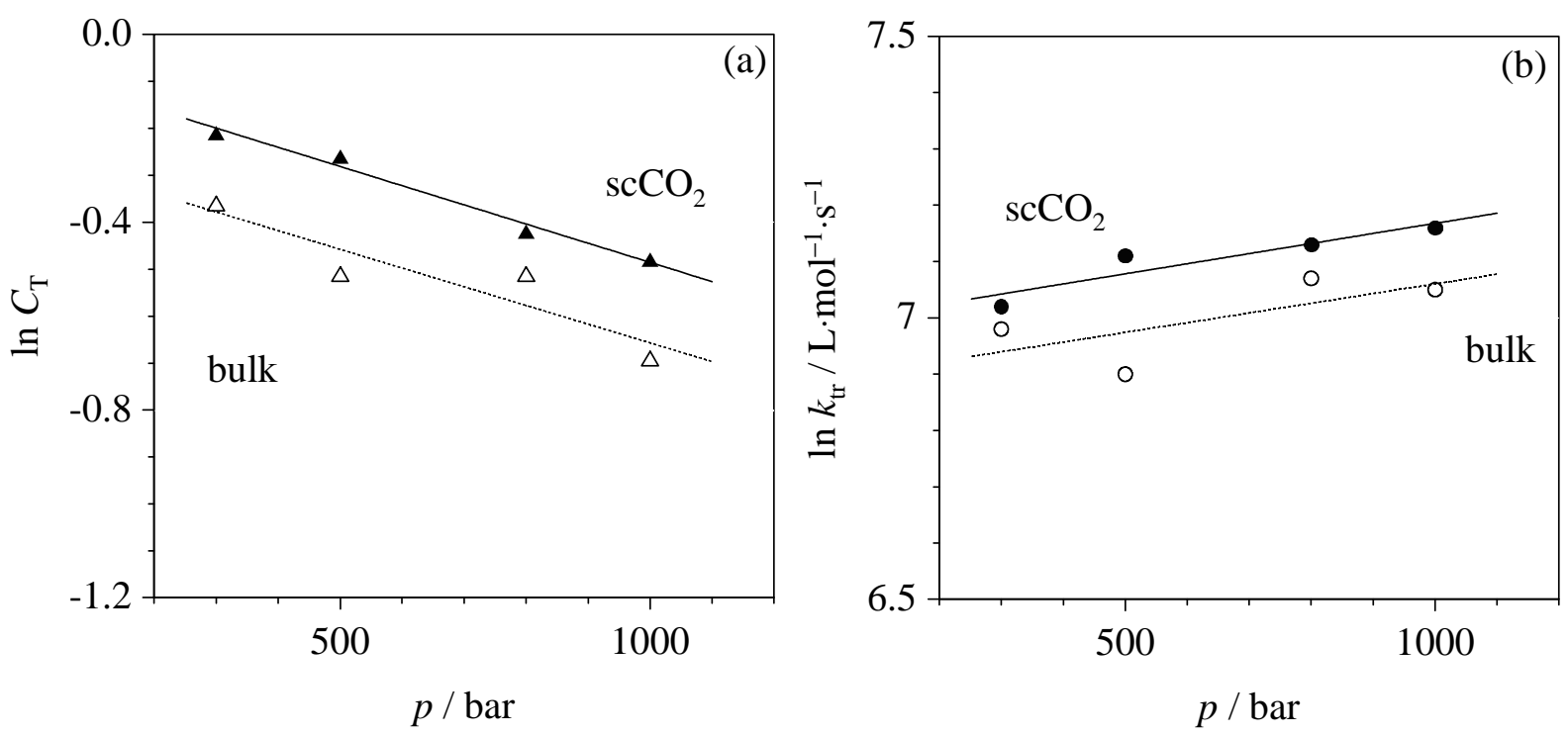

Figure 5.8: $\quad$ Pressure dependence of the chain-transfer constant (a) and of the chaintransfer rate coefficient (b) for MMA homopolymerizations in 40 wt \% scCO $\mathrm{CO}_{2}$ and in bulk at $80^{\circ} \mathrm{C}$. Experimental data are reported in Appendix 2.

$C_{\mathrm{T}}$ decreases with increasing pressure in bulk and in $\mathrm{scCO}_{2}$. The lines fitted to the experimental $C_{\mathrm{T}}$ data in both reaction media are parallel. Moreover, $C_{\mathrm{T}}$ values determined in 
$\mathrm{scCO}_{2}$ are very close to the bulk values in the entire pressure range. In contrast to $C_{\mathrm{T}}, k_{\mathrm{tr}}$ is enhanced in both media, as seen in Fig. 5.8b. However, the pressure dependence of $k_{\text {tr }}$ is low: For example, in $\mathrm{scCO}_{2}$ the $k_{\mathrm{tr}}$ values are $1.14 \cdot 10^{3}$ and $1.28 \cdot 10^{3} \mathrm{~L} \cdot \mathrm{mol}^{-1} \cdot \mathrm{s}^{-1}$ at 300 and $1000 \mathrm{bar}$, respectively. In addition, $k_{\mathrm{tr}, \mathrm{bulk}} / k_{\mathrm{tr}, \mathrm{scCO} 2}$ are 0.95 and 0.9 at 300 and 1000 bar, respectively, which shows a minor difference in the pressure dependence of $k_{\mathrm{tr}}$ in both media.

The pressure dependence of $k_{\mathrm{tr}}$ and $C_{\mathrm{T}}$ for polymerizations in bulk and in $\mathrm{scCO}_{2}$ may be expressed by Eqs. 5.5-5.8:

$$
\begin{aligned}
& \ln C_{\mathrm{T}}=-(0.267 \pm 0.086)-(3.72 \pm 2) \cdot 10^{-4}(p / \text { bar }) \\
& \ln \left[k_{\mathrm{tr}} /\left(\mathrm{L} \cdot \mathrm{mol}^{-1} \cdot \mathrm{s}^{-1}\right)\right]=(6.88 \pm 0.27)+(1.79 \pm 1.27) \cdot 10^{-4}(p / \text { bar }) \\
& \left(\text { bulk, } 80^{\circ} \mathrm{C}, 300 \leq p \leq 1000 \text { bar }\right) \\
& \ln C_{\mathrm{T}}=-(0.095 \pm 0.024)-(3.61 \pm 1.02) \cdot 10^{-4}(p / \text { bar }) \\
& \ln \left[k_{\mathrm{tr}} /\left(\mathrm{L} \cdot \mathrm{mol}^{-1} \cdot \mathrm{s}^{-1}\right)\right]=(7.02 \pm 0.11)+(1.44 \pm 1.01) \cdot 10^{-4}(p / \text { bar }) \\
& \left(40 \mathrm{wt} \% \mathrm{scCO}_{2}, 80^{\circ} \mathrm{C}, 300 \leq p \leq 1000 \mathrm{bar}\right) .
\end{aligned}
$$

The respective activation volumes are as follows:

$$
\begin{array}{lll}
\text { bulk: } & \Delta V^{\#}\left(C_{\mathrm{T}}\right)=+(10.9 \pm 10.6) \mathrm{cm}^{3} \cdot \mathrm{mol}^{-1} & \Delta V^{\#}\left(k_{\mathrm{tr}}\right)=-(5.3 \pm 3.7) \mathrm{cm}^{3} \cdot \mathrm{mol}^{-1} \\
\mathrm{scCO}_{2}: & \Delta V^{\#}\left(C_{\mathrm{T}}\right)=+(10.6 \pm 3.0) \mathrm{cm}^{3} \cdot \mathrm{mol}^{-1} & \Delta V^{\#}\left(k_{\mathrm{tr}}\right)=-(4.4 \pm 2.9) \mathrm{cm}^{3} \cdot \mathrm{mol}^{-1}
\end{array}
$$

The activation volume of $C_{\mathrm{T}}$ is around $-11 \mathrm{~cm}^{3} \cdot \mathrm{mol}^{-1}$ in both media, which confirms the significant pressure dependence of $C_{\mathrm{T}}$. Within experimental uncertainty, $\Delta V^{\#}\left(k_{\mathrm{tr}}\right)$ in bulk and in $\mathrm{scCO}_{2}$ are slightly pressure dependent. $\Delta V^{\#}\left(k_{\mathrm{tr}}\right)$ values are equivalent in both media. The extrapolation of $C_{\mathrm{T}}$ in bulk to 1 bar via Eq. 5.5 gives a value of 0.765 , which is in very good agreement with the value of 0.711 determined by Hutchinson et al. ${ }^{1}$.

\subsubsection{Copolymerization of styrene and MMA}

The chain-transfer reaction of DDM in copolymerizations of styrene and MMA was studied at $80^{\circ} \mathrm{C}$ and four different pressures. The chain-transfer rate coefficients were obtained using the $C_{\mathrm{T}}$ values measured and $k_{\mathrm{p}}$ data for copolymerizations listed in Appendix 1, which were 
obtained as explained in section 6.1 applying the IPUE model. Fig. 5.9 shows the $C_{\mathrm{T}}$ values obtained at $80^{\circ} \mathrm{C}$ and 300 bar for different mole fractions of styrene in the monomer feed, $f_{\mathrm{S}}$.

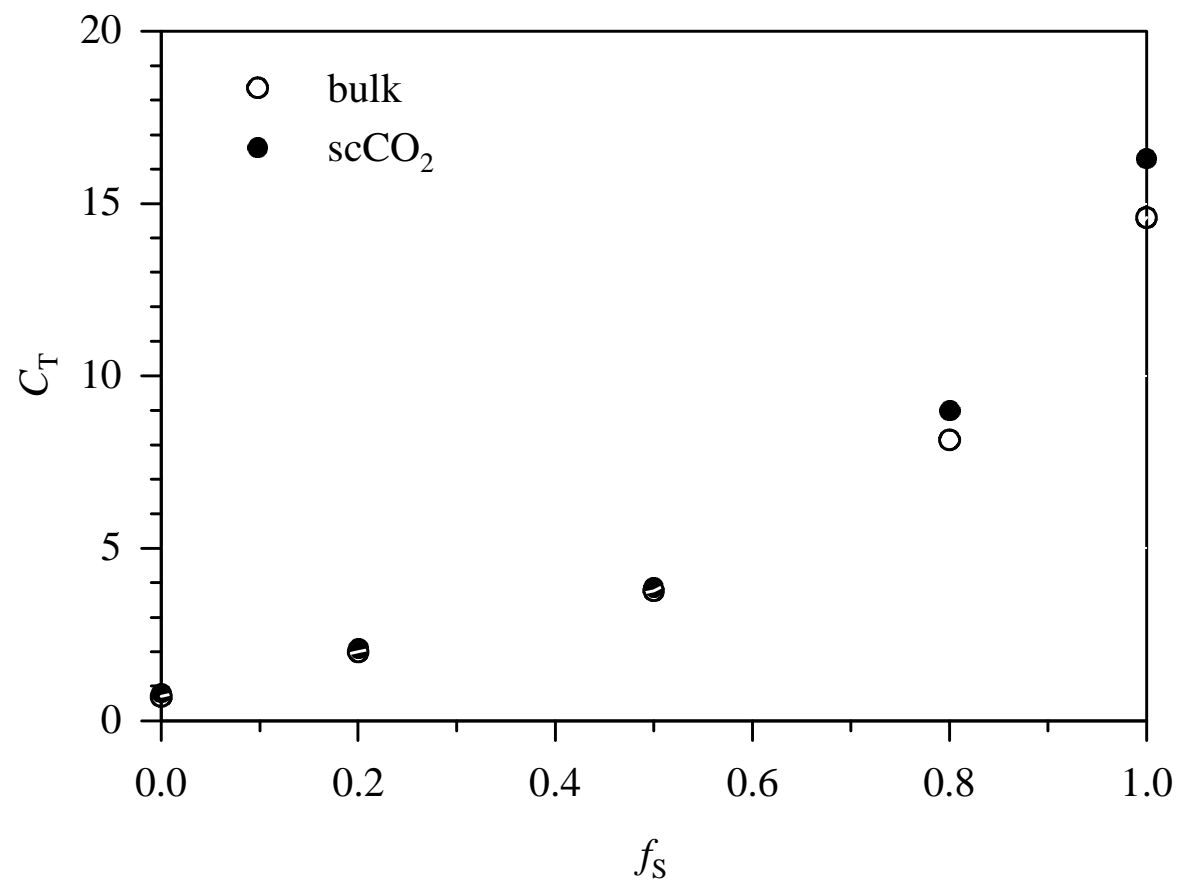

Figure 5.9: Variation of $C_{T}$ with the mole fraction of styrene in the monomer feed for copolymerizations of styrene and MMA in $40 \mathrm{wt} \% \mathrm{scCO}_{2}$ (full circles) and in bulk (open circles) at $80^{\circ} \mathrm{C}$ and 300 bar. Experimental data are reported in Appendix 2.

The variation of $C_{\mathrm{T}}$ with $f_{\mathrm{S}}$ is not linear for reactions in bulk and in $\mathrm{scCO}_{2} . C_{\mathrm{T}}$ increases with $f_{\mathrm{S}}$, which means that $C_{\mathrm{T}}$ of styrene is higher than $C_{\mathrm{T}}$ of MMA. It is also seen that the difference in bulk and $\mathrm{scCO}_{2}$ measurements is not significant in the entire range of $f_{\mathrm{S}}$.

Fig. 5.9 shows that the increase of $C_{\mathrm{T}}$ with $f_{\mathrm{S}}$ is slow at low $f_{\mathrm{S}}$ values. This aspect will be discussed in section 6 .

The variation of the corresponding $k_{\mathrm{tr}}$ values with $f_{\mathrm{S}}$ is shown in Fig. 5.10.

Fig. 5.10 exhibits a linear increase of $\ln k_{\text {tr }}$ with $f_{\mathrm{S}}$ for copolymerizations in $\mathrm{scCO}_{2}$ and in bulk. It is clear that the presence of $\mathrm{scCO}_{2}$ has no influence on $k_{\text {tr }}$ at $80^{\circ} \mathrm{C}$. The literature data included in Fig. 5.10 are calculated from the $C_{\mathrm{T}}$ values reported in refs. 1 and 2 and from $k_{\mathrm{p}}$ given in ref. 2. 


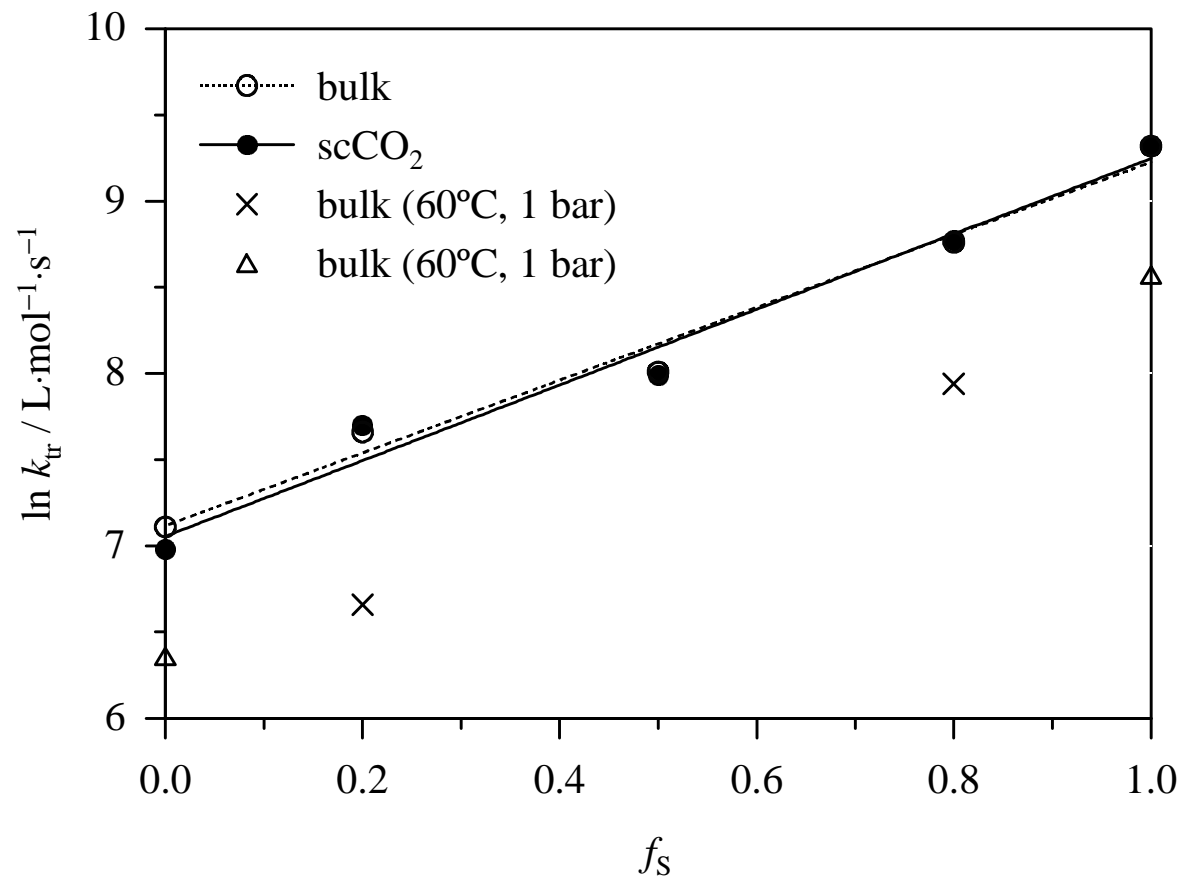

Figure 5.10: Variation of the chain-transfer rate coefficients with the mole fraction of styrene in the monomer feed for copolymerizations of styrene and MMA at $80^{\circ} \mathrm{C}$ and 300 bar. Literature data are taken from ref. $1(\Delta)$ and ref. $2(\times)$. Experimental data are reported in Appendix 2.

The literature data show the same trend as $k_{\text {tr }}$ from this work: $\ln k_{\text {tr }}$ increases linearly with $f_{\mathrm{S}}$. Moreover, the plots of $\ln k_{\mathrm{tr}} \mathrm{vs} . f_{\mathrm{S}}$ at $1 \mathrm{bar}, 60^{\circ} \mathrm{C}$ and at $300 \mathrm{bar}, 80^{\circ} \mathrm{C}$ are parallel, indicating that the variation of $\ln k_{\text {tr }}$ with $f_{\mathrm{S}}$ does not depend on the polymerization conditions (temperature, pressure, and reaction medium). In addition, comparison of $k_{\text {tr }}$ determined at $60^{\circ} \mathrm{C}$ and 1 bar and at $80^{\circ} \mathrm{C}$ and 300 bar shows that $k_{\text {tr }}$ may be temperature and pressure dependent.

\section{Pressure dependence of $C_{\mathrm{T}}$ and $k_{\mathrm{tr}}$}

The pressure dependencies of $C_{\mathrm{T}}$ and $k_{\text {tr }}$ for copolymerization with $f_{\mathrm{S}}=0.5$ at $80^{\circ} \mathrm{C}$ are plotted in Fig. 5.11. The $C_{\mathrm{T}}$ and $k_{\text {tr }}$ values determined at each pressure are very close in bulk and in $\mathrm{scCO}_{2}: C_{\mathrm{T}, \text { bulk }} / C_{\mathrm{T}, \mathrm{scCO} 2}$ are in the range from 0.9 to 1 . As seen for styrene and MMA homopolymerizations, $C_{\mathrm{T}}$ decreases, whereas $k_{\text {tr }}$ slightly increases with pressure. Moreover, the effect of $\mathrm{CO}_{2}$ as a solvent on $C_{\mathrm{T}}$ and $k_{\text {tr }}$ is not significant in the entire pressure range. 

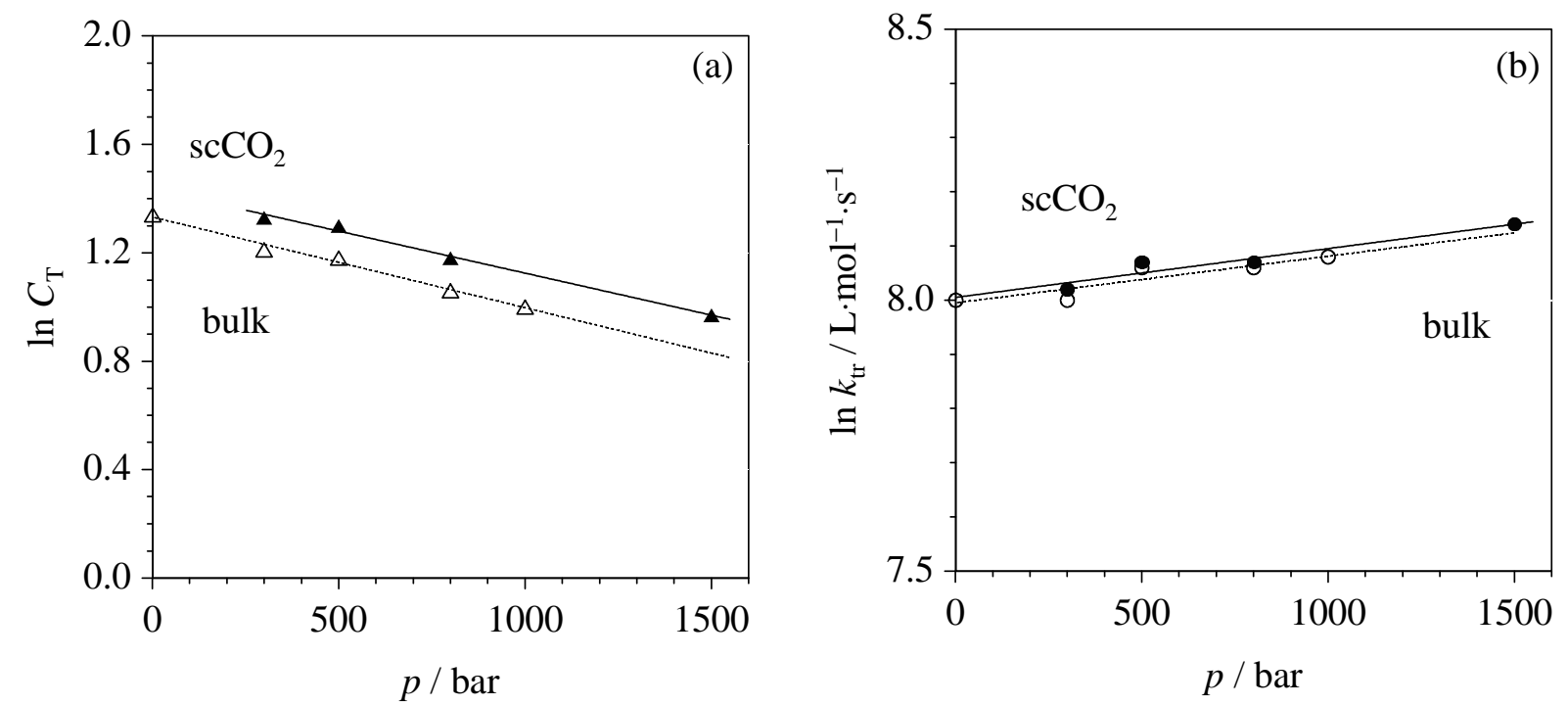

Figure 5.11: Pressure dependence of the chain-transfer constant (a) and of the chaintransfer rate coefficient (b) for copolymerizations of styrene and MMA $\left(f_{S}=\right.$ 0.5) in $40 w t \% \mathrm{scCO}_{2}$ and in bulk at $80^{\circ} \mathrm{C}$. Experimental data are given in Appendix 2.

The pressure dependence of $k_{\mathrm{tr}}$ and $C_{\mathrm{T}}$ for copolymerizations $\left(f_{\mathrm{S}}=0.5\right)$ in bulk and in $\mathrm{scCO}_{2}$ may be expressed by Eqs. 5.9-5.12:

$$
\begin{aligned}
& \ln C_{\mathrm{T}}=(1.33 \pm 0.05)-(3.33 \pm 0.71) \cdot 10^{-4}(p / \text { bar }) \\
& \ln \left[k_{\mathrm{tr}} /\left(\mathrm{L} \cdot \mathrm{mol}^{-1} \cdot \mathrm{s}^{-1}\right)\right]=(7.99 \pm 0.04)+(8.82 \pm 7.08) \cdot 10^{-5}(p / \text { bar }) \\
& \text { (bulk, } f_{\mathrm{S}}=0.5,80^{\circ} \mathrm{C}, 300 \leq p \leq 1000 \text { bar) } \\
& \ln C_{\mathrm{T}}=(1.43 \pm 0.05)-(3.07 \pm 0.58) \cdot 10^{-4}(p / \text { bar }) \\
& \ln \left[k_{\mathrm{tr}} /\left(\mathrm{L} \cdot \mathrm{mol}^{-1} \cdot \mathrm{s}^{-1}\right)\right]=(8.00 \pm 0.05)+(9.46 \pm 6.43) \cdot 10^{-5}(p / \text { bar }) \\
& \text { (40 wt } \% \mathrm{scCO}_{2}, f_{\mathrm{S}}=0.5,80^{\circ} \mathrm{C}, 300 \leq p \leq 1000 \text { bar) }
\end{aligned}
$$

The corresponding activation volumes are as follows:

bulk: $\quad \Delta V^{\#}\left(C_{\mathrm{T}}\right)=+(9.8 \pm 2.1) \mathrm{cm}^{3} \cdot \mathrm{mol}^{-1}$ $\Delta V^{\#}\left(k_{\mathrm{tr}}\right)=-(2.6 \pm 2.8) \mathrm{cm}^{3} \cdot \mathrm{mol}^{-1}$

$\mathrm{scCO}_{2}: \Delta V^{\#}\left(C_{\mathrm{T}}\right)=+(9.0 \pm 1.7) \mathrm{cm}^{3} \cdot \mathrm{mol}^{-1}$ $\Delta V^{\#}\left(k_{\mathrm{tr}}\right)=-(2.8 \pm 1.9) \mathrm{cm}^{3} \cdot \mathrm{mol}^{-1}$ 
The activation volume for $C_{\mathrm{T}}$ is approximately $+9.5 \mathrm{~cm}^{3} \cdot \mathrm{mol}^{-1}$ in bulk and in $\mathrm{scCO}_{2}$. This value indicates a significant pressure dependence of $C_{\mathrm{T}}$ in both media. The variation of $C_{\mathrm{T}}$ with pressure is close to the one determined in homopolymerizations of styrene and MMA. In contrast, the activation volume for $k_{\mathrm{tr}}$ is approximately $-2.7 \mathrm{~cm}^{3} \cdot \mathrm{mol}^{-1}$ in bulk and in $\mathrm{scCO}_{2}$, thus $k_{\text {tr }}$ shows a minor pressure dependence. Within experimental uncertainty, the values of $\Delta V^{\#}\left(k_{\mathrm{tr}}\right)$ in copolymerizations are similar to the values for homopolymerizations. This finding indicates that $\Delta V^{\#}\left(k_{\mathrm{tr}}\right)$ is not dependent on the monomer feed used, which will be discussed in section 5.4 .

Since $k_{\mathrm{tr}}$ is not pressure dependent, the difference in $k_{\mathrm{tr}}$ between literature data and data from this work, shown in Fig. 5.10, is due to the different temperatures applied. Thus, $k_{\text {tr }}$ is temperature dependent in styrene and MMA copolymerization.

\subsubsection{Summary}

The table below summarizes the results obtained for homo- and copolymerizations of MMA and styrene in bulk and in $\mathrm{scCO}_{2}$ at $80^{\circ} \mathrm{C}$ with DDM as chain-transfer agent. $C_{\mathrm{T}}$ and $k_{\mathrm{tr}}$ are given for polymerizations at $80^{\circ} \mathrm{C}$ and 300 bar. 


\begin{tabular}{|c|c|c|}
\hline \multicolumn{3}{|c|}{ MMA } \\
\hline & $C_{\mathrm{T}}$ & $k_{\mathrm{tr}}$ \\
\hline $\mathrm{scCO}_{2}$ & $0.811 \pm 0.098$ & $(1.14 \pm 0.25) \cdot 10^{3} \mathrm{~L} \cdot \mathrm{mol}^{-1} \cdot \mathrm{s}^{-1}$ \\
\hline bulk & $0.702 \pm 0.071$ & $(1.08 \pm 0.21) \cdot 10^{3} \mathrm{~L} \cdot \mathrm{mol}^{-1} \cdot \mathrm{s}^{-1}$ \\
\hline \multirow[t]{2}{*}{$\mathrm{scCO}_{2}$ influence } & no influence in the & no influence in the \\
\hline & entire pressure range & entire pressure range \\
\hline \multirow[t]{2}{*}{$\Delta V^{\#} / \mathrm{cm}^{3} \cdot \mathbf{m o l}^{-1}$} & bulk: $+(10.9 \pm 10.6)$ & bulk: $-(5.3 \pm 3.7)$ \\
\hline & $s c \mathrm{CO}_{2}:+(10.6 \pm 3.0)$ & $s c \mathrm{CO}_{2}:-(4.4 \pm 2.9)$ \\
\hline \multicolumn{3}{|c|}{ styrene } \\
\hline & $C_{\mathbf{T}}$ & $k_{\mathrm{tr}}$ \\
\hline $\mathrm{scCO}_{2}$ & $16.3 \pm 1.5$ & $(11.2 \pm 2.1) \cdot 10^{3} \mathrm{~L} \cdot \mathrm{mol}^{-1} \cdot \mathrm{s}^{-1}$ \\
\hline bulk & $14.6 \pm 1.8$ & $(11.2 \pm 1.4) \cdot 10^{3} \mathrm{~L} \cdot \mathrm{mol}^{-1} \cdot \mathrm{s}^{-1}$ \\
\hline \multirow[t]{2}{*}{$\mathrm{scCO}_{2}$ influence } & no influence in the & no influence in the \\
\hline & entire pressure range & entire pressure range \\
\hline \multirow[t]{2}{*}{$\Delta V^{\#} / \mathbf{c m}^{3} \cdot \mathbf{m o l}^{-1}$} & bulk: $+(6.3 \pm 0.7)$ & bulk: $-(4.5 \pm 1.0)$ \\
\hline & $\mathrm{scCO}_{2}:+(9.7 \pm 3.8)$ & $s c \mathrm{CO}_{2}:-(1.8 \pm 3.5)$ \\
\hline \multicolumn{3}{|c|}{ styrene / MMA $\left(f_{\mathrm{S}}=0.5\right)$} \\
\hline & $C_{\mathrm{T}}$ & $k_{\mathrm{tr}}$ \\
\hline $\mathrm{scCO}_{2}$ & $3.77 \pm 0.35$ & $(3.03 \pm 0.62) \cdot 10^{3} \mathrm{~L} \cdot \mathrm{mol}^{-1} \cdot \mathrm{s}^{-1}$ \\
\hline bulk & $3.34 \pm 0.25$ & $(2.98 \pm 0.55) \cdot 10^{3} \mathrm{~L} \cdot \mathrm{mol}^{-1} \cdot \mathrm{s}^{-1}$ \\
\hline \multirow[t]{2}{*}{$\mathrm{scCO}_{2}$ influence } & no influence in the & no influence in the \\
\hline & entire pressure range & entire pressure range \\
\hline \multirow[t]{2}{*}{$\Delta V^{\#} / \mathbf{c m}^{3} \cdot \mathbf{m o l}^{-1}$} & bulk: $+(9.8 \pm 2.1)$ & bulk: $-(2.6 \pm 2.8)$ \\
\hline & $s c \mathrm{CO}_{2}:+(9.0 \pm 1.7)$ & $s c \mathrm{CO}_{2}:-(2.8 \pm 1.9)$ \\
\hline
\end{tabular}




\subsection{COPhBF as catalytic chain-transfer agent}

Catalytic chain-transfer agents (CCTAs) have been developed during recent years ${ }^{8,9}$. Frequently cobalt (II)-complexes are used, which are able to catalyze chain-transfer reaction. The mechanism of the catalytic chain-transfer reaction is illustrated in scheme 5.2. Cobalt (II)-complexes abstract a hydrogen atom from a $\beta$-carbon on the radical chain, creating a dead polymer with a vinyl end-group and a $\mathrm{Co}(\mathrm{III})-\mathrm{H}$ species. This $\mathrm{Co}(\mathrm{III})-\mathrm{H}$ species transfers the hydrogen atom to a monomer molecule, initiating a new chain. CCTAs are advantageous as compared to conventional CTAs, because the CCTA is regenerated during the polymerization and only a small amount (ppm range) of the complex is required.

$$
\begin{gathered}
\mathrm{R}_{\mathrm{n}}{ }^{+}+\mathrm{Co}(\mathrm{II}) \stackrel{k_{\mathrm{tr}}}{\longrightarrow} \mathrm{P}_{\mathrm{n}}+\mathrm{Co}(\mathrm{III})-\mathrm{H} \\
\mathrm{Co}(\mathrm{III})-\mathrm{H}+\mathrm{M} \longrightarrow \mathrm{R}_{1} \cdot \mathrm{Co}(\mathrm{II})
\end{gathered}
$$

(a)

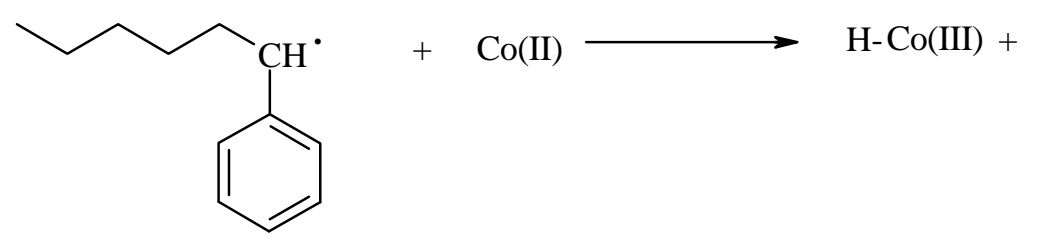<smiles>CCCC/C=C\c1ccccc1</smiles>

(b)

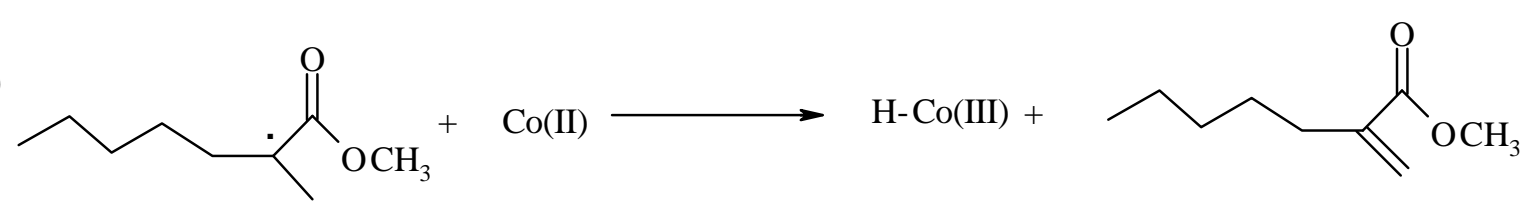

Scheme 5.2: Typical reaction scheme for catalytic chain-transfer. Chain-transfer reaction for styrene (a) and for MMA (b) homopolymerizations.

The mechanism of scheme 5.2 is usually presented for the catalytic chain-transfer reaction with cobalt-complexes. Although, recently several authors ${ }^{10,11,12}$ suspected the formation of a cobalt-carbon bond in the $\mathrm{Co}(\mathrm{II}) /$ styrene system, as discussed in section 5.4. In the following part $C_{\mathrm{T}}$, thus $k_{\mathrm{tr}}$ values are based using scheme 5.2. $C_{\mathrm{T}}$ and $k_{\mathrm{tr}}$ observed are noted as $C_{\mathrm{T}}{ }^{\text {obs }}$ and $k_{\mathrm{tr}}{ }^{\text {obs }}$ since the reaction scheme is not clear.

Investigations reported in the literature focus on CCTAs in MMA and styrene polymerizations at ambient pressure. The only $C_{\mathrm{T}}{ }^{\text {obs }}$ data reported ${ }^{13}$ so far in MMA 
polymerization in solution of $\mathrm{scCO}_{2}$ shows a significant influence of $\mathrm{scCO}_{2}$ as a solvent. The pressure dependence of $C_{\mathrm{T}}$ for catalytic chain-transfer has not yet been studied. Thus, the pressure dependencies of $C_{\mathrm{T}}{ }^{\text {obs }}$ and $k_{\mathrm{tr}}{ }^{\text {obs }}$ are investigated in $\mathrm{scCO}_{2}$ and in bulk in this work.

The cobalt-complex used is the bis(methanol) complex of bis(difluoroboryl) diphenylglyoximato cobalt (II), the so-called COPhBF (description in section 3.4). This complex is known to be air sensitive, therefore few polymerizations with $\mathrm{COPhBF}$ are carried out in section 5.2.1 in order to evaluate its air sensitivity.

The polymerizations are carried out in bulk and in $40 \mathrm{wt} \% \mathrm{scCO}_{2}$ applying the PLP technique with a laser pulse repetition rate of $1 \mathrm{~Hz}$ and a photoinitiator concentration of $0.2 \mathrm{mmol} \cdot \mathrm{L}^{-1}$, as explained in section 4 . The $[\mathrm{COPhBF}] /[\mathrm{M}]$ range from $10^{-8}$ to $10^{-6}$ is used for the different systems: Homo- and copolymerizations. Low COPhBF concentrations are used in order to prevent the obtention of polymer with too low molecular weight. The homogeneity of the system is checked visually and by IR monitoring during the polymerization.

\subsubsection{Preliminary investigations}

Preliminary investigations are performed under the same experimental conditions as in the literature ${ }^{9,12}$ in order to compare the $C_{\mathrm{T}}{ }^{\text {obs }}$ values obtained, thus to check the validity of the technique used to prepare the mixtures of monomer, initiator, and CTA. In the follownig part, MMA polymerizations are performed in bulk at $60^{\circ} \mathrm{C}$ and ambient pressure using $\mathrm{COPhBF}$ as CCTA and AIBN as initiator. In this case, the PLP-technique is not applied and the polymerization is thermally initiated. The time required for a monomer conversion of approximately $2 \%$ is about 10 minutes.

Fig. 5.12 shows the CLD plots obtained for MMA homopolymerizations performed in bulk at $60^{\circ} \mathrm{C}$ and ambient pressure. One set of experiments is performed without any precautions towards oxygen (insert of Fig. 5.12). The mixtures of COPhBF, monomer, and initiator are not degassed and prepared under normal atmosphere. The polymerization is carried out as described in section 3.1. Two others sets of experiments are performed under oxygen free conditions (circles in Fig. 5.12). In one set the reaction mixtures are prepared in a glove box (full circles) and in the other one, the stock solutions are degassed using a freeze-pump-thaw procedure prior to preparation of the reaction mixtures in the glove box (open circles). 


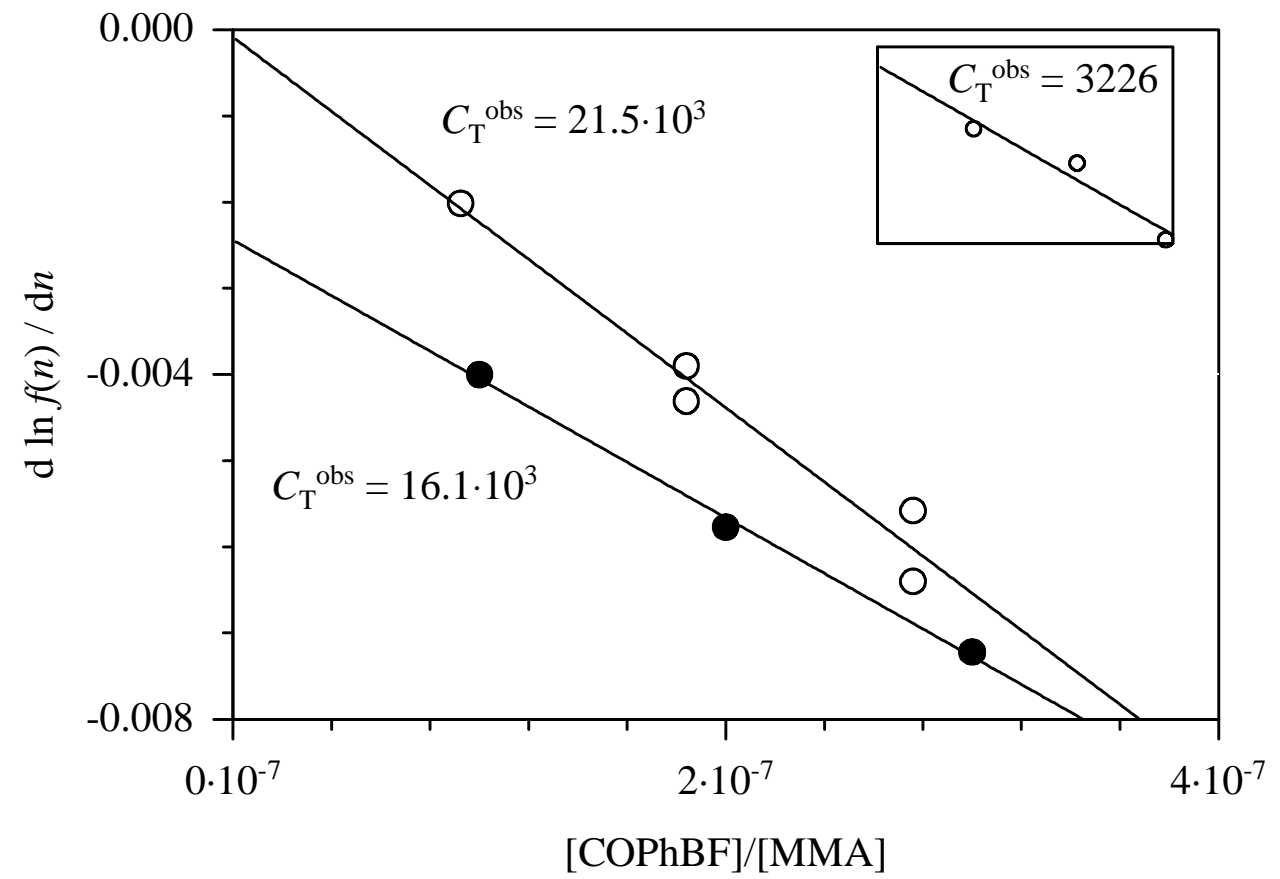

Figure 5.12: CLD plots for MMA polymerizations at 1 bar and $60^{\circ} \mathrm{C}$ using AIBN as initiator. The methods used to prepare the mixtures are given in the preceding text.

Fig. 5.12 clearly shows a difference in the slope, thus in $C_{\mathrm{T}}{ }^{\text {obs }}$, for the different methods used for the preparation of the reaction mixture. $C_{\mathrm{T}}{ }^{\text {obs }}$ of $21.5 \cdot 10^{3}$, which corresponds to the reaction mixtures prepared in a glove box and degassed, is higher than the $C_{\mathrm{T}}{ }^{\text {obs }}$ value of $16.1 \cdot 10^{3}$ obtained for polymerizations where the reaction mixtures are prepared in a glove box but are not degassed. The value of $C_{\mathrm{T}}{ }^{\text {obs }}$ determined for experiments without any oxygen free precautions is 3226 , which is about one order of magnitude lower than $C_{\mathrm{T}}{ }^{\text {obs }}$ determined in oxygen free conditions. It is obvious that $\mathrm{COPhBF}$ in solution is less reactive in terms of the chain-transfer reaction when it is in contact with oxygen.

Davis et al. ${ }^{12}$ performed MMA polymerizations at $60^{\circ} \mathrm{C}$ and ambient pressure considering the air sensitivity of the cobalt-complex. The solutions of MMA, initiator, and COPhBF were degassed by the freeze-pump-thaw procedure and the reactions performed using standard Schlenk apparatus and syringe techniques under oxygen free conditions. The values reported are in the range from $19.5 \cdot 10^{3}$ to $25.8 \cdot 10^{3}$, which is consistent with the $C_{\mathrm{T}}{ }^{\text {obs }}$ value of $21.5 \cdot 10^{3}$ determined in this work.

In summary, precautions have to be taken to measure the kinetics of $\mathrm{COPhBF}$ as catalytic chain-transfer agent. Thus, all reaction mixtures are prepared under oxygen free conditions: The solutions of monomer, initiator, and CTA are prepared in a glove box and degassed using 
the freeze-pump-thaw procedure. The method followed for preparation of the reactions mixtures in $\mathrm{scCO}_{2}$ is described in section 3.1.9.

\subsubsection{Homopolymerization of MMA}

MMA is the most frequently studied monomer in polymerizations with COPhBF as CCTA. As already mentioned, the pressure dependence of $C_{\mathrm{T}}{ }^{\text {obs }}$ and ${k_{\mathrm{tr}}}^{\text {obs }}$ was not studied so far. Several reports with cobalt-complexes as CCTA for MMA polymerization ${ }^{14,15,16}$ suggest that $C_{\mathrm{T}}{ }^{\text {obs }}$ is temperature independent. Therefore, MMA homopolymerizations were performed at $80^{\circ} \mathrm{C}$ in bulk and in $40 \mathrm{wt} \% \mathrm{scCO}_{2}$ at pressures between 300 and 1000 bar.

The molecular weight distributions obtained from MMA homopolymerizations in $\mathrm{scCO}_{2}$ at $80^{\circ} \mathrm{C}, 300$ bar and different COPhBF concentrations are shown in Fig. 5.13.

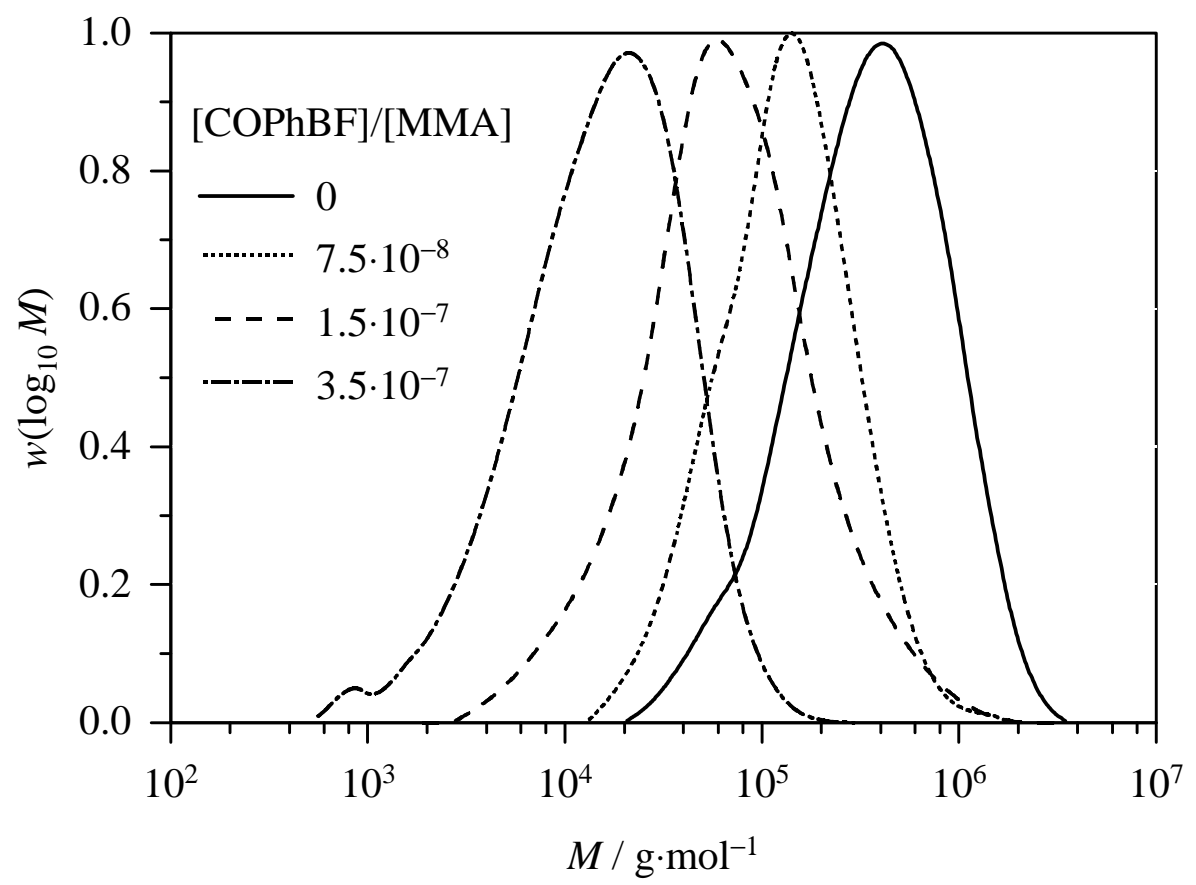

Figure 5.13: Molecular weight distributions of PMMA from polymerizations in 40 wt \% scCO $\mathrm{C}_{2}$ at $80^{\circ} \mathrm{C}, 300 \mathrm{bar}$, and $\mathrm{COPhBF}$ concentration as indicated.

The addition of COPhBF shifts the resulting MWDs to lower molecular weights. PMMA obtained in the absence of COPhBF yields $M_{\mathrm{w}}$ of $5 \cdot 10^{5} \mathrm{~g} \cdot \mathrm{mol}^{-1}$ and in the presence of only $5 \cdot 10^{-5}$ wt $\%$ of $\mathrm{COPhBF}\left([\mathrm{COPhBF}] /[\mathrm{MMA}]=7.5 \cdot 10^{-8}\right) M_{\mathrm{w}}$ is shifted to a value of $2.1 \cdot 10^{5}$ $\mathrm{g} \cdot \mathrm{mol}^{-1}$. For the highest amount of COPhBF, $2 \cdot 10^{-4}$ wt $\%\left([\mathrm{COPhBF}] /[\mathrm{MMA}]=3.5 \cdot 10^{-7}\right)$, a value of $2.6 \cdot 10^{4} \mathrm{~g} \cdot \mathrm{mol}^{-1}$ is obtained for $M_{\mathrm{w}}$. The addition of small amounts of COPhBF 
strongly shifts $M_{\mathrm{w}}$ to lower values. The results demonstrate the exceptional transfer capacity of the cobalt-complex.

The corresponding $\ln f(M)$ vs. $M$ plots of Fig. 5.13 are reported in Fig. 5.14. The bold lines indicate the region where the slope required for the determination of $C_{\mathrm{T}}{ }^{\text {obs }}$ is measured, as explained in section 4 .

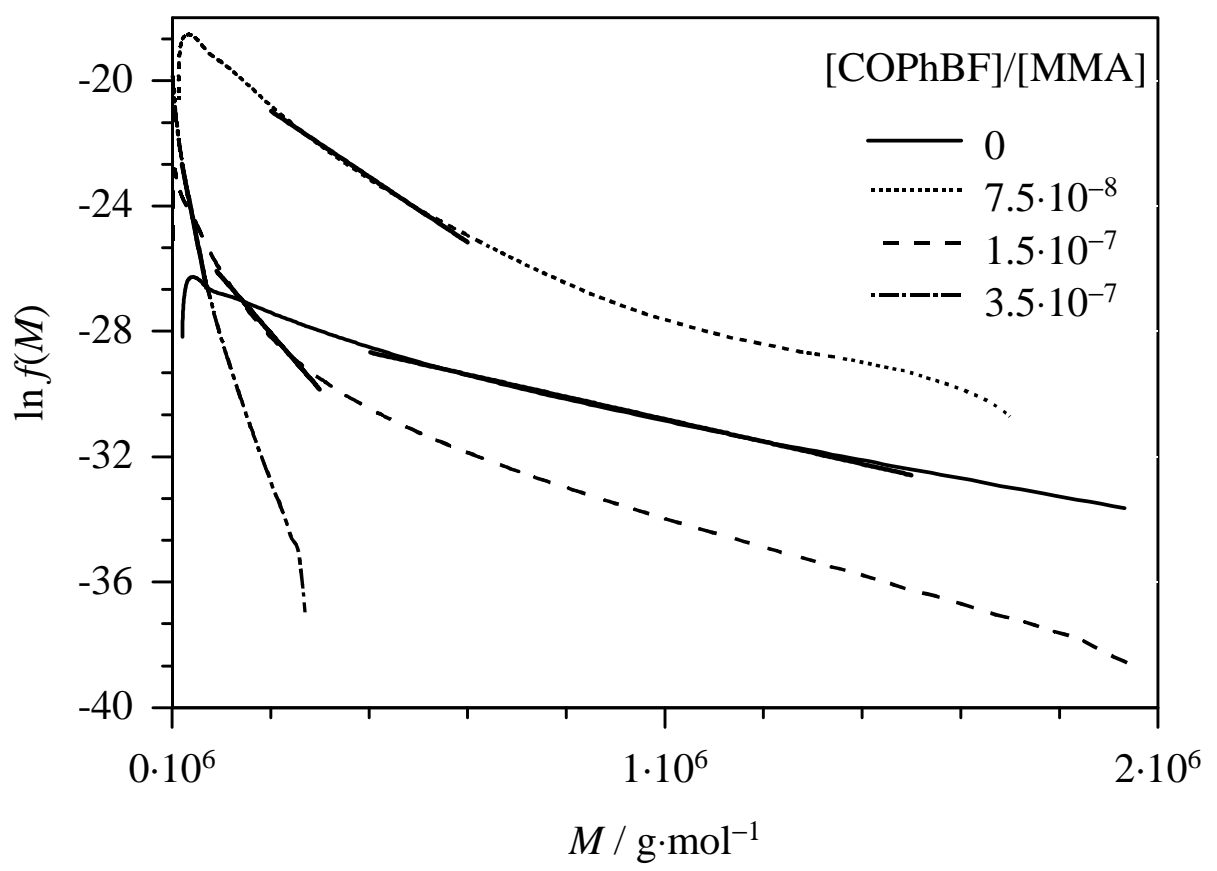

Figure 5.14: In $f(M)$ plots for PMMA from polymerizations in $40 \mathrm{wt} \% \mathrm{scCO} \mathrm{O}_{2}$ at $80^{\circ} \mathrm{C}, 300$ bar, and COPhBF-concentration as indicated.

The slope is strongly enhanced with increasing COPhBF concentration. For example, the slopes corresponding to polymerizations without $\mathrm{CTA}$ and with $[\mathrm{COPhBF}] /[\mathrm{MMA}]$ of $1.5 \cdot 10^{-7}$ are $-3.56 \cdot 10^{-6}$ and $-1.80 \cdot 10^{-5}$, respectively. This indicates a change in the transfer activity when the concentration of $\mathrm{COPhBF}$ increases.

The CLD plots for MMA homopolymerizations in $\mathrm{scCO}_{2}$ and in bulk at $80^{\circ} \mathrm{C}, 300$ bar (a) and 1000 bar (b) are shown in Fig. 5.15, which slope gives $-C_{\mathrm{T}}{ }^{\text {obs }}$.

The values of $C_{\mathrm{T}}{ }^{\text {obs }}$ determined at 300 bar are $(21.1 \pm 5.1) \cdot 10^{3}$ and $(14.1 \pm 2.2) \cdot 10^{3}$ in $\mathrm{scCO}_{2}$ and bulk, respectively, which indicates a high chain-transfer activity of COPhBF. The difference in $C_{\mathrm{T}}{ }^{\text {obs }}$ between bulk and in $\mathrm{scCO}_{2}$ is clearly illustrated in Fig. 5.15b: $C_{\mathrm{T}}{ }^{\text {obs }}$ in $\mathrm{scCO}_{2}$ is 3 times higher than in bulk. In addition, $C_{\mathrm{T}}{ }^{\text {obs }}$ determined at 300 bar is higher than $C_{\mathrm{T}}{ }^{\text {obs }}$ at 1000 bar. 

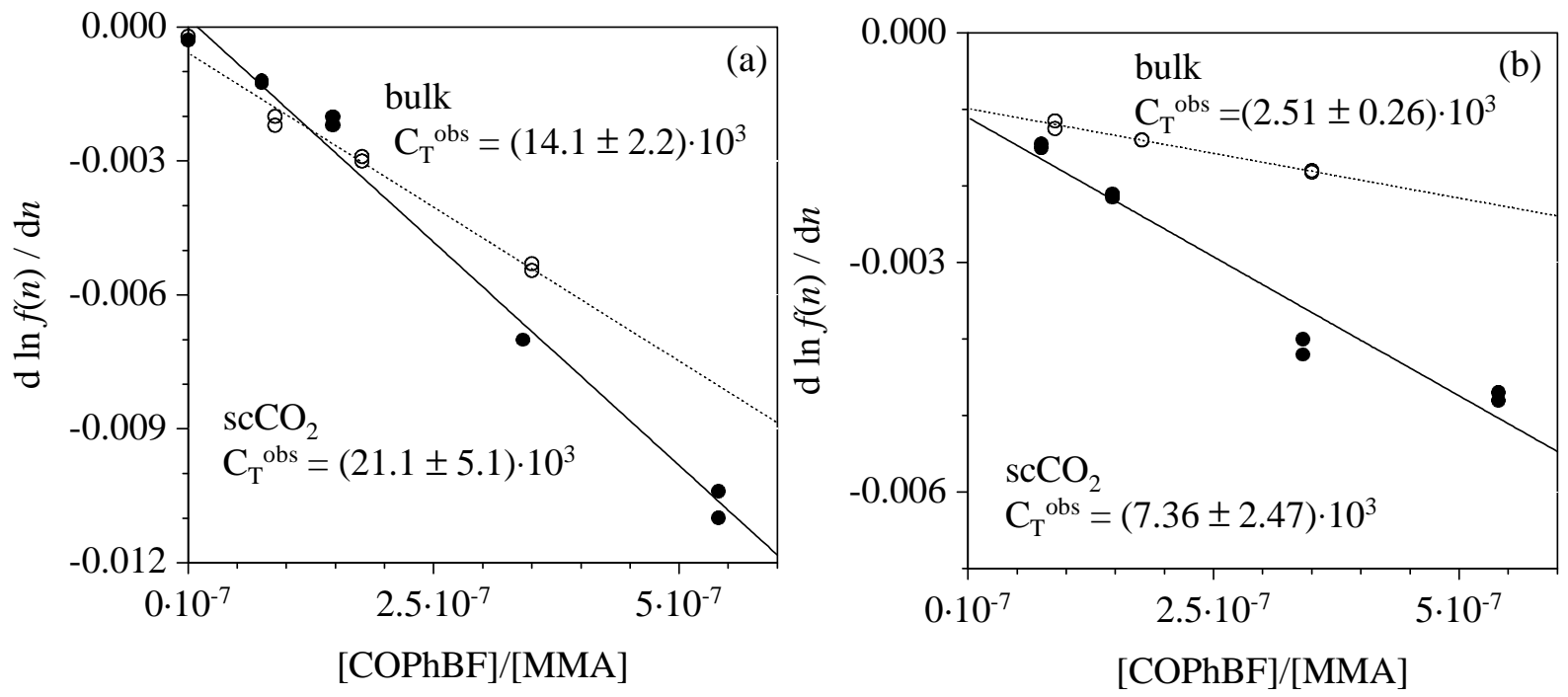

Figure 5.15: CLD plots for MMA homopolymerizations in 40 wt \% scCO (full circles) and in bulk (open circles) at $80^{\circ} \mathrm{C}, 300$ bar (a) and 1000 bar (b) with COPhBF as catalytic chain-transfer agent.

\section{Pressure dependence of $\boldsymbol{k}_{\mathrm{tr}}$ and $C_{\mathrm{T}}$}

The pressure dependence of $C_{\mathrm{T}}{ }^{\text {obs }}$ and $k_{\mathrm{tr}}{ }^{\text {obs }}$ was studied for MMA homopolymerizations in bulk and in $\mathrm{scCO}_{2}$ at $80^{\circ} \mathrm{C}$ and pressures varying between 300 and 1000 bar, as seen in Fig. 5.16. The values of ${k_{\mathrm{tr}}}^{\text {obs }}$ were calculated with $C_{\mathrm{T}}{ }^{\text {obs }}$ values and $k_{\mathrm{p}}$ data given in Appendix 1 (for comparison see section 5.1.2).
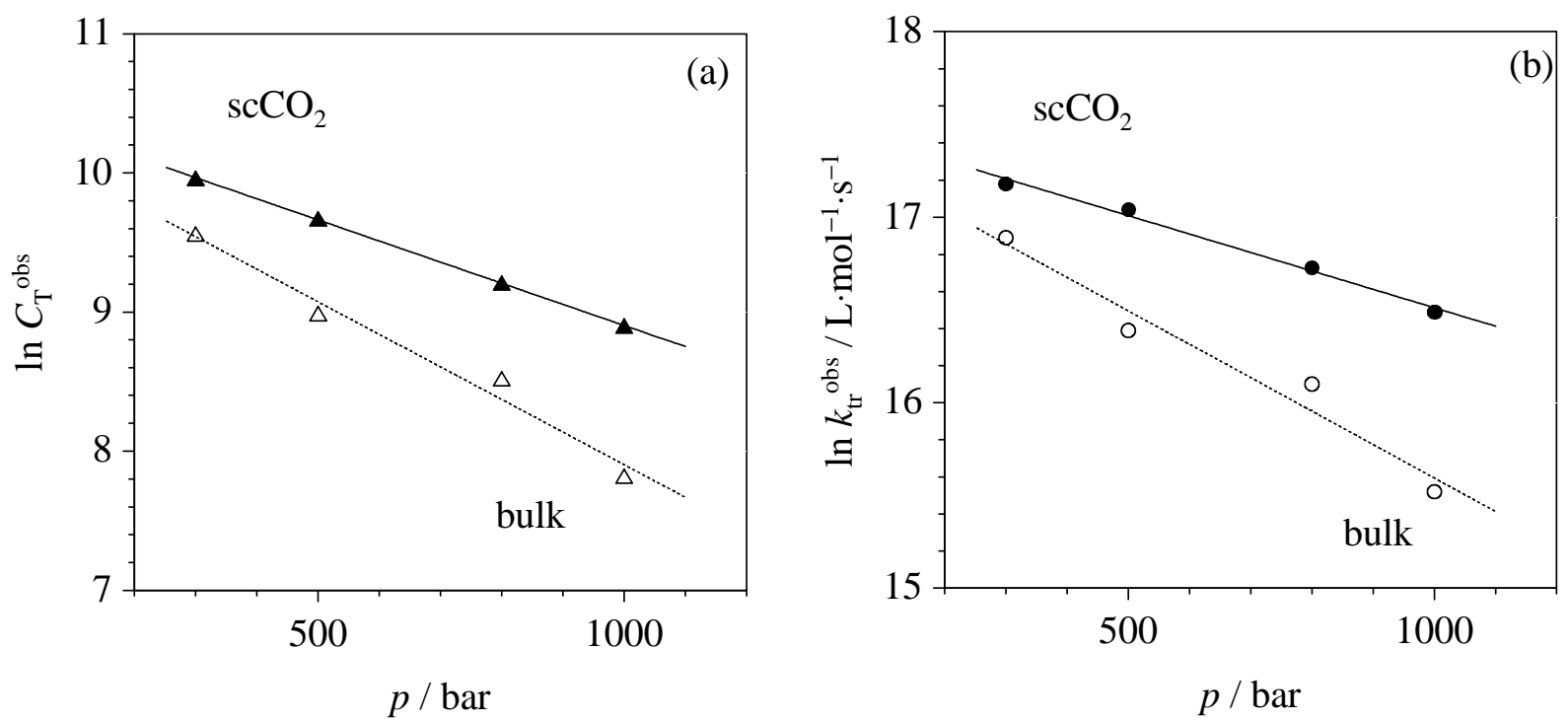

Figure 5.16: Pressure dependence of the chain-transfer constant (a) and of the chaintransfer rate coefficient (b) for MMA homopolymerizations in bulk and in $40 \mathrm{wt} \% \mathrm{CO}_{2}$ at $80^{\circ} \mathrm{C}$. Experimental data are listed in Appendix 3. 
As seen in Fig. 5.16, $C_{\mathrm{T}}{ }^{\text {obs }}$ decreases with increasing pressure, which is slightly more pronounced in bulk than in $\mathrm{scCO}_{2}$. In addition, $k_{\mathrm{tr}}^{\text {obs }}$ determined in bulk and in $\mathrm{scCO}_{2}$ polymerizations decreases with increasing pressure.

The values of $k_{\mathrm{tr}}{ }^{\text {obs }}$, reported in Appendix 3, are very high in the range of $10^{7} \mathrm{~L} \cdot \mathrm{mol}^{-1} \cdot \mathrm{s}^{-1}$ and are similar in size to the rate coefficients for bimolecular termination reactions in free-radical polymerizations, which are known to be diffusion controlled ${ }^{17}$. This finding will be discussed in section 5.4 .

Eqs. 5.13 to 5.16 correspond to the linear fits of the experimental data for $C_{\mathrm{T}}{ }^{\text {obs }}$ and $k_{\mathrm{tr}}{ }^{\text {obs }}$ given in Fig. 5.16 .

$$
\begin{aligned}
& \ln {C_{\mathrm{T}}}^{\text {obs }}=(10.2 \pm 0.2)-(2.33 \pm 0.80) \cdot 10^{-3}(p / \text { bar }) \\
& \ln \left[k_{\mathrm{tr}}{ }^{\mathrm{obs}} /\left(\mathrm{L} \cdot \mathrm{mol}^{-1} \cdot \mathrm{s}^{-1}\right)\right]=(17.4 \pm 0.3)-(1.61 \pm 0.54) \cdot 10^{-3}(p / \text { bar }) \\
& \text { (bulk, } 80^{\circ} \mathrm{C}, 300 \leq p \leq 1000 \text { bar) } \\
& \ln {C_{\mathrm{T}}}^{\text {obs }}=(10.4 \pm 0.2)-(1.51 \pm 0.41) \cdot 10^{-3}(p / \text { bar }) \\
& \ln \left[k_{\mathrm{tr}}{ }_{\mathrm{tr}}^{\mathrm{obs}} /\left(\mathrm{L} \cdot \mathrm{mol}^{-1} \cdot \mathrm{s}^{-1}\right)\right]=(17.5 \pm 0.16)-(1.07 \pm 0.25) \cdot 10^{-3}(p / \text { bar }) \\
& \text { (40 wt } \% \mathrm{scCO}_{2}, 80^{\circ} \mathrm{C}, 300 \leq p \leq 1000 \text { bar) }
\end{aligned}
$$

According to $\delta\left(\ln k_{\mathrm{tr}}\right) / \delta p=-\Delta V^{\#} /(\mathrm{R} \cdot T)$ and $\delta\left(\ln C_{\mathrm{T}}\right) / \delta p=-\Delta V^{\#} /(\mathrm{R} \cdot T)$, the activation volumes for $C_{\mathrm{T}}$ and $k_{\mathrm{tr}}$ are calculated as:

bulk: $\quad \Delta V^{\#}\left(C_{\mathrm{T}}{ }^{\text {obs }}\right)=+(68.7 \pm 23.5) \mathrm{cm}^{3} \cdot \mathrm{mol}^{-1} \quad \Delta V^{\#}\left(k_{\mathrm{tr}}{ }^{\text {obs }}\right)=+(47.5 \pm 15.8) \mathrm{cm}^{3} \cdot \mathrm{mol}^{-1}$

$\mathrm{scCO}_{2}: \quad \Delta V^{\#}\left(C_{\mathrm{T}}{ }^{\text {obs }}\right)=+(44.3 \pm 12.1) \mathrm{cm}^{3} \cdot \mathrm{mol}^{-1} \quad \Delta V^{\#}\left(k_{\mathrm{tr}}{ }^{\text {obs }}\right)=+(31.5 \pm 7.3) \mathrm{cm}^{3} \cdot \mathrm{mol}^{-1}$

The above given activation volumes for $C_{\mathrm{T}}{ }^{\text {obs }}$ and $k_{\mathrm{tr}}{ }^{\text {obs }}$ demonstrate the strong pressure dependence of the transfer reaction in bulk and in $\mathrm{scCO}_{2}$ polymerizations. Within experimental uncertainty, $\Delta V^{\#}\left(k_{\mathrm{tr}}{ }^{\text {obs }}\right)$ and $\Delta V^{\#}\left(C_{\mathrm{T}}^{\text {obs }}\right)$ are close in bulk and in $\mathrm{scCO}_{2}$. The activation volumes of $\Delta V^{\#}\left(k_{\mathrm{tr}}{ }^{\text {obs }}\right)$, in the range of $+35 \mathrm{~cm}^{3} \cdot \mathrm{mol}^{-1}$, are surprisingly high. For comparison, $\Delta V^{\#}$ of the termination rate coefficent is typically in the order of $20 \mathrm{~cm}^{3} \cdot \mathrm{mol}^{-1}$. These findings will be discussed in section 5.4.

The $C_{\mathrm{T}}{ }^{\text {obs }}$ value of $2.68 \cdot 10^{4}$, which is extrapolated to ambient pressure via Eq. 5.13 in bulk, is in the same order of magnitude as $C_{\mathrm{T}}{ }^{\text {obs }}$ of $21.5 \cdot 10^{3}$ determined at $60^{\circ} \mathrm{C}$ and 1 bar in section 
5.2.1. Thus, this extrapolated value is in good agreement with the literature data ${ }^{12}$ determined at 1 bar and $60^{\circ} \mathrm{C}$ in the range from $19.5 \cdot 10^{3}$ to $25.8 \cdot 10^{3}$. Davis et al ${ }^{13}$ performed polymerizations of MMA in $80 \mathrm{wt} \% \mathrm{scCO}_{2}$ at $50^{\circ} \mathrm{C}$ and 150 bar. The reported $C_{\mathrm{T}}{ }^{\text {obs }}$ value was $1.13 \cdot 10^{5}$, which is approximately one order of magnitude higher than $C_{\mathrm{T}}{ }^{\text {obs }}$ of $2.62 \cdot 10^{4}$ extrapolated to $150 \mathrm{bar}$, in $40 \mathrm{wt} \% \mathrm{scCO}_{2}$ via Eq. 5.15. The difference is certainly due to the fact that pressure, temperature, and $\mathrm{CO}_{2}$ content are not the same. More details about this aspect are given in section 5.4 .

\subsubsection{Homopolymerization of styrene}

The only study ${ }^{14}$ on the temperature dependence of catalytic chain-transfer polymerizations of styrene reported in the literature up to date indicates a different behavior as observed in MMA polymerizations: Although a large scatter in the data, $C_{\mathrm{T}}{ }^{\text {obs }}$ appears to decrease with temperature at ambient pressure. This induces that $k_{\text {tr }}$ is only slightly temperature dependent. Informations on the pressure dependence of $C_{\mathrm{T}}{ }^{\text {obs }}$ and $k_{\mathrm{tr}}{ }^{\text {obs }}$ as well as the influence of $\mathrm{scCO}_{2}$ on CCT in styrene polymerizations are not yet available.

In the following section, the pressure dependence of $k_{\mathrm{tr}}{ }^{\text {obs }}$ and $C_{\mathrm{T}}{ }^{\text {obs }}$ and the influence of $\mathrm{scCO}_{2}$ as a solvent in styrene polymerization are investigated.

Fig. 5.17a shows the molecular weight distributions for polystyrene obtained in $40 \mathrm{wt} \%$ $\mathrm{scCO}_{2}$ at $80^{\circ} \mathrm{C}$ and 300 bar with different amounts of COPhBF. The MWDs are shifted to lower molecular weights when the concentration of the cobalt-complex increases. In the absence of $\mathrm{COPhBF}$, the reaction yields polymer with a $M_{\mathrm{w}}$ of $3.77 \cdot 10^{5} \mathrm{~g} \cdot \mathrm{mol}^{-1}$ and upon the addition of $7 \cdot 10^{-5}$ wt $\%$ of $\mathrm{COPhBF}\left([\mathrm{COPhBF}] /[\mathrm{sty}]=10^{-7}\right)$, the $M_{\mathrm{w}}$ decreases to $1.9 \cdot 10^{5}$ $\mathrm{g} \cdot \mathrm{mol}^{-1}$. 

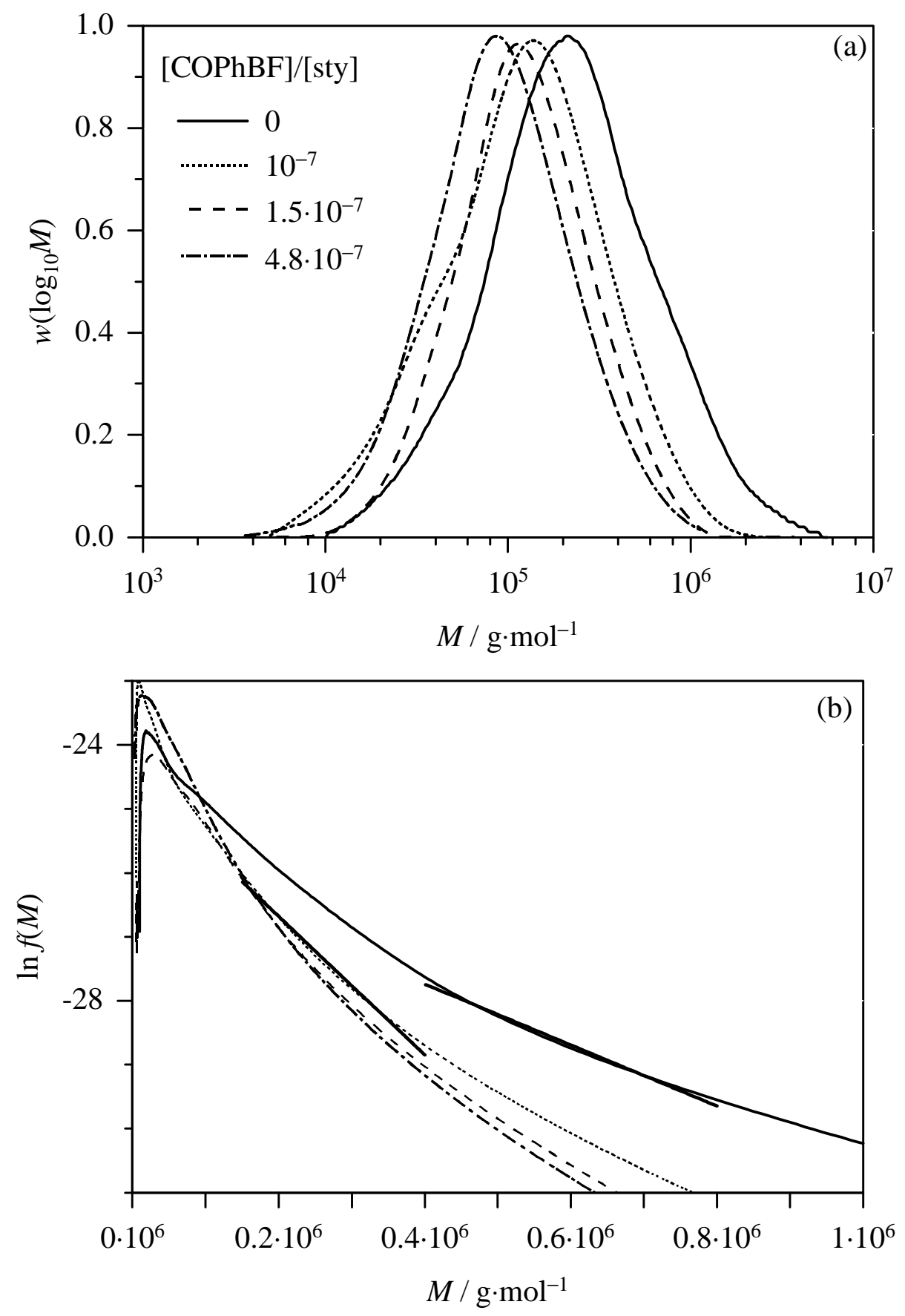

Figure 5.17: Molecular weight distributions (a) and corresponding $\ln f(M)$ vs. M plots $(b)$ of polystyrene from polymerizations in $40 \mathrm{wt} \% \mathrm{scCO} \mathrm{O}_{2}$ at $80^{\circ} \mathrm{C}$ and 300 bar and COPhBF concentration as indicated. The bold lines indicate the region where the slope is measured for [COPhBF $] /[$ styrene $]=0$ and $10^{-7}$.

As expected, the corresponding $\ln f(M)$ vs. $M$ plots (Fig. 5.17b) show that the slope increases with increasing the amount of the complex. Although the slopes represented by the bold lines seem to be not linear, correlation coefficients of 0.998 are obtained. This indicates that the 
slight curvature of the plot may not affect the determination of $C_{\mathrm{T}}$ (for comparison see section 4). The CLD plots for polymerizations in bulk and in $40 \mathrm{wt} \% \mathrm{scCO}_{2}$ at $80^{\circ} \mathrm{C}$ and 300 bar are pictured in Fig. 5.18.

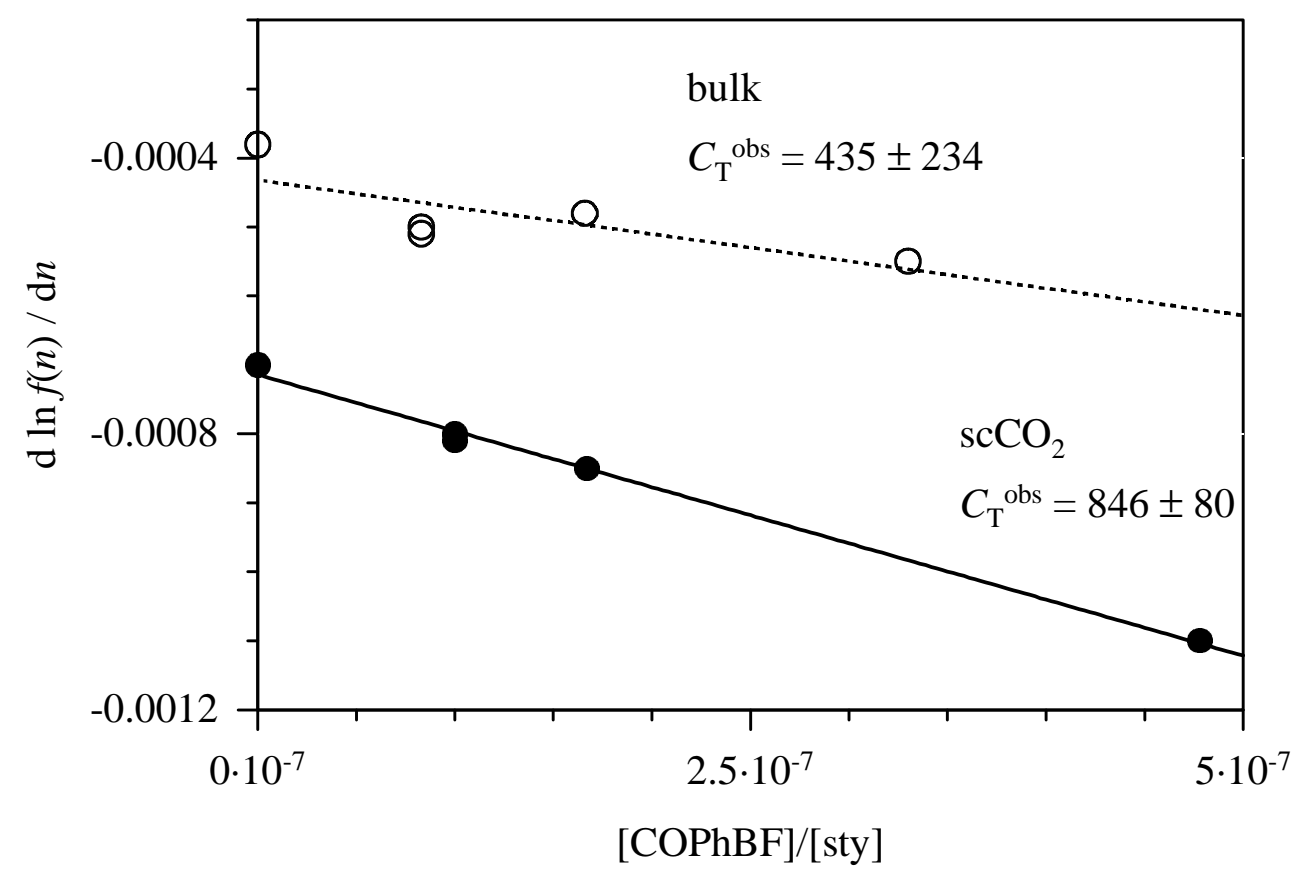

Figure 5.18: CLD plots for styrene homopolymerizations in $40 \mathrm{wt} \% \mathrm{scCO}_{2}$ (full circles) and in bulk (open circles) at $80^{\circ} \mathrm{C}$ and 300 bar.

The $C_{\mathrm{T}}{ }^{\text {obs }}$ values determined are $(846 \pm 80)$ and $(435 \pm 234)$ in $\mathrm{scCO}_{2}$ and in bulk, respectively. The influence of $\mathrm{scCO}_{2}$ on the chain-transfer activity of $\mathrm{COPhBF}$ is not obvious: The significant error calculated in bulk polymerization shows that $\mathrm{scCO}_{2}$ has probably a little influence in the $C_{\mathrm{T}}{ }^{\text {obs }}$ value.

\section{Pressure dependence of $k_{\mathrm{tr}}$ and $C_{\mathrm{T}}$}

The pressure dependence of $C_{\mathrm{T}}{ }^{\text {obs }}$ and ${k_{\mathrm{tr}}}^{\text {obs }}$ was determined varying the pressure between 300 and 1000 bar. The $k_{\mathrm{tr}}{ }^{\text {obs }}$ values were calculated from the experimental $C_{\mathrm{T}}{ }^{\text {obs }}$ values and the $k_{\mathrm{p}}$ values reported in the literature ${ }^{5,6}$ under the same conditions of pressure and temperature, which are listed in Appendix 1. Fig. 5.19 shows the pressure dependence of $C_{\mathrm{T}}{ }^{\text {obs }}$ and $k_{\mathrm{tr}}{ }^{\text {obs }}$ in styrene homopolymerizations at $80^{\circ} \mathrm{C}$. 

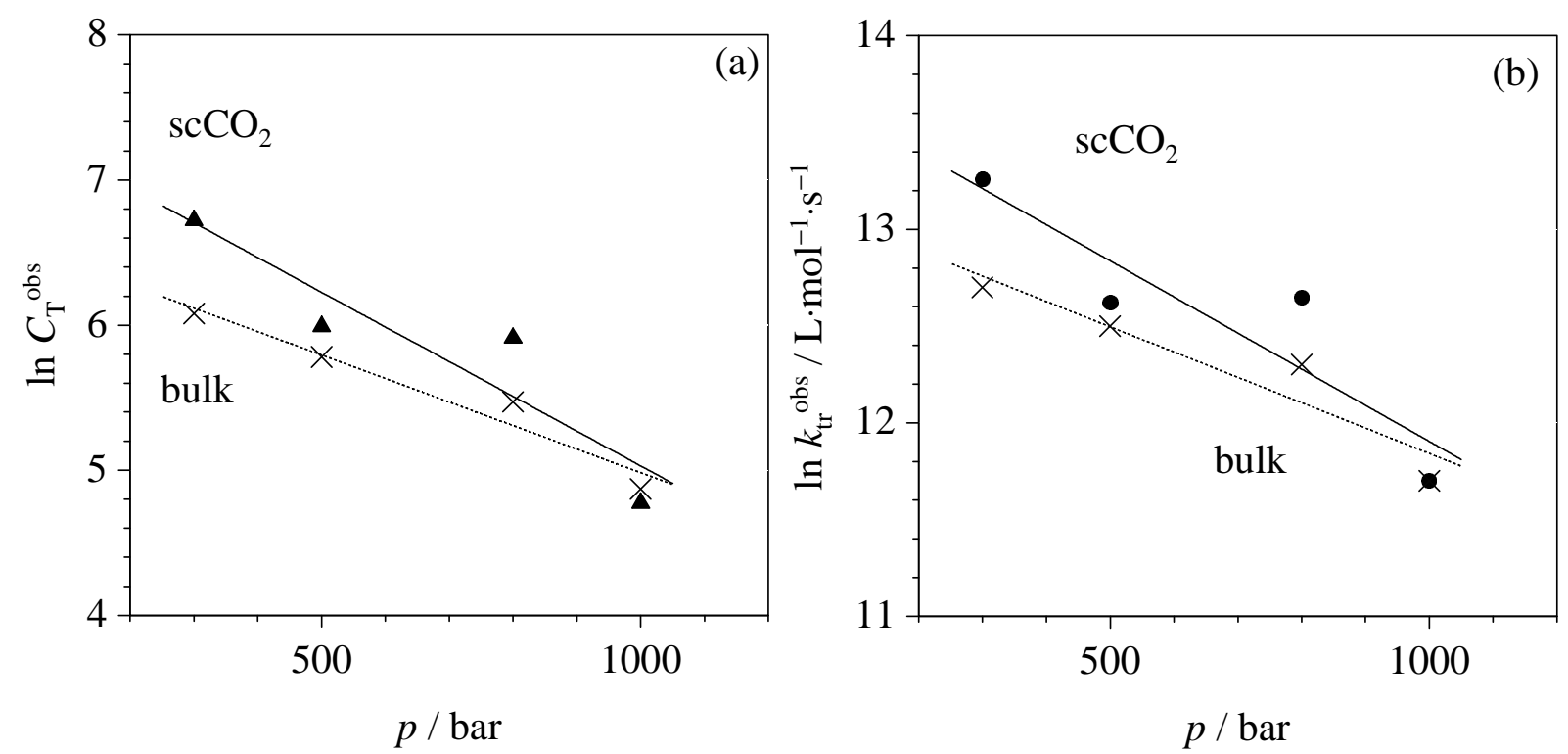

Figure 5.19: Pressure dependence of the chain-transfer constant (a) and the chain-transfer rate coefficient (b) for styrene homopolymerizations in bulk and in $40 \mathrm{wt} \%$ $\mathrm{CO}_{2}$ at $80^{\circ} \mathrm{C}$. Experimental data are listed in Appendix 3.

Fig. 5.19 shows a large scatter in the data, which is stronger in $\mathrm{scCO}_{2} . C_{\mathrm{T}}$ and $k_{\mathrm{tr}}$ decrease with increasing pressure in bulk and in $\mathrm{scCO}_{2}$. The values determined at 500 and 1000 bar are almost equivalent in bulk and in $\mathrm{scCO}_{2}$. In contrast, the values determined at 300 and 800 bar differ in both media. Nevertheless, considering the significant errors calculated in $C_{\mathrm{T}}{ }^{\text {obs }}$ and $k_{\mathrm{tr}}{ }^{\text {obs }}$, the values are close in both media in the entire pressure range which indicates that $C_{\mathrm{T}}$ and $k_{\mathrm{tr}}$ in styrene polymerization at 300 bar are not influenced by $\mathrm{scCO}_{2}$.

The pressure dependence of $C_{\mathrm{T}}{ }^{\text {obs }}$ and $k_{\mathrm{tr}}{ }^{\text {obs }}$ may be expressed by Eqs. 5.17-5.20:

$$
\begin{aligned}
& \ln C_{\mathrm{T}}{ }^{\text {obs }}=(6.60 \pm 0.18)-(1.62 \pm 0.52) \cdot 10^{-3}(p / \text { bar }) \\
& \ln \left[k_{\mathrm{tr}}{ }^{\mathrm{obs}} /\left(\mathrm{L} \cdot \mathrm{mol}^{-1} \cdot \mathrm{s}^{-1}\right)\right]=(13.2 \pm 0.2)-(1.31 \pm 0.33) \cdot 10^{-3}(p / \text { bar }) \\
& \text { (bulk, } 80^{\circ} \mathrm{C}, 300 \leq p \leq 1000 \text { bar) } \\
& \ln C_{\mathrm{T}}{ }^{\text {obs }}=(7.42 \pm 0.49)-(2.39 \pm 0.69) \cdot 10^{-3}(p / \text { bar }) \\
& \ln \left[k_{\mathrm{tr}}{ }^{\mathrm{obs}} /\left(\mathrm{L} \cdot \mathrm{mol}^{-1} \cdot \mathrm{s}^{-1}\right)\right]=(13.8 \pm 0.4)-(1.86 \pm 0.63) \cdot 10^{-3}(p / \text { bar }) \\
& \text { (40 wt } \% \mathrm{scCO}_{2}, 80^{\circ} \mathrm{C}, 300 \leq p \leq 1000 \text { bar) }
\end{aligned}
$$


The corresponding activation volumes in bulk and in $40 \mathrm{wt} \% \mathrm{scCO}_{2}$ are as follows:

bulk: $\quad \Delta V^{\#}\left(C_{\mathrm{T}}{ }^{\text {obs }}\right)=+(45.6 \pm 15.3) \mathrm{cm}^{3} \cdot \mathrm{mol}^{-1} \quad \Delta V^{\#}\left(k_{\mathrm{tr}}{ }^{\text {obs }}\right)=+(38.5 \pm 9.6) \mathrm{cm}^{3} \cdot \mathrm{mol}^{-1}$

$\operatorname{scCO}_{2}: \quad \Delta V^{\#}\left(C_{\mathrm{T}}{ }^{\mathrm{obs}}\right)=+(70.2 \pm 20.3) \mathrm{cm}^{3} \cdot \mathrm{mol}^{-1} \quad \Delta V^{\#}\left(k_{\mathrm{tr}}{ }^{\mathrm{obs}}\right)=+(54.6 \pm 18.4) \mathrm{cm}^{3} \cdot \mathrm{mol}^{-1}$

The above activation volumes for $C_{\mathrm{T}}{ }^{\text {obs }}$ and $k_{\mathrm{tr}}{ }^{\text {obs }}$ indicate a strong pressure dependence of the transfer reaction in both media. The activation volumes in bulk and in $\mathrm{scCO}_{2}$ are very close considering the uncertainty in $\Delta V^{\#}$. As seen in MMA polymerization, $\Delta V^{\#}$ for $k_{\mathrm{tr}}^{\text {obs }}$ is exceptionally high, as compared to the activation volume of the termination rate coefficient.

Eq. 5.17 is used to extrapolate $C_{\mathrm{T}}{ }^{\text {obs }}$ to ambient pressure at $80^{\circ} \mathrm{C}$. The value of 733 obtained is in very good agreement with the literature data ${ }^{12}$, ranging from 478 to 718 .

\subsubsection{Copolymerization of styrene and MMA}

Copolymerizations of styrene and MMA were investigated at $80^{\circ} \mathrm{C}$ and at pressures between 300 and 1000 bar.

The MWDs obtained for copolymers $\left(f_{\mathrm{S}}=0.2\right)$ in bulk and in $\mathrm{scCO}_{2}$ at $80^{\circ} \mathrm{C}$ and 300 bar are pictured in Fig. 5.20. The MWDs in bulk and in $\mathrm{scCO}_{2}$ are shifted to lower values with increasing $\mathrm{COPhBF}$ concentration. In addition, the MWDs in $\mathrm{scCO}_{2}$ are shifted to lower values compared to bulk MWDs. For example, the copolymerization performed with $8 \cdot 10^{-5}$ wt $\%$ of COPhBF (lowest CTA concentration in Fig. 5.20) generates $M_{\mathrm{w}}$ of $1.85 \cdot 10^{5} \mathrm{~g} \cdot \mathrm{mol}^{-1}$ and $5.7 \cdot 10^{4} \mathrm{~g} \cdot \mathrm{mol}^{-1}$ in bulk and in $\mathrm{scCO}_{2}$, respectively. This indicates that the transfer activity of $\mathrm{COPhBF}$ is strongly increased due to the presence of $\mathrm{scCO}_{2}$. 


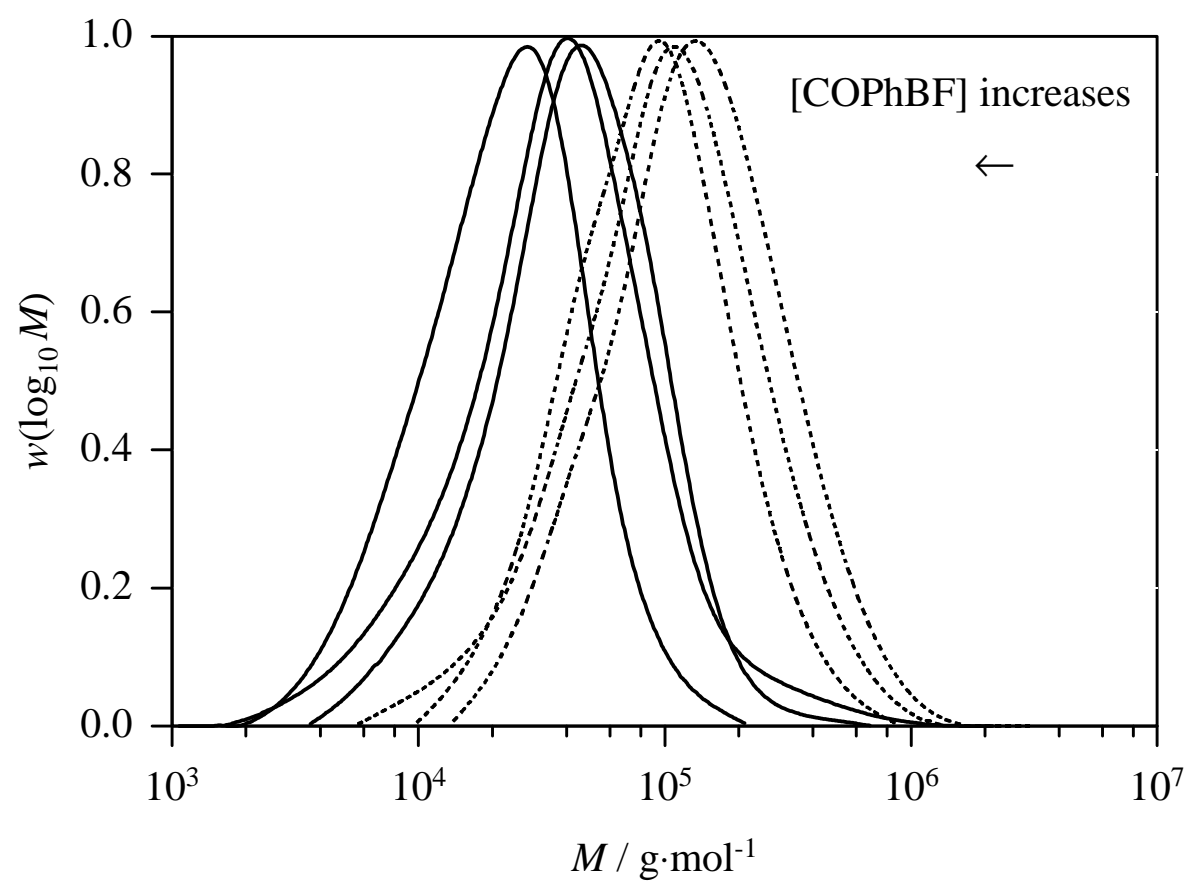

Figure 5.20: $\quad$ Molecular weight distributions of styrene-MMA copolymers $\left(f_{S}=0.2\right)$ obtained in $40 w t \% \mathrm{scCO}_{2}$ (full line) and in bulk (dotted line) at $80^{\circ} \mathrm{C}$ and $300 \mathrm{bar}$ varying the amount of $\mathrm{COPhBF}$. [COPhBF]/[M] range is from $1.5 \cdot 10^{-7}$ to $4.6 \cdot 10^{-7}$ and from $1.5 \cdot 10^{-7}$ to $5.8 \cdot 10^{-7}$ in bulk and in $\mathrm{scCO}_{2}$, respectively.

Fig. 5.21 summarizes the CLD plots obtained in styrene and MMA copolymerization with $f_{\mathrm{S}}=0.2,0.5$, and 0.8 , at $80^{\circ} \mathrm{C}, 300$ bar, in bulk and in $\mathrm{scCO}_{2}$. For copolymerization with $f_{\mathrm{S}}$ of 0.2 and 0.5 , the $C_{\mathrm{T}}{ }^{\text {obs }}$ values are approximately by a factor of 3 higher in $\mathrm{scCO}_{2}$ than in bulk, which indicates a strong effect on $C_{\mathrm{T}}{ }^{\text {obs }}$ of $\mathrm{scCO}_{2}$ as a solvent. In polymerizations with $f_{\mathrm{S}}=0.8$, the bulk data are very scattered and the $C_{\mathrm{T}}{ }^{\text {obs }}$ values are equivalent in both media, which indicates that $\mathrm{scCO}_{2}$ has no significant influence in $C_{\mathrm{T}}{ }^{\text {obs }}$. 

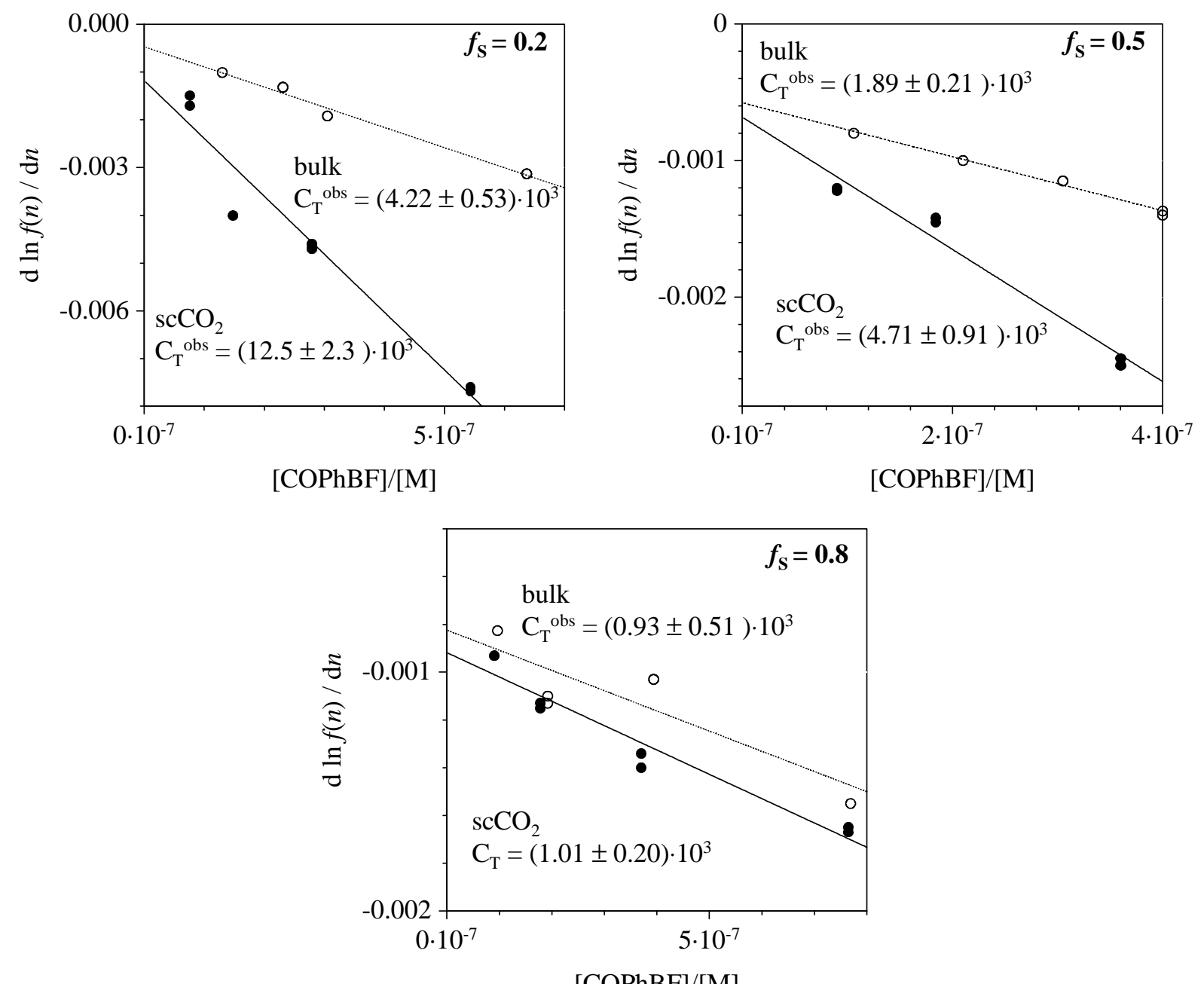

Figure 5.21: CLD plots for copolymerizations of styrene and MMA at $f_{S}$ of 0.2, 0.5, and 0.8, $80^{\circ} \mathrm{C}, 300 \mathrm{bar}$, in $40 \mathrm{wt} \% \mathrm{scCO}$ (full circles) and in bulk (open circles).

The variation of $C_{\mathrm{T}}{ }^{\text {obs }}$ with $f_{\mathrm{S}}$ for copolymerizations at $80^{\circ} \mathrm{C}, 300$ bar in bulk and in $\mathrm{scCO}_{2}$ is shown in Fig. 5.22. $C_{\mathrm{T}}{ }^{\text {obs }}$ decreases with increasing $f_{\mathrm{S}}$ in both media, which indicates that $C_{\mathrm{T}}{ }^{\text {obs }}$ in styrene polymerizations is lower than $C_{\mathrm{T}}{ }^{\text {obs }}$ in MMA polymerizations. Indeed, at 300 bar in both media $C_{\mathrm{T}, \mathrm{MMA}}{ }^{\text {obs }}$ is more than one order of magnitude higher than $C_{\mathrm{T}, \text { styrene }}{ }^{\text {obs }}$. The variation of $C_{\mathrm{T}}{ }^{\text {obs }}$ with $f_{\mathrm{S}}$ is different in bulk and in $\mathrm{scCO}_{2}: C_{\mathrm{T}}{ }^{\text {obs }}$ in bulk shows a stronger decrease compared to $C_{\mathrm{T}}{ }^{\text {obs }}$ in $\mathrm{scCO}_{2}$, when a little amount of styrene is added in the copolymerization. $C_{\mathrm{T}}{ }^{\text {obs }}$ in $\mathrm{scCO}_{2}$ are $2.11 \cdot 10^{4}$ and $1.25 \cdot 10^{4}$ at $f_{\mathrm{S}}=0$ and 0.2 , respectively, whereas $C_{\mathrm{T}}{ }^{\text {obs }}$ in bulk are $1.41 \cdot 10^{4}$ and $4.22 \cdot 10^{3}$ at $f_{\mathrm{S}}=0$ and 0.2 , respectively. At $f_{\mathrm{S}}=0.8$, $C_{\mathrm{T}}{ }^{\text {obs }}$ are equivalent in bulk and in $\mathrm{scCO}_{2}$. These findings and the preceding observations in the homopolymerizations suggest that at high $f_{\mathrm{S}}, C_{\mathrm{T}}{ }^{\text {obs }}$ are equivalent in bulk and in $\mathrm{scCO}_{2}$. 


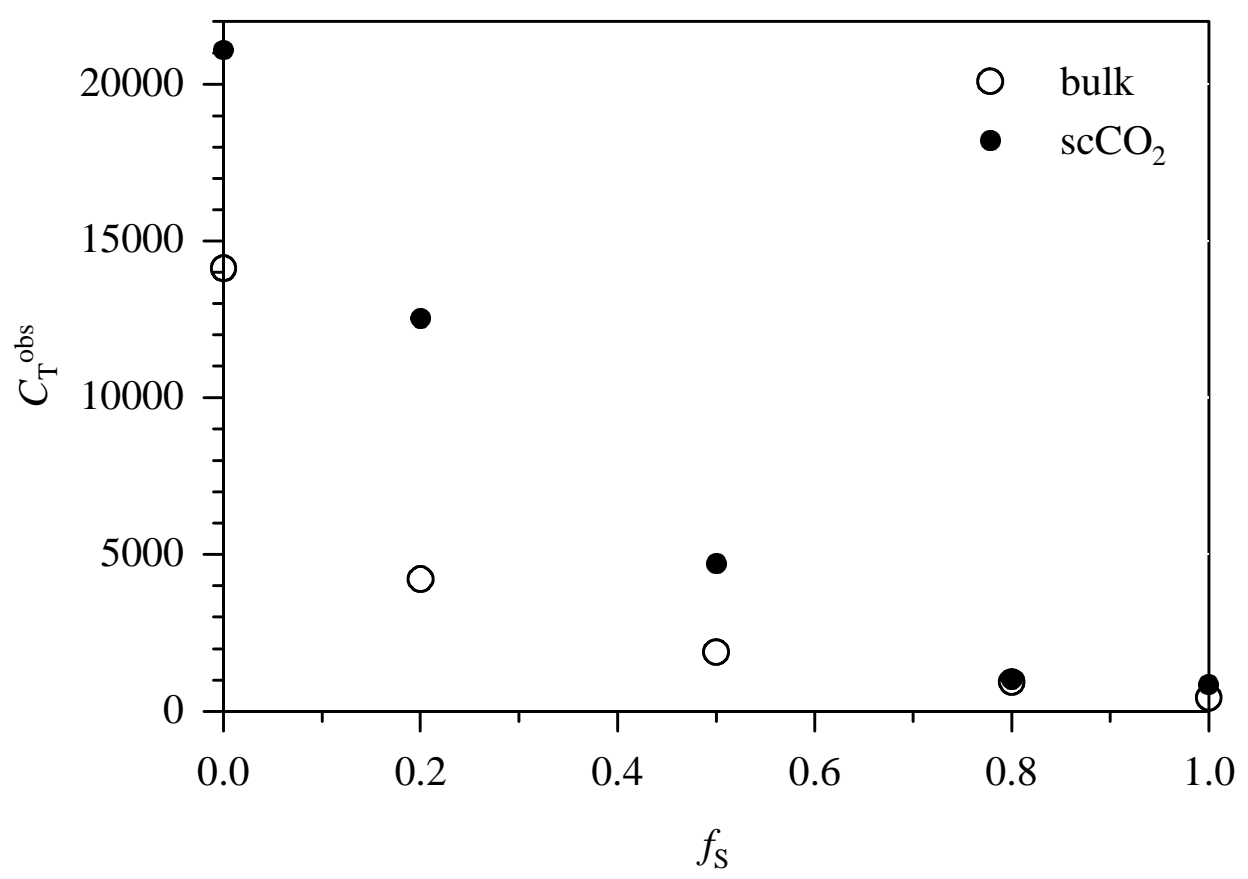

Figure 5.22: Variation of the chain-transfer constant with the mole fraction of styrene in the monomer feed for polymerization of styrene and MMA in bulk (open circles) and in $\mathrm{scCO}_{2}$ (full circles) at $80^{\circ} \mathrm{C}$ and 300 bar. The experimental data are listed in Appendix 3.

The next plot shows the comparison of the variation of $C_{\mathrm{T}}{ }^{\text {obs }}$ with $f_{\mathrm{S}}$ in bulk obtained in this work $\left(80^{\circ} \mathrm{C}\right.$ and 300 bar) and reported in literature ${ }^{9}\left(1\right.$ bar and $\left.40^{\circ} \mathrm{C}\right)$.

The variation of $C_{\mathrm{T}}{ }^{\text {obs }}$ with $f_{\mathrm{S}}$ is the same here and in the literature: $C_{\mathrm{T}}{ }^{\text {obs }}$ decreases with increasing $f_{\mathrm{S}}$. As already mentioned, literature reported that $C_{\mathrm{T}}{ }^{\text {obs }}$ is independent on the temperature in MMA homopolymerization ${ }^{14,15,16}$, whereas a decrease in $C_{\mathrm{T}}{ }^{\text {obs }}$ is observed when the temperature increases in styrene homopolymerization ${ }^{14} . C_{\mathrm{T}}{ }^{\text {obs }}$ reported at $40^{\circ} \mathrm{C}$ and 1 bar are slightly higher than $C_{\mathrm{T}}{ }^{\text {obs }}$ determined in this work at $80^{\circ} \mathrm{C}$ and 300 bar. It is obvious that $C_{\mathrm{T}}{ }^{\text {obs }}$ decreases with increasing pressure independently of the temperature. 


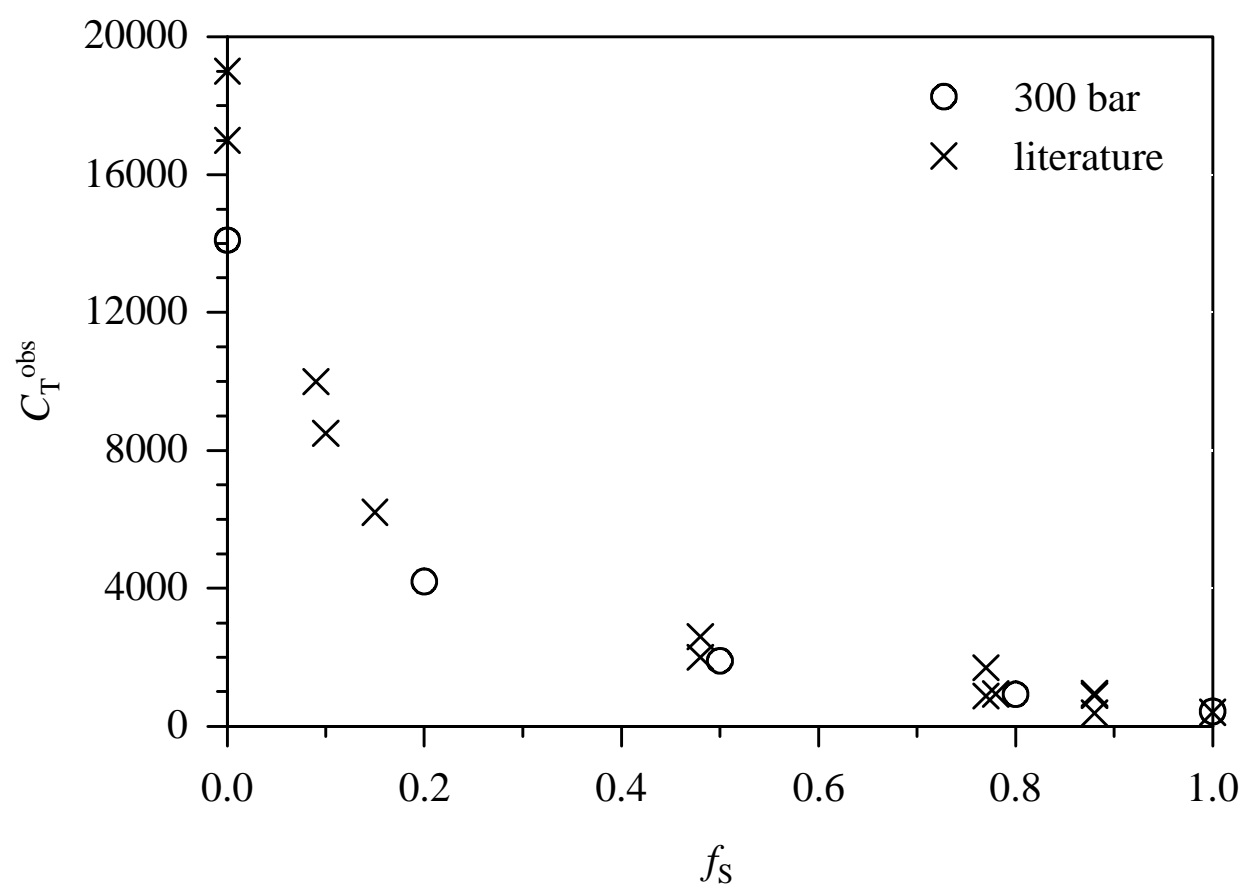

Figure 5.23: Dependence of the chain-transfer constant on the mole fraction of styrene in the monomer feed for copolymerizations in bulk at $80^{\circ} \mathrm{C}$ and 300 bar. The literature data measured in bulk at $40^{\circ} \mathrm{C}$ and 1 bar $(\times)$ are taken from ref. 9. Experimental data are listed in Appendix 3.

The corresponding $k_{\mathrm{tr}}{ }^{\text {obs }}$ values were obtained from $C_{\mathrm{T}}{ }^{\text {obs }}$ measured and the copolymerizations $k_{\mathrm{p}}$ data, listed in Appendix 1, which were obtained as explained in section 6. The variation of $\ln k_{\mathrm{tr}}{ }^{\text {obs }}$ with $f_{\mathrm{S}}$ is shown in Fig. 5.24: The left hand side (a) shows the variation of $k_{\mathrm{tr}}{ }^{\text {obs }}$ in bulk and in $\mathrm{scCO}_{2}$ and on the right hand side (b) $k_{\mathrm{tr}}{ }^{\text {obs }}$ obtained in bulk are compared with the literature data.

Fig. 5.24a clearly shows that $\ln k_{\text {tr }}^{\text {obs }}$ decreases linearly with increasing $f_{\mathrm{S}}$ in bulk and in $\mathrm{scCO}_{2}$. The lines fitted to the $k_{\mathrm{tr}}^{\text {obs }}$ data obtained in both media are parallel, which is also seen in Fig 5.24b. The variation of $\ln k_{\text {tr }}^{\text {obs }}$ with $f_{\mathrm{S}}$ is the same for the different systems, which indicates that the variation of $\ln k_{\mathrm{tr}}^{\text {obs }}$ with $f_{\mathrm{S}}$ is independent of the reaction conditions (pressure, temperature, and reaction medium). 

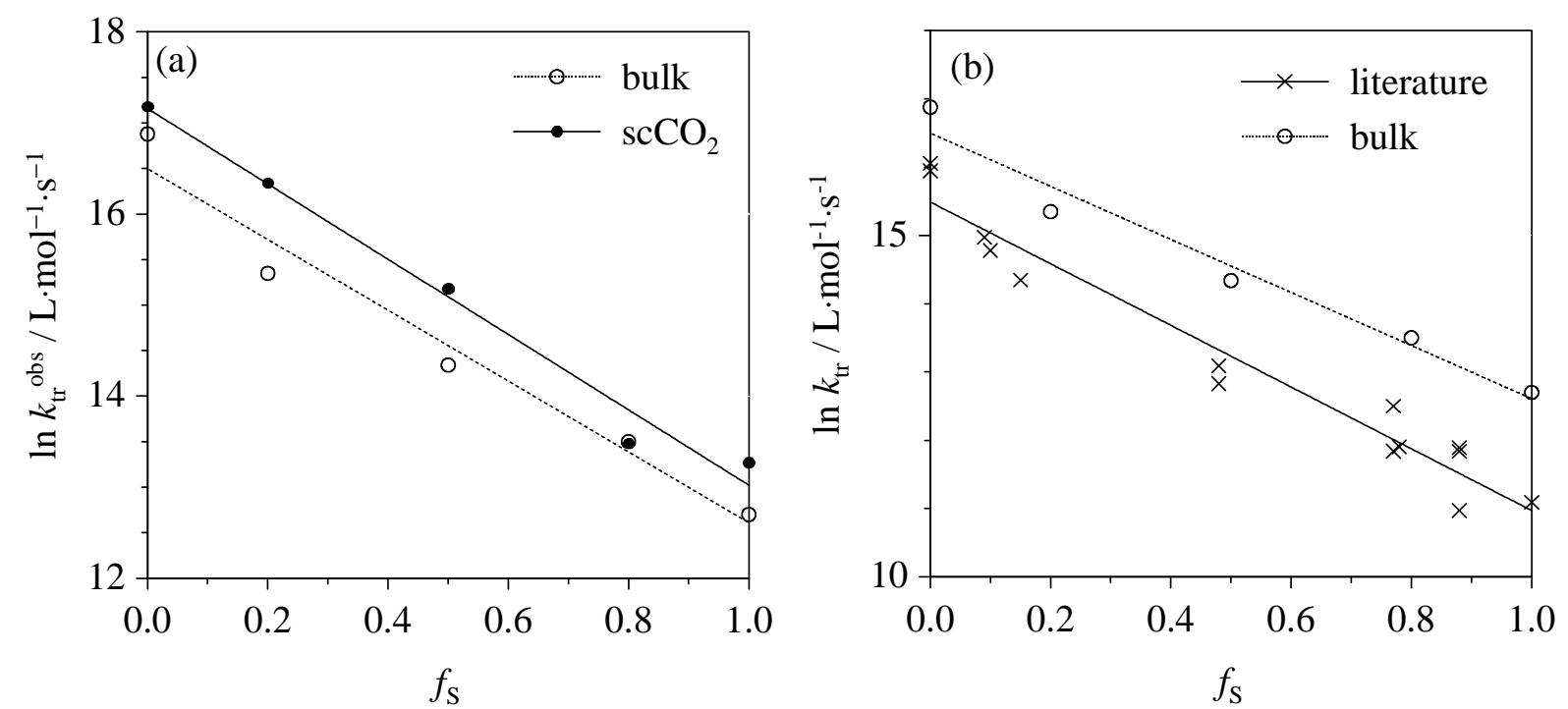

Figure 5.24: Variation of the chain-transfer rate coefficient with the mole fraction of styrene in the monomer feed for copolymerization of styrene and MMA in bulk (open circles) and in $40 \mathrm{wt} \% \mathrm{scCO}$ (full circles) at $80^{\circ} \mathrm{C}$ and $300 \mathrm{bar}$. The literature data $(\times)$ were calculated using the parameters $\left(C_{T}^{\text {obs }}\right.$ and $\left.k_{p}\right)$ determined in bulk at $40^{\circ} \mathrm{C}$ and 1 bar, which are listed in ref. 9. Experimental data are listed in Appendix 3.

As seen for MMA homopolymerizations, the $k_{\mathrm{tr}}$ values determined at $f_{\mathrm{S}}=0.2$ in $\mathrm{scCO}_{2}$ are very high in the range of $10^{7} \mathrm{~L} \cdot \mathrm{mol}^{-1} \cdot \mathrm{s}^{-1}$ and are similar in size to the rate coefficients obtained for bimolecular termination reactions in free-radical polymerizations, which are known to be diffusion-controlled ${ }^{17}$.

\section{Pressure dependence of $k_{\mathrm{tr}}$ and $C_{\mathrm{T}}$}

Fig. 5.25 shows the pressure dependence of ${C_{\mathrm{T}}}^{\text {obs }}$ and ${k_{\mathrm{tr}}}^{\text {obs }}$ for copolymerizations of styrene and MMA $\left(f_{\mathrm{S}}=0.5\right)$ in bulk and in $\mathrm{scCO}_{2}$ at $80^{\circ} \mathrm{C}$ and 300 bar. 

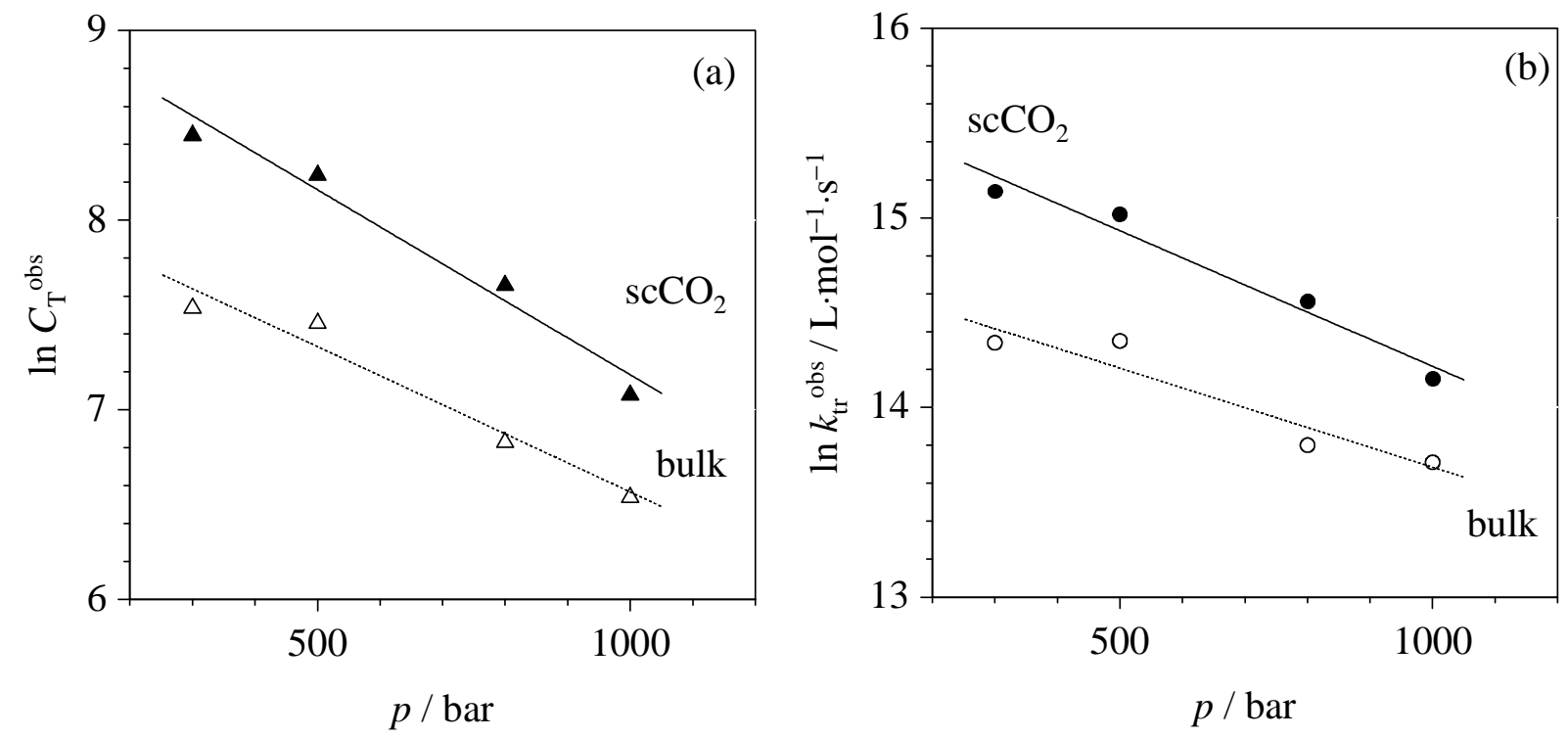

Figure 5.25: Pressure dependence of the chain-transfer rate constant (a) and of the chaintransfer rate coefficient (b) for copolymerizations of styrene and MMA $\left(f_{S}=\right.$ 0.5) at $80^{\circ} \mathrm{C}$. Experimental data are listed in Appendix 3.

$C_{\mathrm{T}}{ }^{\text {obs }}$ and $k_{\mathrm{tr}}{ }^{\text {obs }}$ decrease with increasing pressure in both media, which is slightly more pronounced in $\mathrm{scCO}_{2}$ than in bulk.

The pressure dependence of $C_{\mathrm{T}}$ and $k_{\text {tr }}$ may be expressed by Eqs 5.21-5.24.

$$
\begin{aligned}
& \ln C_{\mathrm{T}}{ }^{\text {obs }}=(8.10 \pm 0.15)-(1.53 \pm 0.44) \cdot 10^{-3}(p / \text { bar }) \\
& \ln \left[k_{\mathrm{tr}}{ }^{\mathrm{obs}} /\left(\mathrm{L} \cdot \mathrm{mol}^{-1} \cdot \mathrm{s}^{-1}\right)\right]=(14.7 \pm 0.2)-(1.02 \pm 0.23) \cdot 10^{-3}(p / \text { bar }) \\
& \text { (bulk, } f_{\mathrm{S}}=0.5,80^{\circ} \mathrm{C}, 300 \leq p \leq 1000 \mathrm{bar} \text { ) } \\
& \ln C_{\mathrm{T}}{ }^{\text {obs }}=(9.14 \pm 0.17)-(1.95 \pm 0.48) \cdot 10^{-3}(p / \text { bar }) \\
& \ln \left[k_{\mathrm{tr}}{ }^{\text {obs }} /\left(\mathrm{L} \cdot \mathrm{mol}^{-1} \cdot \mathrm{s}^{-1}\right)\right]=(15.6 \pm 0.1)-(1.43 \pm 0.19) \cdot 10^{-3}(p / \text { bar }) \\
& \text { (40 wt } \% \mathrm{scCO}_{2}, f_{\mathrm{S}}=0.5,80^{\circ} \mathrm{C}, 300 \leq p \leq 1000 \text { bar) }
\end{aligned}
$$

The corresponding activation volumes in $\mathrm{scCO}_{2}$ and in bulk are as follows:

$$
\begin{aligned}
& \text { bulk: } \quad \Delta V^{\#}\left(C_{\mathrm{T}}{ }^{\text {obs }}\right)=+(44.9 \pm 12.9) \mathrm{cm}^{3} \cdot \mathrm{mol}^{-1} \quad \Delta V^{\#}\left(k_{\mathrm{tr}}{ }^{\text {obs }}\right)=+(29.9 \pm 6.8) \mathrm{cm}^{3} \cdot \mathrm{mol}^{-1} \\
& \mathrm{scCO}_{2}: \quad \Delta V^{\#}\left(C_{\mathrm{T}}{ }^{\text {obs }}\right)=+(57.2 \pm 14.1) \mathrm{cm}^{3} \cdot \mathrm{mol}^{-1} \quad \Delta V^{\#}\left(k_{\mathrm{tr}}{ }^{\text {obs }}\right)=+(42.0 \pm 6.7) \mathrm{cm}^{3} \cdot \mathrm{mol}^{-1}
\end{aligned}
$$


The activation volumes for $C_{\mathrm{T}}^{\text {obs }}$ and ${k_{\mathrm{tr}}}^{\text {obs }}$ indicate a strong pressure dependence in bulk and in $\mathrm{scCO}_{2}$ as seen for the homopolymerization systems. Within experimental uncertainty, $\Delta V^{\#}\left(k_{\mathrm{tr}}{ }^{\text {obs }}\right)$ and $\Delta V^{\#}\left(C_{\mathrm{T}}{ }^{\text {obs }}\right)$ are similar in both media: In the range of +50 and $+35 \mathrm{~cm}^{3} \cdot \mathrm{mol}^{-1}$ for $C_{\mathrm{T}}{ }^{\text {obs }}$ and $k_{\mathrm{tr}}{ }^{\text {obs }}$, respectively. $C_{\mathrm{T}}{ }^{\text {obs }}$ is extrapolated to ambient pressure via Eq. 5.21 resulting in $C_{\mathrm{T}}{ }^{\text {obs }}=3.3 \cdot 10^{3}$, which is in very good agreement with the literature data of $3.3 \cdot 10^{3}$ reported at $40^{\circ} \mathrm{C}$ and $f_{\mathrm{S}}=0.48$.

\subsubsection{Closing remarks}

As mentioned before, the $C_{\mathrm{T}}{ }^{\text {obs }}$ data calculated are based on the reaction scheme 5.2, such as all the $C_{\mathrm{T}}{ }^{\text {obs }}$ values reported in the literature. However, recently a carbon-cobalt bond formation was directly measured in methyl acrylate polymerization ${ }^{18}$. The authors reported that this effect may be also seen in styrene homopolymerization. Thus, the $k_{\text {tr }}^{\text {obs }}$ values determined in this work in styrene and MMA copolymerizations and in styrene homopolymerization may be not accurate. $k_{\mathrm{tr}}^{\text {obs }}$ determined in these conditions may be underestimated as explained in more details in section 5.4.

The Table below summarizes the results obtained for homo- and copolymerization of MMA and styrene in bulk and in $\mathrm{scCO}_{2}$ at $80^{\circ} \mathrm{C}$ and 800 bar with $\mathrm{COPhBF}$ as catalytic chaintransfer agent. 


\section{MMA}

\begin{tabular}{|c|c|c|}
\hline & $C_{\mathrm{T}}{ }^{\text {obs }}$ & $k_{\text {tr }}^{\text {obs }}$ \\
\hline $\mathrm{scCO}_{2}$ & $(10.0 \pm 1.5) \cdot 10^{3}$ & $(18.6 \pm 4.5) \cdot 10^{6} \mathrm{~L} \cdot \mathrm{mol}^{-1} \cdot \mathrm{s}^{-1}$ \\
\hline bulk & $(5.01 \pm 8.30) \cdot 10^{3}$ & $(9.82 \pm 2.62) \cdot 10^{6} \mathrm{~L} \cdot \mathrm{mol}^{-1} \cdot \mathrm{s}^{-1}$ \\
\hline \multirow[t]{2}{*}{$\mathrm{scCO}_{2}$ influence } & influence in the & influence in the \\
\hline & entire pressure range & entire pressure range \\
\hline \multirow[t]{2}{*}{$\Delta V^{\#} / \mathrm{cm}^{3} \cdot \mathrm{mol}^{-1}$} & bulk: $+(68.7 \pm 23.5)$ & bulk: $+(47.5 \pm 15.8)$ \\
\hline & $\mathrm{scCO}_{2}:+(44.3 \pm 12.1)$ & $\mathrm{scCO}_{2}:+(31.5 \pm 7.3)$ \\
\hline \multicolumn{3}{|c|}{ styrene } \\
\hline & $C_{\mathrm{T}}^{\text {obs }}$ & $k_{\mathrm{tr}}^{\mathrm{obs}}$ \\
\hline $\mathrm{scCO}_{2}$ & $376 \pm 45$ & $(3.12 \pm 0.72) \cdot 10^{5} \mathrm{~L} \cdot \mathrm{mol}^{-1} \cdot \mathrm{s}^{-1}$ \\
\hline bulk & $237 \pm 15$ & $(2.19 \pm 0.36) \cdot 10^{5} \mathrm{~L} \cdot \mathrm{mol}^{-1} \cdot \mathrm{s}^{-1}$ \\
\hline \multirow[t]{2}{*}{$\mathrm{scCO}_{2}$ influence } & no influence in the & no influence in the \\
\hline & entire pressure range & entire pressure range \\
\hline \multirow[t]{2}{*}{$\Delta V^{\#} / \mathrm{cm}^{3} \cdot \mathrm{mol}^{-1}$} & bulk: $+(45.6 \pm 15.3)$ & bulk: $+(38.5 \pm 9.6)$ \\
\hline & $\mathrm{scCO}_{2}:+(70.2 \pm 20.3)$ & $s c \mathrm{CO}_{2}:+(54.6 \pm 18.4)$ \\
\hline
\end{tabular}

styrene / MMA $\left(f_{\mathrm{S}}=\mathbf{0 . 5}\right)$

\begin{tabular}{ccc}
\hline & $\boldsymbol{C}_{\mathbf{T}}{ }^{\text {obs }}$ & $\boldsymbol{k}_{\text {tr }}^{\text {obs }}$ \\
\hline bcCOlk & $(2.15 \pm 0.38) \cdot 10^{3}$ & $(21.1 \pm 6.3) \cdot 10^{5} \mathrm{~L} \cdot \mathrm{mol}^{-1} \cdot \mathrm{s}^{-1}$ \\
$\mathbf{s c C O}$ influence & $(0.93 \pm 0.08) \cdot 10^{3}$ & $(10.1 \pm 2.1) \cdot 10^{5} \mathrm{~L} \cdot \mathrm{mol}^{-1} \cdot \mathrm{s}^{-1}$ \\
& influence in the & influence in the \\
$\Delta \boldsymbol{V}^{\#} / \mathbf{c m}^{\mathbf{3}} \cdot \mathbf{m o l}^{-\mathbf{1}}$ & entire pressure range & entire pressure range \\
& bulk: $+(44.9 \pm 12.9)$ & bulk: $+(29.9 \pm 6.8)$ \\
\hline \hline
\end{tabular}




\subsection{MMA trimer as chain-transfer agent}

Methyl methacrylate macromonomers have recently become of importance as precursors to block $^{19,20}$, graft copolymers ${ }^{21}$, and as chain-transfer agents ${ }^{22,23}$. Currently there are data available on the chain-transfer constants of macromonomers only for few systems ${ }^{20,23,24,25}$. In addition, these investigations were only made at ambient pressure for bulk polymerizations. MMA macromonomers are usually prepared via catalytic chain-transfer polymerization, which is able to produce low molecular weight. The most favoured reaction of a macromonomer in a polymerization is the radical addition-fragmentation or $\beta$-scission reaction. Scheme 5.3 illustrates the transfer reaction of MMA trimer as chain-transfer agent in styrene (a) and MMA (b) polymerization. The first step is the addition of the radical chain to the macromonomer, which creates a macroradical. The second step of the chain-transfer reaction is a $\beta$-scission reaction of the macroradical, releasing a dead polymer and a new radical species derived from the macromonomer, which in turn can initiate residual monomer. Moad et al. ${ }^{23}$ performed a study with several MMA macromonomers of different chain length in MMA polymerization. The chain-transfer constant for MMA dimer has been reported to be one order of magnitude lower than MMA trimer (MMAt), whereas a little increase in $C_{\mathrm{T}}$ is seen as chain length increases to tetramer, pentamer, etc. In addition, the transfer constants showed only a small temperature dependence and no variation with conversion. In this work MMA trimer was chosen as CTA in MMA and styrene polymerizations performed at $80^{\circ} \mathrm{C}$. The fraction of MMA trimer, which was contained in the macromonomer mixture (dimer, trimer, tetramer, and pentamer) provided by DuPont Performance Coatings, was isolated by fractionated distillation under reduced pressure, as described in section 3.4.4. It has been seen that the distilled MMA trimer polymerizes after few days. Thus, all experiments with one monomer were carried out with the same MMA trimer fraction. After the homopolymerization studies, several distillations of the macromonomer mixture were performed. It was observed that MMA trimer polymerized immediately after the distillation. For this reason, the copolymerizations of styrene and MMA with MMA trimer as CTA are not investigated in this work. 
(a)<smiles>[M]CC(=CCCC)CC(CC(CCCCC)c1ccccc1)C(C)=O</smiles><smiles>[M]CC(CC(C)=O)CC(CCCCC)c1ccccc1</smiles>

(b)<smiles>[M]CC(=C)C(C)=[O+]C(C)(C)C(=O)OC(C)=O</smiles><smiles>[M]CC(CC(C)(C)C(=O)OC)CC(C)(CCCCC)C(C)=O</smiles><smiles>CC(=O)C(C)(C)CC(C)(C#[W])C(C)=O</smiles>

Scheme 5.3: Reaction scheme for the chain transfer of MMA trimer in homopolymerization of styrene (a) and MMA (b).

As mentioned before, the determination of $C_{\mathrm{T}}$ reported in the literature for macromonomers as CTAs were only investigated at ambient pressure in bulk polymerizations. Thus, in this work chain-transfer constants and chain-transfer rate coefficients of MMA trimer as CTA are 
determined in bulk and in 40 wt $\%$ solution of $\mathrm{scCO}_{2}$ in styrene and MMA homopolymerizations. The pressure dependencies of $C_{\mathrm{T}}$ and $k_{\text {tr }}$ are also investigated in both media since the pressure dependence has never been studied so far. The PLP technique is applied using a laser pulse repetition rate of $1 \mathrm{~Hz}$ and [DMPA] of $0.2 \mathrm{mmol} \cdot \mathrm{L}^{-1}$ (see section 4 for more details). The same range of MMA trimer concentration is used for both homopolymerizations.

The detailed discussion about MMA trimer as CTA in homopolymerizations of styrene and MMA is given in section 5.4.

\subsubsection{Homopolymerization of styrene}

Styrene homopolymerizations were carried out with MMA trimer as chain-transfer agent at $80^{\circ} \mathrm{C}$ in $40 \mathrm{wt} \% \mathrm{scCO}_{2}$ and in bulk, varying the pressure between 300 and 1500 bar.

The MWDs of PS obtained for polymerizations in $\mathrm{scCO}_{2}$ at $80^{\circ} \mathrm{C}, 300$ bar, and various amounts of MMA trimer are shown in Fig. 5.26.

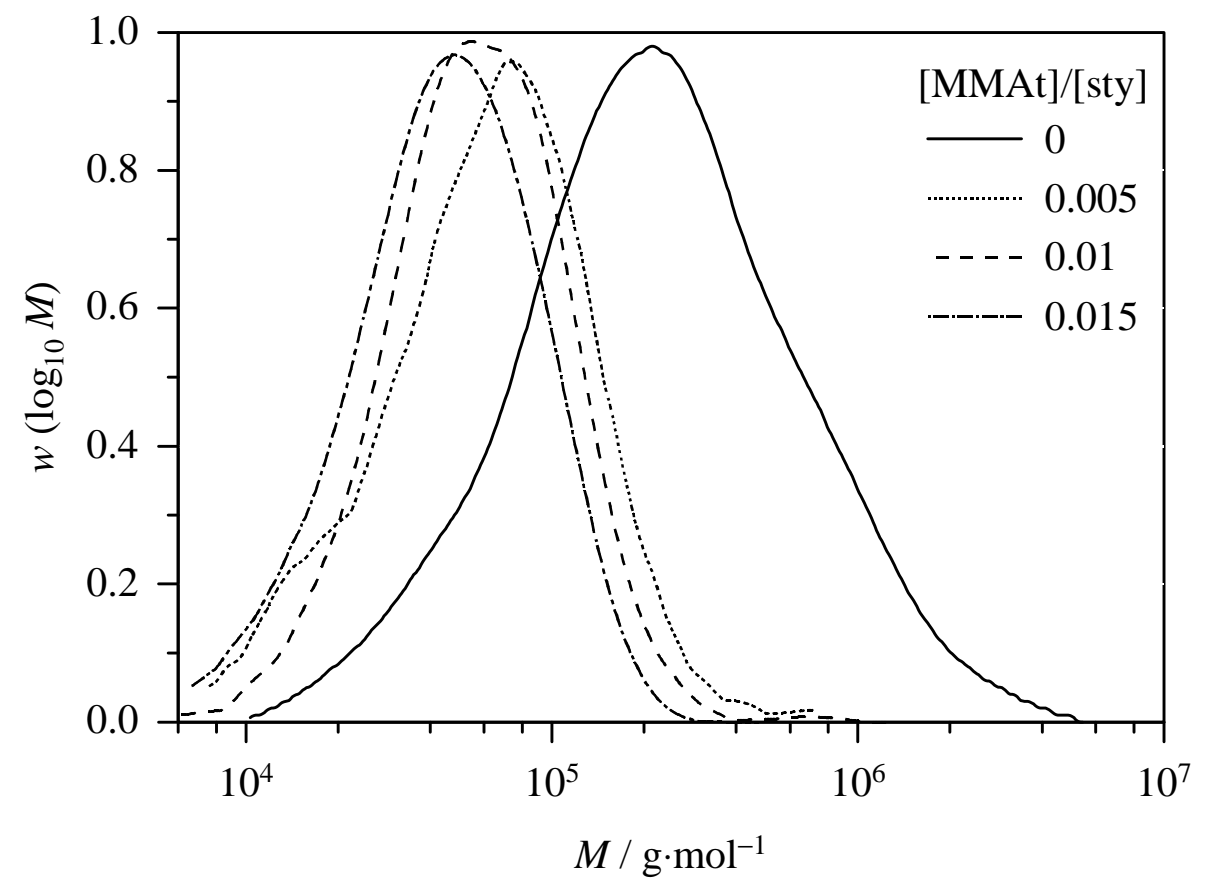

Figure 5.26: Molecular weight distributions of PS from polymerizations in 40 wt \% scCO at $80^{\circ} \mathrm{C}, 300 \mathrm{bar}$, and MMAt concentration as indicated.

The MWDs are shifted to lower molecular weights when the concentration of MMA trimer increases. In the absence of MMA trimer, the reaction yields polymer with a weight average 
molecular weight of $3.77 \cdot 10^{5} \mathrm{~g} \cdot \mathrm{mol}^{-1}$, and upon the addition of $1.5 \mathrm{wt} \%$ of MMA trimer ([MMAt] $/[$ sty $]=0.005) M_{\mathrm{w}}$ decreases to a value of $9.77 \cdot 10^{4} \mathrm{~g} \cdot \mathrm{mol}^{-1}$. Therefore, the addition of only a small amount of CTA leads to a shift of the MWD to lower values.

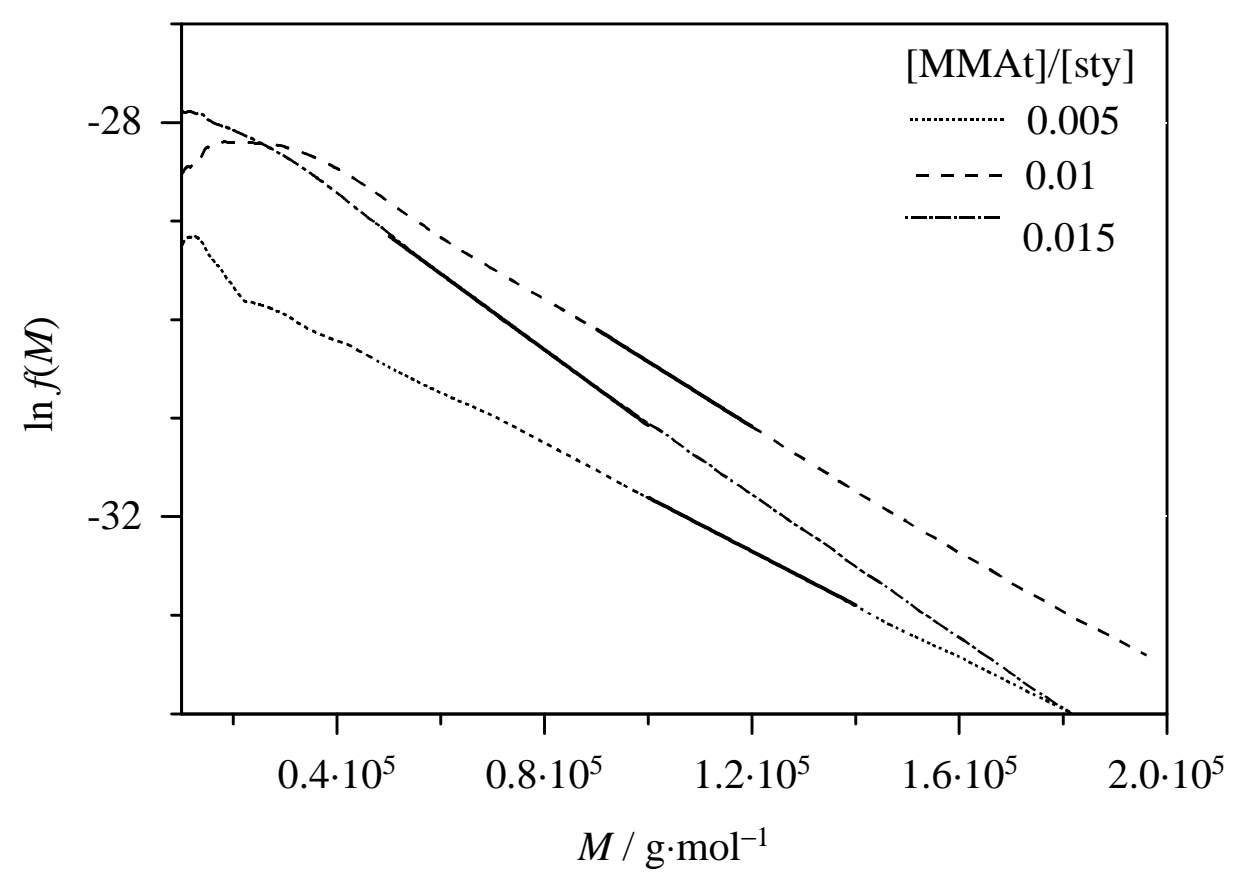

Figure 5.27: $\ln f(M)$ vs. $M$ plots of PS from polymerizations in $40 \mathrm{wt} \% \mathrm{scCO} \mathrm{O}_{2}$ at $80^{\circ} \mathrm{C}$ and 300 bar with MMAt-concentration as indicated. For more details see the text below.

The corresponding $\ln f(M)$ vs. $M$ plots are pictured in Fig. 5.27. The bold line indicates the MW range for which the slope has been determined. The slope increases with increasing MMA trimer concentration as expected. Fig. 5.28 shows the so called CLD plots for styrene homopolymerizations at $80^{\circ} \mathrm{C}$ and 300 bar in $\mathrm{scCO}_{2}$ and in bulk. The slopes, which give $-C_{\mathrm{T}}$, are slightly different and the values of $C_{\mathrm{T}}$ determined are $0.173 \pm 0.010$ and $0.208 \pm 0.024$ in bulk and in 40 wt $\% \mathrm{scCO}_{2}$, respectively. Within experimental uncertainty the chain-transfer constant obtained in $\mathrm{scCO}_{2}$ is close to the bulk value, which indicates no significant influence of $\mathrm{scCO}_{2}$ on the transfer activity of MMA trimer in styrene homopolymerization. 


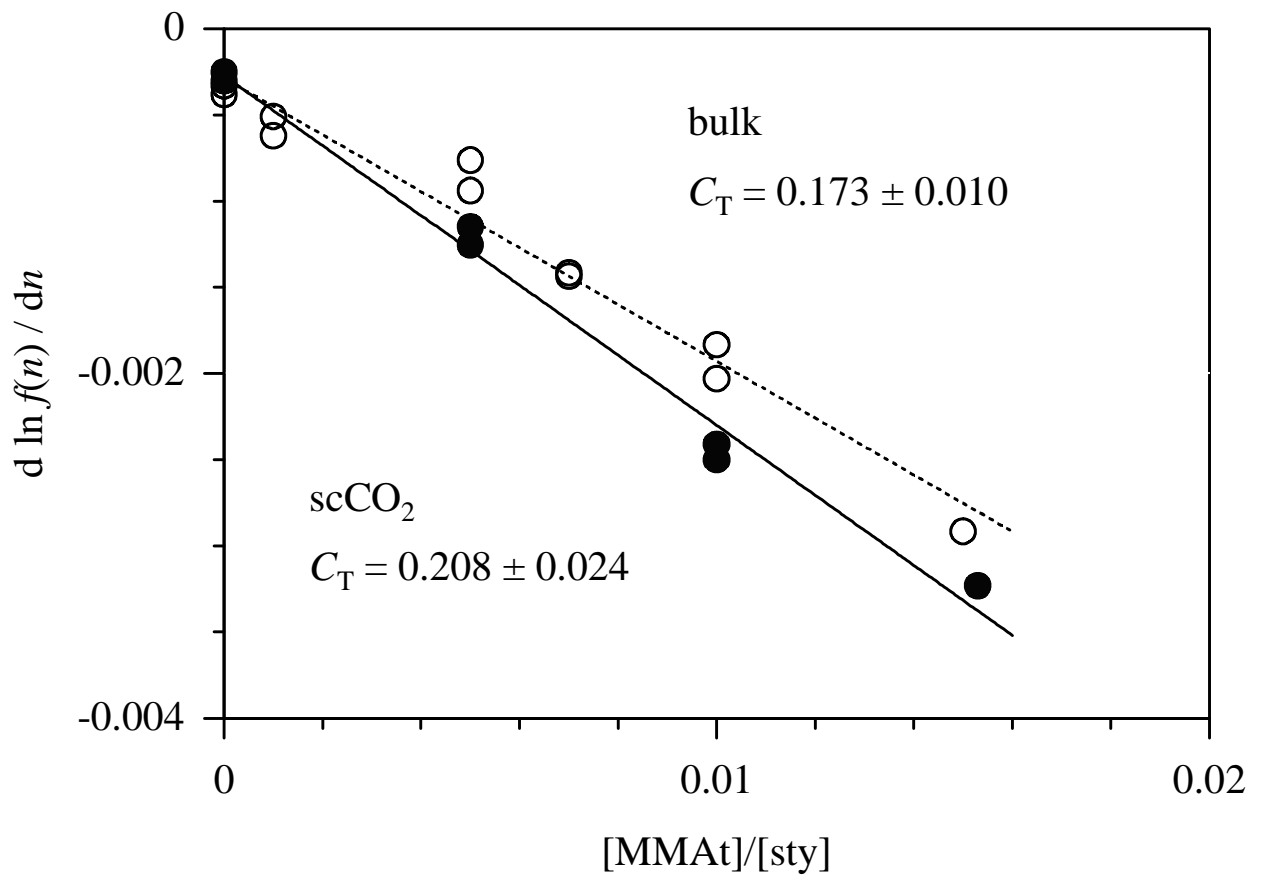

Figure 5.28: Determination of the chain-transfer constant from a plot of $d \ln f(n) / d n v s$. [MMAt]/[sty] for styrene homopolymerizations at $80^{\circ} \mathrm{C}, 300 \mathrm{bar}$, in $40 \mathrm{wt} \%$ $\mathrm{scCO}_{2}$ (solid line) and in bulk (dotted line).

\section{Pressure dependence of $C_{\mathrm{T}}$ and $\boldsymbol{k}_{\mathrm{tr}}$}

The pressure dependence of $C_{\mathrm{T}}$ and $k_{\mathrm{tr}}$ for the homopolymerization of styrene was studied at $80^{\circ} \mathrm{C}$ and pressures varying between 300 and 1500 bar $^{*}$. The corresponding chain-transfer rate coefficients were determined from the $C_{\mathrm{T}}$ values obtained in this study and the propagation rate coefficients reported in the literature ${ }^{5,6}$ under the same conditions of pressure and temperature. The $k_{\mathrm{p}}$ values used are listed in Appendix 1.

Fig. 5.29 shows the pressure dependencies of $C_{\mathrm{T}}$ (a) and $k_{\text {tr }}$ (b) for polymerizations at $80^{\circ} \mathrm{C}$ in $\mathrm{scCO}_{2}$ and in bulk. $C_{\mathrm{T}}$ and $k_{\text {tr }}$ decrease with increasing pressure in both media. It is shown that there is no significant difference in $C_{\mathrm{T}}$ and in $k_{\mathrm{tr}}$ in bulk and in $\mathrm{scCO}_{2}$ over the entire pressure range: The $C_{\mathrm{T}, \text { bulk }} / C_{\mathrm{T}, \mathrm{scCO} 2}$ values at 300 and 1500 bar are 0.83 and 0.93 , respectively.

\footnotetext{
* As already explained, MMA trimer polymerizes after few days and styrene polymerization could only be studied at three pressures with the same batch of MMA trimer.
} 

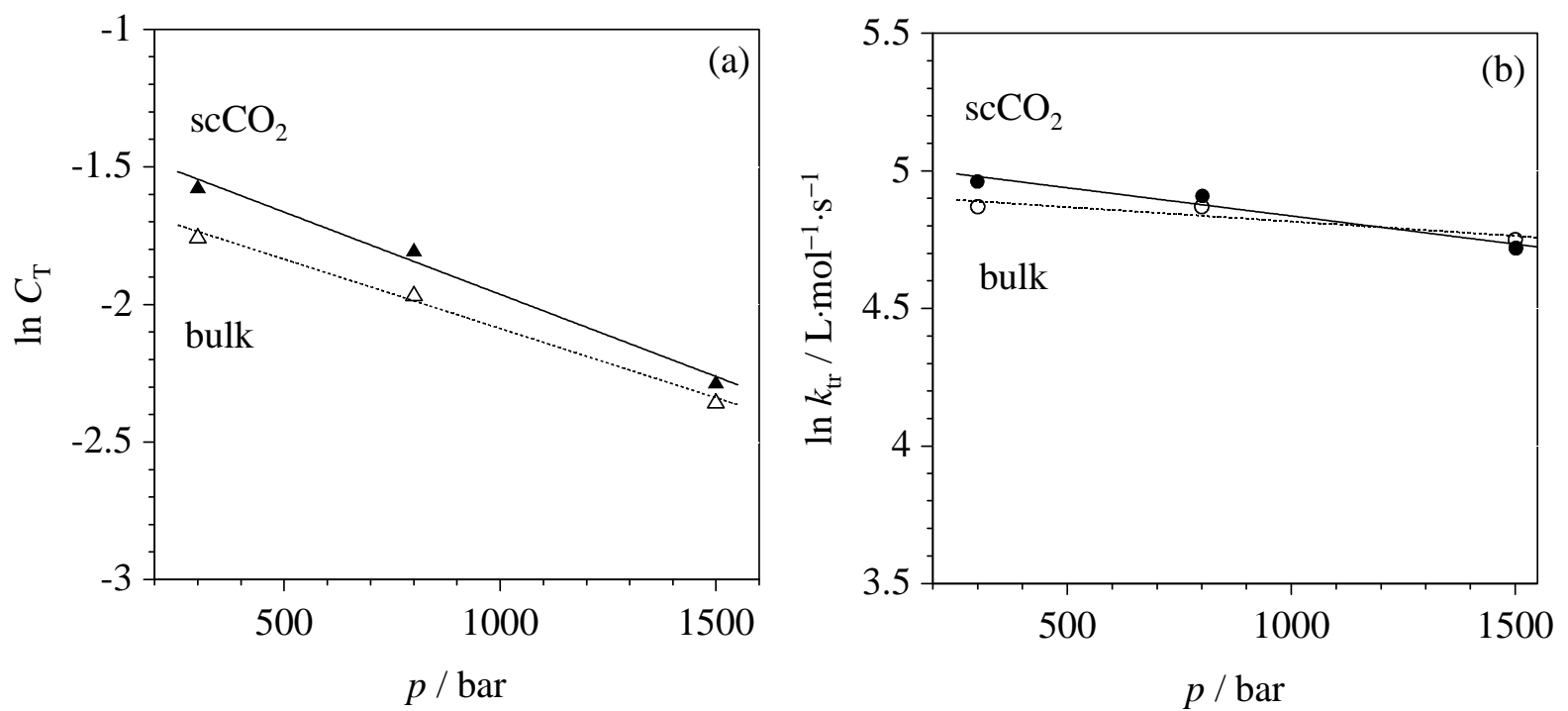

Figure 5.29: Pressure dependence of the chain-transfer constant (a) and of the chaintransfer rate coefficient (b) for styrene homopolymerizations at $80^{\circ} \mathrm{C}$ in $40 w t \% \mathrm{scCO}_{2}$ and in bulk. Experimental data are reported in Appendix 4.

Eqs. 5.25 to 5.28 correspond to the linear fits of the experimental data for $C_{\mathrm{T}}$ and $k_{\text {tr }}$ given in Fig. 5.29:

$$
\begin{aligned}
& \ln C_{\mathrm{T}}=-(1.58 \pm 0.47)-(5.05 \pm 1.64) \cdot 10^{-4}(p / \text { bar }) \\
& \ln \left[k_{\mathrm{tr}} /\left(\mathrm{L} \cdot \mathrm{mol}^{-1} \cdot \mathrm{s}^{-1}\right)\right]=(4.92 \pm 1.30)-(1.13 \pm 1.04) \cdot 10^{-4}(p / \text { bar }) \\
& \text { (bulk, } 80^{\circ} \mathrm{C}, 300 \leq p \leq 1500 \text { bar) } \\
& \ln C_{\mathrm{T}}=-(1.31 \pm 0.37)-(6.37 \pm 1.40) \cdot 10^{-4}(p / \text { bar }) \\
& \ln \left[k_{\mathrm{tr}} /\left(\mathrm{L} \cdot \mathrm{mol}^{-1} \cdot \mathrm{s}^{-1}\right)\right]=(5.03 \pm 1.62)-(1.97 \pm 1.6) \cdot 10^{-4}(p / \text { bar }) \\
& \text { (40 wt \% } \mathrm{scCO}_{2}, 80^{\circ} \mathrm{C}, 300 \leq p \leq 1500 \text { bar) }
\end{aligned}
$$

According to $\delta\left(\ln k_{\mathrm{tr}}\right) / \delta p=-\Delta V^{\#} /(\mathrm{R} \cdot T)$ and $\delta\left(\ln C_{\mathrm{T}}\right) / \delta p=-\Delta V^{\#} /(\mathrm{R} \cdot T)$, the activation volumes for $C_{\mathrm{T}}$ and $k_{\mathrm{tr}}$ are calculated as:

bulk: $\Delta V^{\#}\left(C_{\mathrm{T}}\right)=+(14.8 \pm 4.7) \mathrm{cm}^{3} \cdot \mathrm{mol}^{-1}$ $\Delta V^{\#}\left(k_{\mathrm{tr}}\right)=+(3.3 \pm 3.1) \mathrm{cm}^{3} \cdot \mathrm{mol}^{-1}$ $\mathrm{scCO}_{2}: \quad \Delta V^{\#}\left(C_{\mathrm{T}}\right)=+(18.7 \pm 4.1) \mathrm{cm}^{3} \cdot \mathrm{mol}^{-1} \quad \Delta V^{\#}\left(k_{\mathrm{tr}}\right)=+(5.8 \pm 4.7) \mathrm{cm}^{3} \cdot \mathrm{mol}^{-1}$ 
The values of $\Delta V^{\#}$ for $C_{\mathrm{T}}$ determined in $\mathrm{scCO}_{2}$ and in bulk indicate a significant pressure dependence, whereas no pressure dependence is seen for $k_{\mathrm{tr}}$. Considering the significant uncertainty determined in $\Delta V^{\#}, \Delta V^{\#}$ for $C_{\mathrm{T}}$ and $k_{\mathrm{tr}}$ in bulk are close to the corresponding values in $\mathrm{scCO}_{2}$. As these are the first data reported for styrene polymerization with MMA trimer as CTA, comparison with literature data is not possible.

\subsubsection{Homopolymerization of MMA}

MMA homopolymerizations were carried out at $80^{\circ} \mathrm{C}$ in 40 wt $\% \mathrm{scCO}_{2}$, in bulk and pressures varying between 300 and 1500 bar.

Fig. 5.30 shows typical molecular weight distribution of PMMA from polymerizations in $\mathrm{scCO}_{2}$ at $80^{\circ} \mathrm{C}$ and 300 bar with the indicated amount of MMA trimer. The MWDs are shifted to lower molecular weights with increasing CTA concentration. In the absence of MMA trimer, the reaction yields polymer with $M_{\mathrm{w}}$ of $5 \cdot 10^{5} \mathrm{~g} \cdot \mathrm{mol}^{-1}$, and upon addition of $3 \mathrm{wt} \%$ MMA trimer $([\mathrm{MMAt}] /[\mathrm{MMA}]=0.01) M_{\mathrm{w}}$ decreases to a value of $2.4 \cdot 10^{5} \mathrm{~g} \cdot \mathrm{mol}^{-1}$.

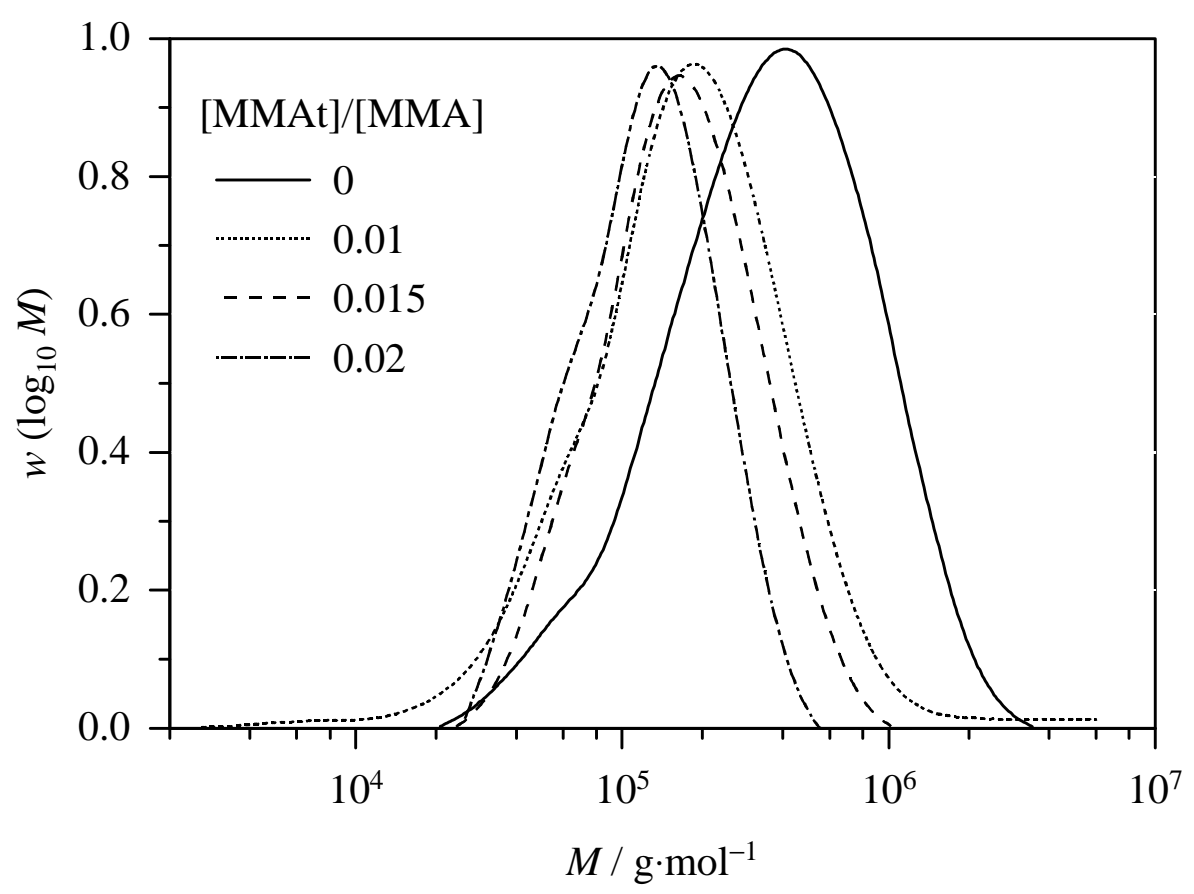

Figure 5.30: Molecular weight distributions of PMMA from polymerizations in 40 wt \% sc $\mathrm{CO}_{2}$ at $80^{\circ} \mathrm{C}, 300$ bar, and MMAt concentration as indicated. 
The corresponding $\ln f(M)$ vs. $M$ plots are pictured in Fig. 5.31. The part of the distribution used to calculate $C_{\mathrm{T}}$ is indicated by the bold lines. The slope of this MW region is enhanced with increasing [MMAt].

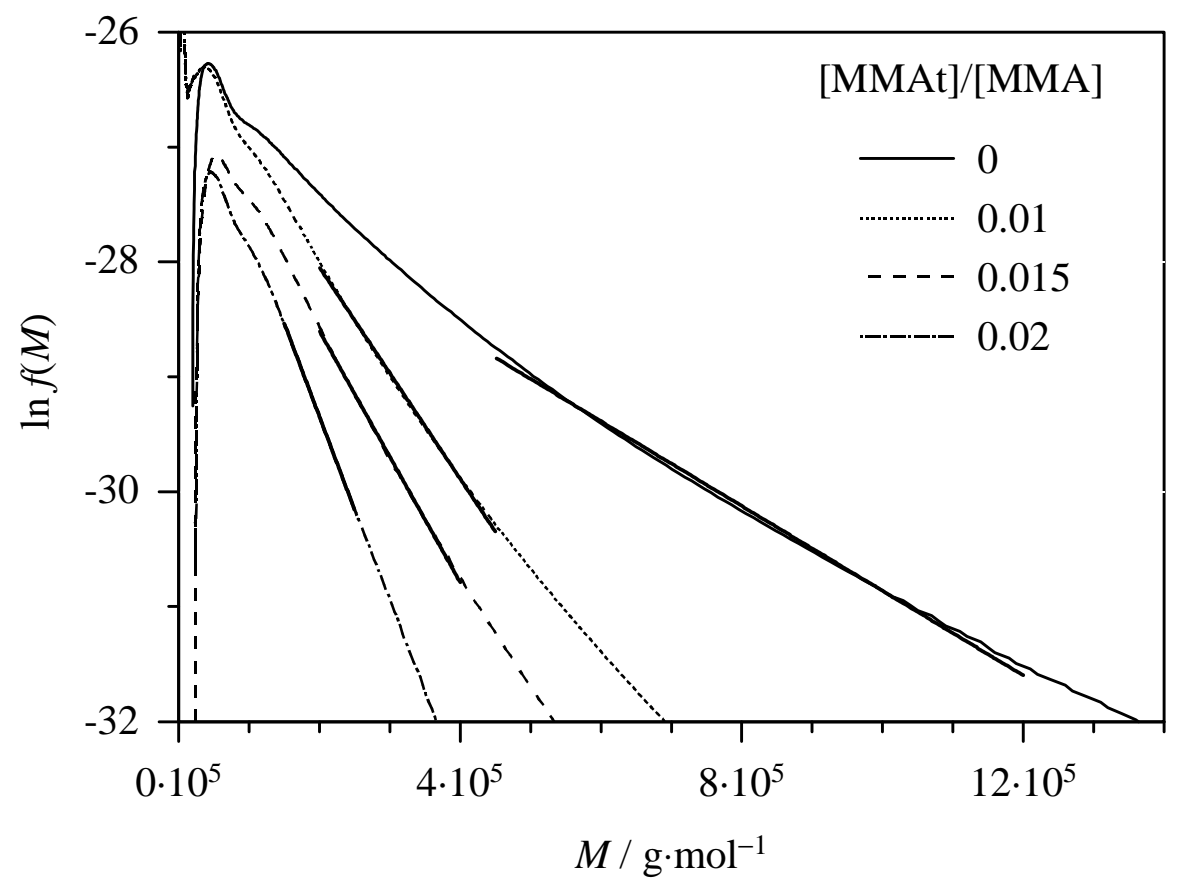

Figure. 5.31: In $f(M)$ vs. M plots for MMA homopolymerizations in 40 wt \% scCO at $80^{\circ} \mathrm{C}$ and 300 bar with MMAt concentration as indicated.

Fig. 5.32 exhibits the CLD plots of MMA homopolymerizations at $80^{\circ} \mathrm{C}$ and 300 bar in bulk and in $\mathrm{scCO}_{2}$.

The $C_{\mathrm{T}}$ values obtained in $\mathrm{scCO}_{2}$ and in bulk are 0.063 and 0.066 , respectively. It is obvious that both $C_{\mathrm{T}}$ are identical, which indicates that $\mathrm{scCO}_{2}$ as a solvent has no effect on the transfer activity of MMA trimer in MMA polymerization. 


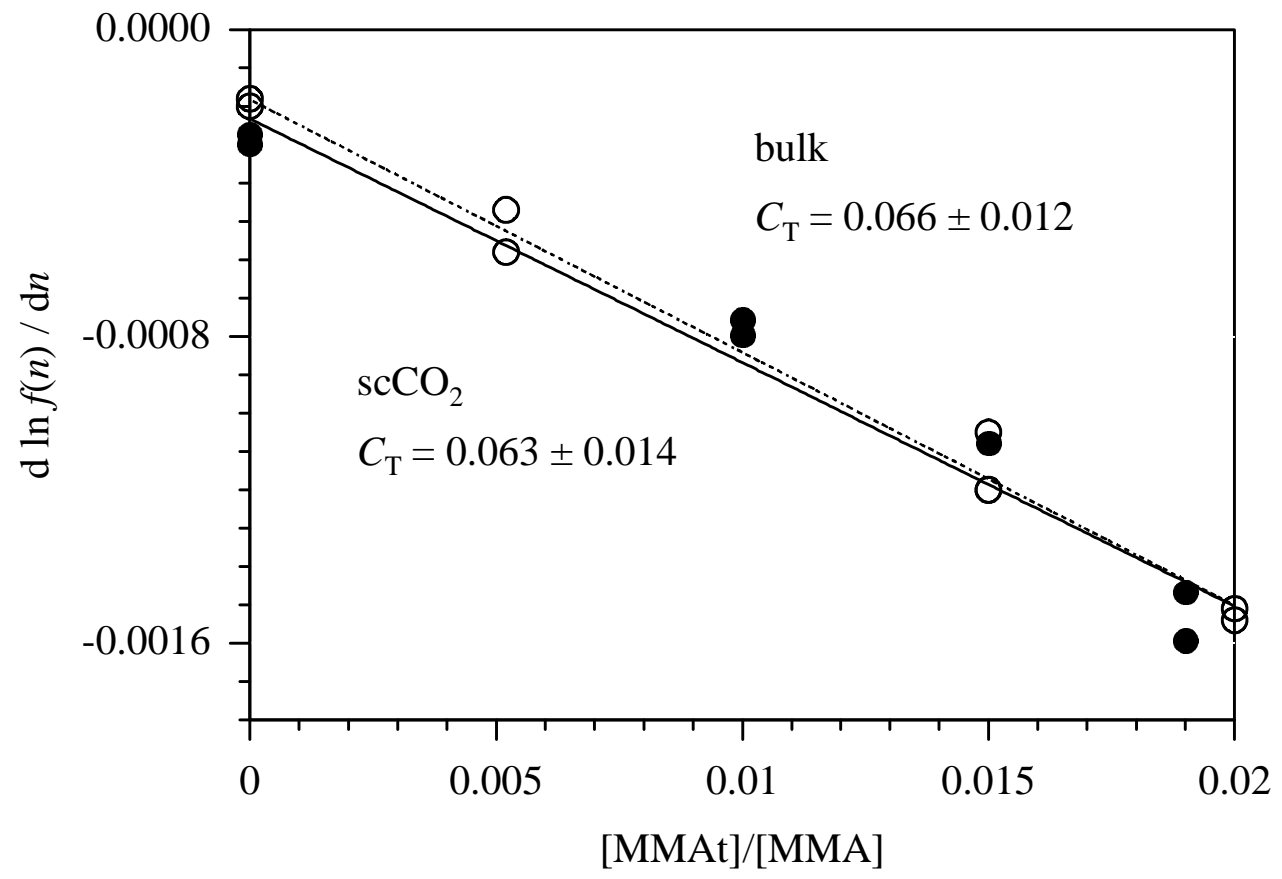

Figure 5.32: Determination of the chain-transfer constant from a plot of $d \ln f(n) / d n v s$. [MMAt]/MMA] for MMA homopolymerizations at $80^{\circ} \mathrm{C}, 300 \mathrm{bar}$, in 40 wt \% $\mathrm{scCO}_{2}$ (solid line) and in bulk (dotted line).

\section{Pressure dependence of $C_{\mathrm{T}}$ and $\boldsymbol{k}_{\mathrm{tr}}$}

The pressure dependence of $C_{\mathrm{T}}$ and $k_{\mathrm{tr}}$ for MMA homopolymerization was studied in a pressure range from 300 to 1500 bar. The values of $k_{\text {tr }}$ were calculated with $C_{\mathrm{T}}$ values and $k_{\mathrm{p}}$ data given in Appendix 1 (for comparison see section 5.1.2).

Fig. 5.33 shows the pressure dependence of $C_{\mathrm{T}}$ and $k_{\mathrm{tr}}$ for polymerizations in $\mathrm{scCO}_{2}$ and in bulk. In both media, $C_{\mathrm{T}}$ decreases with increasing pressure. It is obvious that $C_{\mathrm{T}}$ in $\mathrm{scCO}_{2}$ and in bulk are very close, which confirms that $\mathrm{scCO}_{2}$ has no influence on $C_{\mathrm{T}}$ in the entire pressure range. In contrast to $C_{\mathrm{T}}, k_{\mathrm{tr}}$ is enhanced with pressure as seen in Fig. $5.33 \mathrm{~b}$. $k_{\mathrm{tr}}$ values determined in $\mathrm{scCO}_{2}$ are slightly lower than in bulk. Nevertheless, within experimental uncertainty, $k_{\text {tr }}$ is close in both media. In addition, the $k_{\text {tr }}$ values determined in $\mathrm{scCO}_{2}$ are 87.3 and $113 \mathrm{~L} \cdot \mathrm{mol}^{-1} \cdot \mathrm{s}^{-1}$ at 300 and $1500 \mathrm{bar}$, respectively, which indicates a minor pressure dependence. The lines fitted to the $k_{\mathrm{tr}}$ data in both reaction media are parallel. 

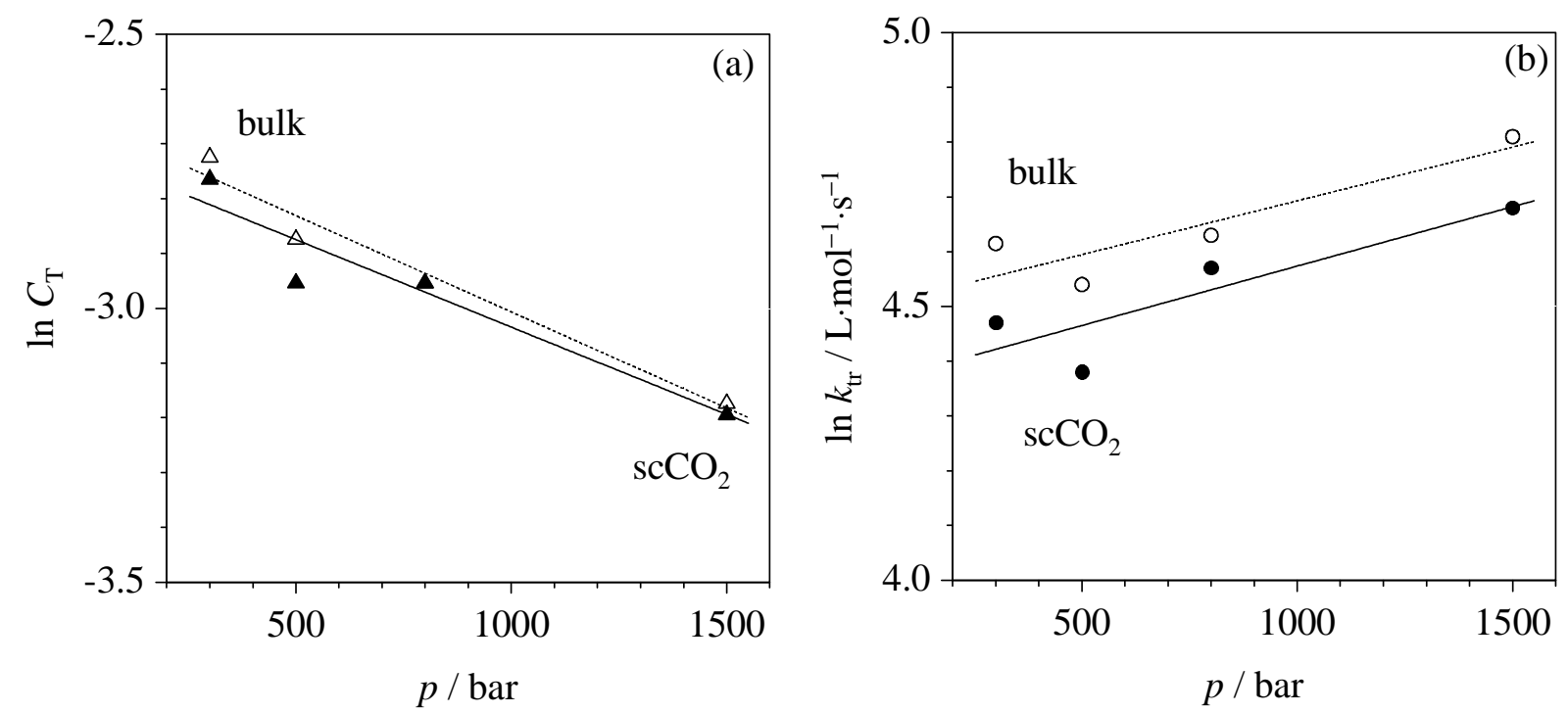

Figure 5.33: Pressure dependence of the chain-transfer constant (a) and of the chaintransfer rate coefficient (b) for MMA homopolymerizations in $40 \mathrm{wt} \% \mathrm{scCO}$ and in bulk at $80^{\circ} \mathrm{C}$. Experimental data are reported in Appendix 4.

The expressions for the pressure dependence of $C_{\mathrm{T}}$ and $k_{\mathrm{tr}}$ are given by Eqs. 5.29-5.32.

$$
\begin{aligned}
& \ln C_{\mathrm{T}}=-(2.66 \pm 0.04)-(3.51 \pm 0.92) \cdot 10^{-4}(p / \text { bar }) \\
& \ln \left[k_{\mathrm{tr}} /\left(\mathrm{L} \cdot \mathrm{mol}^{-1} \cdot \mathrm{s}^{-1}\right)\right]=(4.5 \pm 0.06)+(1.96 \pm 0.97) \cdot 10^{-4}(p / \text { bar }) \\
& \left(\text { bulk, } 80^{\circ} \mathrm{C}, 300 \leq p \leq 1500 \mathrm{bar}\right) \\
& \ln C_{\mathrm{T}}=-(2.72 \pm 0.06)-(3.19 \pm 1.43) \cdot 10^{-4}(p / \text { bar }) \\
& \ln \left[k_{\mathrm{tr}} /\left(\mathrm{L} \cdot \mathrm{mol}^{-1} \cdot \mathrm{s}^{-1}\right)\right]=(4.36 \pm 0.07)+(2.17 \pm 1.53) \cdot 10^{-4}(p / \text { bar }) \\
& \left(40 \mathrm{wt} \% \mathrm{scCO}_{2}, 80^{\circ} \mathrm{C}, 300 \leq p \leq 1500 \text { bar }\right) .
\end{aligned}
$$

The corresponding activation volumes are as follows:

bulk: $\quad \Delta V^{\#}\left(C_{\mathrm{T}}\right)=+(10.3 \pm 2.7) \mathrm{cm}^{3} \cdot \mathrm{mol}^{-1}$ $\Delta V^{\#}\left(k_{\mathrm{tr}}\right)=-(5.8 \pm 2.8) \mathrm{cm}^{3} \cdot \mathrm{mol}^{-1}$

$\mathrm{scCO}_{2}: \quad \Delta V^{\#}\left(C_{\mathrm{T}}\right)=+(9.4 \pm 4.2) \mathrm{cm}^{3} \cdot \mathrm{mol}^{-1}$ $\Delta V^{\#}\left(k_{\mathrm{tr}}\right)=-(6.4 \pm 4.3) \mathrm{cm}^{3} \cdot \mathrm{mol}^{-1}$

The values of $\Delta V^{\#}$ for $C_{\mathrm{T}}$ and $k_{\mathrm{tr}}$ show different trends, which were already observed in Fig. 5.33. The activation volumes for $C_{\mathrm{T}}$ in bulk and in $\mathrm{scCO}_{2}$ are approximately $+10 \mathrm{~cm}^{3} \cdot \mathrm{mol}^{-1}$, 
which shows a significant decrease in $C_{\mathrm{T}}$ with pressure. In contrast, the $\Delta V^{\#}$ values for $k_{\mathrm{tr}}$ in both media, which are around $-6 \mathrm{~cm}^{3} \cdot \mathrm{mol}^{-1}$, indicate a slight increase in $k_{\mathrm{tr}}$ with pressure.

The extrapolation of $C_{\mathrm{T}}$ in bulk to 1 bar via Eq. 5.29 gives a value of 0.07. Moad et al. ${ }^{20}$ reported a value of 0.188 in bulk at $80^{\circ} \mathrm{C}$ and 1 bar, which is higher than the $C_{\mathrm{T}}$ of this work. The SEC analysis of the isolated fraction used in this work showed traces of MMA dimer, which may influence the $C_{\mathrm{T}}$ values. As previously mentioned, the transfer activity of MMA dimer is lower than for MMA trimer. Therefore, the presence of MMA dimer in the CTA contributes to a lower value of $C_{\mathrm{T}}$ as expected for pure MMA trimer. In the literature a $C_{\mathrm{T}}$ value $^{20}$ of 0.015 is reported for MMA dimer as CTA. Thus $C_{\mathrm{T}}$ of 0.07 extrapolated from Eq. 5.29 is in between the $C_{\mathrm{T}}$ values for MMA dimer and MMA trimer.

\subsubsection{Summary}

The Table below summarizes the results obtained for MMA and styrene homopolymerizations in bulk and in $\mathrm{scCO}_{2}$ at $80^{\circ} \mathrm{C}$ with $\mathrm{MMA}$ trimer as chain-transfer agent. $C_{\mathrm{T}}$ and $k_{\mathrm{tr}}$ are given for polymerizations at $80^{\circ} \mathrm{C}$ and $800 \mathrm{bar}$. 


\begin{tabular}{|c|c|c|}
\hline \multicolumn{3}{|c|}{ MMA } \\
\hline & $C_{\mathbf{T}}$ & $k_{\mathrm{tr}}$ \\
\hline $\mathrm{scCO}_{2}$ & $0.052 \pm 0.002$ & $97.1 \pm 8.5 \mathrm{~L} \cdot \mathrm{mol}^{-1} \cdot \mathrm{s}^{-1}$ \\
\hline bulk & $0.053 \pm 0.002$ & $103 \pm 8 \mathrm{~L} \cdot \mathrm{mol}^{-1} \cdot \mathrm{s}^{-1}$ \\
\hline \multirow[t]{2}{*}{$\mathrm{scCO}_{2}$ influence } & no influence in the & no influence in the \\
\hline & entire pressure range & entire pressure range \\
\hline \multirow[t]{2}{*}{$\Delta V^{\#} / \mathbf{c m}^{3} \cdot \mathbf{m o l}^{-1}$} & bulk: $+(10.3 \pm 2.7)$ & bulk: $-(5.8 \pm 2.8)$ \\
\hline & $\mathrm{scCO}_{2}:+(9.4 \pm 4.2)$ & $s c \mathrm{CO}_{2}:-(6.4 \pm 4.3)$ \\
\hline \multicolumn{3}{|c|}{ styrene } \\
\hline & $C_{\mathrm{T}}$ & $k_{\mathrm{tr}}$ \\
\hline $\mathrm{scCO}_{2}$ & $0.165 \pm 0.011$ & $136 \pm 18 \mathrm{~L} \cdot \mathrm{mol}^{-1} \cdot \mathrm{s}^{-1}$ \\
\hline bulk & $0.141 \pm 0.009$ & $131 \pm 14 \mathrm{~L} \cdot \mathrm{mol}^{-1} \cdot \mathrm{s}^{-1}$ \\
\hline \multirow[t]{2}{*}{$\mathrm{scCO}_{2}$ influence } & no influence in the & no influence in the \\
\hline & entire pressure range & entire pressure range \\
\hline \multirow[t]{2}{*}{$\Delta V^{\#} / \mathrm{cm}^{3} \cdot \mathrm{mol}^{-1}$} & bulk: $+(14.8 \pm 4.7)$ & bulk: $+(3.3 \pm 3.1)$ \\
\hline & $s c C O_{2}:+(18.7 \pm 4.1)$ & $s c \mathrm{CO}_{2}:+(5.8 \pm 4.7)$ \\
\hline
\end{tabular}




\subsection{Discussions}

The experimental results presented in the preceding sections showed very different trends for $k_{\mathrm{tr}} \cdot k_{\mathrm{tr}}$ values obtained for polymerizations of MMA at $80^{\circ} \mathrm{C}$ and pressures varying between 300 and 1000 bar differ by orders of magnitude: Close to $10^{2}, 10^{3}$ and $10^{7} \mathrm{~L} \cdot \mathrm{mol}^{-1} \cdot \mathrm{s}^{-1}$ for the MMA trimer, for DDM and for COPhBF, respectively. The $\mathrm{scCO}_{2}$ influence on $k_{\mathrm{tr}}$ in MMA and styrene homo- and copolymerizations is dependent on the monomer-CTA system under consideration. As shown in the schemes 5.1, 5.2, and 5.3, the mechanisms of the transfer reaction are very different for the CTAs.

As mentioned in section 5.2, $C_{\mathrm{T}}{ }^{\text {obs }}$ and $k_{\mathrm{tr}}{ }^{\text {obs }}$ values determined in the presence of COPhBF in styrene-MMA homo- and copolymerizations are based on a direct abstraction of the hydrogen atom from the polymer radical by $\mathrm{COPhBF}$, as illustrated in scheme 5.2. Recently it has been suggested that this scheme may be not adequate for the transfer reaction with $\mathrm{COPhBF}$ in styrene polymerization ${ }^{10}$. The different reaction schemes proposed for the transfer process in styrene polymerization are presented in the following part. Implications on $C_{\mathrm{T}}$ and $k_{\mathrm{tr}}$ values are discussed in section 5.4.1.3.

The first part of the discussion deals with the mechanism of the chain-transfer reaction for the different CTAs, in order to explain the difference on $k_{\text {tr }}$ in styrene and MMA polymerizations. The second part deals with the $k_{\text {tr }}$ values obtained for the different systems, which are discussed in terms of pressure dependence and $\mathrm{scCO}_{2}$ influence.

\subsubsection{Mechanism of the chain-transfer reaction}

The table below summarizes the $k_{\mathrm{tr}}$ values $\left(\mathrm{L} \cdot \mathrm{mol}^{-1} \cdot \mathrm{s}^{-1}\right)$ obtained in styrene and MMA homoand copolymerization in $\mathrm{scCO}_{2}$ at $80^{\circ} \mathrm{C}$ and 300 bar.

\begin{tabular}{cccc}
\hline$f_{\mathrm{S}}$ & $10^{-3} \cdot k_{\mathrm{tr}, \mathrm{DDM}}$ & $10^{-5} \cdot k_{\mathrm{tr}, \mathrm{COPhBF}}{ }^{\mathrm{obs}}$ & $k_{\mathrm{tr}, \mathrm{MMAt}}$ \\
\hline 0 & $1.14 \pm 0.25$ & $292 \pm 100$ & $87.3 \pm 14.1$ \\
\hline 0.5 & $3.03 \pm 0.62$ & $37.6 \pm 12.1$ & - \\
\hline 1 & $11.2 \pm 2.1$ & $5.79 \pm 1.18$ & $142 \pm 23$ \\
\hline
\end{tabular}




\subsubsection{DDM}

The $k_{\mathrm{tr}}$ values, in the range from $10^{3}$ to $10^{4} \mathrm{~L} \cdot \mathrm{mol}^{-1} \cdot \mathrm{s}^{-1}$, obtained in MMA and styrene polymerizations with DDM indicate a good transfer activity. The $C_{\mathrm{T}}$ values of 0.771 and 15.5 extrapolated or obtained at $80^{\circ} \mathrm{C}$ and ambient pressure in MMA and styrene bulk homopolymerizations, respectively, are in very good agreement with the literature data: Hutchinson et al. ${ }^{1}$ reported $C_{\mathrm{T}}$ values of 0.711 and 15.6 in MMA and styrene homopolymerizations, respectively, under the same experimental conditions.

As described in scheme 5.1, the transfer reaction of DDM with a growing radical is composed of two steps: the abstraction of a hydrogen atom of DDM by the polymer radical and the addition of the thiyl radical formed with a monomer molecule. The hydrogen abstraction is the rate-determining step in the transfer process with DDM since it creates the polymer.

Styryl radicals are known to be very $\operatorname{stable}^{26}$, which induces a very low propagation rate coefficient compared to methacrylates and acrylates monomers, e.g. at 300 bar and $80^{\circ} \mathrm{C}$ in bulk $k_{\mathrm{p}}$ for styrene is $763 \mathrm{~L} \cdot \mathrm{mol}^{-1} \cdot \mathrm{s}^{-1}$ and for MMA is $1540 \mathrm{~L} \cdot \mathrm{mol}^{-1} \cdot \mathrm{s}^{-1}$. If the reactivity of the styryl or methacrylic radical is the determining factor for the transfer rate, it is expected that the transfer reaction of DDM with styryl radicals should be slower than the transfer reaction with methacrylic radicals. However, the experimental results have shown that the hydrogen abstraction is clearly more difficult with methacrylic radicals, which are hindered due to the $\alpha$-methyl group. Thus, it seems that not only the polymer radical reactivity determines the rate of the hydrogen abstraction. Interactions between DDM and polymer radicals may influence the rate of the transfer reaction. In addition, as styryl radicals propagate more slowly than methacrylic radicals, those are more prone to possible side reactions.

Tronche et al. ${ }^{27}$ have shown that the rate of a hydrogen abstraction of octadecanethiol by a radical decreases by one order of magnitude when the radical contains polar substituents. An extreme example ${ }^{28}$ for this polar effect is the reaction of a perfluoroalkyl radical with phenylthiol which is a factor of 500 less rapid than reaction of an alkyl radical. A styryl radical, which is obviously less polar than a methacrylic radical, is thus supposed to abstract more rapidly the hydrogen atom of DDM than a methacrylic radical. This observation is consistent with the results of this work, thus the polarity of the monomer seems to be an important factor in the transfer process of DDM. 


\subsubsection{MMA trimer}

The mechanism of the transfer reaction of a macromonomer with a vinyl monomer is illustrated in scheme 5.3. Since chain transfer occurs via an addition-fragmentation mechanism, $k_{\text {tr }}$ is composed of $k_{\text {add }}$ and $k_{\beta}$, which are the addition and the $\beta$-scission rate coefficients, respectively. For efficient chain-transfer to occur it is important that the lifetime of the intermediate macroradical is short with respect to the lifetime of a propagating species. Moad et al. ${ }^{23}$ found that there is no retardation in MMA polymerization carried out in the presence of macromonomers CTAs compared to experiments without CTA. They concluded that fragmentation is fast relative to addition. $k_{\mathrm{tr}}$ is thus determined by the reactivity of the MMA trimer double bond towards the addition of a propagating radical in MMA homopolymerization. In styrene homopolymerization it has been shown that a competition between fragmentation and copolymerization of the macroradical formed after addition of the styrene radical may occur in some cases ${ }^{29}$, as illustrated in scheme 5.4 below.
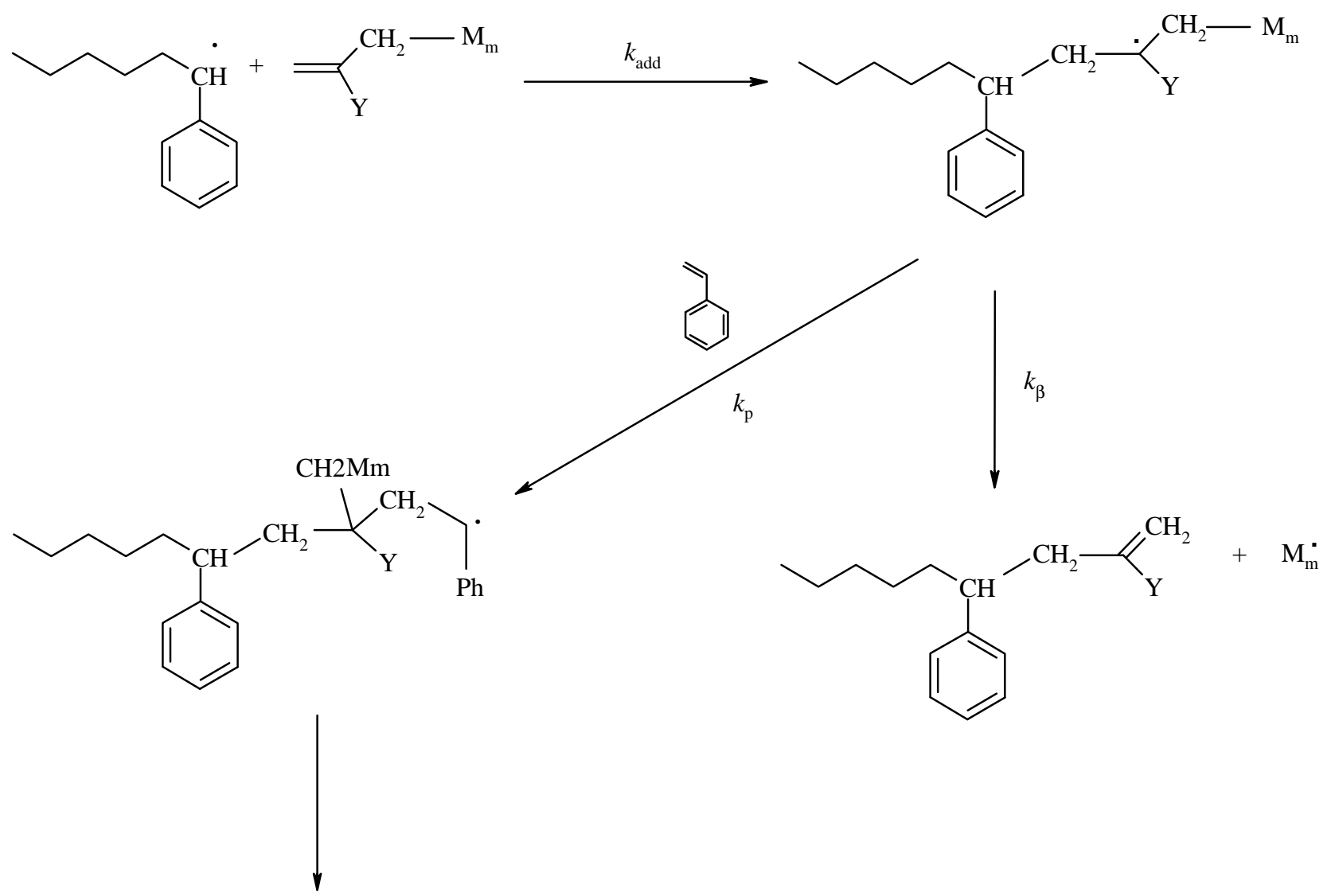

graft polymers

Scheme 5.4: Competition between fragmentation and copolymerization in the chaintransfer process with macromonomer. 
The competition between fragmentation and copolymerization has also been shown for acrylate polymerizations, which are non-sterically hindered monomers such as styrene. In contrast, the incorporation of macromonomers into polymethacrylates via copolymerization was seen to be close to zero ${ }^{30}$.

In case of copolymerizations as side reaction, the molecular weight distribution of the polymer obtained should be broader, due to the presence of graft polymers, as compared to MMA homopolymerization where the copolymerization reaction does not take place. Such an observation was not made for the MWD of the polystyrene obtained here. MWDs obtained for styrene and MMA homopolymerizations have approximately the same polydispersity index $\left(\mathrm{PDI}=M_{\mathrm{w}} / M_{\mathrm{n}}\right)$, which characterizes the broadness of a molecular weight distribution.

The copolymerization of a styrene monomer and the macroradical may be compared to a styrene-MMA propagation reaction. Thus, it can be anticipated that the copolymerization rate will increase with pressure, as seen for $k_{\mathrm{p}}$ in MMA-styrene copolymerization ${ }^{31}$. The formation of graft polymers resulting from this copolymerization will be increased, and the yield of polymers issued from the transfer process will be reduced. A change in the MWD of the polymer obtained, thus an enhanced PDI, is expected when increasing pressure. This was not observed here, where PDI is almost constant with pressure. In summary, these observations confirm the absence of the copolymerization as side reaction in styrene homopolymerization under the experimental reaction conditions applied in this work, and thus the applicability of the calculated chain-transfer rate coefficients.

$k_{\text {tr }}$ values obtained for MMA trimer as CTA in styrene and MMA homopolymerizations are very low, in the range of $10^{2} \mathrm{~L} \cdot \mathrm{mol}^{-1} \cdot \mathrm{s}^{-1}$, indicating a very slow chain-transfer process. In styrene homopolymerization $k_{\text {tr }}$ is higher than in MMA homopolymerization. It should be kept in mind that the batches of MMA trimer used are different for styrene and MMA polymerization (see section 5.3). Although SEC analysis showed that both batches of macromonomer contain approximately the same amount of MMA dimer and MMA trimer, it can not be excluded that small differences in $k_{\mathrm{tr}}$ as seen in this work may be due to the use of different batches of CTA. It has been shown that $C_{\mathrm{T}}$ of MMA dimer is lower than $C_{\mathrm{T}}$ of MMA trimer in MMA homopolymerization ${ }^{23}$.

In a recent study, Bon et al. ${ }^{32}$ performed polymerizations of styrene and MMA with an allyl bromide as CTA. The structure of an allyl bromide is comparable to the one of a MMA macromonomer since only $M_{m}$ (see scheme 5.4) is different: $M_{m}=B r$ in case of the allyl bromide and $\mathrm{M}_{\mathrm{m}}=2 \mathrm{MMA}$ units in case of the MMA trimer. In addition, the transfer reaction scheme proposed with an allyl bromide is an addition-fragmentation, such as here. The results 
have shown that $k_{\text {tr }}$ obtained in styrene polymerization is higher than in MMA polymerization, as seen in this work. Thus, the literature data support the experimental results of this work.

The rate-determining step of the transfer process in MMA and styrene homopolymerization with MMA trimer, which is the addition reaction, may be compared to the MMA and styreneMMA propagation reactions, respectively. The propagation kinetics of the copolymerization of styrene and MMA is described satisfactorily by the implicit penultimate model ${ }^{31,33,34}$. This implies that the cross-propagation coefficient, $k_{\mathrm{psty} / \mathrm{MMA}}$, of $1004 \mathrm{~L} \cdot \mathrm{mol}^{-1} \cdot \mathrm{s}^{-1}$ is evaluated from the reactivity ratio ${ }^{31} r_{\text {styrene }}(0.76)$ and from $k_{\mathrm{p}, \text { styrene }}\left(763 \mathrm{~L} \cdot \mathrm{mol}^{-1} \cdot \mathrm{s}^{-1}\right)$ determined at $300 \mathrm{bar}$ and $80^{\circ} \mathrm{C}$ in bulk polymerization. $k_{\mathrm{p}, \mathrm{MMA}}$ is $1540 \mathrm{~L} \cdot \mathrm{mol}^{-1} \cdot \mathrm{s}^{-1}$ under the same experimental conditions. The chain-transfer rate coefficients of styrene and MMA homopolymerization with MMA trimer, determined here at $300 \mathrm{bar}$ and $80^{\circ} \mathrm{C}$ in bulk, are 131 and $101 \mathrm{~L} \cdot \mathrm{mol}^{-1} \cdot \mathrm{s}^{-1}$, respectively. This indicates that MMA radicals are more reactive than styryl radicals with MMA as "comonomer", whereas styryl radicals are more reactive than MMA radicals with MMA trimer as "comonomer". Thus, MMA trimer is not comparable with MMA in terms of reactivity. In addition, MMA trimer is 7 times less reactive than MMA towards a styryl radical and 15 times less reactive than MMA towards a methyl methacrylic radical. It is obvious that the reactivity of MMA trimer with a growing radical is very low compared to the homopropagation reaction of the monomer. This finding may be explained by the bulkiness of the MMA trimer. The addition reaction of the MMA trimer with sterically hindered radicals such as methacrylic radical is clearly more difficult than with styryl radicals. Thus, as seen here $k_{\mathrm{tr}}$ in styrene homopolymerization is higher than in MMA homopolymerization with MMA trimer as CTA.

\subsubsection{COPhBF}

$k_{\text {tr }}$ values determined for COPhBF as catalytic chain-transfer agent (CCTA) are approximately two orders of magnitude lower in styrene polymerization $\left(10^{5} \mathrm{~L} \cdot \mathrm{mol}^{-1} \cdot \mathrm{s}^{-1}\right)$ than in MMA polymerization $\left(10^{7} \mathrm{~L} \cdot \mathrm{mol}^{-1} \cdot \mathrm{s}^{-1}\right)$. The values of $C_{\mathrm{T}}$ obtained in Section 5.2 are in accordance with the literature data, which are reported to be for $60^{\circ} \mathrm{C}$ and ambient pressure in the range of $10^{2}$ and $10^{4}$ in styrene and MMA homopolymerizations ${ }^{35}$, respectively. The $k_{\text {tr }}$ values are in accordance with a diffusion-controlled transfer process in MMA polymerization (more details are given in the next part) and with a chemically-controlled process in styrene homopolymerization. 
Catalytic chain transfer is most effective for tertiary propagating radicals such as in methacrylates, from which a hydrogen atom is abstracted from the $\alpha$-carbon atom in the substituent $^{36,37,38}$, as seen in scheme 5.2. In contrast, for secondary radicals such as styryl, the chain-transfer reaction is less effective. Styrene lacks an $\alpha$-methyl group, and hydrogen abstraction is proposed to occur from an internal $\beta-\mathrm{H}$ atom on the backbone ${ }^{47,39}$. Abstraction of a hydrogen atom from the backbone is likely to be more difficult than from an $\alpha$-methyl group due to steric hindrance and should yield lower $k_{\text {tr }}$ values, which supports the results obtained in this work. This steric effect may be not sufficient to explain the strong difference in $k_{\text {tr }}$ for styrene and MMA homopolymerizations. It may also be explained by the chaintransfer mechanism. No conclusive evidence exists regarding the actual chain-transfer mechanism other than presented in scheme 5.2, i.e., a hydrogen is abstracted from the growing radical, which is the rate-determining step and the hydrogen is transferred to the monomer. This mechanism seems to be the most conceivable and generally accepted mechanism to date. However, it is known from organometallic chemistry ${ }^{40,41,42}$ that many $\mathrm{Co}(\mathrm{II})$ complexes have the ability to form reversible $\mathrm{Co}-\mathrm{C}$ bonds with organic radicals. Electron spin resonance (ESR) studies showed a decrease of Co(II) concentration in the catalytic chain-transfer polymerization of styrene, but not for MMA and this was attributed to a reversible Co-C bond formation ${ }^{35}$. Recently, Roberts et al. ${ }^{18}$ directly observed the formation of cobalt-carbon bonds in CCT polymerization with methyl acrylate, with $C_{\mathrm{T}}$ being by orders of magnitude lower than for methacrylate polymerization. Therefore, it is obvious that the $\mathrm{Co}-\mathrm{C}$ bond formation depends on the type of radical present in the system, and that the $\mathrm{Co}-$ radical complex is more stable when secondary (styrenic, acrylic) rather than tertiary (methacrylic) radicals are present. In some cases, such as acrylates, free-radical polymerization in the presence of Co-complexes leads to living polymerization characteristics $^{43,44,45}$.

Three different mechanisms are suggested for styrene polymerizations with $\mathrm{COPhBF}$ as CCTA, for more details see ref. 10.

Firstly, the well-known two-step mechanism involving $\mathrm{Co}-\mathrm{H}$ intermediates as shown in scheme 5.2.

$$
\begin{gathered}
\mathrm{R}_{\mathrm{n}}{ }^{\bullet}+\mathrm{Co}(\mathrm{II}) \stackrel{k_{\mathrm{tr}, \mathrm{Co}(\mathrm{II})}}{\longrightarrow} \mathrm{P}_{\mathrm{n}}+\mathrm{Co}(\mathrm{III}) \mathrm{H} \\
\mathrm{Co}(\mathrm{III}) \mathrm{H}+\mathrm{M} \longrightarrow \mathrm{Co}(\mathrm{II})+\mathrm{R}_{1}
\end{gathered}
$$

Scheme 5.2 
The reaction scheme 5.2 is the most widely accepted version of the catalytic chain-transfer process and it is this mechanism on which all the $C_{\mathrm{T}}$ values published have been based upon. A clear and thorough discussion of this mechanism is given in ref. 46.

The second mechanism, given in scheme 5.5, is related to the reaction of a monomer molecule and a radical coordinately bound to the cobalt center.

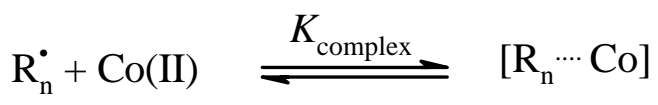

Scheme 5.5

The third mechanism is similar to the second one but with the exception that the monomer (M) acts as a ligand of the cobalt center, see scheme 5.6. This mechanism was previously suggested by Haddleton and co-workers ${ }^{47}$ to explain the decrease in $C_{\mathrm{T}}$ of a cobalt-complex for MMA polymerizations in solution of toluene as compared to bulk reactions. Solvent effects may be explained by the formation of a strong solvent-catalyst complex, leading to a decrease in active catalyst concentration. However, Davis et al. ${ }^{10}$ have not observed significant solvent effects of this nature except when using pyridine, which is known to be a very strong ligand.

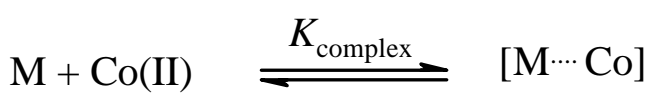

Scheme 5.6

Considering that the reversible cobalt-carbon bond occurs in catalytic chain transfer of styrene polymerization, as illustrated in scheme 5.5 and 5.6, the effective concentration of CTA is probably lower than what one expects. Thus, the true $[\mathrm{COPhBF}] /[\mathrm{M}]$ ratios are lower than the $[\mathrm{COPhBF}]_{0} /[\mathrm{M}]$, which are used to determine $C_{\mathrm{T}}$ (see Eq. 4.17). This implies that $C_{\mathrm{T}}{ }^{\text {obs }}$ is lower than the true $C_{\mathrm{T}}, C_{\mathrm{T}}$ true . This means that the true ratio will be obtained by a horizontal shift of the points to lower values on the $\operatorname{CLD}$ plot $\left(\Lambda \cdot M_{0}\right.$ vs $\left.[\mathrm{COPhBF}] /[\mathrm{M}]\right)$, yielding a steeper slope and hence a higher $C_{\mathrm{T}}$.

Since $\Lambda$ in Eq. 4.7 is directly governed by the product of $C_{\mathrm{T}}$ and [CTA], the relationship between the observed $C_{\mathrm{T}}$ and the true $C_{\mathrm{T}}$ is given by:

$$
C_{\mathrm{T}}^{\text {true }} \cdot[\mathrm{COPhBF}]_{\text {true }}=C_{\mathrm{T}}^{\text {obs }} \cdot[\mathrm{COPhBF}]_{\text {initial }}
$$


Thus, considering a transfer process with a reversible cobalt-carbon bond, the $C_{\mathrm{T}}^{\text {true }}$ might be easily accessible knowing the $[\mathrm{COPhBF}]_{\text {true }}$ and using $C_{\mathrm{T}}{ }^{\text {obs }}$ determined in this work assuming scheme 5.2 to occur.

In other words, $k_{\mathrm{tr}}{ }^{\text {obs }}$ may be underestimated and this may explain that catalytic chain-transfer polymerization of MMA is diffusion controlled and apparently chemically controlled in styrene. Considering the above finding, this difference may be actually smaller and its conceivable that catalytic chain-transfer in styrene is also diffusion controlled. Thus, it may be anticipated that $k_{\text {tr }}$ values of styrene and MMA are in the same range, as seen for $k_{\text {tr }}$ determined in the presence of DDM and MMA trimer. In addition, styrene and MMA have shown to have $k_{\mathrm{p}}$ and $k_{\mathrm{t}}$ values in the same range $\mathrm{e}^{31}$.

\subsubsection{Activation volume $\Delta V^{\#}$ and $\operatorname{scCO}_{2}$ influence on $k_{\text {tr }}$}

The table below summarizes the activation volumes of $k_{\mathrm{tr}}, \Delta V^{\#}\left(k_{\mathrm{tr}}\right) / \mathrm{cm}^{3} \cdot \mathrm{mol}^{-1}$, obtained in styrene and MMA homo- and copolymerization with the different CTAs at $80^{\circ} \mathrm{C}$.

\begin{tabular}{ccccc}
\hline & & 0 & 0.5 & 1 \\
\hline$\Delta V_{\mathrm{S}}^{\#}\left(k_{\mathrm{tr}, \mathrm{DDM}}\right)$ & bulk & $-(5.3 \pm 3.7)$ & $-(2.6 \pm 2.8)$ & $-(4.5 \pm 1)$ \\
& $\mathrm{scCO}_{2}$ & $-(4.4 \pm 2.9)$ & $-(2.8 \pm 1.9)$ & $-(1.8 \pm 3.5)$ \\
\hline$\Delta V^{\#}\left(k_{\mathrm{tr}, \mathrm{COPhBF}}{ }^{\mathrm{obs}}\right)$ & bulk & $+(47.5 \pm 15.8)$ & - & - \\
\hline & $\mathrm{scCO}_{2}$ & $+(31.5 \pm 7.3)$ & - & + \\
\hline$V^{\#}\left(k_{\mathrm{tr}, \mathrm{MMA} \text { trimer }}\right)$ & bulk & $-(5.8 \pm 2.8)$ & - & $+(3.3 \pm 3.1)$ \\
& $\mathrm{scCO}_{2}$ & $-(6.4 \pm 4.3)$ & - & $+(5.8 \pm 4.7)$ \\
\hline
\end{tabular}

Assuming the uncertainty on the $k_{\mathrm{tr}}{ }^{\text {obs }}$ values relative to the system styrene-COPhBF reported above, activation volumes are not discussed for styrene polymerizations with $\mathrm{COPhBF}$ as catalytic CTA.

\subsubsection{DDM}

In Section 5.1 it was shown that $\ln k_{\mathrm{tr}, \mathrm{copo}}$ in styrene-MMA polymerization varies linearly with the styrene content in the monomer feed, which holds for reactions in bulk and in $\mathrm{scCO}_{2}$ and 
for pressure ranging from 300 to 1000 bar. In addition, $k_{\text {tr }}$ determined in $\mathrm{scCO}_{2}$ is close to the bulk value in the entire pressure range independently of $f_{\mathrm{S}}$. Thus, the activation volumes of $k_{\mathrm{tr}}$ measured in both reaction media are similar, as reported in the table above. This aspect is also seen for $k_{\mathrm{p}}$ obtained in styrene and MMA homo- and copolymerizations in the same conditions of experiment. Beuermann et al. ${ }^{5}$ showed that the propagation rate coefficients and consequently the pressure dependence of $k_{\mathrm{p}}$ for styrene in $\mathrm{scCO}_{2}$ at $80^{\circ} \mathrm{C}$ are very close to the bulk data. In addition, $k_{\mathrm{p}}$ determined for MMA polymerizations at $80^{\circ} \mathrm{C}$ performed in this work, which are listed in Appendix 1, also show no influence of $\mathrm{scCO}_{2}$. In addition, $k_{\mathrm{tr}}$ values indicate that the transfer reaction is chemically controlled, as already seen for the propagation reaction ${ }^{5}$.

The independence of $k_{\mathrm{tr}}$ on $\mathrm{scCO}_{2}$ as a solvent suggests that the viscosity of the system is not a determining factor. This observation is in agreement with the results reported by Foster et $\mathrm{al}^{48}$. Investigations in bulk polymerizations of methacrylates with ester groups largely different in size (MMA and 2-phenoxyethyl methacrylate (POEMA)) showed for both monomers the same $k_{\mathrm{tr}}$, despite a significant difference in the viscosity of the system: The viscosities of POEMA and MMA are 2.51 and $0.37 \mathrm{cP}$, respectively, at reaction conditions. It provides strong evidence that viscosity effects are negligible in a conventional chain-transfer reaction of theses monomers. The insensitivity of $\Delta V^{\#}$ on the reaction medium supports the view that the dynamics of the transfer reaction is essentially the same in both media. Madruga et al. ${ }^{3}$ report a similar effect: $k_{\text {tr }}$ values for styrene and MMA homo- and copolymerizations in solution of benzene are similar to the corresponding bulk values. As seen in this work for $\mathrm{scCO}_{2}$, the solvent effect is negligible in conventional transfer polymerizations in solvents of poor polarity. However, Gnanou et al. ${ }^{49}$ investigated the polymerization of styrene in various solvents with different thiols containing an ester group. An increase of the polarity of the reaction medium results in an enhancement of $k_{\mathrm{tr}}$. They explained that this is most likely due to the transferring functionality that is made more accessible to the growing radical in such media. It is in accordance with a study of Tronche et al. ${ }^{27}$, which indicates an increase of the transfer rate of a radical with 1-butane thiol increasing the polarity of the solvent. Summary of the literature studies shows that solvents with high polarity increase the rate of the transfer process, whereas solvent with weak polar nature have no influence on $k_{\mathrm{tr}}$. $\mathrm{scCO}_{2}$ is a poor polar solvent, thus it is expected that there is no influence on $k_{\mathrm{tr}}$ using $\mathrm{scCO}_{2}$ as a solvent. The results reported in this work are consistent with this observation. 
Within experimental uncertainty, the pressure dependence of the transfer rate coefficient is not significant for styrene and MMA homo- and copolymerizations in both media. However a significant pressure dependence is observed in the propagation reaction ${ }^{5,50}: \Delta V^{\#}\left(k_{\mathrm{p}}\right)$ for MMA and for styrene are around $-16 \mathrm{~cm}^{3} \cdot \mathrm{mol}^{-1}$ and $-11 \mathrm{~cm}^{3} \cdot \mathrm{mol}^{-1}$, respectively. $k_{\mathrm{p}}$ and $k_{\mathrm{tr}}$ are in the same range, thus a comparison of both processes is adequate. A difference between $\Delta V^{\#}\left(k_{\mathrm{p}}\right)$ and $\Delta V^{\#}\left(k_{\mathrm{tr}}\right)$ is expected because the radical-monomer addition, in the propagation reaction, should be accompanied by a greater volume contraction than the transfer reaction, in which a thiyl-hydrogen bond must be broken. Tooney et al. ${ }^{51}$ reported that $\Delta V^{\#}\left(k_{\mathrm{tr}}\right)$ for triethylamine in styrene homopolymerization at $60^{\circ} \mathrm{C}$ up to 4400 bar is in the range from -2 to $-3 \mathrm{~cm}^{3} \cdot \mathrm{mol}^{-1}$, as seen for the values reported in this work. In both cases, transfer with DDM and triethylamine, the rate-determining step of the transfer process is a hydrogen abstraction of the CTA by the polystyryl radical. Walling and Pellon ${ }^{52}$ have indicated that $\Delta V^{\#}\left(k_{\mathrm{tr}}\right)$ for carbon tetrachloride in styrene homopolymerization at $60^{\circ} \mathrm{C}$ up to 4000 bar is close to the $\Delta V^{\#}\left(k_{\mathrm{p}}\right)$ in the same conditions. In this last case, the rate determining step is a chlorine abstraction of the CTA by the polystyryl radical. This may indicate that $\Delta V^{\#}$ for the transfer reaction is strongly dependent on the radius of the atom abstracted, thus on the CTA. In contrast, the nature of the polymer radical does influence the pressure dependence of the transfer reaction significantly.

In summary in MMA and styrene homo- and copolymerization, it has been shown here that $\mathrm{scCO}_{2}$, which is a solvent with a weak polar nature, has no influence on $k_{\mathrm{tr}}$. The variation of $k_{\text {tr }}$ with pressure is not significant as the abstracted atom, a hydrogen atom, is small. Thus, in styrene and MMA polymerization with DDM as CTA, $k_{\text {tr }}$ is not influenced by the viscosity of the system.

\subsubsection{MMA trimer}

The $k_{\mathrm{tr}}$ values, and thus the activation volumes of $k_{\mathrm{tr}}$, determined in styrene and MMA homopolymerizations are similar in bulk and in solution of $\mathrm{scCO}_{2}$, as reported in section 5.3. The $k_{\text {tr }}$ values indicate a chemically-controlled transfer process. In an addition-fragmentation transfer process it has been shown that the rate-determining step is the addition reaction of the polymer radical and the MMA trimer ${ }^{23}$. This step is comparable to a propagation reaction since in both cases the addition of a polymer radical with a vinyl oligomer (or monomer) occurs. Thus, $k_{\mathrm{tr}}$ determined in styrene and MMA homopolymerization are compared to $k_{\mathrm{p}}$ 
styrene-MMA and MMA polymerization, respectively. Previous studies have shown that the values of $k_{\mathrm{p}, \mathrm{MMA}}$ and $k_{\mathrm{psty} / \mathrm{MMA}}$ determined in $\mathrm{scCO}_{2}$ are very close to the bulk values under the same conditions of experiments of this work ${ }^{31}$. These observations are in accordance with the results obtained here, where no $\mathrm{scCO}_{2}$ effect is seen for $k_{\mathrm{tr}}$ in the presence of MMA trimer (see Table above).

Within experimental uncertainty the enhancement of $k_{\text {tr }}$ in MMA homopolymerization is not significant with increasing pressure and the pressure dependence of $k_{\text {tr }}$ is close to the one observed with DDM as CTA $\left(\Delta V^{\#}\left(k_{\mathrm{tr}, \mathrm{DDM}}\right)=-(5.3 \pm 3.7) \mathrm{cm}^{3} \cdot \mathrm{mol}^{-1}\right.$ and $\Delta V^{\#}\left(k_{\mathrm{tr}, \text { MMAt }}\right)=-$ $(5.8 \pm 2.8) \mathrm{cm}^{3} \cdot \mathrm{mol}^{-1}$ in bulk polymerization). $\Delta V^{\#}\left(k_{\mathrm{tr}}\right)$ obtained in styrene homopolymerization is close to zero. The positive activation volume for $k_{\text {tr }}$ in styrene homopolymerization is probably due to the very low values determined for $C_{\mathrm{T}}$, thus for $k_{\mathrm{tr}}$, which increases the uncertainty of the data. In a chemically-controlled process, an addition reaction becomes faster with pressure, whereas a fragmentation is slowed down with pressure. Considering the results obtained, the addition to the double bond is the rate-determining step in the transfer process for MMA homopolymerization, as previously suggested by Moad et al. ${ }^{23}$. In addition, since the fragmentation reaction is supposed to be faster, the macroradical formed is immediately transformed to a dead polymer and a new radical. As a consequence the volume variation of the system does not significantly change, which induces a low pressure dependence as seen in this work.

In summary, the activation volumes of $k_{\mathrm{tr}}$ determined in styrene and MMA homopolymerizations in the presence of MMA trimer are not significant and are not influenced by the presence of $\mathrm{scCO}_{2}$ as a solvent. In addition, the values of $\Delta V^{\#}\left(k_{\mathrm{tr}}\right)$ are close to the ones determined with DDM as CTA, which transfer process is chemically controlled.

\subsubsection{COPhBF}

The results obtained in MMA homopolymerization with COPhBF as CCTA suggest a significant $\mathrm{scCO}_{2}$ influence on $k_{\mathrm{tr}}\left(k_{\mathrm{tr}}\right.$ at $80^{\circ} \mathrm{C}$ and 1000 bar are $14.5 \cdot 10^{6}$ and $5.5 \cdot 10^{6} \mathrm{~L} \cdot \mathrm{mol}^{-1} \cdot \mathrm{s}^{-}$ ${ }^{1}$ in $\mathrm{scCO}_{2}$ and in bulk, respectively) and high positive activation volumes are determined $\left(\Delta V^{\#}\left(k_{\mathrm{tr}}\right)\right.$ is around $+35 \mathrm{~cm}^{3} \cdot \mathrm{mol}^{-1}$ in both media). These findings are in accordance with a diffusion-controlled transfer process.

In the literature ${ }^{53}$ the kinetic results from catalytic chain-transfer reactions with methacrylates indicate also a diffusion-controlled transfer reaction. For methacrylates with ester groups of 
different size, Arrhenius parameters for the transfer reaction are reported: Activation energies around $E_{\mathrm{A}}\left(k_{\mathrm{tr}}\right)=+23 \mathrm{~kJ} \cdot \mathrm{mol}^{-1}$, which induces $E_{\mathrm{A}}\left(C_{\mathrm{T}}\right)=0 \mathrm{~kJ} \cdot \mathrm{mol}^{-1}$, and frequency factors around $A=10^{10} \mathrm{~L} \cdot \mathrm{mol}^{-1} \cdot \mathrm{s}^{-1}$. The significant $E_{\mathrm{A}}\left(k_{\mathrm{tr}}\right)$ indicates the presence of a reaction barrier and the high $A$ is atypical for a chemically-controlled bimolecular reaction between a polymeric radical and a small molecule ${ }^{54,55}$, which is generally lower than $10^{5} \mathrm{~L} \cdot \mathrm{mol}^{-1} \cdot \mathrm{s}^{-1}$. It was also shown that $k_{\text {tr }}$ decreases with increasing ester chain in a homologous series of methacrylates ${ }^{48,56}$. This phenomenon was assigned to a diffusion-controlled transfer reaction and the individual $k_{\text {tr }}$ value was directly proportional to the inverse viscosity of the monomer: e.g., the higher the viscosity, the lower $k_{\text {tr }}$. The results obtained in MMA homopolymerization in this work are in accordance with this observation: $k_{\text {tr }}$ is enhanced in $\mathrm{scCO}_{2}$ and decreases with increasing pressure. The presence of $\mathrm{scCO}_{2}$ decreases the viscosity of the system, whereas high pressure increases the viscosity of the system. Davis et al. ${ }^{13}$ performed MMA polymerization in approximately 80 wt $\% \mathrm{scCO}_{2}$ at $50^{\circ} \mathrm{C}$ and 150 bar with $\mathrm{COPhBF}$ as CCTA. The reported $k_{\text {tr }}$ in the range of $10^{8} \mathrm{~L} \cdot \mathrm{mol}^{-1} \cdot \mathrm{s}^{-1}$ is also consistent with a diffusioncontrolled transfer reaction: $k_{\text {tr }}$ increases strongly in the presence of $\mathrm{scCO}_{2}$ and $k_{\text {tr }}$ is very high, comparable to termination rate coefficients which are known to be diffusion controlled.

The following part will focus on the influence of the viscosity on the $k_{\mathrm{tr}}$ values because literature data and the results of this work clearly indicate a dependence of $k_{\text {tr }}$ on the viscosity of the system. In addition, one of the special features of using $\mathrm{scCO}_{2}$ as an alternate solvent is the very low viscosity of $\mathrm{CO}_{2}$ compared to the monomer viscosity. The above mentioned $k_{\text {tr }}$ value around $10^{8}$ in the catalytic chain-transfer polymerization of MMA at $50^{\circ} \mathrm{C}$ and $150 \mathrm{bar}$ in $80 \mathrm{wt} \% \mathrm{scCO}_{2}$ is one order of magnitude higher than the $k_{\text {tr }}$ value around $10^{7}$ extrapolated at $80^{\circ} \mathrm{C}$ and 150 bar in $40 \mathrm{wt} \% \mathrm{scCO}_{2}$ in Section 5.2.2. $E_{\mathrm{A}}\left(k_{\mathrm{tr}}\right)$ was reported to be around +23 $\mathrm{kJ} \cdot \mathrm{mol}^{-1}$ so that $k_{\mathrm{tr}}$ increases with temperature. Therefore, if a temperature dependence is anticipated in $\mathrm{scCO}_{2}, k_{\mathrm{tr}}$ at $50^{\circ} \mathrm{C}$ should be slightly lower than $k_{\mathrm{tr}}$ at $80^{\circ} \mathrm{C}$. The reported above values are not in accordance with this finding. Thus, the difference in $k_{\text {tr }}$ between literature data and this work is due to the different $\mathrm{scCO}_{2}$ contents. This indicates that viscosity is an important parameter in MMA polymerization with $\mathrm{COPhBF}$ since the viscosity of the mixture with $80 \mathrm{wt} \% \mathrm{scCO}_{2}$ is lower than the one with $40 \mathrm{wt} \% \mathrm{scCO}_{2}$.

It may be considered that the presence of $\mathrm{COPhBF}$ does not influence the viscosity since only a small amount of $\mathrm{COPhBF}$ is used to prepare the solutions. At $80^{\circ} \mathrm{C}$ and 300 bar, the $\mathrm{CO}_{2}$ viscosity of $658 \mu \mathrm{P}$ is by about one order of magnitude lower than the MMA viscosity, estimated to be approximately $3000 \mu \mathrm{P}$. The $\mathrm{CO}_{2}$ viscosity is taken from ref. 57 , whereas the 
MMA viscosity is estimated from the $30^{\circ} \mathrm{C}$ data given by $\mathrm{Ogo}$ et al. ${ }^{58}$ and the $60^{\circ} \mathrm{C}$ data given by Foster et al. ${ }^{48}$. The viscosity for MMA- $\mathrm{CO}_{2}$ mixtures is not available in the literature. Therefore the viscosity of the mixture ${ }^{5}$ is estimated from the data of the pure components according to: $\ln \eta_{\text {mix }}=x\left(\mathrm{CO}_{2}\right) \cdot \ln \eta\left(\mathrm{CO}_{2}\right)+x(\mathrm{MMA}) \cdot \ln \eta(\mathrm{MMA})$, with the molar fractions $x\left(\mathrm{CO}_{2}\right)$ and $x(\mathrm{MMA})$ of $\mathrm{CO}_{2}$ and MMA in the mixture. As in the work of Fischer et al. ${ }^{59}$ polymer contributions are not taken into account, as the monomer conversion was below $4 \%$ in all experiments of this work. A value of $1200 \mu \mathrm{P}$ is estimated, which shows that the viscosity of the monomer- $\mathrm{CO}_{2}$ mixture is significantly reduced compared to pure MMA. Thus the reduced viscosity may be the cause for the observed enhancement of $k_{\text {tr }}$ in the presence of $\mathrm{CO}_{2}$. This phenomenon was previously $\operatorname{seen}^{5}$ for the termination rate coefficient in styrene homopolymerization in $\mathrm{scCO}_{2}$, which is also diffusion controlled.

The significant solvent effect observed in MMA homopolymerization may also be exerted via a ligation mechanism and partitioning of the catalyst. These two possibilities are discussed in the following part. In a recent work, it was shown that the solvent effects on catalytic chaintransfer (methacrylate polymerizations) are not significant for solvents that are weak ligands, such as toluene and butyl acetate ${ }^{53}$. Solvent effect only becomes important for strong ligand such as pyridine. Neither toluene nor $\mathrm{CO}_{2}$ are strong ligands and therefore it seems unlikely that the strong effects observed in polymerization in $\mathrm{scCO}_{2}$ can be attributed to direct chemically interactions. An enhanced chain-transfer process may be possible if the local cobalt-complex concentration around the radical is increased. Klingler and Rathke ${ }^{60}$ studied the hydrogenation of dicobalt octacarbonyl in $\mathrm{scCO}_{2}$ and found no significant solvent effects in comparison to nonpolar organic solvents. Therefore it seems unlikely that the increase of $k_{\text {tr }}$ in $\mathrm{scCO}_{2}$ may be attributed to partitioning.

The activation volumes obtained for $k_{\text {tr }}$ in MMA homopolymerization are surprisingly high $\left(\sim+35 \mathrm{~cm}^{3} \cdot \mathrm{mol}^{-1}\right)$ compared to other systems and kinetic parameters studied so far. For example, the activation volume of the termination reaction ${ }^{50}$ in MMA homopolymerization $\Delta V^{\#}\left(k_{\mathrm{t}}\right)$ around $+16 \mathrm{~cm}^{3} \cdot \mathrm{mol}^{-1}$ is lower than the value of $\Delta V^{\#}\left(k_{\mathrm{tr}}\right)$ observed for the transfer reaction determined here. Both reactions, transfer and termination, are assumed to be diffusion controlled. The difference on $\Delta V^{\#}$ of $k_{\mathrm{tr}}$ and $k_{\mathrm{t}}$ indicates the presence of a stronger reaction barrier in the transfer than in the termination process, thus a consequent pressure dependence. As discussed before, the viscosity of the system, which increases with increasing pressure, may also explain this phenomenon. However the pressure dependence of the viscosity, $\Delta V^{\#}(\mu)$, is lower than the reported $\Delta V^{\#}\left(k_{\mathrm{tr}}\right): \Delta V^{\#}(\mu)=+14 \mathrm{~cm}^{3} \cdot \mathrm{mol}^{-1}$ for $\mathrm{MMA}^{58}$. 
Therefore, the strong pressure dependence observed for $k_{\text {tr }}$ may not only be explained by a diffusion-controlled reaction. Other phenomenons may have additive effects, which induces such unusual activation volume.

Considering the mechanism proposed for MMA homopolymerization (Scheme 5.2) it may be supposed that the structure of the cobalt-complex changes during the abstraction of the hydrogen atom, which undergoes a significant variation of the volume of the system. This hypothesis could be verified by knowing the structure of the complex. A crystal analysis gives informations on the structure, which was not successful for this complex (see Section 3).

Another cobalt-complex was also used as a CTA in the literature ${ }^{61}$ : the bis(difluoroboryl) dimethylglyoximato cobalt (II) (COBF). The structure of COBF is very close to the one of COPhBF: substituting phenyl groups by methyl groups. COBF was reported to have a transfer constant, thus $k_{\mathrm{tr}}$, one order of magnitude higher than the one of $\mathrm{COPhBF}$, which was explained by the restricted mobility of COPhBF due to the presence of phenyl groups. Thus, the abstraction of a hydrogen atom is made more difficult with $\mathrm{COPhBF}$. It may be anticipated that the mobility of the $\mathrm{COPhBF}$ molecules is much more restricted with increasing pressure due to the enhancement of the viscosity. Thus, $k_{\text {tr }}$ will strongly decrease with increasing pressure, which is consistent with the results of this work.

In summary, the viscosity of the system is a significant rate-determining factor in the MMA homopolymerization with COPhBF as CCTA, thus $k_{\text {tr }}$ is higher in the presence of $\mathrm{scCO}_{2}$ as a solvent. In addition, the bulky COPhBF molecule contributes to a strong and positive activation volume of $k_{\mathrm{tr}}$.

\subsection{References}

1. Hutchinson, R. A.; Paquet, D. A.; Mc Minn, J. H. Macromolecules 1995, 28, 5655.

2. De la Fuente, J. L.; Madruga, E. L. J. Polym. Sc., Polym. Chem. Ed. 1998, 36, 2913.

3. De la Fuente, J. L.; Madruga, E. L. J. Polym. Sc., Polym. Chem. Ed. 2000, 38, 170.

4. Isemer, C.; Wahl, A. private communication.

5. Beuermann, S.; Buback, M.; Isemer, C.; Lacik, I.; Wahl, A. Macromolecules, in preparation for publications.

6. Buback, M.; Kuchta, F.-D. Macromol. Chem. Phys. 1995, 196, 1887.

7. Beuermann, S.; Buback, M.; Russell, G. T. Macromol. Rapid. Commun. 1994, 15, 351. 
8. Gridnev, A.; J. Polym. Sci., Polym. Chem. Ed. 2000, 38, 1753.

9. Heuts, J. P. A.; Kukulj, D.; Foster, D. J.; Davis, T. P. Macromolecules 1998, 31, 2894.

10. Heuts, J. P. A.; Foster, D. J.; Davis, T. P. ACS symposium series 768, Transition Metal Catalysis in Macromolecular Design 2000, p 254.

11. Kowollik, C.; Davis, T. P. J. Polym. Sci., Polym. Chem. 2000, 38, 3303.

12. Heuts, J. P. A.; Foster, D. J.; Davis, T. P.; Yamada, B.; Yamazoe, H.; Azukizawa, M. Macromolecules 1999, 32, 2511.

13. Foster, D. J.; Heuts, P. A.; Lucien, F. P.; Davis, T. P. Macromolecules 1999, 32, 5514.

14. Kukulj, D.; Davis, T. P. Macromol. Chem. Phys. 1998, 199, 1697.

15. Heuts, J. P. A.; Foster, D. J.; Davis, T. P. Macromolecules 1998, 31. 6034.

16. Haddleton, D. M.; Maloney, D. R.; Suddaby, K. G.; Muir, A. V. G.; Richards, S. N. Macromol. Symp. 1996,111, 37.

17. Russell, G. T. Macromol. Theory. Simul. 1995, 4, 497.

18. Roberts, G. E.; Heuts, J. P.A.; Davis, T. P. Macromolecules 2000, 33, 7765.

19. Krstina, J.; Moad, G.; Rizzardo, E.; Winsor, C. L.; Berge, C. T.; Fryd, M Macromolecules 1995, 28. 5381.

20. Moad, G.; Moad, C. L.; Krstina, J.; Rizzardo, E.; Berge, C. T.; Darling, T. R. PCT Int. Appl. WO 9615157, Chem. Abstr. 1996, 125, 299554.

21. Rizzardo, E.; Meijs, G. F.; Thang, S. H.; Macromol. Symp. 1995, 98, 101.

22. Darmon, M. J.; Berge, C. T.; Antonelli, J. A.; US 5362826, Chem. Abstr. 1993, 120, 299554.

23. Moad, L. C.; Moad, G.; Rizzardo, E.; Thang, S. H. Macromolecules 1996, 29, 7717.

24. Harrison, D. M. Appl. Sc., The Chemistry of $\omega$-unsaturated Oligomers and Polymers. Swinburne Institute of Technology, 1988.

25. Tanaka, H.; Kawa, H.; Sato., T. J. Polym. Sci., Part A: Polym. Chem. 1989, 27. 1741.

26. Lechner, M. D.; Gehrke, K.; Nordmeier, E. H. Makromolekulare Chemie, Birkhäuser Verlag, Basel 1993.

27. Tronche, C.; Martinez, F.; Horner, J. H.; Newcomb, M.; Senn, M.; Giese, B. Tetrahedron. Lett. 1996, 37, 5845

28. Rong, X. X.; Pan, H. Q.; Dolbier, W. R.; Smart, B. E. J. Am. Chem. Soc. 1994, 116, 521.

29. Colombani, D.; Chaumont, P. Prog. Polym. Sci. 1996, 21, 439.

30. Berge, C. T.; Darmon, M. J.; Antonelli, J. A. US Patent US 5, 1994, 362, 826.

31. Isemer, C. Ph.-D Thesis 2000, Göttingen. 
32. Bon, S. E.; Morsley, S. R.; Waterson, C.; Haddleton, D. M. Macromolecules 2000, 33, 5818.

33. Coote, M. L.; Zammit, M. D.; Davis, T. P. Willett, G. D. Macromolecules 1997, 30, 8182 .

34. Coote, M. L.; Johnston, L. P.; Davis, T. P. Macromolecules 1997, 30. 8191.

35. Heuts, J. P. A.; Foster, D. J.; Davis, T. P. Macromolecules 1999, 32, 2511.

36. Sanayei, R. A.; O'Driscoll, K. F. J. Macromol.Sci. 1989, A26, 1137.

37. Enikolopyan, N. S.; Smirnov, B. R.; Ponomarev, G. V.; Belgovskii, I. M.; J Polym. Sci. Polym. Chem. Ed. 1981, 19, 879

38. Smirnov, B. R.; Morozaza, I. S.; Marchenko, A. P.; Markevic, M. A.; Pushchaeva, 1: M.; Enikolopyan, N. S. Dokl. Akad. Nauk. SSSR (Engl. Transl.) 1980, 253, 891.

39. Smirnov, B. R.; Plotnikov, V. D.; Ozerkovskii, B. V.; Roschupkin, V. P.; Enikolopyan, N. S. Polym. Sci. USSR (Engl. Transl.) 1981, 23, 2894.

40. Brookhart, M.; Green, M. L. H.; Wong, L. L. Prop. Inorg. Chem. 1988, 36,1.

41. Halpern, J.; Rempel, G. L.; Ng, F. T. J. Am. Chem. Soc. 1979, 101, 7124.

42. Gridnev, A. A.; Belgovskii, I. M.; Enikolopyan, N. S. Dokl. Akad. Nauk USSR (Engl. Trans.) 1986, 289, 1408.

43. Wayland, B. B., Poszmik, G.; Mukerjee, S. L.; Fryd, M. J. Am. Chem. Soc. 1994, 116, 7643.

44. Wayland, B. B.; Basickes, L.; Mukerjee, S. L.; Wie, M.; Fryd, M. Macromolecules 1997, 30, 8109 .

45. Wayland, B. B.; Mukerjee, S.; Posznik, G.; Woska, D. C.; Basiches, L.; Gridnev, A. A.; Fryd, M.; Ittel, S. D. In Controlled Radical Polymerization; Matyjaszewski, K.; Ed.; ACS Symposium Series, 685; American Chemical Society: Washington, DC, 1998, 305.

46. Gridnev, A. A.; Wayland, B. B.; Fryd, M. Organometallics 1996, 15, 5116.

47. Haddleton, D. M.; Maloney, D. R.; Suddaby, K. G.; Muir, A. V. G.; Richards, S. N. Macromol. Symp. 1996, 111, 37.

48. Foster, D. J.; Heuts, J. P. A.; Davis, T. P. Polymer 2000, 41, 1385.

49. Businelli, L.; Gnanou, Y.; Maillard, B. Macromol. Chem. Phys. 2000, 201, 2805.

50. Beuermann, S.; Buback, M.; Russell, G. T. Macromol. Rapid. Commun. 1994, 15, 351.

51. Tooney, C. A.; Weale, K. E. Transactions of the Faraday Society 1962, 58, 2446. 
52. Walling, C.; Pellon, J. J. Am. Chem. Soc. 1957, 79, 4776.

53. Heuts, J. P. A.; Foster, D. J.; Davis, T. P. Macromolecules 1999, 32, 3907.

54. Beuermann, S: Buback, M.; Davis, T. P.; Gilbert, R. G., Hutchinson, R. A.; Olaj, O. F.; Russell, G. T.; Schweer, J.; van Herk, A. M. Macromol. Chem. Phys. 1997, 198, 1545.

55. Heuts, J. P. A.; Gilbert, R. G.; Radom, L. Macromolecules 1995, $28,8771$.

56. Mironychev, V. Y.; Mogilevich, M. M.; Smirnov, B. R.; Shapiro, Y. Y.; Golikov, J. V. Polym. Sci. USSR 1986, 28, 2103.

57. Stephan, K.; Lucas, K. Viscosity of Dense Fluids, Plenum, New York 1979.

58. Ogo, Y.; Kyonati, T. Makromol. Chem. 1978, 179, 2407.

59. Fischer, J. P.; Mücke, G.; Schulz, G. V. Ber. Bunsenges. Physik. Chem. 1970, 73, 1077.

60. Klingler, R. J.; Rathke, J. W. J. Am. Chem. Soc. 1994, 116, 4772.

61. Sanayei, S. A.; O'Driscoll, K. F. J. Macromol. Sci. 1989, A26(8), 1137. 


\section{Kinetic modeling}

In order to understand the results obtained for chain-transfer rate coefficients, $k_{\mathrm{tr}, \text { copo, }}$ in styrene-MMA copolymerizations with $\mathrm{DDM}$ and COPhBF as CTAs, $k_{\mathrm{tr} \text {,copo }}$ are modeled applying the terminal and the penultimate unit effect models. As explained in section 5.2, $k_{\mathrm{tr}}{ }^{\text {obs }}$ obtained in styrene-MMA homo- and copolymerization with $\mathrm{COPhBF}$ are based on the transfer process described in scheme 5.2, which assumes a direct hydrogen abstraction by the Co(II) species. Recently ${ }^{1}$ it has been suggested that other transfer reactions may occur in the catalytic chain-transfer reaction of $\mathrm{COPhBF}$ in the presence of styrene as comonomer. However, no conclusive evidence exists regarding the actual chain-transfer mechanism other than presented in scheme 5.2. Thus, in the following part $k_{\mathrm{tr}}^{\text {obs }}$ in styrene and MMA copolymerizations are also modeled.

The fractions of endgroups, $\Phi_{\mathrm{A}}$, formed are estimated for styrene-MMA copolymers.

The program package PREDICI ${ }^{\circledR}$ is used to simulate the molecular weight distribution of polymers obtained in the presence of DDM for styrene and MMA copolymerization. The results are compared to the corresponding experimental MWDs in order to confirm or disprove the predictions made in section 6.2 , whether a terminal or a penultimate unit model describes the transfer process. In case of COPhBF, MWDs are modeled via PREDICI ${ }^{\circledR}$ in MMA homopolymerization.

\subsection{Theoretical background}

\subsubsection{Simulations of $k_{\mathrm{tr}}$ applying terminal and PUE models}

\section{Free-radical copolymerization}

In a copolymer system, the number of reactions occurring is higher than in free-radical homopolymerization, due to the presence of different types of radicals and monomers.

Chain growth proceeds via four distinct propagation steps $^{2}$, i.e., the addition of monomers A and $\mathrm{B}$ to propagating chains terminating in $\mathrm{A}$ or $\mathrm{B}$, as shown in the following reaction scheme: 
$\mathrm{RA}^{\bullet}+\mathrm{A} \stackrel{k_{\mathrm{pAA}}}{\rightarrow} \mathrm{RAA}^{\cdot}$

$\mathrm{RA}^{\bullet}+\mathrm{B} \stackrel{k_{\mathrm{pAB}}}{\rightarrow} \mathrm{RAB}^{\bullet}$

$\mathrm{RB}^{\bullet}+\mathrm{B} \stackrel{k_{\mathrm{pBB}}}{\rightarrow} \mathrm{RBB}^{\bullet}$

$\mathrm{RB}^{\bullet}+\mathrm{A} \stackrel{k_{\mathrm{pBA}}}{\rightarrow} \mathrm{RBA}^{\bullet}$

$k_{\mathrm{pAA}}$ and $k_{\mathrm{pBB}}$ refer to the homopropagation, and $k_{\mathrm{pAB}}$ and $k_{\mathrm{pBA}}$ to cross-propagation.

This model is called the terminal or Lewis-Mayo model, which considers only the influence of the terminal unit of a macroradical on the propagation rate coefficient and copolymer composition.

Within the terminal model, the mole fraction of monomer $\mathrm{A}$ in the instantaneously formed copolymer, $F_{\mathrm{A}}$, can be expressed as a function of the mole fraction of the monomer $\mathrm{A}$ in the monomer feed, $f_{\mathrm{A}}$ :

$F_{\mathrm{A}}=\frac{r_{\mathrm{A}} f_{\mathrm{A}}^{2}+f_{\mathrm{A}} f_{\mathrm{B}}}{r_{\mathrm{A}} f_{\mathrm{A}}^{2}+2 f_{\mathrm{A}} f_{\mathrm{B}}+r_{\mathrm{B}} f_{\mathrm{B}}^{2}}$

where, $r_{\mathrm{A}}$ is the monomer reactivity ratio given by

$r_{\mathrm{A}}=\frac{k_{\mathrm{pAA}}}{k_{\mathrm{pAB}}}$

The propagation rate coefficient, $k_{\mathrm{p}, \mathrm{copo}}$, is given by the expression:

$$
k_{\mathrm{p}, \text { copo }}=\frac{r_{\mathrm{A}} f_{\mathrm{A}}^{2}+2 f_{\mathrm{A}} f_{\mathrm{B}}+r_{\mathrm{B}} f_{\mathrm{B}}^{2}}{\left(r_{\mathrm{A}} f_{\mathrm{A}} / k_{\mathrm{pAA}}\right)+\left(r_{\mathrm{B}} f_{\mathrm{B}} / k_{\mathrm{pBB}}\right)}
$$

In general, the terminal model is found to adequately describe the copolymer composition (Eq. 6.2), but it fails to describe the average propagation rate coefficient, simultaneously ${ }^{2,3}$. 
Several models have been proposed to account for the discrepancy between the terminal model predictions and the experimentally found average propagation rate coefficients ${ }^{2,3}$. The most frequently used model is the so-called "Penultimate Unit Effect" (PUE) model, which assumes that the radical reactivity is affected by the preceding unit on the chain as well. PUE model was first formulated by Merz et al. ${ }^{4}$. This model has attracted a lot of attention due to the work of Fukuda et al. ${ }^{5}$. In the penultimate model the radical reactivities $s$ (e.g., $s_{\mathrm{A}}=k_{\mathrm{pBAA}} /$ $\left.k_{\mathrm{pAAA}}\right)$ are defined in addition to the reactivity ratios $r$ (e.g., $r_{\mathrm{AA}}=k_{\mathrm{pAAA}} / k_{\mathrm{pAAB}}$ ). These radical reactivities describe the effect of the penultimate unit on the homopropagation rate. A complete description of the development of the penultimate model can be found at ref. 6 .

The following scheme summarizes all equations describing the kinetic coefficients in the implicit PUE (IPUE) model. More details about IPUE model are found at refs. 7 and 6.

$$
\begin{array}{ll}
\bar{k}_{\mathrm{pAA}}=\frac{k_{\mathrm{pAAA}}\left(r_{\mathrm{A}} f_{\mathrm{A}}+f_{\mathrm{B}}\right)}{r_{\mathrm{A}} f_{\mathrm{A}}+\frac{f_{\mathrm{B}}}{s_{\mathrm{A}}}} & (6.5) \bar{k}_{\mathrm{pBB}}=\frac{k_{\mathrm{pBBB}}\left(r_{\mathrm{B}} f_{\mathrm{B}}+f_{\mathrm{A}}\right)}{r_{\mathrm{B}} f_{\mathrm{B}}+\frac{f_{\mathrm{A}}}{s_{\mathrm{B}}}} \\
r_{\mathrm{A}}=\frac{\bar{k}_{\mathrm{pAA}}}{k_{\mathrm{pAB}}} & (6.7) r_{\mathrm{B}}=\frac{\bar{k}_{\mathrm{pBB}}}{k_{\mathrm{pBA}}} \\
s_{\mathrm{A}}=\frac{k_{\mathrm{pBAA}}}{k_{\mathrm{pAAA}}} & \text { (6.9) } s_{\mathrm{B}}=\frac{k_{\mathrm{pABB}}}{k_{\mathrm{pBBB}}}
\end{array}
$$

The mean homopropagation rate coefficients, $\bar{k}_{\mathrm{pii}}$, are calculated using the mean reactivity ratio, $r$, the radical reactivities, $s$, homopropagation rate coefficients, $k_{\text {piii }}$, and the monomer mole fractions using Eqs. 6.5 and 6.6.

Both the instantaneous copolymer composition and the propagation rate coefficient implicitly contain the ratio of the two propagating radical concentrations, $A_{\mathrm{AB}}$, of which an expression (Eq. 6.11) can be derived from the steady state assumption in all propagating radical concentrations. This ratio is important as it is basically a weighting factor for the contributions of the reactions of either radical to the overall observed kinetics and copolymer composition. 
From this ratio the fraction of the different propagating terminal radicals, $\phi_{\mathrm{A}}$, is easily derived and given by Eq. $6.12^{8}$.

$$
\begin{aligned}
& A_{\mathrm{AB}}=\frac{\left[\mathrm{RA}^{\cdot}\right]}{\left[\mathrm{RB}^{\bullet}\right]}=\frac{\bar{k}_{\mathrm{pBB}} r_{\mathrm{A}} f_{\mathrm{A}}}{\bar{k}_{\mathrm{pAA}} r_{\mathrm{B}} f_{\mathrm{B}}} \\
& \phi_{\mathrm{A}}=\frac{A_{\mathrm{AB}}}{1+A_{\mathrm{AB}}}
\end{aligned}
$$

Considering the PUE model the fraction of propagating penultimate radicals, $\phi_{\mathrm{AA}}$, may be expressed as:

$$
\phi_{\mathrm{AA}}=\phi_{\mathrm{A}}-\phi_{\mathrm{BA}}=\frac{r_{\mathrm{A}} \cdot f_{\mathrm{A}} \cdot \phi_{\mathrm{A}}}{r_{\mathrm{A}} \cdot f_{\mathrm{A}}+\frac{f_{\mathrm{B}}}{s_{\mathrm{A}}}}
$$

The population $\phi_{\mathrm{BB}}$ is calculated analog to $\phi_{\mathrm{AA}}$.

$\phi_{\mathrm{AA}}, \phi_{\mathrm{AB}}, \phi_{\mathrm{BB}}$ and $\phi_{\mathrm{BA}}$ are the fractions of the propagating terminal radicals $\mathrm{AA}, \mathrm{AB}, \mathrm{BB}$, and BA, respectively.

\section{Copolymerizations in the presence of a chain-transfer agent}

In the literature it is shown that different propagating radicals have an impact on the propagation kinetics, by evidence of their propagation rate coefficients values ${ }^{9}$. Modeling of the termination rate coefficient, $k_{\mathrm{t}, \mathrm{copo}}$, as a function of the initial monomer feed in the reaction mixture has been thoroughly addressed by Fukuda et al. ${ }^{10}$. These models such as for the propagation rate coefficients apply the terminal and penultimate unit effect models. In case of transfer reaction in a copolymerization, the polymer radicals which react with the chaintransfer agent should also be differentiated. Thus, it is expected that a similar effect as seen for the propagation and termination reactions might exist for the chain-transfer reaction.

The present work extends to chain-transfer reaction the models based on the terminal and penultimate unit effect, which were proposed for propagation and termination reactions. 
The reactions shown in Eqs. 6.14a and 6.14b are those for a general chain-transfer process in a chain-transfer copolymerization considering only the terminal unit of a macroradical. Both reactions have an associated chain-transfer rate coefficient, $k_{\mathrm{tr}, \mathrm{A}}$ and $k_{\mathrm{tr}, \mathrm{B}}$.

$\mathrm{RA}^{\bullet}+\mathrm{X} \stackrel{k_{\mathrm{tr}, \mathrm{A}}}{\rightarrow} \mathrm{P}+\mathrm{X}^{\bullet}$

$\mathrm{RB}^{\bullet}+\mathrm{X} \stackrel{k_{\mathrm{tr}, \mathrm{B}}}{\rightarrow} \mathrm{P}+\mathrm{X}^{\bullet}$

These two chain-transfer reactions will contribute to an observed chain-transfer rate coefficient, $k_{\mathrm{tr}, \mathrm{copo}}$, which can be expressed as an average of the two individual rate coefficients, weighted by the radical fractions.

Model A:

$$
k_{\mathrm{tr}, \mathrm{copo}}=\phi_{\mathrm{A}} \cdot k_{\mathrm{tr}, \mathrm{A}}+\left(1-\phi_{\mathrm{A}}\right) \cdot k_{\mathrm{tr}, \mathrm{B}}
$$

Model A, which is described by Eq. 6.15, assumes that penultimate unit effects are negligible in the chain-transfer reaction. This assumption is not readily tested, and it is difficult to make an a priori estimate of the magnitude of potential penultimate unit effects.

In case of a penultimate unit effect in the transfer reaction, four (penultimate) transfer coefficients are taken into account, which are associated with the equations below.

$$
\begin{aligned}
& \mathrm{RAA}^{\bullet}+\mathrm{X} \stackrel{k_{\mathrm{tr}, \mathrm{AA}}}{\rightarrow} \mathrm{P}+\mathrm{X}^{\bullet} \\
& \mathrm{RBB}^{\bullet}+\mathrm{X} \stackrel{k_{\mathrm{tr}, \mathrm{BB}}}{\rightarrow} \mathrm{P}+\mathrm{X}^{\bullet} \\
& \mathrm{RBA}^{\bullet}+\mathrm{X} \stackrel{k_{\mathrm{tr}, \mathrm{BA}}}{\rightarrow} \mathrm{P}+\mathrm{X}^{\bullet} \\
& \mathrm{RAB}^{\bullet}+\mathrm{X} \stackrel{k_{\mathrm{tr}, \mathrm{AB}}}{\rightarrow} \mathrm{P}+\mathrm{X}^{\bullet}
\end{aligned}
$$

The corresponding chain-transfer rate coefficient for the copolymerization is simply given by the following Eq. 6.17.

Model B: $\quad k_{\mathrm{tr}, \mathrm{copo}}=k_{\mathrm{tr}, \mathrm{AA}} \cdot \phi_{\mathrm{AA}}+k_{\mathrm{tr}, \mathrm{BB}} \cdot \phi_{\mathrm{BB}}+k_{\mathrm{tr}, \mathrm{AB}} \cdot \phi_{\mathrm{AB}}+k_{\mathrm{tr}, \mathrm{BA}} \cdot \phi_{\mathrm{BA}}$ 
Bamford et al. ${ }^{11}$ proposed Model B for the estimation of $C_{\mathrm{T}}$.

Model B is also used to predict the termination rate coefficient in copolymerization assuming an arithmetic mean approximation ${ }^{10}$ for the determination of $k_{\mathrm{t}}$ for reactions between two different "penultimate" free radicals. In this case, the model assumes that the polymer radical with endgroup $A B$ terminates with the same radical (endgroup $A B$ ). Thus, the number of penultimate termination rate coefficients is reduced from ten to four. More details about this model are given in ref. 10. A second model, here Model C, differs from the last one in that a geometric mean approximation is applied. Model $\mathrm{C}$ is converted to $k_{\mathrm{tr}}$ simulation since the transfer reaction scheme considers also four reactions (Eqs. 6.16a-6.16d) when a PUE is taken into account.

Model $\mathrm{C}$ is described by the following Eq. 6.18.

Model C: $\quad k_{\mathrm{tr}, \mathrm{copo}}^{0.5}=k_{\mathrm{tr}, \mathrm{AA}}^{0.5} \cdot \phi_{\mathrm{AA}}+k_{\mathrm{tr}, \mathrm{BB}}^{0.5} \cdot \phi_{\mathrm{BB}}+k_{\mathrm{tr}, \mathrm{AB}}^{0.5} \cdot \phi_{\mathrm{AB}}+k_{\mathrm{tr}, \mathrm{BA}}^{0.5} \cdot \phi_{\mathrm{BA}}$

Once $k_{\mathrm{tr}, \mathrm{copo}}$ is known as a function of the initial monomer feed for the two systems of this work, styrene-MMA copolymerizations in the presence of DDM and COPhBF as CTAs, a thorough analysis of the experimental data by model $\mathrm{A}$ is carried out in the next section. For models $\mathrm{B}$ and $\mathrm{C}$, the experimental data $\left(k_{\mathrm{tr}}\right)$ is fitted to derive the variables $k_{\mathrm{tr}, \mathrm{AB}}\left(C_{\mathrm{T}, \mathrm{AB}}\right)$ and $k_{\mathrm{tr}, \mathrm{BA}}\left(C_{\mathrm{T}, \mathrm{BA}}\right)$. An error function for the calculation of residuals is defined and the individual residuals are weighted such that both contributions are of similar size. The error function usually is:

error $=\sum \sqrt{\left(\text { data }_{\exp }-\text { data }_{\text {model }}\right)^{2}}$

The least squares fitting procedure according to Levenberg-Marquardt ${ }^{12,13}$ is started and the program provides a set of optimum parameters. 


\subsubsection{Endgroups estimate}

The most important aspects of free-radical polymerization with and without chain-transfer agent were outlined $\left(k_{\mathrm{p}}\right.$ and $\left.k_{\mathrm{tr}}\right)$ in the preceding part. These concepts are now combined for the prediction of the fraction of a particular endgroup in chain-transfer copolymerization. It is clear that for a particular endgroup to be formed, the radicals of desired nature and a large reactivity of these radicals towards the chain-transfer agent are required. Thus, the probability of the formation of an endgroup of type $\mathrm{A}$ is defined as the product of the probability of finding a radical type $\mathrm{A}$ and the probability of $\mathrm{RA}^{\bullet}$ reacting with CTA. The former probability is given by the fraction of $\mathrm{RA}^{\bullet}$ radicals, $\phi_{\mathrm{A}}$, as given by Eq. 6.12 . The probability of radicals reacting with the chain-transfer agent, $\mathrm{P}(\mathrm{A} / \mathrm{CTA})$, is given by the ratio of the rate of reaction with CTA and all possible reaction rates involving RA radicals (Eqs 20-21) ${ }^{14,15,16,17}$. The transfers to monomer are assumed to be negligible in case of a styrene-MMA copolymerization in the reaction conditions ${ }^{18}$. In a transfer dominated system, transfer events largely dominate termination events (see Chap. 4). Thus, terminations by combination and disproportionation may be negligible.

$$
\begin{aligned}
& \mathrm{P}(\mathrm{A} / \mathrm{CTA})=\frac{\text { rate of } \mathrm{RA} \cdot \text { reacting with CTA }}{\sum_{\text {all possible } \mathrm{x}} \text { rate of } \mathrm{RA} \cdot \text { reacting with } \mathrm{x}} \\
& \mathrm{P}(\mathrm{A} / \mathrm{CTA})=\frac{k_{\mathrm{tr}, \mathrm{A}} \cdot\left[\mathrm{RA}^{\bullet}\right] \cdot[\mathrm{CTA}]}{\left(k_{\mathrm{tr}, \mathrm{A}} \cdot[\mathrm{CTA}]+k_{\mathrm{pAA}} \cdot[\mathrm{A}]+k_{\mathrm{pAB}} \cdot[\mathrm{B}]\right) \cdot\left[\mathrm{RA}^{\bullet}\right]}
\end{aligned}
$$

Using, $C_{\mathrm{T}, \mathrm{A}}=\frac{k_{\mathrm{tr}, \mathrm{A}}}{k_{\mathrm{pAA}}}$ and Eq. 6.3 gives:

$$
\mathrm{P}(\mathrm{A} / \mathrm{CTA})=\frac{C_{\mathrm{T}, \mathrm{A}}[\mathrm{CTA}]}{C_{\mathrm{T}, \mathrm{A}}[\mathrm{CTA}]+[\mathrm{A}]+[\mathrm{B}] \mathrm{r}_{\mathrm{A}}^{-1}}
$$

where, $C_{\mathrm{T}, \mathrm{A}}$ and $[\mathrm{CTA}]$ are the chain-transfer constant for homopolymerization of $\mathrm{A}$ and the concentration of chain-transfer agent, respectively. [A] and [B] are the concentrations of monomer $\mathrm{A}$ and $\mathrm{B}$, respectively. 
The calculation of $\mathrm{P}(\mathrm{A} / \mathrm{CTA})$ only involves the knowledge of kinetic parameters, which are already required for the modeling of the chain-transfer coefficient. To derive an expression for the fraction of A endgroups, $\Phi_{A}$, the probability of forming an A endgroup, i.e., $\phi_{\mathrm{A}} \cdot \mathrm{P}(\mathrm{A} / \mathrm{CTA})$, needs to be normalized by the overall probability of forming an endgroup. If this is taken into account, the fraction of A endgroups is given by Eq. $6.23^{14,15,16,17}$.

$$
\Phi_{\mathrm{A}}=\frac{\phi_{\mathrm{A}} \cdot \mathrm{P}(\mathrm{A} / \mathrm{CTA})}{\phi_{\mathrm{A}} \cdot \mathrm{P}(\mathrm{A} / \mathrm{CTA})+\left(1-\phi_{\mathrm{A}}\right) \cdot \mathrm{P}(\mathrm{B} / \mathrm{CTA})}
$$

\subsubsection{Simulation tool PREDICI ${ }^{\circledR}$}

The kinetic model described in this work is implemented into the simulation program PREDICI $^{\circledR}$ (Polyreaction distributions by Countable System Integration) developed by M. Wulkow $^{19,20}$. The program uses a highly efficient algorithm, called discrete hp-algorithm for solving complex sets of countable differential equations. An integrated function interpreter enables the coupling of rate coefficients of elementary reaction steps with individual species concentrations, conversion, copolymer composition, number and weight average of the formed polymer or chain lengths of individual species. As a special feature of PREDICI ${ }^{\circledR}$, the full molecular weight distribution can be derived without any assumption of closure conditions.

\subsection{Simulation of $k_{\mathrm{tr}}$ applying terminal and PUE models}

In this section, the copolymerization behavior of styrene and MMA in terms of the fraction of propagating styrene radicals, $\phi_{\mathrm{S}}$, is modeled. The applicability of models A through $\mathrm{C}$ (Eqs. $6.15,6.17,6.18)$ is tested for the description of a conventional (DDM) and a catalytic $(\mathrm{COPhBF})$ chain transfer reaction in the copolymerization of styrene and MMA. 


\subsubsection{Free-radical copolymerization}

Fig. 6.1 shows the variation of $\phi_{S}$ with the mole fraction of styrene in the monomer feed for copolymerizations of styrene and $\mathrm{MMA}$ in bulk and in $\mathrm{scCO}_{2}$ at $80^{\circ} \mathrm{C}$ and 300 bar applying the terminal and IPUE models in Eq. 6.11 (A and B correspond to styrene and MMA, respectively).
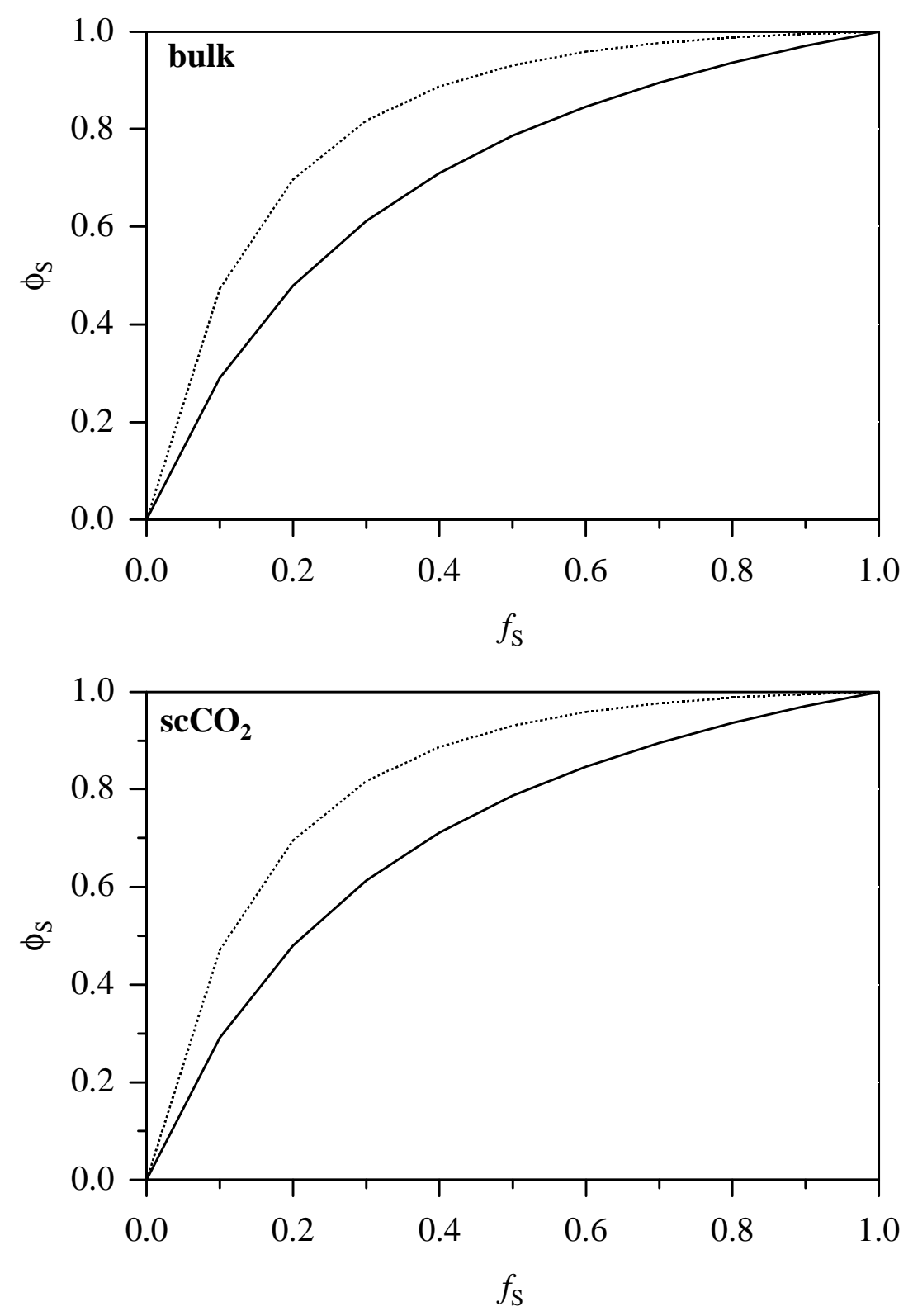

Figure 6.1: $\quad$ Fraction of propagating styrene radicals as a function of $f_{S}$ in styrene-MMA copolymerization in bulk and in $\mathrm{scCO}_{2}$ at $80^{\circ} \mathrm{C}$ and 300 bar. Implicit penultimate predictions (dotted line) and terminal predictions (solid line). 
The parameters used to calculate $\phi_{\mathrm{S}}$ are collected in Table 6.1.

\begin{tabular}{ccccc}
\hline & \multicolumn{2}{c}{ MMA } & \multicolumn{2}{c}{ styrene } \\
\hline & bulk & $\mathrm{scCO}_{2}$ & bulk & $\mathrm{scCO}_{2}$ \\
\hline$k_{\mathrm{p}} / \mathrm{L} \cdot \mathrm{mol}^{-1} \cdot \mathrm{s}^{-1}$ & 1540 & 1382 & 740 & 685 \\
\hline IPUE model & $r_{\mathrm{B}}=0.43$ & $r_{\mathrm{B}}=0.50$ & $r_{\mathrm{A}}=0.85$ & $r_{\mathrm{A}}=0.87$ \\
& $s_{2}=10$ & $s_{\mathrm{B}}=10$ & $s_{\mathrm{A}}=0.5$ & $s_{\mathrm{A}}=0.5$ \\
\hline Terminal model & $r_{\mathrm{B}}=0.41$ & $r_{\mathrm{B}}=0.47$ & $r_{\mathrm{A}}=0.82$ & $r_{\mathrm{A}}=0.86$ \\
\hline
\end{tabular}

Table 6.1: $\quad$ Parameters used to determine $\phi_{S}$ at $80^{\circ} \mathrm{C}$ and 300 bar in bulk and in $\mathrm{scCO}_{2}$ via the IPUE and the terminal models. $k_{p, s t y r e n e}, k_{p, M M A}, r$, and $s$ are taken from refs. 9,21 and 22 .

Fig. 6.1 shows that the fraction of propagating styrene radicals increases with increasing $f_{\mathrm{S}}$. The simple terminal model and the more complex IPUE model give qualitatively the same trend for $\phi_{\mathrm{S}}$.

As indicated in the literature, $k_{\mathrm{p}}$ decreases with increasing the mole fraction of styrene in the monomer feed $^{9,23,24}$. Therefore, $k_{\mathrm{p}}$ styrene is lower than $k_{\mathrm{p}}$ MMA in the same conditions of experiment. It has already been reported that the $k_{\mathrm{p}}$ behavior in styrene and MMA copolymerization is well described by the IPUE model ${ }^{9,23,24}$. Thus, in this work $\phi_{\mathrm{S}}$ and $k_{\mathrm{p} \text {,copo }}$ are determined applying the IPUE model.

In Fig. 6.1, the fraction of the radicals derived from the slower propagating monomer, styrene, is always larger than the corresponding fraction in the monomer feed. For example, at $f_{\mathrm{S}}=0.5$, the corresponding $\phi_{\mathrm{S}}$ value is around 0.9 . Thus, even at low $f_{\mathrm{S}}$ styryl radicals are the dominant radicals in the copolymerization system. Basically this means that the styrene radicals have a longer life time before they propagate and in the meantime are more prone to possible side reactions. It is indeed this behavior that is used in endgroup control. Therefore, in section 6.4, the study will be focused on styrene as endgroup. 


\subsubsection{Copolymerization in the presence of DDM}

Fig. 6.2 shows the $k_{\text {tr }}$ values for copolymerizations of styrene and MMA in $\mathrm{scCO}_{2}$ with $\mathrm{DDM}$ as CTA at $80^{\circ} \mathrm{C}$ and 300 bar obtained experimentally (circles) and via models A through C (lines). The experimental $k_{\text {tr }}$ data, which were determined in section 5.1, are listed in Appendix 2. The reported values show that $k_{\text {tr }}$ in bulk and in $\mathrm{scCO}_{2}$ are similar. Thus, copolymerizations $k_{\text {tr }}$ in bulk are not modeled since it is expected to have the same trend as $k_{\text {tr }}$ copolymerization in $\mathrm{scCO}_{2}$.

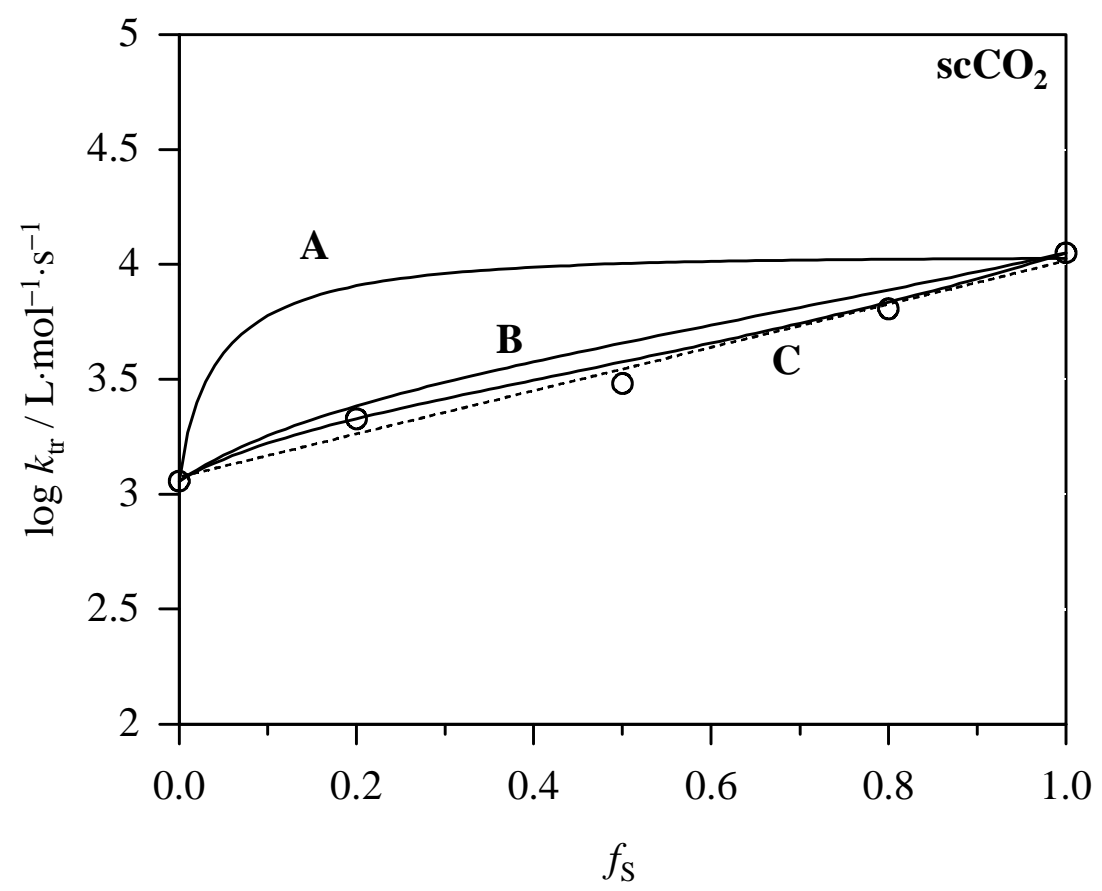

Figure 6.2: $\quad$ Chain-transfer rate coefficients of styrene-MMA copolymerizations in $40 \mathrm{wt} \%$ sc $\mathrm{CO}_{2}$ with DDM as chain-transfer agent at $80^{\circ} \mathrm{C}, 300$ bar plotted against the mole fraction of styrene. The lines $(\boldsymbol{A})$ through $(\boldsymbol{C})$ correspond to the copolymerization $k_{t r}$ models given in the text of Section 6.1.1. The dotted lines correspond to the linear fit of the experimental data listed in Appendix 2.

The copolymerization transfer rate coefficients for the penultimate radicals, $k_{\mathrm{tr}, \mathrm{AB}}$ and $k_{\mathrm{tr}, \mathrm{BA}}$, as obtained from fitting the $k_{\text {tr,copo }}$ data to model $\mathrm{C}$ are listed in Table 6.2. The rate coefficients $k_{\mathrm{tr}, \mathrm{AB}}$ and $k_{\mathrm{tr}, \mathrm{BA}}$ obtained are between the homotransfer rate coefficients and are very close to each other. This would allow to reduce the number of parameters for $k_{\mathrm{tr}, \mathrm{copo}}$ modeling. 


\begin{tabular}{cc}
\hline $\log k_{\mathrm{tr}, \mathrm{AB}} / \mathrm{L} \cdot \mathrm{mol}^{-1} \cdot \mathrm{s}^{-1}$ & $\log k_{\mathrm{tr}, \mathrm{BA}} / \mathrm{L} \cdot \mathrm{mol}^{-1} \cdot \mathrm{s}^{-1}$ \\
\hline 3.17 & 3.47 \\
\hline
\end{tabular}

Table 6.2: $\quad$ Transfer rate coefficients for penultimate radicals as deduced from models $C$ for styrene (A) and MMA (B) copolymerizations at $80^{\circ} \mathrm{C}$ and 300 bar in $\mathrm{scCO}_{2}$ using DDM as CTA.

In both cases, for the experimental data and the predictions, the addition of the slowly propagating monomer styrene to the copolymer system, leads to an increase of $k_{\mathrm{tr}}$. As can be seen upon inspection of Fig. 6.2, the plot of $\log k_{\mathrm{tr}}$ vs $f_{\mathrm{S}}$ is clearly linear for the values experimentally determined. It is obvious that models $\mathrm{C}$ and $\mathrm{B}$, which assume four kinds of penultimate free radicals species, allow for a good representation of the experimental data. Model C provides a better representation of the experimental data. In other words, the simple terminal model, described by model A, does not allow for an accurate description of the chain-transfer rate coefficient for DDM as CTA and the more complex PUE model is required.

The fraction of propagating styryl radicals is the dominant radical endgroup even at low $f_{\mathrm{S}}$ as seen in Fig. 6.1. The results obtained in section 5.1 have shown that $k_{\text {tr }}$ in styrene homopolymerization is higher than $k_{\text {tr }}$ in MMA homopolymerization. Thus, it is expected that $k_{\text {tr }}$ significantly increases even at low $f_{\mathrm{S}}$, as depicted by the model A in Fig. 6.2. This effect is not seen for DDM, which confirms that the simple terminal model does not allow for an accurate description of $k_{\text {tr }}$ for DDM as CTA.

Such PUE model considers steric factors, in particular a shielding of the free-radical chain end. Substituents on the terminal and on the penultimate unit should contribute to this effect. The values of $k_{\mathrm{tr}, \mathrm{AB}}$ and $k_{\mathrm{tr}, \mathrm{BA}}$ determined with model $\mathrm{C}$ are close to $k_{\mathrm{tr}, \mathrm{AA}}$ determined in MMA homopolymerization. This indicates that MMA, which is sterically hindered, strongly influences the transfer process as terminal and penultimate unit.

\subsubsection{Copolymerization in the presence of $\mathrm{COPhBF}$}

$k_{\mathrm{tr}}$ values for copolymerizations of styrene and MMA in bulk and in $\mathrm{scCO}_{2}$ with $\mathrm{COPhBF}$ as CTA at $80^{\circ} \mathrm{C}$ and 300 bar obtained experimentally (circles) and via models A through C (lines) are pictured in Fig. 6.3. The experimental $k_{\mathrm{tr}}{ }^{\text {obs }}$ data, which were determined 
considering scheme 5.2 to be valid, are listed in Appendix 3. Copolymerization $k_{\mathrm{tr}}^{\text {obs }}$ are modeled in both media since the reported values show an influence of $\mathrm{scCO}_{2}$ as a solvent on $k_{\mathrm{tr}}^{\mathrm{obs}}$.
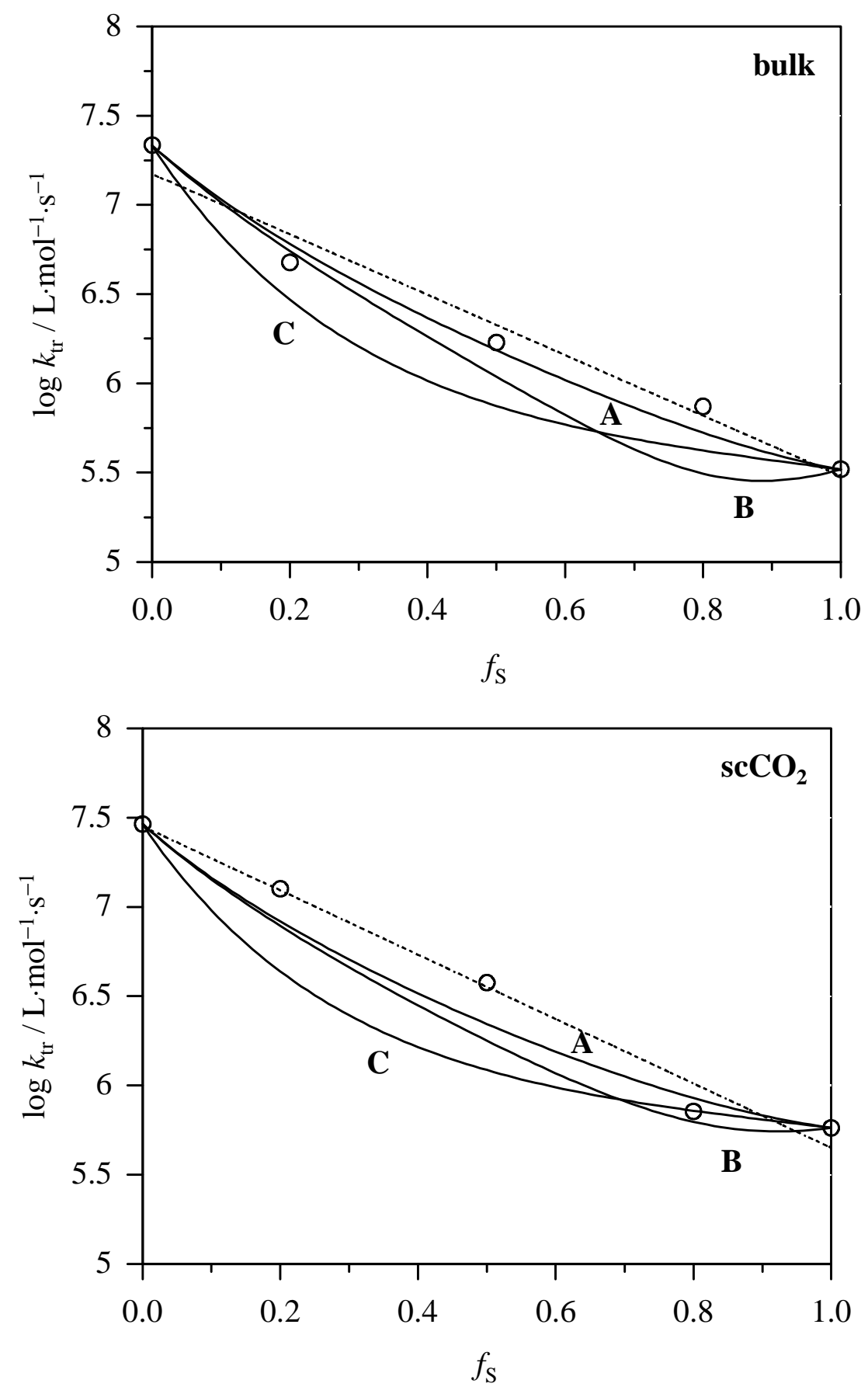

Figure 6.3: $\quad$ Chain-transfer rate coefficients of styrene-MMA copolymerizations in bulk and in 40 wt \% scCO $\mathrm{CO}_{2}$ at $80^{\circ} \mathrm{C}, 300$ bar with $\mathrm{COPhBF}$ as chain-transfer agent plotted against the mole fraction of styrene. The lines $(\boldsymbol{A})$ through $(\boldsymbol{C})$ correspond to the copolymerization $k_{t r}$ models given in the text of Section 6.1.1. The dotted lines correspond to the linear fit of the experimental data which are listed in Appendix 3. 
Fig. 6.3 shows that in both cases, models $\mathrm{A}$ through $\mathrm{C}$ and experimental data, $k_{\mathrm{tr}}{ }^{\text {obs }}$ decreases with increasing $f_{\mathrm{S}}$. As reported in Appendix 3, the uncertainties of the experimental data are relatively significant. Thus, it may be anticipated that within experimental uncertainty model A, which considers only two types of radicals, provides a better description of $k_{\text {tr }}^{\text {obs }}$ for $\mathrm{COPhBF}$ as catalytic chain-transfer agent in bulk and in $\mathrm{scCO}_{2}$. The terminal model is sufficient to describe the $k_{\mathrm{tr}}{ }^{\text {obs }}$ in styrene and MMA copolymerization with COPhBF. In case of $\mathrm{COPhBF}, k_{\mathrm{tr}}^{\text {obs }}$ in styrene homopolymerization is lower than $k_{\mathrm{tr}}^{\text {obs }}$ in MMA homopolymerization (see Section 5.2). If the terminal model describes the transfer reaction well, $k_{\mathrm{tr}}{ }^{\text {obs }}$ should significantly decrease for $f_{\mathrm{S}}$ from 0 to 2 . The values of $k_{\mathrm{tr}}{ }^{\text {obs }}$ reported in Appendix 2, clearly show this effect $\left(k_{\mathrm{tr}}{ }^{\text {obs }}\right.$ in bulk at 300 bar are $2.16 \cdot 10^{7}$ and $4.64 \cdot 10^{6} \mathrm{~L} \cdot \mathrm{mol}^{-}$ ${ }^{1} \cdot \mathrm{s}^{-1}$ for $f_{\mathrm{S}}=0$ and 0.2 , respectively). Thus, a terminal model is expected for the description of the transfer process with $\mathrm{COPhBF}$ as catalytic CTA.

\subsection{Modeling of full molecular weight distributions of styrene-MMA copolymers via PREDICI ${ }^{\circledR}$}

\subsubsection{Experimental considerations}

In this section, the modeling of full molecular weight distributions, MWDs, of polymers is investigated. As described in the preceding section, IPUE has already been demonstrated to describe the propagation rate coefficients ${ }^{9,21,22}$ for copolymerization of styrene (S) and MMA (M). $k_{\mathrm{pSSS}}$ and $k_{\mathrm{pMMM}}$ are the propagation rate coefficients of styrene and MMA homopolymerization, respectively. The propagation rate coefficients, $k_{\mathrm{pSM}}, k_{\mathrm{pMS}}, \bar{k}_{\mathrm{pSS}}, \bar{k}_{\mathrm{pMM}}$ are determined using Eqs. 6.5-6.8. $k_{\mathrm{pSSS}}, k_{\mathrm{pMMM}}, r_{\mathrm{S}}$ and $r_{\mathrm{M}}$ are listed in Table 6.1 for the conditions required.

The general reaction scheme used for the copolymerization of styrene and MMA with a transfer agent is as follows: 


\begin{tabular}{|c|c|c|}
\hline Initiation & $\begin{array}{c}\mathrm{I}^{\bullet}+\mathrm{S} \rightarrow \mathrm{RS}_{1}^{\bullet} \\
\mathrm{I}^{\bullet}+\mathrm{M} \rightarrow \mathrm{RM}_{1}^{\bullet}\end{array}$ & $\begin{array}{c}k_{\mathrm{pSSS}} \\
k_{\mathrm{pMMM}}\end{array}$ \\
\hline \multirow{4}{*}{ Propagation } & $\mathrm{RS}_{\mathrm{n}} \cdot+\mathrm{S} \rightarrow \mathrm{RS}_{\mathrm{n}+1} \cdot$ & $\bar{k}_{\mathrm{pSS}}$ \\
\hline & $\mathrm{RM}_{\mathrm{n}}{ }^{\bullet}+\mathrm{M} \rightarrow \mathrm{RM}_{\mathrm{n}+1^{\bullet}}$ & $\bar{k}_{\mathrm{pMM}}$ \\
\hline & $\mathrm{RS}_{\mathrm{n}}{ }^{+}+\mathrm{M} \rightarrow \mathrm{RM}_{\mathrm{n}+1}$ & $k_{\mathrm{pSM}}$ \\
\hline & $\mathrm{RM}_{\mathrm{n}}{ }^{+}+\mathrm{S} \rightarrow \mathrm{RS}_{\mathrm{n}+1} \cdot$ & $k_{\mathrm{pMS}}$ \\
\hline \multirow{3}{*}{$\begin{array}{l}\text { Termination } \\
\text { (combination and } \\
\text { disproportionation) }\end{array}$} & $\mathrm{RS}_{\mathrm{n}}{ }^{\cdot}+\mathrm{RS}_{\mathrm{m}}^{\cdot} \rightarrow \mathrm{P}_{\mathrm{n}+\mathrm{m}}, \mathrm{P}_{\mathrm{n}}+\mathrm{P}_{\mathrm{m}}$ & $k_{\mathrm{tc}, \mathrm{S},} k_{\mathrm{td}, \mathrm{S}}$ \\
\hline & $\mathrm{RM}_{\mathrm{n}}{ }^{\cdot}+\mathrm{RM}_{\mathrm{m}} \cdot \rightarrow \mathrm{P}_{\mathrm{n}+\mathrm{m}}, \mathrm{P}_{\mathrm{n}}+\mathrm{P}_{\mathrm{m}}$ & $k_{\mathrm{tc}, \mathrm{M}}, k_{\mathrm{td}, \mathrm{M}}$ \\
\hline & $\mathrm{RS}_{\mathrm{n}} \cdot+\mathrm{RM}_{\mathrm{m}} \cdot \rightarrow \mathrm{P}_{\mathrm{n}+\mathrm{m}}, \mathrm{P}_{\mathrm{n}}+\mathrm{P}_{\mathrm{m}}$ & $k_{\mathrm{tc}, \mathrm{copo}}, k_{\mathrm{td}, \mathrm{copo}}$ \\
\hline \multirow{4}{*}{ Transfer to monomer } & $\mathrm{RS}_{\mathrm{n}} \cdot+\mathrm{S} \rightarrow \mathrm{P}_{\mathrm{n}}+\mathrm{S}_{1} \cdot$ & $k_{\mathrm{trM}, \mathrm{S}}$ \\
\hline & $\mathrm{RM}_{\mathrm{n}}+\mathrm{M} \rightarrow \mathrm{P}_{\mathrm{n}}+\mathrm{M}_{1}$ & $k_{\mathrm{trM}, \mathrm{M}}$ \\
\hline & $\mathrm{RS}_{\mathrm{n}}{ }^{\bullet}+\mathrm{M} \rightarrow \mathrm{P}_{\mathrm{n}}+\mathrm{M}_{1}^{\bullet}$ & $k_{\mathrm{trM}, \mathrm{copo}}$ \\
\hline & $\mathrm{RM}_{\mathrm{n}}{ }^{\bullet}+\mathrm{S} \rightarrow \mathrm{P}_{\mathrm{n}}+\mathrm{S}_{1} \cdot$ & $k_{\text {trM,copo }}$ \\
\hline
\end{tabular}

Scheme 6.1: $\quad$ Typical reaction scheme for copolymerizations of styrene (S) and MMA (M). $k_{t, c}$ and $k_{t, d}$ are the termination rate coefficients for combination and disproportionation, respectively. $k_{t r M}$ is the chain-transfer rate coefficients to monomer.

The modeling of MWDs via PREDICI ${ }^{\circledR}$ was carried out for polymerizations in bulk and in $\mathrm{scCO}_{2}$ at 300 bar and $80^{\circ} \mathrm{C}$. The termination rate coefficients, $k_{\mathrm{tc}}$ and $k_{\mathrm{td}}$, are obtained considering that the ratio of combination and disproportionation is 7 as suggested in ref. 25 . As already mentioned, in a transfer dominated system the termination events are negligible as compared to the transfer events. In addition, in styrene-MMA copolymerization the transfer rate coefficients to monomer are very low. Therefore, the following approximations are applied. $k_{\mathrm{tc}, \text { copo }}, k_{\mathrm{td}, \text { copo }}$ and $k_{\mathrm{trM} \text {,copo }}$ are the arithmetic average values of the corresponding homo values. These coefficients are listed in Table 6.3. 


\begin{tabular}{lccc}
\hline \multicolumn{2}{c}{$k_{\mathrm{tc}} / \mathrm{L} \cdot \mathrm{mol}^{-1} \cdot \mathrm{s}^{-1}$} & $k_{\mathrm{trM}} / \mathrm{L} \cdot \mathrm{mol}^{-1} \cdot \mathrm{s}^{-1}$ \\
\hline bulk & $\mathrm{scCO}_{2}$ & \\
\hline \multirow{2}{*}{ MMA } & $5 \cdot 10^{7}$ & $10^{8}$ & 0.06 \\
& ref. $9^{*}$ & ref. $9^{*}$ & ref. 18 \\
\hline \multirow{2}{*}{ styrene } & $10^{8}$ & $8 \cdot 10^{8}$ & 0.07 \\
& ref. 21 & ref. 21 & ref. 18 \\
\hline
\end{tabular}

Table 6.3: $\quad$ Kinetic coefficients used for modeling the molecular weight distribution of styrene and MMA polymerizations in bulk and in $40 \mathrm{wt} \% \mathrm{scCO} \mathrm{O}_{2}$ at $80^{\circ} \mathrm{C}$ and 300 bar. ${ }^{*}$ The initiator used was AIBN.

In the PLP-SEC MWDs, the laser pulse rate is also a very important parameter, which determines the initial radical concentration, $c_{\mathrm{R}}^{\mathrm{O}} \cdot c_{\mathrm{R}}^{\mathrm{O}}$ is given by Eq. 6.24 as follows:

$c_{\mathrm{R}}^{\mathrm{O}}=2 \cdot \Phi \cdot \frac{n_{\mathrm{abs}}}{V}$

where $\Phi$ is the primary quantum yield, $n_{\text {abs }}$ is the number of absorbed photons and $V$ is the irradiated volume. The primary quantum yield is the product of the laser efficiency $\varphi$ and the initiator efficiency $f$ and corresponds to a value of 0.24 for DMPA ${ }^{26}$. According to the BeerLambert's law, the number of absorbed photons can be calculated by Eq. 6.25.

$n_{\mathrm{abs}}=\frac{E_{\mathrm{p}}}{E_{\lambda}} \cdot\left(1-10^{-\varepsilon c d}\right)$

$E_{\mathrm{p}}$, the energy of a single laser pulse, is measured using a laser power meter for known laser pulse repetition rate. $E_{\lambda}$ is the energy of one mol of photons at the laser wavelength of 351 $\mathrm{nm}$. $\varepsilon$ is the molar absorption coefficient of the initiator molecule at $351 \mathrm{~nm}$, which is $200 \cdot 10^{3}$ $\mathrm{cm}^{2} \cdot \mathrm{mol}^{-1}$ for DMPA, $c$ is the photoinitiator concentration and $d$ is the optical path length. 
The radical concentration used for the simulation via PREDICI ${ }^{\circledR}$ is estimated to be $1.5 \cdot 10^{-6}$ $\mathrm{mol} \cdot \mathrm{L}^{-1}$.

\section{Broadening of the MWD}

Previously, it has been reported that a simulated MWD should be broadened in order to account for the broadening due to axial dispersion in experimental SEC analysis ${ }^{27}$. The SEC set-up used for the determination of the polymer MWD shows only very little broadening, which may be characterized by a $\sigma$-value of 0.03-0.04 ref. 27 . The procedure to determine this broadening value has been described by Buback and coworkers ${ }^{28}$. Fig. 6.4 shows a comparison between MWDs as obtained via PREDICI ${ }^{\circledR}$ simulation (lines) and MWDs which were broadened applying a $\sigma$-value of $0.04(\mathrm{x})$.

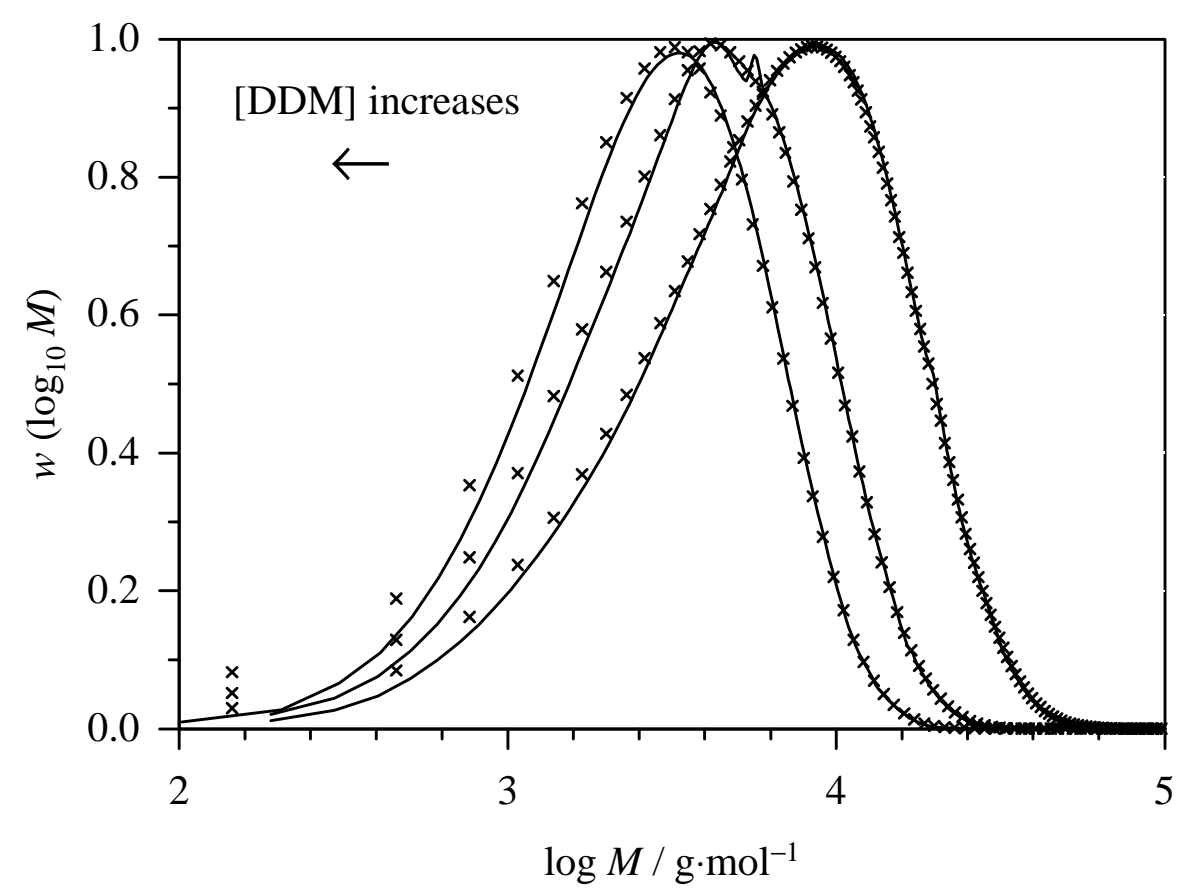

Figure 6.4: MWDs obtained from simulations without (lines) and after applying broadening $(x)$ for copolymerizations of styrene and $M M A\left(f_{S}=0.5\right)$ at $80^{\circ} \mathrm{C}$, 300 bar in $\mathrm{scCO}_{2}$. [DDM]/[M] =0.005, 0.01, 0.015.

It is obvious from Fig. 6.4 that the impact of broadening MWDs is not significant. Especially the high molecular weight region of the distribution used in the CLD method (see section 4) is 
not affected by broadening. Thus, MWDs obtained from modeling presented in the following Sections are given without applying any broadening.

\subsubsection{DDM as chain-transfer agent}

The modeling of MWD for styrene-MMA polymer with DDM is investigated in order to confirm the prediction of the presence of penultimate effect in the transfer process. The validity of the transfer rate coefficients, $k_{\mathrm{tr}, \mathrm{AB}}$ and $k_{\mathrm{tr}, \mathrm{BA}}$, determined in section 6.2 is also tested.

\section{Reaction scheme}

In the following modeling of MWD, PUE model is applied as it has been suggested in section 6.2 to describe the transfer process well. The mechanism followed is shown in scheme 6.2.
Transfer to transfer agent
$\mathrm{RMM}_{\mathrm{n}}+\mathrm{X} \rightarrow \mathrm{P}_{\mathrm{n}}+\mathrm{X}^{\bullet}$
$k_{\mathrm{trX}, \mathrm{MM}}$
$\mathrm{RSM}_{\mathrm{n}}+\mathrm{X} \rightarrow \mathrm{P}_{\mathrm{n}}+\mathrm{X}^{\bullet}$
$k_{\mathrm{trX}, \mathrm{SM}}$
$\mathrm{RMS}_{\mathrm{n}} \cdot \mathrm{X} \rightarrow \mathrm{P}_{\mathrm{n}}+\mathrm{X}^{\bullet}$
$k_{\mathrm{trX}, \mathrm{MS}}$
$\mathrm{RSS}_{\mathrm{n}}+\mathrm{X} \rightarrow \mathrm{P}_{\mathrm{n}}+\mathrm{X}^{\bullet}$
$k_{\text {trX,SS }}$

Propagation of transfer agent

$$
\begin{array}{cc}
\mathrm{X}^{\bullet}+\mathrm{M} \rightarrow \mathrm{XM}_{1} \cdot & k_{\mathrm{pX}}=k_{\mathrm{pMMM}} \\
\mathrm{X}^{\bullet}+\mathrm{S} \rightarrow \mathrm{XS}_{1}{ }^{\bullet} & k_{\mathrm{pX}}=k_{\mathrm{pSSS}}
\end{array}
$$

\section{Scheme 6.2: Chain-transfer reactions for copolymerizations with DDM.}

$k_{\text {trX,MM }}$ and $k_{\text {trX,SS }}$ are the chain-transfer rate coefficients for MMA and styrene homopolymerizations, respectively. $k_{\mathrm{trX}, \mathrm{SM}}$ and $k_{\mathrm{trX}, \mathrm{MS}}$ correspond to the chain-transfer rate coefficients of the penultimate unit radicals SM and MS, respectively, which were estimated 
using model C in section $6.2\left(k_{\mathrm{trX}, \mathrm{SM}}\right.$ and $k_{\mathrm{trX}, \mathrm{MS}}$ are $k_{\mathrm{tr}, \mathrm{AB}}$ and $k_{\mathrm{tr}, \mathrm{BA}}$, respectively and are listed in Table 6.2).

The propagation rate coefficient of the transfer agent with a monomer $\mathrm{A}, k_{\mathrm{pX}}$, is assumed to be similar to the homopropagation rate coefficient of A, $k_{\mathrm{pAAA}}$.

\section{Modeling of MWDs and $\boldsymbol{k}_{\mathrm{tr}}$}

PREDICI $^{\circledR}$ simulations of MWD were investigated for styrene-MMA copolymerizations $\left(f_{\mathrm{S}}=0.1,0.4\right.$ and 0.6$)$ at $80^{\circ} \mathrm{C}$ and 300 bar in bulk. Fig. 6.5 shows, as example, the modeled MWDs obtained for polymerizations in bulk with $f_{\mathrm{S}}=0.1$ in the presence of different amounts of DDM. As $k_{\mathrm{tr}}$ is not influenced by the presence of $\mathrm{scCO}_{2}$ as compared to the bulk value, the same results are expected in both media.

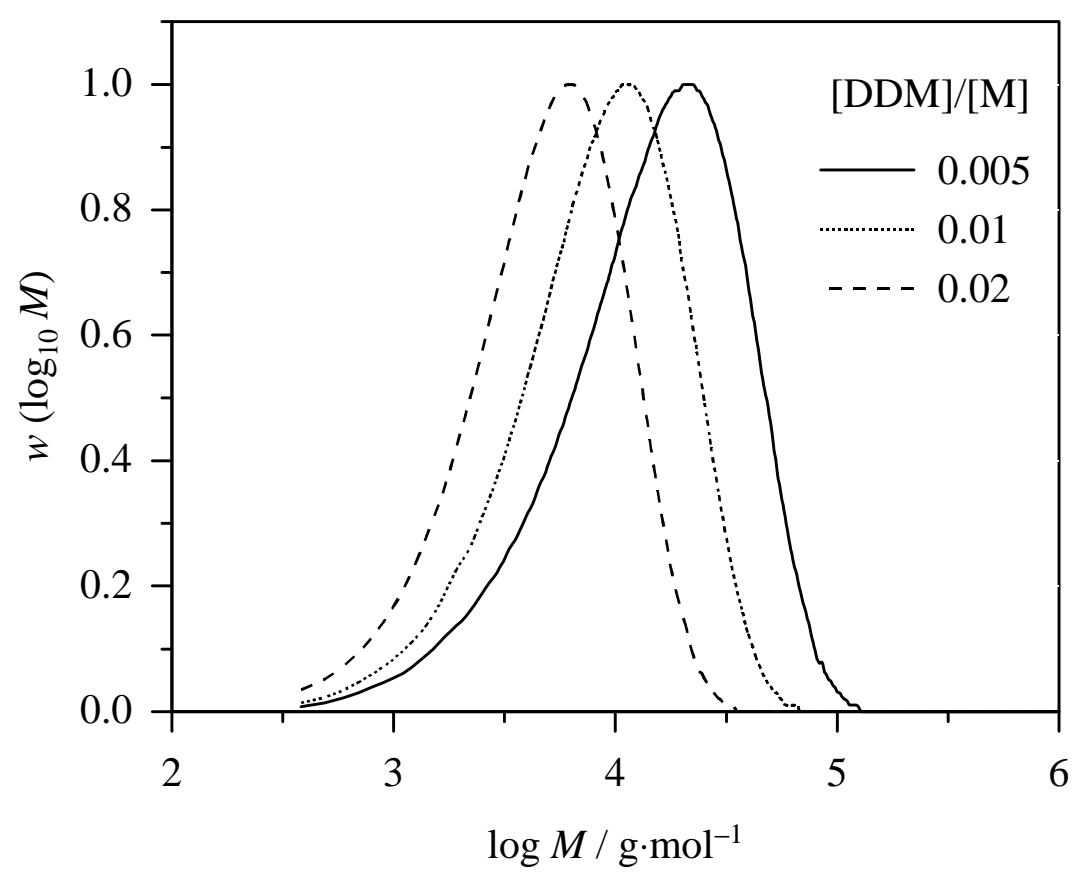

Figure 6.5: $\quad$ Simulated molecular weight distributions for copolymerizations of styrene and $M M A\left(f_{S}=0.1\right)$ at $80^{\circ} \mathrm{C}, 300$ bar with different amounts of DDM.

As expected, Fig. 6.5 shows that MWD obtained via PREDICI ${ }^{\circledR}$ is shifted to lower MW values increasing the amount of DDM.

In order to compare $k_{\text {tr }}$ values obtained experimentally in section 5.2 and $k_{\text {tr }}$ values obtained by modeling the MWD via PREDICI ${ }^{\circledR}$, chain-transfer rate coefficients were determined using the 
same method (CLD method as explained in section 4). Fig. 6.6 pictures $\log k_{\mathrm{tr}}$, derived from modeling (full circle) and experimentally determined (open circle), as a function of $f_{\mathrm{S}}$ for copolymerizations of styrene and MMA in bulk at $80^{\circ} \mathrm{C}$ and 300 bar.

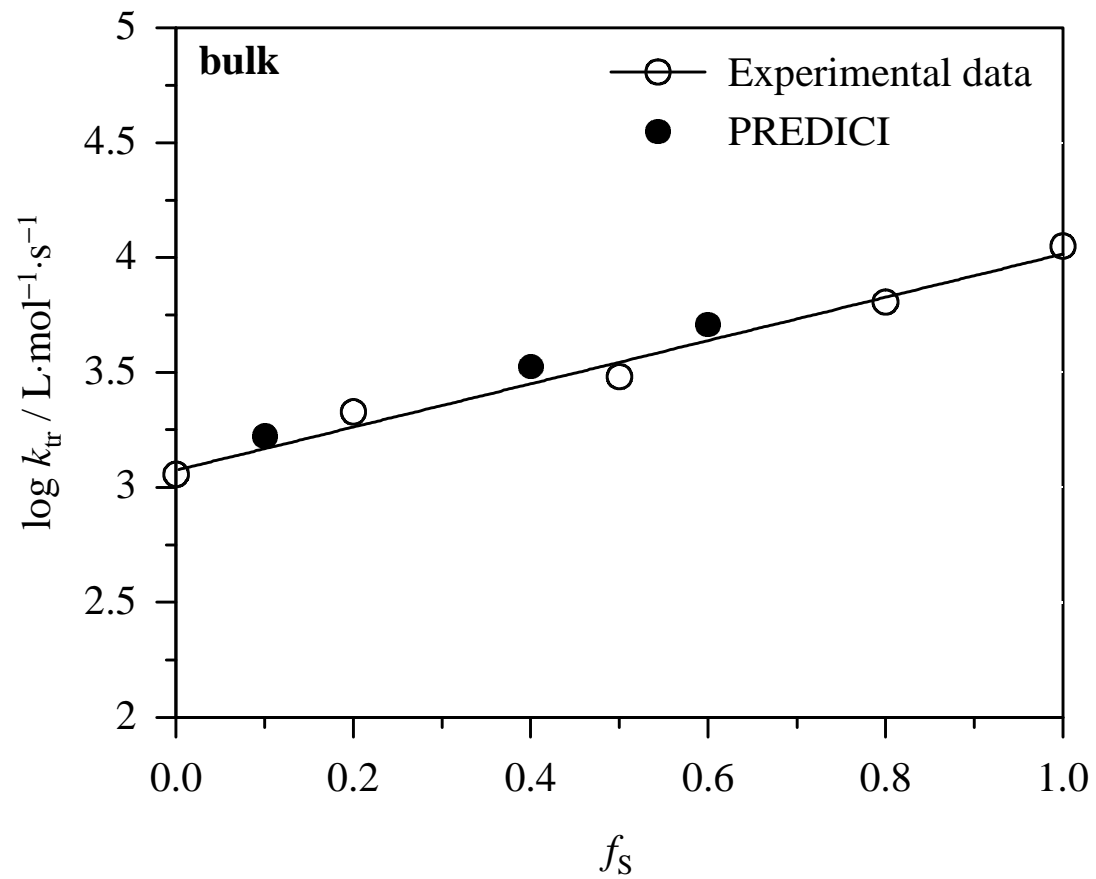

Figure 6.6: $\quad \log k_{t r}$ obtained from MWDs modeled with PREDICI ${ }^{\circledR}$ (full circle) and obtained experimentally (open circle) for bulk copolymerizations of styrene and $\mathrm{MMA}$ at $80^{\circ} \mathrm{C}$ and 300 bar as a function of the mole fraction of styrene in the monomer feed.

Fig. 6.6 shows a very good agreement between the $k_{\text {tr }}$ values, determined via PREDICI ${ }^{\circledR}$ using $k_{\mathrm{tr}, \mathrm{AB}}$ and $k_{\mathrm{tr}, \mathrm{BA}}$ reported in table 6.2, and the $k_{\mathrm{tr}}$ values obtained experimentally. As mentioned before, the plot of $\log k_{\mathrm{tr}}$ vs. $f_{\mathrm{S}}$ is linear, which induces that knowing homopolymerizations $k_{\mathrm{tr}}$ values, copolymerization $k_{\text {tr }}$ may be estimated at each $f_{\mathrm{S}}$.

It is clear that the kinetic model and the kinetic coefficients, $k_{\mathrm{tr}, \mathrm{AB}}$ and $k_{\mathrm{tr}, \mathrm{BA}}$, applied here are available to describe the copolymerization of styrene-MMA in bulk with DDM as CTA via PREDICI $^{\circledR}$.

The present work indicates that styrene-MMA copolymerization with DDM as CTA is adequately represented by the PUE model in the transfer reaction.

In order to confirm that terminal model does not allow for an accurate description of the transfer process with DDM, few MWDs were modeled considering a terminal model for the 
transfer reaction with DDM. In this case only two transfer reactions are taken into account associated to the MMA and styrene homopropagation transfer rate coefficients.

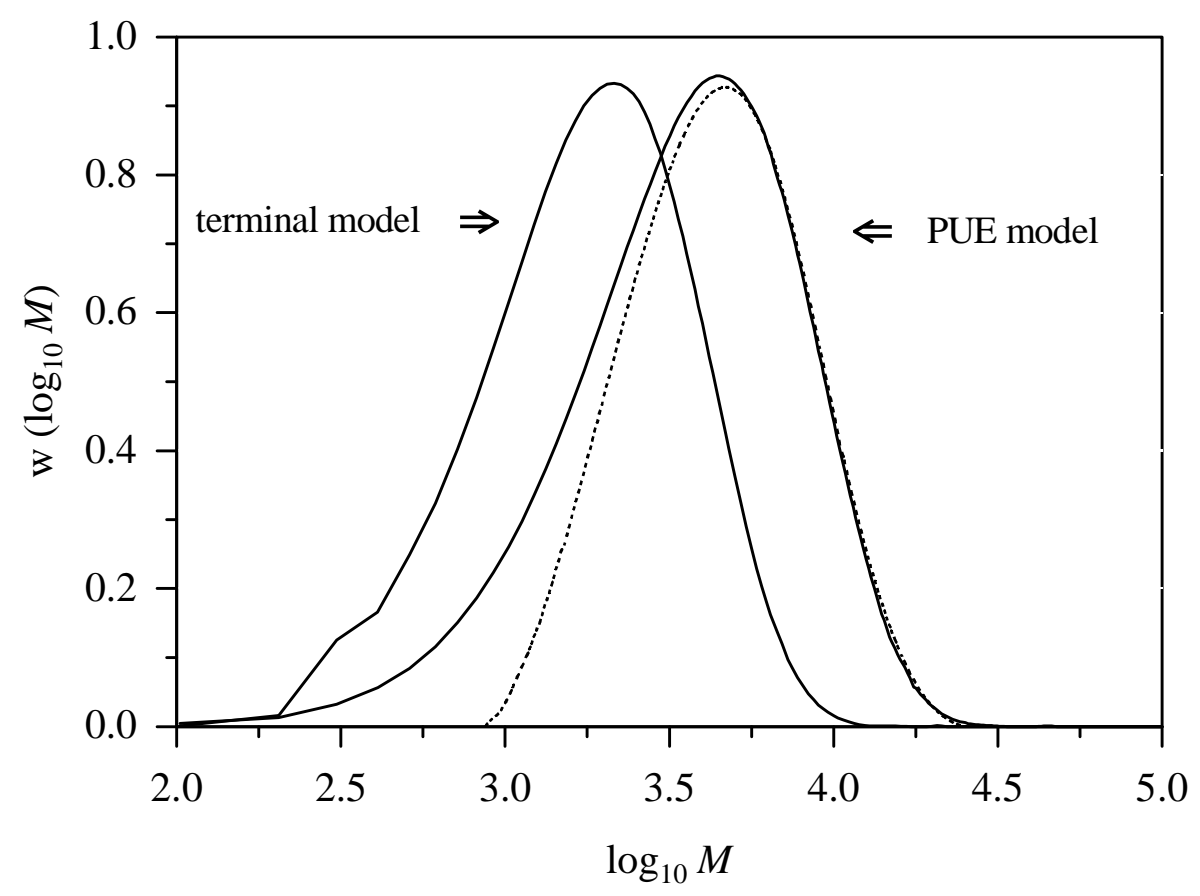

Figure 6.7: $\quad$ Simulated (solid line) and experimental (dotted line) molecular weight distributions for the copolymerization of styrene and MMA $\left(f_{S}=0.5\right)$ in bulk at $80^{\circ} \mathrm{C}$ and 300 bar with $[D D M] /[$ sty $]=0.01$.

Fig. 6.7 shows, as example, the MWD obtained for bulk polymerizations at $80^{\circ} \mathrm{C}, 300$ bar, and $f_{\mathrm{S}}=0.5$. As expected the MWD modeled using PUE model in the transfer reaction is in very good agreement with the experimental MWD. In contrast, the modeled MWD obtained considering a terminal model in the transfer reaction, is shifted to lower values of MW compared to the experimental MWD. This provides strong evidence that terminal model is not sufficient to allow a good representation of the transfer process with DDM. 


\subsubsection{COPhBF as catalytic chain-transfer agent}

As mentioned in section 5.4, $k_{\mathrm{tr}}^{\text {obs }}$ determined in styrene and MMA homo- and copolymerization are based on scheme 5.2. The fraction of propagating styryl radicals is very large at low $f_{\mathrm{S}}$ as seen in Fig. 6.2. Thus, it is not adequate to perform the modeling of MWD for styrene-MMA copolymer even at low $f_{\mathrm{S}}$ since the transfer scheme for radical terminated styrene is unclear. In the next part investigations into MWDs for MMA homopolymerization are performed.

\section{Reaction scheme}

The mechanism of the catalytic chain-transfer reaction in MMA homopolymerization is illustrated in Scheme 6.3. The rate determining step within this reaction sequence is the hydrogen abstraction by the $\mathrm{Co}(\mathrm{II})$ complex, which is believed to proceed with a rate coefficient, $k_{\mathrm{trX}, \mathrm{M}}$, which is $k_{\mathrm{tr}}$ determined for MMA homopolymerization. The second step of the transfer reaction, which initiates a new radical, is considered to be fast.

Transfer to tranfer agent

$$
\begin{array}{r}
\mathrm{RM}_{\mathrm{n}} \cdot \mathrm{Co}(\mathrm{II}) \rightarrow \mathrm{P}_{\mathrm{n}}+\mathrm{Co}(\mathrm{III})-\mathrm{H} \\
\mathrm{Co}(\mathrm{III})-\mathrm{H}+\mathrm{M} \rightarrow \mathrm{M}_{1} \cdot \operatorname{Co}(\mathrm{II})
\end{array}
$$$$
k_{\text {trX,M }}
$$$$
k_{\text {fast }}
$$
Scheme 6.3: Catalytic chain-transfer reactions for MMA homopolymerization with $\mathrm{COPhBF}$

\section{Modeling of MWDs}

The MWDs obtained via PREDICI ${ }^{\circledR}$ for MMA homopolymerizations at $80^{\circ} \mathrm{C}, 300$ bar, in bulk and in $\mathrm{scCO}_{2}$ are pictured in Fig. 6.8. The $k_{\mathrm{tr}}{ }^{\text {obs }}$ used are listed in Appendix 3. 

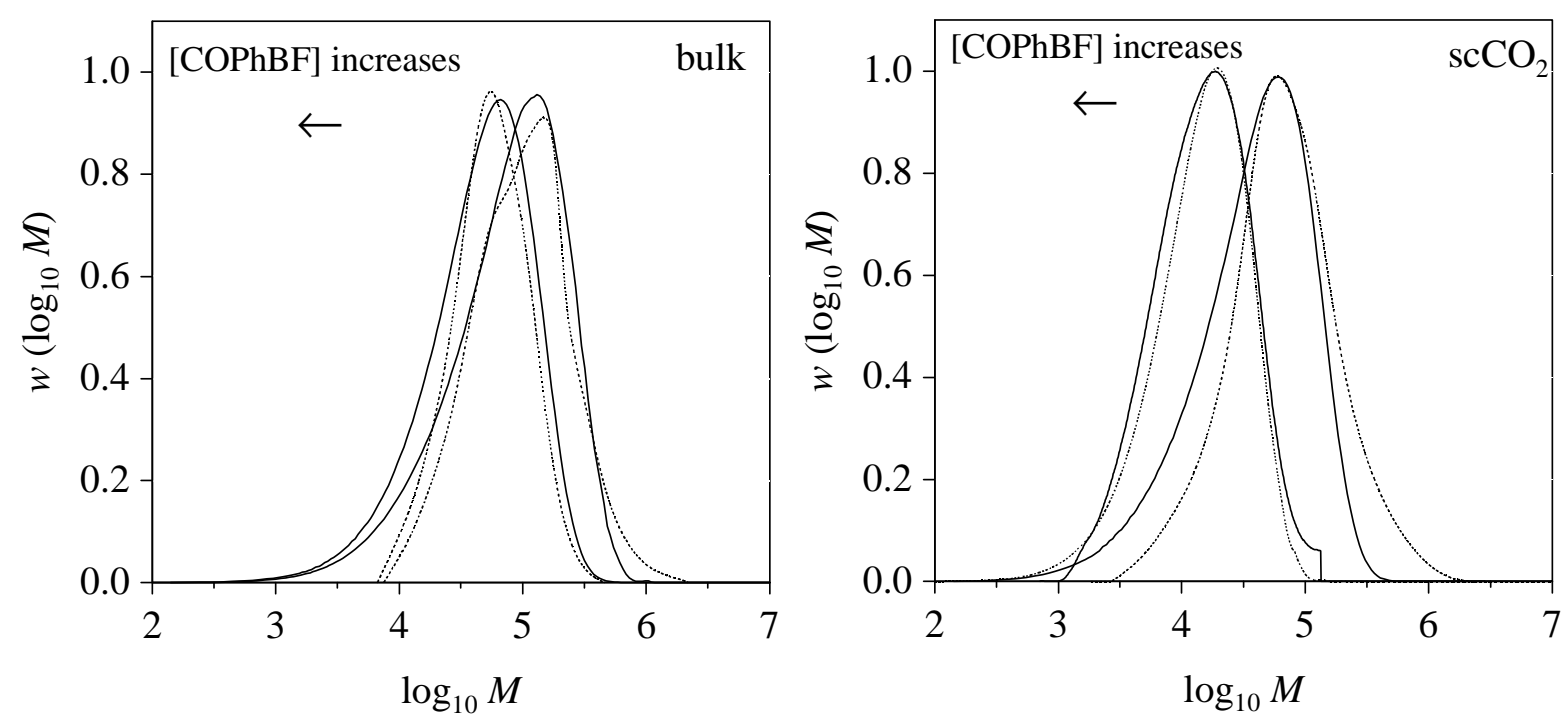

Figure 6.8: $\quad$ Simulated (solid line) and experimental (dotted line) molecular weight distributions for MMA homopolymerizations in bulk and in $\mathrm{scCO}_{2}$ at $80^{\circ} \mathrm{C}$ and 300 bar with $[\mathrm{COPhBF}] /[\mathrm{MMA}]=5.410^{-7}, 1.510^{-7}$ and $8.810^{-8}, 1.510^{-7} \mathrm{in}$ $\mathrm{scCO}_{2}$ and in bulk, respectively.

The shape and peak position of the experimental and modeled MWDs are slightly different, which may be explained by uncertainties in the COPhBF concentration. As explained in Section 3, the amount of complex used is small and thus uncertainty in the concentration may significantly shift the MWD distribution. However the high molecular weight region, which is used for determining $k_{\mathrm{tr}}$, is not affected. Thus, $k_{\mathrm{tr}}{ }^{\text {obs }}$ values determined in MMA homopolymerization following scheme 5.2 are considered as accurate.

\subsubsection{Closing remarks}

In this work PREDICI ${ }^{\circledR}$ can not be considered as an effective method to verify the validity of $k_{\text {tr }}$ experimentally obtained, assuming that the implemented transfer coefficients are directly derived from the experimental MWD. Nevertheless, transfer rate coefficients and transfer process have been precisely determined for the system styrene-MMA with DDM as CTA.

Hutchinson et al. ${ }^{29}$ have reported that $C_{\mathrm{T}}$ of DDM is identical for methacrylates with different ester sizes. Thus, by way of $k_{\mathrm{tr}}$ reported in this work and other kinetics coefficients reported in the literature, PREDICI ${ }^{\circledR}$ appears to be a powerful tool for simulation of homo-, copo- or even terpolymerizations of styrene and methacrylates with DDM as CTA over a wide range of temperature and pressure. 


\subsection{Endgroups estimate}

Fig. 6.2 has shown that the more slowly propagating radicals are the more reactive radical towards DDM, leading to an increase of $k_{\text {tr }}$ with increasing $f_{\mathrm{S}}$. This latter behavior is exactly what is required for an effective endgroup control. The addition of styrene leads to an increase in $\phi_{\mathrm{S}}$ and an increase in the overall chain-transfer probability. The a priori prediction that at some monomer feed composition with $f_{\mathrm{S}}<<1$, the nature of the dominant endgroups will be that of styrene, i.e, $\Phi_{\mathrm{S}}=1$.

The predictions made by Eq. 6.23 on the fraction of styrene endgroups, $\Phi_{\mathrm{S}}$, for styrene-MMA copolymers in $\mathrm{scCO}_{2}$ with DDM as CTA, are shown in Fig. 6.9. The monomer concentrations are calculated from mole fraction, density and molecular weight of the monomers. The CTA concentration is obtained considering that $[\mathrm{CTA}] /[$ sty $]$ are 0.015 , which were the conditions of the measurements (see section 5.1).

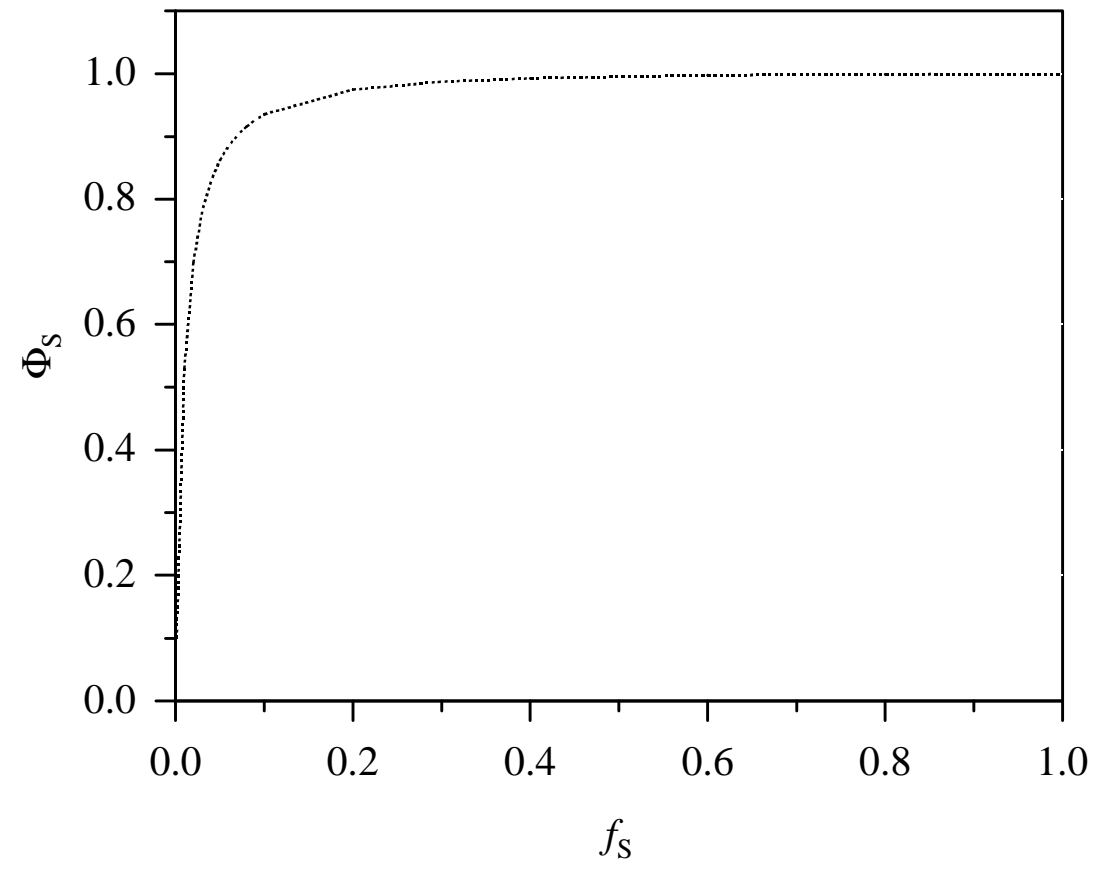

Figure 6.9: $\quad$ Fraction of styrene endgroups as a function of the mole fraction of styrene in the monomer feed for styrene-MMA copolymerizations in $40 \mathrm{wt} \% \mathrm{scCO} \mathrm{O}_{2}$ at $80^{\circ} \mathrm{C}$ and 300 bar with DDM as CTA.

$\Phi_{\mathrm{S}}$ strongly increases for $f_{\mathrm{S}}<0.1$ and then stays almost constant by $\Phi_{\mathrm{S}}$ close to 1 . The fraction of styrene endgroups in the styrene-MMA copolymer depends on the affinity of styrene to 
CTA. In Fig. 6.9, the qualitative expectations are clearly recognized. The synergistic effects in copolymerization with DDM lead to a situation in which nearly all chains have a styrene endgroup at $f_{\mathrm{S}}=0.1$. The amount of DDM was also varied and no significant effect is observed on $\Phi_{\mathrm{S}}: \Phi_{\mathrm{S}}$ slightly increases by decreasing [DDM].

Davis et al. ${ }^{30}$ found the same synergistic effect as for DDM here for the copolymerization of styrene and $\alpha$-methyl styrene with $\mathrm{COPhBF}$ as CTA, where $\alpha$-methyl styrene is the more slowly propagating monomer. It was shown that the addition of $\alpha$-methyl styrene to the system leads to an increase in the fraction of propagating $\alpha$-methyl styrene radicals and an increase in overall chain-transfer probability. The kinetic modeling was performed assuming scheme 5.2 available for the transfer process.

In case of $\mathrm{COPhBF}$, the more slowly propagating radicals, styryl, are less reactive towards $\mathrm{COPhBF}$ and this induces a decrease of $k_{\mathrm{tr}}$ with increasing $f_{\mathrm{S}}$. In this case, there are two opposing effects for the production of a certain endgroup; Addition of styrene leads to an increase in $\phi_{\mathrm{S}}$ but the overall chain-transfer probability decreases. Overall, no prediction of the nature of the dominant endgroups in this system can be given.

In summary, the fraction of endgroup in a copolymer is controlled by the nature of monomer and chain-transfer agent. In a styrene-MMA comonomer mixture, the monomer required as the endgroup needs to display a very low reactivity towards addition to another monomer, but a high reactivity towards the CTA. The monomer making up the main chain of the polymer should be highly reactive towards addition to monomer and be relatively unreactive towards the $\mathrm{CTA}^{30}$. These observations were also confirmed in the literature ${ }^{30}$ for other systems.

\subsection{References}

1. Heuts, J. P. A.; Foster, D. J.; Davis, T. P. ACS symposium series 768, Transition Metal Catalysis in Macromolecular Design 2000, p 254.

2. Fukuda, T.; Kubo,K.; Ma, Y. D. Prop. Polym Sci 1992, 17, 87.

3. Maxwell, I. A.; Aerdts, A. M.; German, A. L. Macromolecules 1993, 26, 1956.

4. Merz, E.; Alfrey, T.; Goldfinger, G. J. Polym. Sci. 1946, 1, 75.

5. $\quad$ Fukuda, T.; Ma, Y.-D.; Inagaki, H.Macromolecules 1995, 18, 1985. 
6. Fukuda, T.; Ma, Y.-D; Inagaki, H. Makromol. Chem. Rapid Commun. 1987, 8, 495.

7. Fukuda, T.; Ma, Y.-D.; Inagaki, H.; Kubo, M. Macromolecules 1991, 24, 370.

8. $\quad$ Odian, G. Principles of Polymerization, 2nd Ed., Wiley: New york, 1981.

9. Isemer, C. Ph.-D Thesis 2000, Göttingen.

10. Fukuda, T.; Die, N.; Ma, Y.-D: Macromol. Symp. 1996, 111, 305.

11. Bamford, C. H. J. Chem. Soc. 1976, 72, 2805.

12. Data reduction and error analysis for the Physical Sciences, Bevingtion, A.; McGrawHill: New York, 1969.

13. Numerical Recipes, Press, Flammery, Teukolsky, Vetterling, Cambridge University Press: Cambridge 1989.

14. Heuts, J. P.A.; Kukulj, D.; Foster, D. J.; Davis, T. P. Macromolecules 1998, 2894, 31.

15. Kukulj, D.; Heuts, J. P. A.; Davis, T. P. Macromolecules 1998, 31, 6034.

16. Galbraith, M. N.; Moad, G.; Solomon, D. H.; Spurling, T. H. Macromolecules 1987, 20,675 .

17. Heuts, J. P. A.; Coote, M. L.,; Davis, T. P.; Johnston, L. P. M. Im Controlled Radical Polymerization; Matyjaszewski, K.; Ed.; ACS Symposium Series, vol 685; American Chemical Society: Washington, DC, 1998, p 120.

18. Polymer Handbook, 3rd ed.; Brandup, A.; Immergut, E. H. Eds.; Wiley-Inetrscience: New York, 1989.

19. Wulkow, M. Macromol. Theory Simul. 1996, 5, 393.

20. Wulkow, M., CiT GmbH, Oldenburger Str. 200, 26180 Ratede.

21. Beuermann, S.; Buback, M.; Isemer, C.; Lacik, I.; Wahl, A. Macromolecules, in preparation for publications.

22. Beuermann, S.; Buback, M.; Russell, G. T. Macromol. Rapid. Commun. 1994, 15, 351.

23. Coote, M. L.; Zammit, M. D.; Davis, T. P. Willett, G. D. Macromolecules 1997, 30, 8182 .

24. Coote, M. L.; Johnston, L. P.; Davis, T. P. Macromolecules 1997, 30.8191.

25 Moad, G.; Salomon, D. H. in Comprehensive Polymer Science, G. Allen, J. C. Bevington, Eds., vol 3, Chap. 11, Pergamon Press, New York 1989.

26. Fouassier, J. P.; Jacques, P.; Lougnot, D. J. J. Rad. Cur. 1983, 4, 9.

27. van Boxtel, H. C. M. Ph.- D. Thesis 2000, Göttingen.

28. Buback, M.; Busch, M.; Lämmel, R. A. Macromol. Theory Simul. 1996, 5, 845. 
29. Hutchinson, R. A.; Paquet, D. A.; Mc Minn, J. H. Macromolecules 1995, 28, 5655.

30. Heuts, P. A.; Morrison, D. A.; Davis, T. P. Im Controlled/Living Radical Polymerization; Matyjaszewski, K.; Ed.; ACS Symposium Series, vol 768; American Chemical Society: Washington, DC, 2000, p 313. 


\section{Closing remarks}

This work has shown that using various chain-transfer agents, different orders of magnitude of chain-transfer rate coefficients are accessible. In styrene and MMA homo- and copolymerizations in the presence of DDM and MMA trimer as chain-transfer agents, $k_{\mathrm{tr}}$ values are in the range of $10^{3}$ and $10^{2} \mathrm{~L} \cdot \mathrm{mol}^{-1} \cdot \mathrm{s}^{-1}$, respectively. The transfer process is chemically controlled. In both cases, DDM and MMA trimer as CTAs, $k_{\mathrm{tr}}$ is not influenced by the presence of $\mathrm{scCO}_{2}$ as a solvent and the pressure dependence of $k_{\mathrm{tr}}$ is not significant. For MMA homopolymerizations in the presence of $\mathrm{COPhBF}$ as catalytic CTA, $k_{\mathrm{tr}}$ obtained in $\mathrm{scCO}_{2}$ is significantly higher than in bulk, e.g. at 1000 bar and $80^{\circ} \mathrm{C} k_{\text {tr }}$ values are $145 \cdot 10^{5}$ and $55.1 \cdot 10^{5} \mathrm{~L} \cdot \mathrm{mol}^{-1} \cdot \mathrm{s}^{-1}$ in $\mathrm{scCO}_{2}$ and in bulk, respectively. In addition, the activation volume for $k_{\text {tr }}$ of $+35 \mathrm{~cm}^{3} \cdot \mathrm{mol}^{-1}$ is high. These observations are consistent with a diffusion-controlled transfer process.

The particular case of styrene polymerization with COPhBF indicates that the observed $k_{\text {tr }}$ values may be underestimated, since it may not be ruled out that the concentration of active $\mathrm{Co}(\mathrm{II})$ species may be reduced due to the formation of a reversible cobalt-carbon bond $(\mathrm{Co}(\mathrm{III}))$. This transfer process is not clear so far and true rate coefficients related to actual concentration of $\mathrm{Co}$ (II) species in the system are not available. The data presented here and in the literature are not reliable to draw any mechanistic conclusions. However, it has been shown that this equilibrium between $\mathrm{Co}(\mathrm{II})$ and $\mathrm{Co}(\mathrm{III})$ species does not occur in MMA homopolymerization ${ }^{1}$.

The decrease of Co(II) species concentration in styrene polymerizations ${ }^{1}$ has been observed from indirect analytical method such as electron spin resonance (ESR). It may be interesting to analyze directly the polystyrene formed using matrix-assisted laser desorption ionization time of flight mass spectrometry (MALDI-TOF-MS), thereby permitting the direct observation of the cobalt-carbon bond in styrene polymerization. This technique was successfully used to analyze poly(methyl acrylate) chains formed by catalytic chain-transfer polymerization with a cobalt complex as chain-transfer agent ${ }^{2}$.

In case of a direct observation of the cobalt-carbon bond, the active COPhBF concentration should be reduced, thus the true $k_{\mathrm{tr}}, k_{\mathrm{tr}}^{\text {true }}$, should be higher than $k_{\mathrm{tr}}{ }^{\text {obs }}$. Assuming the validity of scheme 5.2 and taking into consideration the equilibrium between the two species, Co(II) and $\mathrm{Co}(\mathrm{III})$, it should be possible to determine $k_{\mathrm{tr}}^{\text {true }}$, knowing the concentration of active Co(II) molecules and $k_{\mathrm{tr}}{ }^{\text {obs }}$ values determined in this work $\left(k_{\mathrm{tr}}{ }^{\text {obs }} \cdot[\mathrm{Co}(\mathrm{II})]_{\text {initial }}=k_{\mathrm{tr}}^{\text {true }} \cdot[\mathrm{Co}(\mathrm{II})]_{\mathrm{active}}\right)$. 
One approach to determine the active cobalt concentration may be to monitor the $\mathrm{Co}$ (II) species during the polymerization by ESR.

The big pressure dependence of $k_{\mathrm{tr}}$ obtained in MMA homopolymerization with COPhBF is also explained by the bulkiness of the CTA molecule. By increasing the pressure, the mobility of the COPhBF molecule is much more restricted, which induces a decrease in $k_{\mathrm{tr}}$. This assumption may be tested by studying the pressure dependence of $k_{\mathrm{tr}}$ for a less sterically hindered catalytic chain-transfer agent. The bis(difluoroboryl) dimethylglyoximato cobalt (II), COBF, appears to be a good candidate as the structure of this complex is close to the one of $\mathrm{COPhBF}$, substituting the phenyl groups by methyl groups. In addition, COBF is much less sterically hindered than COPhBF. COBF has already shown to have a higher transfer rate coefficient than COPhBF in MMA homopolymerization ${ }^{3,4}$, because hydrogen abstraction is facilitated using COBF. Thus, if the high activation volume of $k_{\text {tr }}$ for $\mathrm{COPhBF}$ is due to the bulkiness of the CTA molecule, it is expected that using COBF as catalytic CTA leads to a lower activation volume.

\subsection{References}

1. Heuts, J. P. A.; Foster, D. J.; Davis, T. P.; Yamada, B.; Yamazoe, H.; Azukizawa, M. Macromolecules 1999, 32, 2511.

2. $\quad$ Roberts, G. E.; Heuts, J. P.A.; Davis, T. P. Macromolecules 2000, 33, 7765.

3. Kukulj, D.; Davis, T. P., Suddaby, K. G.; Haddleton, D. M.; Gilbert, R. G. J. Polym. Sci. Pol. Chem. 1997, 35, 859.

4. Kukulj, D.; Davis, T. P. Macromol. Chem. Phys. 1998, 199, 1697. 


\section{Abbreviations}

$a$

$a_{\text {copo }}$

A

$A_{\mathrm{AB}}$

AIBN

c

CCTA

$C_{\mathrm{I}}$

CLD

$C_{\mathrm{M}}$

$\mathrm{COBF}$

$\mathrm{COPhBF}$

$C_{\mathrm{p}}$

$C_{\mathrm{R}}{ }^{0}$

$C_{\mathrm{T}}$

CTA

d

DDM

DMPA

$D P_{\mathrm{n}}$

$D P_{\text {no }}$

$E_{\mathrm{A}}$

$E_{\lambda}$

$E_{\mathrm{p}}$

ESR

$\varepsilon$

$f_{\mathrm{i}}$

$F_{\mathrm{i}}$

$f(M)$

$\phi_{\mathrm{A}}$

$\phi_{\mathrm{AB}}$
Mark-Houwink parameter

Mark-Houwink parameter of a copolymer

absorbance

instantaneous copolymer composition

azobisisobutyronitril

initiator concentration

catalytic chain-transfer agent

chain-transfer constant for transfer to initiator

chain-length distribution

chain-transfer constant for transfer to monomer

bis(difluoroboryl) dimethylglyoximato cobalt (II)

bis(difluoroboryl) diphenylglyoximato cobalt (II)

chain-transfer constant for transfer to polymer

effective initial radical concentration

chain-transfer constant for transfer to chain-transfer agent

chain-transfer agent

optical path length

n-dodecyl mercaptan

2,2-Dimethoxy-2-phenylacetophenone

number average degree of polymerization in the presence of CTA

number average degree of polymerization in the absence of CTA

activation energy

energy of one mole of photons at the wave length $\lambda$

energy of one laser pulse

electron spin resonance

molar absorption coefficient

mole fraction of component $i$ in the monomer mixture

mole fraction of component $i$ in the polymer mixture

number molecular weight distribution

fraction of the propagating radical with a terminal unit $\mathrm{A}$

fraction of the propagating radical with a penultimate unit $\mathrm{A}$ and a terminal unit B 


\begin{tabular}{|c|c|}
\hline$\Phi_{\mathrm{A}}$ & fraction of A endgroups \\
\hline$\Phi$ & primary quantum yield \\
\hline Int $_{0}$ & peak integral before pulsing \\
\hline $\operatorname{Int}_{\mathrm{p}}$ & peak integral after pulsing \\
\hline IPUE & Implicit penultimate unit effect \\
\hline$K$ & Mark-Houwink parameter \\
\hline$K_{\text {copo }}$ & Mark-Houwink parameter of a copolymer \\
\hline$k_{\mathrm{d}}$ & decomposition rate coefficient \\
\hline$k_{\mathrm{p}}$ & propagation rate coefficient \\
\hline$k_{\mathrm{pAA}}$ & propagation rate coefficient in a homopolymerization of monomer A \\
\hline$k_{\mathrm{pAB}}$ & $\begin{array}{l}\text { propagation rate coefficient for the reaction of a macroradical with } \\
\text { terminal unit } \mathrm{A} \text { and monomer } \mathrm{B}\end{array}$ \\
\hline $\bar{k}_{\mathrm{pAB}}$ & average $k_{\mathrm{pAB}}$ \\
\hline$k_{\mathrm{pABC}}$ & $\begin{array}{l}\text { propagation rate coefficient for the reaction of a macroradical with } \\
\text { penultimate unit } \mathrm{A} \text { and terminal unit } \mathrm{B} \text { with a monomer } \mathrm{C}\end{array}$ \\
\hline$k_{\mathrm{p}, \mathrm{copo}}$ & propagation rate coefficient in a copolymerization \\
\hline$k_{\mathrm{t}}$ & termination rate coefficient in a homopolymerization \\
\hline$k_{\mathrm{t}, \mathrm{c}}$ & termination rate coefficient for termination by combination \\
\hline$k_{\mathrm{t}, \mathrm{copo}}$ & termination rate coefficient in a copolymerization \\
\hline$k_{\mathrm{t}, \mathrm{d}}$ & termination rate coefficient for termination by disproportionation \\
\hline$k_{\mathrm{tr}, \mathrm{A}}$ & chain-transfer rate coefficient in a homopolymerization of monomer A \\
\hline$k_{\mathrm{tr}, \mathrm{AB}}$ & $\begin{array}{l}\text { chain-transfer rate coefficient of a radical with penultimate unit } A \text { and } \\
\text { terminal unit B }\end{array}$ \\
\hline$k_{\mathrm{tr}, \mathrm{I}}$ & chain-transfer rate coefficient for transfer to initiator \\
\hline$k_{\mathrm{tr}, \mathrm{M}}$ & chain-transfer rate coefficient for transfer to monomer \\
\hline$k_{\mathrm{tr}, \mathrm{P}}$ & chain-transfer rate coefficient for transfer to polymer \\
\hline$k_{\mathrm{tr}, \mathrm{X}}$ & chain-transfer rate coefficient for transfer to chain-transfer agent \\
\hline$\Lambda$ & slope of the $\ln f(M)$ vs $M$ plot \\
\hline$\Lambda_{\text {high }}$ & slope of the $\ln f(M)$ vs $M$ plot in the high molecular weight region \\
\hline$\Lambda_{\text {peak }}$ & slope of the $\ln f(M)$ vs $M$ plot in the peak molecular weight region \\
\hline M & monomer \\
\hline MMA & methyl methacrylate \\
\hline MMAt & methyl methacrylate trimer \\
\hline$M_{\mathrm{n}}$ & number average molecular weight \\
\hline
\end{tabular}




$\begin{array}{ll}M_{0} & \text { monomer molecular weight } \\ M_{\mathrm{w}} & \text { weight average molecular weight } \\ \text { MWD } & \text { molecular weight distribution } \\ M_{\mathrm{Z}} & \text { Z average molecular weight } \\ n_{\mathrm{abs}} & \text { number of absorbed photons } \\ p & \text { pressure } \\ \mathrm{P}(\mathrm{A} / \mathrm{CTA}) & \text { probability of the formation of an endgroup of type A } \\ \mathrm{PLP} & \text { pulsed-laser polymerization } \\ \mathrm{PMMA} & \text { poly(methyl methacrylate) } \\ \mathrm{PS} & \text { polystyrene } \\ \mathrm{PUE} & \text { penultimate unit effect } \\ r_{\mathrm{i}} & \text { reactivity ratio (homo propagation to cross propagation) } \\ R_{\mathrm{p}} & \text { rate of propagation } \\ R_{\mathrm{t}} & \text { rate of termination } \\ R_{\mathrm{tr}} & \text { rate of transfer } \\ \mathrm{S} & \text { styrene } \\ S & \text { probability of propagation } \\ \mathrm{SEC} & \text { size-exclusion chromatography } \\ s_{\mathrm{i}} & \text { radical reactivity ratio } \\ t & \text { time } \\ T & \text { absolute temperature } \\ \Delta V^{\ddagger} & \text { activation volume } \\ \mathrm{X} & \text { irradiated volume } \\ & \text { monomer conversion } \\ & \end{array}$




\section{Appendix}

\section{Appendix 1}

Propagation rate coefficients in styrene-MMA copolymerizations in bulk and in $\mathrm{scCO}_{2}$ determined at $80^{\circ} \mathrm{C}$ applying the PLP-SEC method.

The data of the homopropagation $k_{\mathrm{p}}$ are taken from the literature and determined in this work (see section 5.1). The data of the copolymerization $k_{\mathrm{p}}$ are estimated applying the Implicit Penultimate Unit Effect model following Eqs. 6.4-6.10 in section 6. $r$ and $s$ values are listed in Table 6.1.

\begin{tabular}{|c|c|c|c|}
\hline$f_{\mathrm{S}}$ & $p /$ bar & $\begin{array}{c}k_{\mathrm{p}, \mathrm{bulk}} \\
\mathbf{L} \cdot \mathrm{mol}^{-1} \cdot \mathbf{s}^{-1}\end{array}$ & $\begin{array}{c}k_{\mathrm{p}, \mathrm{scCO} 2} \\
\mathrm{~L} \cdot \mathrm{mol}^{-1} \cdot \mathrm{s}^{-1}\end{array}$ \\
\hline 0 & 300 & $1540^{(a)}$ & $1382^{(b)}$ \\
\hline 0 & 500 & $1653^{\text {(a) }}$ & $1597^{(b)}$ \\
\hline 0 & 800 & $1961^{(a)}$ & $1860^{(b)}$ \\
\hline 0 & 1000 & $2197^{\text {(a) }}$ & $1970^{(\mathrm{c})}$ \\
\hline 0 & 1500 & $2922^{\text {(a) }}$ & $2776^{(\mathrm{c})}$ \\
\hline 0.2 & 300 & $1108^{(d)}$ & $1014^{(d)}$ \\
\hline 0.2 & 500 & $1224^{(d)}$ & $1120^{(d)}$ \\
\hline 0.2 & 800 & $1390^{(\mathrm{d})}$ & $1267^{(d)}$ \\
\hline 0.2 & 1000 & $1516^{(d)}$ & $1386^{(d)}$ \\
\hline 0.2 & 1500 & $1884^{(\mathrm{d})}$ & $1730^{(\mathrm{d})}$ \\
\hline 0.5 & 300 & $894^{(\mathrm{d})}$ & $804^{(\mathrm{d})}$ \\
\hline 0.5 & 500 & $977^{\text {(d) }}$ & $875^{(d)}$ \\
\hline 0.5 & 800 & $1096^{(\mathrm{d})}$ & $983^{(d)}$ \\
\hline 0.5 & 1000 & $1188^{(d)}$ & $1167^{(d)}$ \\
\hline 0.5 & 1500 & $1449^{(d)}$ & $1305^{(d)}$ \\
\hline
\end{tabular}




\begin{tabular}{|c|c|c|c|}
\hline$f_{\mathrm{S}}$ & $p /$ bar & $\begin{array}{c}k_{\mathrm{p}, \text { bulk }} \\
\mathbf{L} \cdot \mathrm{mol}^{-1} \cdot \mathrm{s}^{-1}\end{array}$ & $\begin{array}{c}k_{\mathrm{p}, \mathrm{scCO} 2} \\
\mathrm{~L} \cdot \mathrm{mol}^{-1} \cdot \mathrm{s}^{-1}\end{array}$ \\
\hline 0.8 & 300 & $791^{\text {(d) }}$ & $713^{(\mathrm{d})}$ \\
\hline 0.8 & 500 & $865^{(\mathrm{d})}$ & $773^{\text {(d) }}$ \\
\hline 0.8 & 800 & $968^{(\mathrm{d})}$ & $861^{(\mathrm{d})}$ \\
\hline 0.8 & 1000 & $1048^{(\mathrm{d})}$ & $940^{(\mathrm{d})}$ \\
\hline 0.8 & 1500 & $1273^{(\mathrm{d})}$ & $1143^{(\mathrm{d})}$ \\
\hline 1 & 300 & $763^{(\mathrm{e})}$ & $685^{(\mathrm{f})}$ \\
\hline 1 & 500 & $828^{(\mathrm{e})}$ & $742^{(f)}$ \\
\hline 1 & 800 & $929^{(\mathrm{e})}$ & $830^{(\mathrm{f})}$ \\
\hline 1 & 1000 & $1004^{(\mathrm{e})}$ & $901^{(\mathrm{f})}$ \\
\hline 1 & 1500 & $1216^{(\mathrm{e})}$ & $1096^{(\mathrm{f})}$ \\
\hline
\end{tabular}

(a) Beuermann, S.; Buback, M.; Russell, G. T. Macromol. Rapid. Commun. 1994, 15, 351.

(b) measured in this work.

(c) extrapolated.

(d) estimated applying the IPUE model.

(e) Buback, M.; Kuchta, F.-D. Macromol. Chem. Phys. 1995, 196, 1887.

${ }^{(\mathrm{f})}$ Beuermann, S.; Buback, M.; Isemer, C.; Lacik, I.; Wahl, A. Macromolecules, in preparation for publications. 


\section{Appendix 2}

Chain-transfer rate coefficients and chain-transfer constants of styrene-MMA homo- and copolymerizations in bulk and in $40 \mathrm{wt} \% \mathrm{scCO}_{2}$ at $80^{\circ} \mathrm{C}$ in the presence of DDM as chaintransfer agent.

\begin{tabular}{|c|c|c|c|c|c|}
\hline \multirow[t]{2}{*}{$p$ / bar } & \multirow[t]{2}{*}{$\begin{array}{c}\mathrm{wt} \% \\
\mathrm{CO}_{2}\end{array}$} & \multirow[t]{2}{*}{$f_{\mathrm{S}}$} & \multicolumn{2}{|c|}{$C_{\mathrm{T}}$} & \multirow{2}{*}{$\begin{array}{c}10^{-3} \cdot k_{\mathrm{tr}} \\
\mathrm{L} \cdot \mathrm{mol}^{-1} \cdot \mathrm{s}^{-1} \\
\mathrm{CLD}\end{array}$} \\
\hline & & & Mayo & CLD & \\
\hline 300 & 40 & 0 & 0.790 & $0.811 \pm 0.098$ & $1.14 \pm 0.25$ \\
\hline 300 & 0 & 0 & 0.663 & $0.702 \pm 0.071$ & $1.08 \pm 0.21$ \\
\hline 500 & 40 & 0 & 0.751 & $0.771 \pm 0.066$ & $1.24 \pm 0.22$ \\
\hline 500 & 0 & 0 & 0.531 & $0.599 \pm 0.042$ & $0.991 \pm 0.165$ \\
\hline 800 & 40 & 0 & 0.585 & $0.669 \pm 0.052$ & $1.25 \pm 0.22$ \\
\hline 800 & 0 & 0 & 0.609 & $0.604 \pm 0.048$ & $1.18 \pm 0.20$ \\
\hline 1000 & 40 & 0 & 0.641 & $0.639 \pm 0.052$ & $1.28 \pm 0.23$ \\
\hline 1000 & 0 & 0 & 0.552 & $0.514 \pm 0.035$ & $1.16 \pm 0.18$ \\
\hline 300 & 40 & 0.2 & 1.90 & $2.10 \pm 0.15$ & $2.13 \pm 0.36$ \\
\hline 300 & 0 & 0.2 & 2.10 & $2.03 \pm 0.08$ & $2.22 \pm 0.35$ \\
\hline 1 & 0 & 0.5 & 3.85 & $3.83 \pm 0.45$ & $2.98 \pm 0.73$ \\
\hline 300 & 40 & 0.5 & 3.65 & $3.77 \pm 0.35$ & $3.03 \pm 0.62$ \\
\hline 300 & 0 & 0.5 & 3.26 & $3.34 \pm 0.25$ & $2.98 \pm 0.55$ \\
\hline 500 & 40 & 0.5 & 3.54 & $3.66 \pm 0.52$ & $3.20 \pm 0.84$ \\
\hline 500 & 0 & 0.5 & 3.42 & $3.25 \pm 0.48$ & $3.17 \pm 0.89$ \\
\hline 800 & 40 & 0.5 & 3.16 & $3.24 \pm 0.43$ & $3.19 \pm 0.87$ \\
\hline 800 & 0 & 0.5 & 3.05 & $2.88 \pm 0.35$ & $3.16 \pm 0.89$ \\
\hline 1500 & 40 & 0.5 & 2.58 & $2.64 \pm 0.39$ & $3.44 \pm 0.98$ \\
\hline 1000 & 0 & 0.5 & 2.45 & $2.73 \pm 0.25$ & $3.24 \pm 1.25$ \\
\hline
\end{tabular}




\begin{tabular}{cccccc}
\hline$p /$ bar & wt \% & \multicolumn{2}{c}{$\boldsymbol{C}_{\mathrm{S}}$} & \multicolumn{2}{c}{$\mathbf{1 0}^{\mathbf{- 3}} \cdot \boldsymbol{k}_{\text {tr }}$} \\
& $\mathbf{C O}_{2}$ & & Mayo & $\mathbf{C L D}$ & $\mathbf{L} \cdot \mathbf{m o l}^{-\mathbf{1}} \cdot \mathbf{s}^{\mathbf{- 1}}$ \\
\hline $\mathbf{3 0 0}$ & 40 & 0.8 & 7.82 & $8.98 \pm 1.25$ & $\mathbf{6 . 4 0} \pm \mathbf{1 . 6 2}$ \\
$\mathbf{3 0 0}$ & 0 & 0.8 & 7.75 & $8.14 \pm 0.96$ & $\mathbf{6 . 4 4} \pm \mathbf{1 . 4 7}$ \\
\hline $\mathbf{1}$ & 0 & 1 & - & $15.5 \pm 1.2$ & $\mathbf{1 0 . 6} \pm \mathbf{1 . 9}$ \\
$\mathbf{3 0 0}$ & 40 & 1 & - & $16.3 \pm 1.5$ & $\mathbf{1 1 . 2} \pm \mathbf{2 . 1}$ \\
$\mathbf{3 0 0}$ & 0 & 1 & - & $14.6 \pm 1.8$ & $\mathbf{1 1 . 2} \pm \mathbf{1 . 4}$ \\
$\mathbf{5 0 0}$ & 40 & 1 & - & $15.5 \pm 1.3$ & $\mathbf{1 1 . 5} \pm \mathbf{2 . 1}$ \\
$\mathbf{8 0 0}$ & 40 & 1 & - & $14.8 \pm 0.8$ & $\mathbf{1 2 . 3} \pm \mathbf{1 . 9}$ \\
$\mathbf{1 5 0 0}$ & 40 & 1 & - & $11.0 \pm 0.8$ & $\mathbf{1 2 . 1} \pm \mathbf{2 . 1}$ \\
$\mathbf{1 5 0 0}$ & 0 & 1 & - & $11.2 \pm 0.9$ & $\mathbf{1 3 . 4} \pm \mathbf{2 . 7}$ \\
\hline
\end{tabular}




\section{Appendix 3}

Chain-transfer rate coefficients and chain-transfer constants observed in styrene and MMA homo- and copolymerizations in bulk and in $40 \mathrm{wt} \% \mathrm{scCO}_{2}$ at $80^{\circ} \mathrm{C}$ in the presence of $\mathrm{COPhBF}$ as chain-transfer agent. The $C_{\mathrm{T}}$ determination is based on Eq. 4.17 (see section 4), which was derived assuming scheme 5.2 to be valid for catalytic chain-transfer polymerization.

\begin{tabular}{|c|c|c|c|c|c|}
\hline \multirow[t]{2}{*}{$p /$ bar } & \multirow{2}{*}{$\begin{array}{c}\text { wt } \% \\
\mathrm{CO}_{2}\end{array}$} & \multirow[t]{2}{*}{$f_{\mathrm{s}}$} & \multicolumn{2}{|c|}{$10^{-2} \cdot C_{\mathrm{T}}^{\text {obs }}$} & \multirow{2}{*}{$\begin{array}{c}\mathrm{10}^{-5} \cdot \boldsymbol{k}_{\mathrm{tr}}{ }^{\text {obs }} \\
\mathrm{L} \cdot \mathrm{mol}^{-1} \cdot \mathrm{s}^{-1} \\
\mathrm{CLD}\end{array}$} \\
\hline & & & Mayo & CLD & \\
\hline 300 & 40 & 0 & 220 & $211 \pm 51$ & $292 \pm 100$ \\
\hline 300 & 0 & 0 & 128 & $141 \pm 22$ & $216 \pm 55$ \\
\hline 500 & 40 & 0 & 166 & $157 \pm 17$ & $252 \pm 52$ \\
\hline 500 & 0 & 0 & 102 & $80.0 \pm 5.3$ & $131 \pm 22$ \\
\hline 800 & 40 & 0 & 140 & $100 \pm 15$ & $186 \pm 45$ \\
\hline 800 & 0 & 0 & 55.0 & $50.1 \pm 8.3$ & $98.2 \pm 26.2$ \\
\hline 1000 & 40 & 0 & 74 & $73.6 \pm 24.7$ & $145 \pm 62$ \\
\hline 1000 & 0 & 0 & 22.5 & $25.1 \pm 6.2$ & $55.1 \pm 19.1$ \\
\hline 300 & 40 & 0.2 & 111 & $125 \pm 23$ & $126 \pm 39$ \\
\hline 300 & 0 & 0.2 & 39.4 & $42.2 \pm 5.3$ & $46.4 \pm 9.6$ \\
\hline 300 & 40 & 0.5 & 50.5 & $47.1 \pm 9.1$ & $37.6 \pm 12.1$ \\
\hline 300 & 0 & 0.5 & 23.7 & $18.9 \pm 2.1$ & $16.9 \pm 3.7$ \\
\hline 500 & 40 & 0.5 & 37.4 & $38.2 \pm 2.5$ & $33.4 \pm 5.7$ \\
\hline 500 & 0 & 0.5 & 16.6 & $17.5 \pm 1.1$ & $17.1 \pm 2.8$ \\
\hline 800 & 40 & 0.5 & 32.5 & $21.5 \pm 3.8$ & $21.1 \pm 63$ \\
\hline 800 & 0 & 0.5 & 10.5 & $9.30 \pm 0.85$ & $10.1 \pm 2.1$ \\
\hline 1000 & 40 & 0.5 & 10.4 & $12.0 \pm 1.4$ & $14.0 \pm 3.2$ \\
\hline
\end{tabular}




\begin{tabular}{cccccc}
\hline $\boldsymbol{p} /$ bar & $\begin{array}{c}\text { wt \% } \\
\mathbf{C O}_{2}\end{array}$ & $f_{\mathrm{S}}$ & & $\mathbf{1 0}^{-\mathbf{2}} \cdot \boldsymbol{C}_{\mathbf{T}}{ }^{\text {obs }}$ & $\begin{array}{c}\mathbf{1 0}^{-\mathbf{5}} \cdot \boldsymbol{k}_{\text {tr }}{ }^{\text {obs }} \\
\mathbf{L} \cdot \mathbf{m o l}^{-\mathbf{1}} \cdot \mathbf{s}^{-\mathbf{1}}\end{array}$ \\
\hline $\mathbf{1 0 0 0}$ & 0 & 0.5 & 7.16 & $7.12 \pm 2.5$ & $\mathbf{8 . 4 7} \pm \mathbf{4 . 1}$ \\
\hline $\mathbf{3 0 0}$ & 40 & 0.8 & 9.85 & $10.1 \pm 2.0$ & $\mathbf{7 . 1 5} \pm \mathbf{2 . 3 3}$ \\
$\mathbf{3 0 0}$ & 0 & 0.8 & 9.73 & $9.34 \pm 5.11$ & $\mathbf{7 . 3 8} \pm \mathbf{5 . 1 9}$ \\
\hline $\mathbf{3 0 0}$ & 40 & 1 & 7.52 & $8.46 \pm 0.80$ & $\mathbf{5 . 7 9} \pm \mathbf{1 . 1 8}$ \\
$\mathbf{3 0 0}$ & 0 & 1 & 4.31 & $4.35 \pm 2.34$ & $\mathbf{3 . 2 9} \pm \mathbf{2 . 2 7}$ \\
$\mathbf{5 0 0}$ & 40 & 1 & 3.98 & $4.08 \pm 0.35$ & $\mathbf{3 . 0 2} \pm \mathbf{0 . 5 3}$ \\
$\mathbf{5 0 0}$ & 0 & 1 & 3.12 & $3.25 \pm 0.26$ & $\mathbf{2 . 6 9} \pm \mathbf{0 . 4 8}$ \\
$\mathbf{8 0 0}$ & 40 & 1 & 3.55 & $3.76 \pm 0.45$ & $\mathbf{3 . 1 2} \pm \mathbf{0 . 7 2}$ \\
$\mathbf{8 0 0}$ & 0 & 1 & 2.15 & $2.37 \pm 0.15$ & $\mathbf{2 . 1 9} \pm \mathbf{0 3 6}$ \\
$\mathbf{1 0 0 0}$ & 40 & 1 & 1.05 & $1.20 \pm 0.23$ & $\mathbf{1 . 0 8} \pm \mathbf{0 . 3 1}$ \\
$\mathbf{1 0 0 0}$ & 0 & 1 & 1.12 & $1.30 \pm 0.12$ & $\mathbf{1 . 3 1} \pm \mathbf{0 . 2 7}$ \\
\hline & & & & & \\
\hline
\end{tabular}




\section{Appendix 4}

Chain-transfer rate coefficients and chain-transfer constants in styrene and MMA homopolymerizations in bulk and in $40 \mathrm{wt} \% \mathrm{scCO}_{2}$ at $80^{\circ} \mathrm{C}$ in the presence of MMA trimer as chain-transfer agent.

Styrene homopolymerization

\begin{tabular}{ccccc}
\hline$p /$ bar & wt \% & \multicolumn{2}{l}{$C_{\mathbf{T}}$} & $\boldsymbol{k}_{\mathrm{tr}} / \mathbf{L} \cdot \mathbf{m o l}^{\mathbf{- 1}} \cdot \mathbf{s}^{-\mathbf{1}}$ \\
\hline $\mathbf{C O}$ & Mayo & $\mathbf{C L D}$ & $\mathbf{C L D}$ \\
\hline $\mathbf{3 0 0}$ & 40 & 0.198 & $0.208 \pm 0.024$ & $\mathbf{1 4 2} \pm \mathbf{2 3}$ \\
$\mathbf{3 0 0}$ & 0 & 0.164 & $0.173 \pm 0.010$ & $\mathbf{1 3 1} \pm \mathbf{1 4}$ \\
$\mathbf{8 0 0}$ & 40 & 0.167 & $0.165 \pm 0.011$ & $\mathbf{1 3 6} \pm \mathbf{1 8}$ \\
$\mathbf{8 0 0}$ & 0 & 0.122 & $0.141 \pm 0.009$ & $\mathbf{1 3 1} \pm \mathbf{1 4}$ \\
$\mathbf{1 5 0 0}$ & 40 & 0.089 & $0.102 \pm 0.009$ & $\mathbf{1 1 2} \pm \mathbf{2 1}$ \\
$\mathbf{1 5 0 0}$ & 0 & 0.085 & $0.095 \pm 0.003$ & $\mathbf{1 1 5} \pm \mathbf{1 1}$ \\
\hline
\end{tabular}

MMA homopolymerization

\begin{tabular}{ccccc}
\hline$p /$ bar & $\begin{array}{c}\text { wt \% } \\
\mathbf{C O}_{\mathbf{2}}\end{array}$ & \multicolumn{2}{l}{$\boldsymbol{C}_{\mathrm{T}}$} & $\boldsymbol{k}_{\mathrm{tr}} / \mathbf{L} \cdot \mathbf{m o l}^{\mathbf{- 1}} \cdot \mathbf{s}^{\mathbf{- 1}}$ \\
\hline $\mathbf{3 0 0}$ & 40 & 0.096 & $0.063 \pm 0.014$ & $\mathbf{8 7 . 3} \pm \mathbf{1 4 . 1}$ \\
$\mathbf{3 0 0}$ & 0 & 0.063 & $0.066 \pm 0.012$ & $\mathbf{1 0 1} \pm \mathbf{0 8}$ \\
$\mathbf{5 0 0}$ & 40 & 0.037 & $0.052 \pm 0.011$ & $\mathbf{8 3 . 2} \pm \mathbf{2 5 . 2}$ \\
$\mathbf{5 0 0}$ & 0 & 0.052 & $0.057 \pm 0.003$ & $\mathbf{9 4 . 1} \pm \mathbf{1 4 . 5}$ \\
$\mathbf{8 0 0}$ & 40 & 0.043 & $0.052 \pm 0.002$ & $\mathbf{9 7 . 1} \pm \mathbf{8 . 5}$ \\
$\mathbf{8 0 0}$ & 0 & 0.043 & $0.053 \pm 0.002$ & $\mathbf{1 0 3} \pm \mathbf{8}$ \\
$\mathbf{1 5 0 0}$ & 40 & 0.041 & $0.041 \pm 0.006$ & $\mathbf{1 1 3} \pm \mathbf{2 7}$ \\
$\mathbf{1 5 0 0}$ & 0 & 0.039 & $0.042 \pm 0.005$ & $\mathbf{1 2 3} \pm \mathbf{1 6}$ \\
\hline
\end{tabular}




\section{Acknowledgments}

To my supervisor, Prof. Dr. M. Buback, I am indebted for the opportunity for this foray into scientific research which I have enjoyed, and learnt from.

Many thanks to Dr. S. Beuermann for encouragement, interest throughout and helpful discussions.

At the practical level, many thanks to Dr. Hans Peter Vögele for his ability to keep everything running and also for his friendship. Many thanks to Dorit Nelke, Eric Minaux and Mark Egorov for their vigilant proof reading and advice on the preparation of this thesis. Many thanks to the Buback Abteilung as a whole for the very pleasant and cooperative working environment.

Special thanks to Dorit Nelke, Matthias Müller, Achim Feldermann and Michael Jürgens for the advice, discussion, company and friendship. I would like to specially thank Heike Rohmann for friendship, for advice and everything else which is hard to put in a paper.

Many thanks to Dr. Igor lacík for the measurement of numerous MWDs, for the advice, discussion and friendship.

It is a pleasure to acknowledge Prof. Dr. J. Magull who allows me to prepare the cobalt complex. Special thanks to Ruth Dinger and Ulrich Schaller for their help.

I am indebted to the Deutschen Forschungsgemeinschaft, to the European Graduate School and to the European Union for the financial supports.

Je tiens àremercier Eric pour son soutien pendant toute la durée de ma thèse, pour son amitié et ses conseils.

Finalement un remerciement tout particulier à ma mère qui m'a soutenue pendant toute la durée de mes études et pour son amitié. 


\section{Curriculum Vitae}

\section{Personal information}

22.01.1974

Born in Beirut, Lebanon

\section{Education \& qualification}

$1979-1984$

$1984-1992$

$1992-1994$

$1994-1997$

Since April 1998

Ap. 1998 - Ap. 1999

Ap. 1999 - Sept. 2000

Since Sept. 2000
Elementary School in Villeneuve d'Acsq, France.

GCE A Levels in Maths, Physics/Chemistry Biology, History Queneau High School, Villeneuve d'Acsq.

Technological University Institute of Chemistry, University of Lille, France.

Graduation at the University of Lille, France.

Research toward doctorate in the Institute for Physical Chemistry, University of Göttingen, in the research group of Prof. Dr. M. Buback, Germany.

Member of the Graduiertenkolleg "Kinetic und Selectivität chemischer Prozesse in verdichteter fluider Phase".

Member of the european project "Superclean Chemistry 2".

Member of the European Graduate School "Microstructural Control in Free-Radical Polymerization".

Technical training at Norsohaas (water analysis laboratory).

Technical training at "Institut de Recherche dans l'Industrie Sucrière" (sugar analysis laboratory).

Scientific worker at the University of Lille.

Scientific worker at the University of Göttingen. 